\title{
Smoking topography and the assessment of exposure to cigarette smoke compounds
}

Citation for published version (APA):

Pauwels, C. G. G. M. (2021). Smoking topography and the assessment of exposure to cigarette smoke compounds. [Doctoral Thesis, Maastricht University]. Maastricht University. https://doi.org/10.26481/dis.20211004cp

Document status and date:

Published: 01/01/2021

DOI:

10.26481/dis.20211004cp

Document Version:

Publisher's PDF, also known as Version of record

\section{Please check the document version of this publication:}

- A submitted manuscript is the version of the article upon submission and before peer-review. There can be important differences between the submitted version and the official published version of record.

People interested in the research are advised to contact the author for the final version of the publication, or visit the DOI to the publisher's website.

- The final author version and the galley proof are versions of the publication after peer review.

- The final published version features the final layout of the paper including the volume, issue and page numbers.

Link to publication

\footnotetext{
General rights rights.

- You may freely distribute the URL identifying the publication in the public portal. please follow below link for the End User Agreement:

www.umlib.nl/taverne-license

Take down policy

If you believe that this document breaches copyright please contact us at:

repository@maastrichtuniversity.nl

providing details and we will investigate your claim.
}

Copyright and moral rights for the publications made accessible in the public portal are retained by the authors and/or other copyright owners and it is a condition of accessing publications that users recognise and abide by the legal requirements associated with these

- Users may download and print one copy of any publication from the public portal for the purpose of private study or research.

- You may not further distribute the material or use it for any profit-making activity or commercial gain

If the publication is distributed under the terms of Article $25 \mathrm{fa}$ of the Dutch Copyright Act, indicated by the "Taverne" license above, 


Smoking topography and the assessment of exposure to cigarette smoke compounds 
Smoking topography and the assessment of exposure to cigarette smoke compounds

Thesis, Maastricht University, Maastricht, The Netherlands

(c) Charlotte G.G.M. Pauwels, 2021

All rights are reserved. No parts of this book may be reproduced or transmitted in any form or by any means, without the written permission of the author.

Layout Loes Kema

Cover design TWA\&Mwa Photography

Printed by GVO Drukkers \& Vormgevers

ISBN 978-94-6332-780-0

The research described in this thesis was conducted at NUTRIM School of Nutrition and Translational Research in Metabolism of Maastricht University, National Institute for Public Health and the Environment (RIVM) and the Netherlands Food and Consumer Product Safety Authority (NVWA). 


\title{
Smoking topography and the assessment of exposure to cigarette smoke compounds
}

\author{
PROEFSCHRIFT \\ ter verkrijging van de graad van doctor aan de Universiteit Maastricht, \\ op gezag van de Rector Magnificus, Prof. dr. Rianne M. Letschert \\ volgens het besluit van het College van Decanen, \\ in het openbaar te verdedigen \\ op maandag 4 oktober 2021, om 16.00 uur.
}

door

Charlotte Gabriella Guido Margueritte Pauwels

geboren te Duffel (België) op 6 April 1990 


\section{Promotores}

Prof. dr. A. Opperhuizen

Prof. dr. F. J. Van Schooten

\section{Co-promotor}

Dr. R. Talhout (Rijksinstituut voor Volksgezondheid en Milieu, Bilthoven)

Dr. A. W. Boots

\section{Beoordelingscommissie}

Prof. dr. D. Sijm (voorzitter)

Prof. dr. P. Borm (Heinrich Heine University Düsseldorf, DE)

Prof. dr. T. Eissenberg (Virginia Commonwealth University, USA)

Dr. A. Remels

Prof.dr. C. Van Schayck 
Voor papa, van wie ik het doorzettingsvermogen heb 



\section{Contents}

Chapter 1 General introduction 9

Chapter $2 \quad$ Cigarette filter ventilation and smoking protocol 41 influence aldehyde smoke yields

Chapter 3 Smoking regular and low-nicotine cigarettes results in comparable levels of volatile organic compounds in blood and exhaled breath

Chapter 4 Characteristic human individual puffing profiles can generate more TNCO than ISO and Health Canada regimes on smoking machine when the same brand is smoked

Chapter 5 Characteristic puffing topography versus compensatory smoking

Chapter 6 Summary and general discussion

Impact paragraph

Nederlandse samenvatting

Curriculum vitae

List of publications

Dankwoord 



\section{Chapter 1. General introduction}





\section{A cigarette is a legal but lethal consumer product}

The fact that cigarette smoking is related to developing (lung) cancer ${ }^{1}$ and cardiovascular and pulmonary diseases ${ }^{2}$ has been reported since 1950 s. Smoke toxicants entering the smoker's lungs cause pulmonary damage, leading to inflammation and a compromised immune state. The initiation of smoking-induced damage is followed by remodeling and repair mechanisms in all compartments of the respiratory system, from the single-cell alveolar walls to the large conducting airways ${ }^{3}$. The repetition of damage, inflammation, remodeling and repair after each cigarette smoked lead to lung destruction (emphysema and fibrosis). Furthermore, some smoking-derived chemicals induce DNA damage and, if not repaired, this may lead to cancer in the oral and nasal cavities, and the airways. Moreover, many smoke chemicals, either as parent compounds or after being metabolized, are transferred across the lung epithelium, taken up into the blood and distributed in the smoker's body. Throughout the whole body, smoke toxicants or their metabolites can cause damage of cells and tissues after each cigarette consumed. All these processes together lead to the risk of developing tobacco-related diseases, i.e. cardiovascular diseases, cancers, chronic respiratory diseases, reproduction failure and adverse immune responses ${ }^{4}$. In 2018, one in every 4 men and one in every 20 women was a daily smoker and more than 8 million deaths are attributable to tobacco smoking worldwide every year ${ }^{5,6}$, which is 1 person every 4 seconds. There is scientific and public consensus about the fact that smoking leads to tobacco-related diseases ${ }^{7}$ as can also be read in the preamble of the World Health Organization (WHO) Framework Convention on Tobacco Control (FCTC): "...the scientific evidence unequivocally established that the consumption and exposure to tobacco smoke cause death, disease and disability, and that there is a time lag between the exposure to smoking and the uses of other tobacco products, and the onset of tobacco-related diseases".

\section{Smoking a cigarette}

When a cigarette is lit on one side and a puff is drawn from the other side, smoke goes from the burning tip through the tobacco and the filter into the mouth of the smoker. During this transfer, the hot smoke distills compounds, such as nicotine and flavors, from the tobacco filler and delivers them to the smoker to satisfy their craving. Simultaneously, the smoker is exposed to toxic chemicals present in the smoke. Smoking a cigarette is a delicate process in which smoke is cooled down by filter ventilation to prevent inhaling hot smoke. During smoking, the combination of fuel (the tobacco), fire and oxygen in the air generates a combustion process that can reach temperatures up to $950^{\circ} \mathrm{C}^{8-10}$. During puffing by the smoker, two zones inside the burning cigarette can be distinguished: a combustion zone and a pyrolysis 
zone (Figure 2). Inside the combustion zone, oxygen reacts with carbon-containing plant material of the tobacco, thereby producing chemicals such as carbon dioxide and nitric oxides, together with a large number of incomplete oxidation products. Downstream of the combustion zone is the cooler pyrolysis zone where oxygen is scarce and other smoke chemicals such as acrolein and acetaldehyde are produced. Various volatile organic compounds (VOCs) such as carbon monoxide (CO) and benzene are produced both by (incomplete) combustion and pyrolysis ${ }^{8,11}$. In addition, in the absence of puffing, tobacco is further oxidized and pyrolysed during a selfsustaining smoldering process, but at much lower temperatures than during burning ${ }^{8}$.

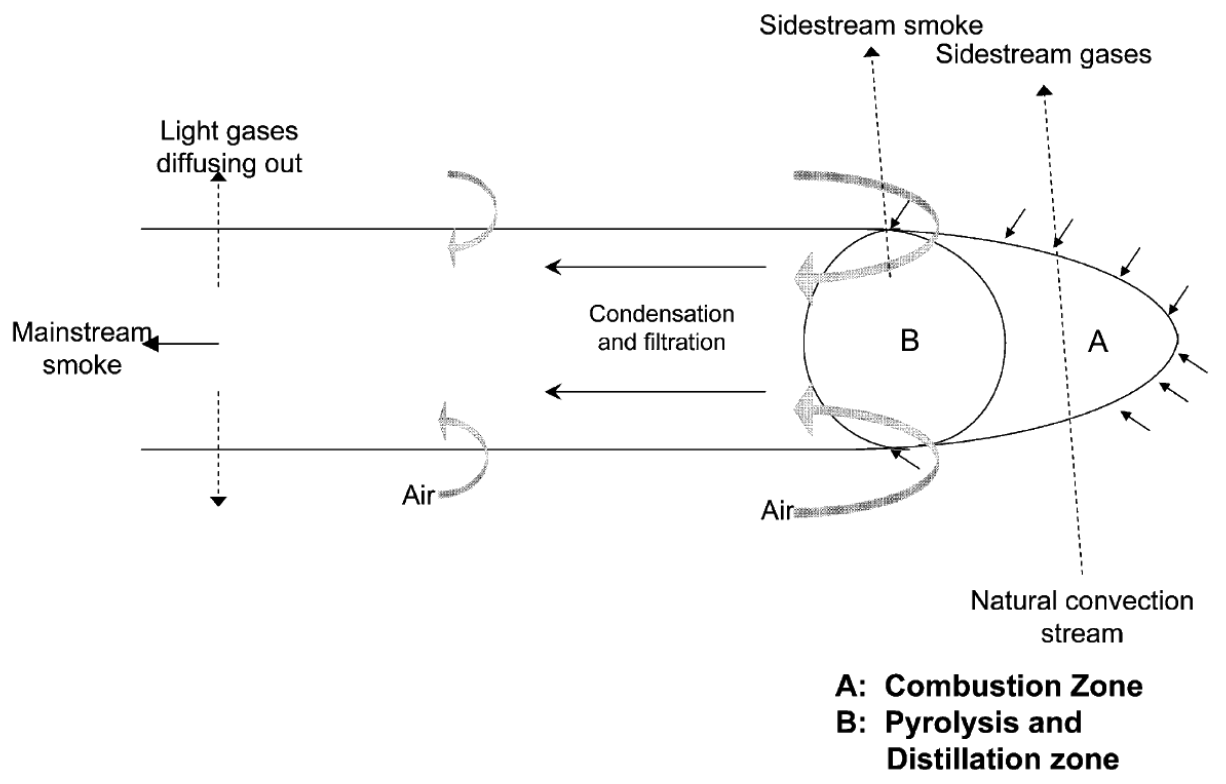

Figure 1. The burning cigarette (adapted from Baker et al ${ }^{8}$ ).

The hot super-saturated vapor generated in the combustion and pyrolysis zones extracts and distils chemicals such as nicotine from the remaining tobacco filler. It also cools within the tobacco rod when transported towards the mouth-end, which leads to condensation of chemicals after puffing ${ }^{11,12}$. During each puff and interpuff smoldering the tobacco rod will become shorter, and the balance between the various chemical and physico-chemical processes changes. Cigarette design features, particularly ventilation, influence the burning, pyrolysis, distillation and condensation processes inside the cigarette as well as the dilution of the smoke before it enters the mouth of the consumer (Figure 2). Hence, the produced cigarette smoke is a complex and dynamic mixture consisting of gases, (semi-)volatiles and 
liquid droplets (particulate phase) with particles ranging between 0.1 and $<1 \mu \mathrm{m}$ in diameter which are able to penetrate deep into the lungs ${ }^{10}$.

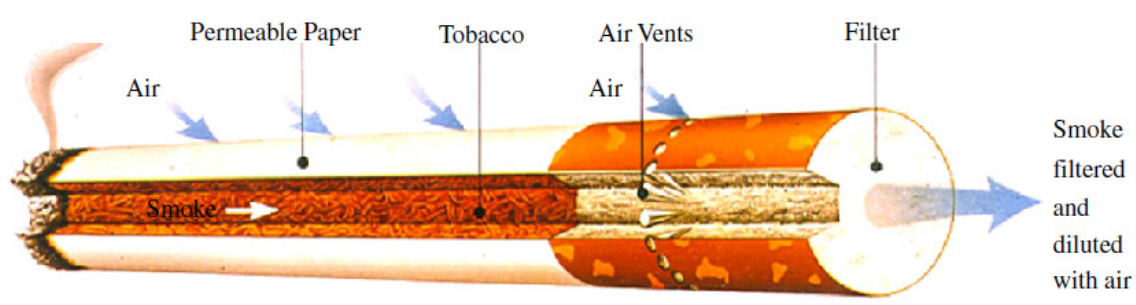

Fig. 1. The modern cigarette.

Figure 2. The modern cigarette (adapted from Thielen et al. ${ }^{10}$ )

\section{Cigarette smoke}

After combustion, pyrolysis, distillation, condensation and dilution of tobacco, the tobacco smoke contains over 6,000 chemicals distributed between the gas- and particulate phase depending on their physical (e.g. volatility) and chemical properties $4,12,13$. Classes of compounds include, but are not limited to, neutral gases, carbon and nitrogen oxides, amides, imides, lactames, carboxylic acids, lactones, esters, aldehydes, ketones, alcohols, phenols, amines, N-nitrosamines, N-heterocyclics, aliphatic hydrocarbons, monocyclic and polycyclic aromatic hydrocarbons (PAHs), nitriles, anhydrides, carbohydrates, ethers, nitro compounds and metals ${ }^{4}$. The gaseous phase consists mainly of nitrogen, but also contains combustion products such as CO, carbon dioxide, nitric oxide, and VOCs ${ }^{10,14}$. Particulate phase consists of PAHs, tobacco-specific nitrosamines (TSNAs), metals and water ${ }^{10,14}$. It is often referred to as 'tar' and quantified without the water content. Semi-volatiles are partitioned between the particulate and gaseous phases. Cigarette smoke has been extensively studied with the use of smoking machines to characterize and quantify its chemical composition. The first comprehensive list of biologically and toxicologically relevant substances in mainstream smoke was the so-called 'Hoffman list' ${ }^{15}$. Counts et al., Talhout et al., Fowles and Dybing and the WHO reported additional toxicants to the growing list of cigarette smoke toxicants ${ }^{16-19}$. Different factors (i.e. smoking behavior, tobacco blend, and filter paper) influence the puffing and smoldering of the cigarette and thus the formed chemical emissions ${ }^{13}$. In other words, taking a small or short puff may not only lead to inhaling less smoke per puff per cigarette, but also to a (slightly) different chemical composition than that of a larger or longer puff. Additionally, smokers may use their smoking behavior to interact with the cigarette brands differing in tobacco blend, filter paper and ventilation ${ }^{20}$. 


\section{Smoking behavior}

The traditional view on why people smoke tobacco is the smoker's nicotine intake to satisfy his or her mental and behavioral needs ${ }^{21}$. Smoking behavior is a multifaceted process and comprises the actual act of smoking, puffing, depth of inhalation, and the frequency of smoking (i.e. cigarettes per day (CPD)). Puffing, i.e. drawing smoke from the cigarette into the mouth, mouth holding and inhalation contribute to the exposure of the smoker to smoke constituents ${ }^{22}$. After puffing, the smoke remains in the mouth because the soft palate at the back of the mouth remains closed ${ }^{23}$. After a period of mouth-holding, the smoker relaxes the soft palate and inhales the smoke. Together with additional 'fresh' air, the smoke is drawn deeply into the alveoli compartment where gaseous chemicals are transported across the blood lung barrier 23. Puff volume and inhalation volume are separate but linked parameters. A smoker may take a large puff with no, or minimal, subsequent inhalation. The converse is also possible, i.e. a small puff volume followed by a large inhalation volume ${ }^{24}$.

When a person inhales nicotine distilled from cigarette smoke, it moves in less than 20 seconds to the brain after entering the arterial blood circulation. Once nicotine diffuses into brain tissue, it binds to nicotinic acetylcholine receptors (nAChR). Particularly binding to the dopaminergic nerves in the ventral tegmental area, which stimulates the release of dopamine in the shell of the nucleus accumbens, is an important mechanism in drug-induced reward ('brain's reward system') ${ }^{25}$. The stimulation of the brain's mesolimbic reward circuit creates a nicotine dependency and contributes to addiction and thus the difficulty of quitting smoking. It has been suggested that there is a threshold for daily nicotine to initiate and sustain addiction of 4 to $6 \mathrm{mg}$ for adults, and probably even lower for adolescents ${ }^{26}$. There are indications that experienced smokers can control and adapt or change their smoking behavior to modulate their nicotine intake ${ }^{27}$. In addition to activating the brain by nicotine taken up by the lungs and transported by blood, also direct activation of the brain by nicotine in the oral and nasal cavity can play an important role. Several studies showed that nerves in the olfactory area of the nasal cavity, as well as the trigeminal nerve, are activated by nicotine ${ }^{28-30}$. The brain's response towards such activations takes only a few seconds. A high dose of nicotine can cause an experience of burning and stinging pain by the smoker due to strong activation of the trigeminal nerve, which may limit the smoker's puffing because the nicotine intake exceeds the threshold for stinging or burning. In addition to nicotine, also flavors in the tobacco smoke, such as menthol, activate nerves in the olfactory region, contributing to the smokers experience of the smoked tobacco product ${ }^{31}$. Furthermore, for example menthol may even influence the nicotine-modulation of the trigeminal nerve during, or shortly after puffing ${ }^{28}$. 
In addition to the variety in cigarette brands as source for varying nicotine intake, two individuals may smoke the same cigarette brand but can be exposed to different levels of nicotine ${ }^{32}$. Ergo, by modulating the nicotine intake by changing their way of smoking, smokers (unconsciously) control the quantity and relative chemical composition of inhaled cigarette smoke, and influence their own exposure to smoke toxicants.

\section{Puffing topography}

Smoking or puffing topography is a term that relates to the physical characteristics of smoking behavior or, more simply phrased, how a person smokes his or her cigarette. Detailed examination of puffing topography involves quantitatively measuring the puffing by the smoker: number of puffs per cigarette, puff duration (s), puff volume $(\mathrm{mL})$ and inter-puff interval (time between successive puffs, (s)) ${ }^{32-35}$. Consecutively, puff flow $(\mathrm{mL} / \mathrm{s})$, total cigarette volume $(\mathrm{mL})$ and cigarette burn time $(\mathrm{s})$ can be calculated. Puff flow is puff volume divided by puff duration. Total cigarette volume is the product puff volume and number of puffs per cigarette. Daily puffing volume is the product of total cigarette volume and CPD. Cigarette burn time is the sum of the durations of all the puffs from a particular cigarette, a parameter not often used in previous studies ${ }^{36}$.

\section{Measuring puffing topography}

Human puffing topography is often recorded by the use of a flowmeter-device between the cigarette and the mouth of the smoker. Basically, the flowmeter captures pressure differences as smoke is inhaled from the cigarette and this pressure is converted into a flowrate via calibrated software. The software records the selected puff topography variables using flow onset, rate and offset measurements. In addition to desktop devices, portable devices were introduced to make it possible to measure naturalistic smoking behavior outside the lab. Whether the use of a puffing topography device influences human smoking behavior, is previously examined by observational video recordings of the sessions ${ }^{37}$ and by comparing smoking with and without mouthpiece ${ }^{32}$. In these studies, smokers were video recorded while smoking with and without topography device and puff duration, time between puffs, puff frequency and total cigarette duration were distilled from the video recordings and compared to the topography device measurements. Results showed similar puffing parameters indicating that smokers did not change their puffing behavior when using the device ${ }^{37}$.

\section{Puffing topography differences between individual characteristics}

Puffing topography is widely studied, and considerable intra-individual and interindividual differences between smokers have been observed. In studies published 
since 2000 the puff volume ranged from $30.8 \mathrm{~mL}^{32}$ to $85.1 \mathrm{~mL}^{38}$ with a duration of $0.9 \mathrm{~s}^{32}$ to $3 \mathrm{~s}^{39}$. On average, smokers take between $8{ }^{40}$ and 20 puffs ${ }^{41}$ per cigarette, with a puff interval between $9{ }^{42}$ and $45 \mathrm{~s}^{38}$. The variation in puff parameters is influenced by several factors as gender, race/ethnicity, nicotine dependence, psychological factors and genetic background. For instance, gender seems to be relevant since women take significantly smaller puffs ( $37.6 \mathrm{~mL} /$ puff vs. $45.8 \mathrm{~mL} /$ puff) of significantly shorter duration (1.33 s/puff vs. $1.48 \mathrm{~s} /$ puff) resulting in significantly more puffs per cigarette (14 vs. 12 ) than men ${ }^{43}$. Age seems not to have a large influence on puffing topography ${ }^{44}$. Nicotine dependence seems to be involved since cigarette volume and maximum puff volume are increased in combination with a more stable puffing profile, for those scoring high in the Fagerström Test for Nicotine Dependence (i.e. standard instrument for assessing the intensity of physical addiction to nicotine) ${ }^{45,46}$. Several studies have shown that the brand smoked (e.g. percentage of filter ventilation) as determined with smoking machines), flavor (menthol), time of the day of smoking, and smoking location is of influence on smoking topography ${ }^{39}$. Limitations to interpret the published data until now are that studies differ in their study design, for instance, allowing the consumption of multiple cigarettes in one study session ${ }^{37}$, or multiple sessions allowing just one cigarette ${ }^{45,47}$. Another limitation is that most studies determine the average puffing parameters per cigarette. However, it has been shown that during the act of smoking a cigarette the puff characteristics change, resulting in a changed chemical puff content over the course of smoking one cigarette ${ }^{48}$. Xie et al, for instance, showed that nicotine per puff increases when puff number increases (in case of a stable puff volume per puff) 49. Since studies predict nicotine exposure levels and other smoke constituents by puff parameters ${ }^{36,40,50-56}$ it is important to study smoking topography under natural smoking circumstances to assess reliably smoking associated chemical exposures.

\section{Puffing parameters influence chemical smoke content}

The puffing topography of a smoker influences the composition of cigarette smoke as it has impact on the burning temperature, the oxygen supply and consecutively the burning, pyrolysis, distillation and condensation of chemicals inside the cigarette. The air stream during puffing influences the heat and mass transfer and thus the tobacco consumed: the higher the puff flow, the higher the temperature. The smoldering period - the duration between puffs (inter-puff interval) - influences the temperature loss. As the smoke moves along the tobacco rod, the smoke particles tend to coagulate, resulting in a higher average particle diameter, and a smaller number of particles. The faster the particles move down the tobacco rod, the less time they have for coagulation and the smaller the average particle size 
will be ${ }^{57}$. Thus, also the level/number and the characteristics of the chemicals formed and the distribution between the particulate and gas phase depend on the puffing parameters. The smoke constituent yields generated in the first puffs are generally lower than in later puffs, due to the time required to form the coal and more extensive filtration and condensation of smoke by the tobacco rod ${ }^{58}$. In the final puffs of a cigarette, higher smoke yields are also generated due to the shorter filtration-condensation path that the smoke passes, and re-distillation of smoke filtered and condensated in earlier puffs ${ }^{59}$. More intense smoking regimes change the thermal process of burning cigarettes, resulting in relative increases or decreases of the chemical compositions ${ }^{16,60,61}$. However, it is difficult to measure the exact influence of a single puffing parameter because, for example, when the puff duration changes, but not the volume, the puff flow will change as well.

\section{Cigarette characteristics}

At the time (1950s) it was discovered that smoking was related to development of tobacco-related diseases, unfiltered cigarettes were smoked. The public's awareness and concern of the harmful effects of smoking rose. Manufacturers responded by introducing the first filter cigarette and claimed reduced tar yields. Because of the reduced inhaled tar in the smoke the filtered cigarettes were marketed as less harmful than the unfiltered cigarettes ${ }^{62}$. Throughout the years, manufacturers kept developing their product. The five biggest tobacco industry companies, Philip Morris International, British American Tobacco, Imperial Brands, Japan Tobacco International, and China Tobacco, all manufacture a variety of cigarette brands and develop unique cigarette brands by engineering a combination of tobacco filler and cigarette design features. Cigarette characteristics are used to increase the attractiveness to consumers by reducing negative experiences (e.g. throat irritation), increasing positive experiences (e.g. optimized draw resistance and mouth feel), appealing to new users and specific target groups, and fostering the perception of less personal risk (e.g. 'light' cigarette) ${ }^{19,20}$.

As stated in the preamble of the WHO FCTC, "...cigarettes and some other products containing tobacco are highly engineered so as to create and maintain dependence, and that the many compounds they contain, and the smoke they produce are pharmacologically active, toxic, mutagenic and carcinogenic, ..... Tobacco filler related aspects are the tobacco type, blend, amount and type of additives used and filler weight. Cigarette design features are cigarette paper, filter type, cigarette rod dimensions (e.g. circumference and length) and the well-known filter (and paper) ventilation ${ }^{63}$. By increasing ventilation in the cigarette, for example by adding 
ventilation holes in the filter, 'low tar' cigarettes were introduced to the consumer markets. This change in cigarette design parallels the increase in adenocarcinoma, a typical form of tobacco-related lung cancer ${ }^{64}$.

There are three main filter types; cellulose acetate (mainly used), pure cellulose or in combination with carbon. The combination of the filter material, paper porosity and draw resistance add to filter efficiency, which is the percentage of incoming smoke components removed by the filter. When a higher suction is needed to draw smoke through the filter (as reflected in the filter pressure drop), filtration efficiency increases due to a reduction in airflow through the cigarette.

\section{Cigarette design features influence smoke content}

The combination of the different cigarette design features affects smoke emissions. For example, cigarette smokers became more aware of the harmful effects of smoking in the 1960s. Subsequently, the tobacco industry introduced a 'healthier alternative': the 'light'-cigarette. These light-cigarettes have filters with visible and/ or microscopically small ventilation holes through which additional air is drawn when taking a puff. The high ventilation leads to dilution of smoke and lower tar, nicotine and $\mathrm{CO}$ (TNCO) yields when machine smoked according to ISO. This is used by the manufacturer to define as a regular, medium-, low- or ultra-low tar cigarette ${ }^{13,65}$. Because the smoke entering the smokers' mouth is diluted, smokers perceived the light-cigarette as milder and less irritating to the throat, which enhances the misperception of consuming a less harmful product (i.e. reduced TNCO-intake). However, it is discussed that the smoker will adapt his or her smoking behavior consciously or unconsciously (compensatory smoking behavior) $64,66,67$ to gain the nicotine to which they are accustomed. If they smoke a cigarette with (more) filter vents, the puff volume might be greater and the concentration of nicotine and other toxicants per puff will change ${ }^{68}$. An increased puffing intensity resulted in an increase in the concentration of tar and nicotine yields because ventilation and tar reduction depend on how fast and large the puff is ${ }^{69,70}$. In order to handle the higher puff volume smokers' inhale more deeply; they also take more and/or longer puffs or even smoke more CPD ${ }^{34,64}$. Smokers may also cover some of the ventilation holes, consciously or unconsciously, with their fingers and mouth while they are smoking. Nowadays, all commercial cigarettes have a certain amount of filter vents located at the filter tip. The amount of additional air drawn in varies from 10 to $83 \%$ and depends on the number, the size and the position of the filter vents ${ }^{64}$. In addition, from machine smoking experiments is known that as filter ventilation increases, the cigarette is burned down less rapidly because of a decreased airflow 
through the burning tip and a drop in temperature. This results in more incomplete combustion, more puffs and thus formation of different toxicants as has been shown using smoking machines ${ }^{64}$. Another effect of filter ventilation is the increase of particle size, due to increased water content, condensation and coagulation of smoke compounds. The slower burn rate of the cigarette and increased residence time of the smoke allows particles to absorb more water, constituents and gases ${ }^{64,71}$. Filter vents appear to have a synergistic effect on the formation of smoke toxicants, which supports the hypothesis of a causal relationship between filter ventilation and increased risk for developing tobacco-related diseases ${ }^{71}$.

\section{Cigarette emissions and smoking machines}

The interaction between the variable puffing topography across smokers and the design features of the product makes that emissions of cigarettes under real-life conditions are hard to predict and thus difficult to control from a regulatory point of view. Generally, smoking machines are used to measure cigarette smoke emissions under standardized conditions in order to guard the consistency of cigarettes, for inter-brand comparison of emissions and for research, e.g., for cigarette toxicity testing or identification of smoke constituents. Cigarettes are usually machine smoked according to a particular puffing regime followed by measuring the chemical emissions in the mainstream smoke. Moreover, standardized machine smoking regimes were introduced to provide information in the relative ranking of cigarettes in terms of TNCO yields. The Federal Trade Commission (FTC) opted a standard method in 1966, followed by comparable methods such as the CORESTA (Cooperation Centre for Scientific Research Relative to Tobacco) Recommended Method in $19699^{72}$ and the DIN method in $1978^{73,74}$. The different methods were harmonized by agreeing on one method, ISO 3308 , which was introduced by the International Standardisation Organisation (ISO) in $1991^{75}$. The puffing parameters are a $35 \mathrm{~mL}$ puff taken for $2 \mathrm{~s}$ every minute. The ISO 3308 regime was, for instance, taken up in the Tobacco Products Directive (TPD). The TPD describes the regulatory standard in the European Union where brands that generate emissions $>10$ $\mathrm{mg}$ of tar, $>1 \mathrm{mg}$ of nicotine or $>10 \mathrm{mg}$ of $\mathrm{CO}$ are prohibited, based on machine smoking according to the ISO regime ${ }^{76}$. However, the ISO 3308 regime is widely acknowledged to be irrelevant for purposes of setting regulatory restrictions as it does not reflect and underestimates human smoking behavior and thus human health 77. The standard settings of ISO 3308 originate from the mid 1960's when cigarette designs differed strongly from nowadays cigarettes. Later on, a more intensive set of puffing parameters for smoking machines was introduced by Health Canada as the Health Canada Intense $(\mathrm{HCl})$ regime; a $55 \mathrm{~mL}$ puff is taken for two seconds twice 
a minute. In addition, any filter ventilation holes of the cigarette are taped, thereby preventing dilution of the smoke. Smoking machine yields of cigarette emissions (i.e. TNCO) generated with $\mathrm{HCl}$ are one average 2-3 times higher than yields generated with an ISO regime, due to the combination of the intense puffing parameters and the blocked filter ventilation ${ }^{10,77,78}$. More importantly, the difference between ISO vs $\mathrm{HCl}$ yields increases as ventilation increases. There is an ongoing dispute to what extend emissions generated by smoking machines can be used for risk assessment and regulation of smoke emissions.

\section{Exposure to smoke toxicants}

The amount of toxicants the smoker is exposed to depends on different factors; the number of cigarettes smoked, the toxicants' yields delivered per cigarette that is associated with the puffing behavior and lastly the inhalation process. The number of cigarettes smoked per day can be determined by self-report or by asking smokers to collect their cigarette butts. The range of toxicants that smokers are exposed to, due to these individual differences in puffing topography, is not completely defined. As a surrogate, smoking machine data using different smoking machines regimes can be used to estimate toxicant yields delivered per cigarette. Different regimes can represent the least and most intense smoker, and/or the protocol resulting in the lowest and highest yields. This can be done for smokers either in general or for an individual smoker specifically. The latter is however not commonly used due to the wide variety in human smoking topography and that it is not feasible in practical terms. Another approach to estimate exposure to smoke is the measurement of smoke chemicals, or their metabolites, in human body fluids such as saliva, blood and urine. As cigarette smoke first enters the mouth, saliva might be used to estimate mouth-level exposure to nicotine or smoke toxicants. Researchers were able to determine cotinine, the metabolite of nicotine, in saliva ${ }^{79-81}$ of smokers and proposed it as a good and non-invasive exposure marker of cigarette smoke ${ }^{81}$. Oral mucosa cells obtained from mouth rinses or brushes can be a source for biomarkers of tobacco smoke exposure and molecular changes that are potentially related to cancer ${ }^{82}$. Blood reflects uptake of smoke toxicants into the circulation and therefore blood and urine levels of nicotine, cotinine and other smoke toxicants and their metabolites can be used to estimate the uptake due to smoking ${ }^{83-88}$. Lastly, exhaled breath might also be used as biomarker of exposure because after inhalation, the smoker exhales the smoke ${ }^{89}$. Due to the intermittent exposure to smoke by lighting several cigarettes throughout the day, sampling randomly during a day does not inform on peak exposure, acute exposure nor exposure due to smoking a single cigarette. There is still a gap in knowledge about how individual smoking behavior 
determines smoke toxicant yields, and the subsequent bodily exposure of these smoke toxicants. To accurately determine the relation between the internal dose of the smoker and their personal smoking behavior, smoke toxicants formed and released under puffing parameter conditions should be measured.

\section{Hazard and risk assessment}

Risk assessment describes the overall process of hazard identification, hazard characterization, exposure characterization, and risk evaluation. First, hazards, which is anything that could be potentially damaging, and risk factors are identified. Then, the risk is analyzed and evaluated, which is the chance that someone will experience the damaging effects upon exposure to the hazard. Risk assessment can be used to inform stakeholders, improve information for the public and may lead to regulation. This principle of risk assessment also applies to the assessment of cigarette smoking-related risks to cause harm and develop diseases. This can be a total risk or a risk to develop a specific disease, and can be based on single toxicants or whole smoke. However, the complexity of the mixture of thousands of chemicals with different concentrations in mainstream smoke, combined with the dynamics of the formation of the smoke that depends on the smoker's behavior and the cigarette design complicate risk assessment of cigarette smoke. In addition to using smoke condensate or mainstream smoke, during the last two decades attempts have been made to assess the risk attributed to various chemical and toxicological classes of smoke constituents. The main data sources for risk assessment are articles listing smoke constituents, particularly the Hoffmann list ${ }^{15,90,91}$. This list formed the basis of Health Canada's monitoring for tobacco constituents ${ }^{92}$. Another list was published by Counts et al. consisting of 44 individual smoke toxicants according to three machine smoking regimes in 48 Philip Morris brands, overlapping with the Hoffmann list ${ }^{16}$. There is also overlap with the list of Rodgman et al. that contains 162 tobacco and/or tobacco smoke components, each of which was classified as biologically adverse ${ }^{93}$. One of the first risk assessments concerning smoke toxicants was done by Vorhees and Dodson and was supported by the Massachusetts Department of Public Health Tobacco Control Program ${ }^{94}$. They used yield data for smoke constituents in 25 brands of conventional cigarettes to calculate cancer risks due to 71 smoke toxicants. Fowles and Dybing provided a hazard prioritization index of 158 toxicants, including 41 carcinogens, based on machine smoking ISO data ${ }^{17}$. They calculated the cancer risk index (CRI) by multiplying the cancer potency factors (CPFs) with yield levels derived from machine smoking cigarettes according to the ISO 3308 regime. The non-cancer risk index was calculated by dividing the ISO yield levels with reference exposure levels (RELs) ${ }^{17}$. This research was already part of the year 
2000-report for the New Zealand Ministry of Health ${ }^{95}$. Pankow et al. 2007 focused on different types of cigarettes ('regular', 'light', and 'ultralight') and calculated the lung cancer risk for 13 smoke toxicants in 26 brands ('regular', 'light', and 'ultralight') and eight potentially reduced exposure tobacco products (PREP) ${ }^{96}$. Data originated from the Massachusetts Benchmark Study that used the Massachusetts smoking machine regime. Cancer risks were calculated for an assumed smoking dose of one pack-year (=7300 cigarettes), a body weight of $70 \mathrm{~kg}$, and a 70-year lifetime. Moreover, a cumulative risk (accumulation of risk factors) was computed with an additive model of the US Environmental Protection Agency. The sum of the risks calculated by Fowles and Dybing was lower than the risks based on epidemiology data. Therefore, the WHO technical report $951{ }^{97}$ revised the method of Fowles and Dybing ${ }^{17}$ in that yields derived from machine smoking according to $\mathrm{HCl}$ were used ${ }^{16}$, after normalization per milligram of nicotine. Using normalized levels of toxicants per $\mathrm{mg}$ nicotine included reduces the misleading differences between levels of toxicants expressed per cigarette due to differences in smoking behavior. Talhout et al. updated the Hoffmann list to identify 'constituents of concern' by generating a database consisting of 542 smoke toxicant levels with an extensive literature search ${ }^{18}$. A human inhalation risk value for 98 compounds was found, based on carcinogenicity, cardiovascular and pulmonary disease endpoints, which can be used for regulatory purposes. In 2014, WHO Study Group on Tobacco Product Regulation (TobReg) updated their priority list to 38 toxicants and suggested that their list should be used for monitoring and regulating the contents and emissions of cigarettes, as required by Article 9 of the WHO FCTC ${ }^{98,99}$. The US Food \& Drug Administration (FDA) has published a list of 106 "harmful or potentially harmful" tobacco and tobacco smoke components (HPHC) and has updated it over time as toxicological knowledge and analytical techniques have advanced ${ }^{100,101}$. Marano et al. addressed numerical increases and decreases in HPHC yields between two or more tobacco products ${ }^{102}$. They considered that $\mathrm{HCl}$ regime yields are representative for human smoking and the default assumption of $100 \%$ absorption should be used. This is a conservative approach because part of the volatiles are exhaled. USEPA environmental site risk assessment methodology, with minor adjustments, was demonstrated to be suitable as risk assessment method for tobacco products. Some risk assessment approaches focused on nicotine ${ }^{103,104}$ or specific smoke toxicants 103,105-109, while others focused on specific endpoints, for example lung related disease 110, or on smokers' characteristics, for example, ethnicity ${ }^{108}$.

Limitations are the number of smoke toxicants with actual measured yields in smoke and gaps in the potency values. The first study using exposure data more 
representative to human smoking was the study of Watanabe et al. ${ }^{111}$. They performed a probabilistic risk assessment (Monte Carlo method), probability distributions of incremental lifetime cancer risk (ILCR)) accounting for uncertainty and variability in the way people smoke cigarettes and differentiates between 'regular' and 'light' cigarettes and the number of cigarettes per day. The focus was on benzo[a]pyrene, $\mathrm{N}$-nitrosonornicotine and nicotine-derived nitrosamine ketone emissions measured under human smoking conditions from Djordjevic et al. (2000) 112. The incremental lifetime cancer risk (ILCR) for male regular smokers was similar to that for female regular smokers and the same trend was seen for 'light' smokers. The advantage of incorporating uncertainty and variability in yields and among smoking behaviors is the more robust estimate of toxicant hazards and risk. Others tried to estimate human exposure by measuring compounds such as nicotine in spent butts ${ }^{113}$ or by using computer models ${ }^{114}$. Pack et al. aimed to estimate the uptake of the 38 toxicants on the WHO TobReg list based on human-smoked toxicant yields in 361 Korean smokers ${ }^{113}$. Nicotine determined in spent cigarette butts (part-filter method (PFM) was compared with the measures of smoking machine experiments (8 regimes). Smokers' systemic uptake of the 38 toxicants was derived by considering loss mechanisms, such as mouth spill (MS) (e.g. smoke escaping from mouth) and respiratory retention (RR), adopted from published results for conventional cigarettes. Consequently, a comprehensive risk was assessed followed by a Korean specific priority list of toxicants. Corley et al. had another approach; machine-smoking data was used as intake in a model to predict specific respiratory tissue exposure ${ }^{114}$. Exposure conditions were calculated based on human body weight, cardiac output, puffing behavior (puffs/cig), and yield per cigarette and per puff, volume and concentration of the oral cavity.

In summary, a variety of lists with hazardous compounds and approaches have been used to assess the hazard and/or risk of tobacco smoke, or classes of smoke constituents. Many studies focused on the particles phase of the smoke, which contains many of the heavy metals, nitrosamines, polycyclic aromatic hydrocarbons (PAHs) and many other chemicals with low boiling or sublimation points. Other focused on the volatile constituents of mainstream tobacco smoke. In the WHO TobReg study it has been shown that machine smoke yields of individual compounds within the class of volatile aldehydes correlate with each other ${ }^{97}$. A similar observation is reported for VOCs. However, it is unclear whether this also applies for actual exposure of smokers. Moreover, more in general, all risk assessments suffer from inadequate exposure assessment. Although cigarette per day and smoking machine yields generate exposure assessment data that to some extend can be used for risk 
assessment, better quantification of exposure of tobacco smoke constituents under standardized testing conditions would serve regulatory measures. Since in Fowles and Dybing ${ }^{17}$, WHO TobReg technical report 95197 and others initially assessed that aldehydes and other VOCs pose the highest risk to cigarette smokers based on smoking machine data, quantification of actual exposure of human smokers contributes to better risk assessment to support product regulation in the future.

\section{WHO Framework Convention on Tobacco Control and tobacco regulation}

It is estimated that during the last century, tobacco consumption was the cause of death of approximately 100 million people worldwide. With the growing world population and the 'highly engineered cigarette products' it is estimated that almost 1 billion people will die due to tobacco consumption in the $21^{\text {st }}$ century ${ }^{115}$. In the last decade of the 20st century, the WHO took the initiative to regulate tobacco products based on an international treaty. The WHO FCTC entered into force as a response to the global tobacco epidemic in $2005{ }^{116}$. The Parties that signed the Convention are legally bound to the treaty's provisions that are described in 38 articles. The first sentence in the preamble of the treaty reads ".. that the spread of the tobacco epidemic is a global problem with serious consequences for public health that calls for the widest possible international cooperation and the participation of all countries in an effective, appropriate and comprehensive international response". The core articles 6 to 14 state the price, tax measures, and non-price measures to reduce the demand for tobacco. The non-price measures include protection from exposure to tobacco smoke, regulation of tobacco products and disclosures, packaging and labelling of tobacco products, education, communication, training, and public awareness, tobacco advertising, promotion and sponsorship, and demand reduction measures concerning tobacco dependence and cessation. Preventing initiation of tobacco product use, promoting cessation of tobacco use, and protecting the public from exposure to second hand smoke are the most effective approaches to reduce tobacco related morbidity and mortality. Article 9 and 10 of the treaty include regulations of the content and disclosures of tobacco products, from a harm reduction perspective ${ }^{116}$. Harm reduction consists of a package of measures that prevents the harmful effects of legal or illegal human behavior without necessarily changing the behavior itself. Harm reduction includes interventions, programs and policy measures that aim to reduce health, social and economic damage of, for example, drug use to individuals, communities and reduce societies (EMCDDA 2010). A tobacco product may be harm reducing if it lowers total tobacco related mortality and morbidity even though use of that product may involve continued exposure to tobacco related chemicals ${ }^{65}$. Health professionals have divided opinions 
on the harm reduction perspective: 1) it is unclear whether dose-response curves are linear and thus whether yield reduction is proportional to harm reduction. 2) It is not possible to sufficiently translate reduced yields to reduced exposure, or even reduced risk. 3) The harm reduction principle might distract from quitting smoking. 4) It might tempt to initiate smoking because 'it is less harmful'.

Critics of harm reduction find that tolerating risky or illegal behavior sends a signal to the community that such behavior is acceptable. Furthermore, they find that some of the proposed measures by the advocates of harm reduction do not limit the long-term damage. Consequently, the focus should also, or mainly, be on lowering attractiveness, addictiveness and toxicity of tobacco products.

The WHO study group on Tobacco Product Regulation proposed mandated lowering of toxicants in cigarette smoke ${ }^{117}$. Such a strategy for regulation is based on product performance measures with the goal of reducing toxicant levels in mainstream cigarette smoke measured under standardized conditions. This is a challenge for which scientific data based on toxicological testing are needed to support regulatory approaches. Particularly the use of smoking machine data retrieved under 'standardized conditions' for regulatory purposes is often criticized. Part of the critiques is that such measures are costly and technical, which can be solved by having the tobacco industry pay for it. The other part of the critique is that the standardized conditions of smoking machines cannot be linked to the risks of human smokers from a scientific and biologically relevant perspective.

\section{Aim of this thesis}

Throughout the years, risk assessment approaches are mainly based on machine smoking data and the assumption that human exposure to smoke toxicants is controlled by the smokers' need for nicotine. The IARC-WHO working group even recommended using the ratio between the concentrations of toxicants and nicotine in tobacco smoke for regulation purposes. Furthermore, machine-smoking yields are used to compare different brands and to classify cigarettes based on their nicotine delivery under standardized machine testing conditions. However, in such studies it remains partly unclear how the emission generated by smoking machines should be linked to cigarette emission during human smoking and how predictive such emissions are for actual uptake in the human body. In parallel, in human volunteer studies biomarkers of exposure are used to show actual uptake of tobacco smoke toxicants. Such studies often show substantially elevated concentrations of (biomarkers of) toxicants in smokers' blood compared to those in the blood of non- 
smokers, indicating an increased health risk. However, such studies not always investigate how the actual exposure doses depend on individual smoking behaviors and individual variations in smoking topography. Moreover, the influence of human smoking behavior on blood concentration of smoke toxicants, in combination with the yields of the used products, is scarcely investigated. Additionally, hardly any studies focus on the actual exposure dose of toxicants in the lungs of smokers. To assure the relevance of using machine-smoking data in risk assessment and product regulation, better knowledge regarding how such laboratory data reflect actual human exposure to smoke toxicants is warranted. This is especially needed and relevant for highly ventilated cigarettes of which it is sometimes assumed that the nicotine exposure is very low, even below the threshold of initiation or sustaining of nicotine addiction (daily dose of less than $\sim 5 \mathrm{mg}$ ) as suggested by Benowitz and Henningfield in $1994^{26}$. Therefore, the aim of this thesis is to:

Relate, for the purpose of risk assessment and cigarette product regulation, the emissions of nicotine, carbon monoxide, and volatile organic compounds produced with smoking machines to emissions produced during human smoking, as well as to the actual uptake in the body of smokers, taking into account the smokers' daily use of cigarettes and their personal puffing topography.

In order to provide scientific support for risk assessment, product classification and regulation, the following research questions have been postulated.

Research Question 1 - Do smokers have characteristic puffing topography profiles?

Research Question 2 - How do the puffing regimes ISO 3308 and $\mathrm{HCl}$ used as settings for smoking machines relate to puffing topography of human smokers?

Research Question 3 - Is the nicotine delivery of 'very low yield' cigarettes above the threshold to initiate and sustain nicotine addiction as postulated by Benowitz and Henningfield (1994) ${ }^{26}$ ?

Research Question 4 - Does the individual nicotine systemic uptake change when a different type of cigarette is smoked and are smokers using their puffing topography to (partially) compensate for differences in nicotine yields of the cigarettes?

Research Question 5 - Is the uptake of $\mathrm{CO}$ or other volatile toxicants in tobacco smoke linked to the nicotine uptake during smoking ventilated cigarettes? 
Research Question 6 - Can toxicant yields of cigarettes produced with a smoking machine be used for human risk assessment purposes, or are there alternatives such as exhaled breath?

Research Question 7 - What are the contributions of (variations of) human puffing topography and (differences between) toxicant smoke yields to the risk of smokers?

In Chapter 2, first the focus is on the variation in smoke constituents yields between brands. A smoking machine is used with four standardized settings to allow comparisons of yields aldehydes generated during smoking of 11 cigarette brands of the Dutch market. Second, the focus is particularly on the potential use of nicotine yields of the same brands and tested under the same conditions to normalize the yields of smoke constituents. Special attention is given to highly ventilated cigarettes.

Chapter 3 focuses on VOCs such as benzene and toluene. The influence of high filter ventilation on smoke VOCs generated by a smoking machine is further investigated. The machine-derived data are compared with data of a human study in which the smoke constituents are measured in (headspace of) blood and in exhaled breath.

In Chapter 4, human puffing topography is addressed and the device used in this study that measures human smoking topography (the number of puffs, puff frequency and puff volume) is critically evaluated.

Chapter 5 further elaborates on the findings about the role of filter ventilation on the yields produced by smoking machines under ISO 3308 standardized conditions relative to $\mathrm{HCl}$ conditions and human puffing. Particularly the link between filter ventilation, smoking topography and nicotine uptake by the smoker is investigated.

In Chapter 6 - the general discussion - a summary of the results is given and the research questions are addressed. 


\section{Tobacco filler}

Tobacco is a natural product, grown in many parts of the world, and subject to weather influences. This leads to crop and year variation therefore multiple crop years are used in blended cigarettes to maintain the cigarette taste or intendent slowly change the cigarette. The blends itself are a combination of types of tobacco differing in curing, density and burn properties. Burley tobacco is air cured, has a high filling power and burns excellent, bright (or Virginia) tobacco is flue cured, has a moderate filling power and a variable burn, and oriental tobacco is air cured, has a low filling power and a slow burn. Reconstituted tobacco consists of scraps and stems and it allows manufacturers to make the most efficient use of their tobacco with little waste. The expanded tobacco is a combination of the three before mentioned tobacco sorts, and treated to reduce the weight of the cigarettes by increasing the filling power and burn rate of tobacco without losing taste. A balanced tobacco weight or density ensures the physical stability of the cigarette; however, a reduced tobacco density reduces smoke yields. Blending is done to achieve specific $\mathrm{pH}$, taste, burning characteristics and nicotine content ${ }^{13}$. The recipe for the type of tobacco blend significantly affects the $\mathrm{pH}$, nicotine content and toxicity of the smoke and are therefore closely kept trade secrets of the manufactory industry. The $\mathrm{pH}$ strongly influences the concentration of so-called freebase nicotine in tobacco smoke, whereas the nitrate content influences the carcinogenic potential of smoke ${ }^{65}$. The uncharged, volatile form of nicotine, free-base nicotine, is formed at a specific $\mathrm{pH}$. The higher the $\mathrm{pH}$ of the smoke, the more free-base nicotine is formed, inhaled and leads to higher levels of nicotine that reach the brain ${ }^{118}$. Tobacco blends with high carbohydrate or sugar-content generate more acidic smoke and therefore lower free base nicotine concentrations ${ }^{119}$. Subsequently, smokers will inhale more deeply to satisfy their nicotine-need, or smoke more frequently ${ }^{77,120}$. Moreover, combustion of sugars in tobacco leads to the production of acetaldehyde ${ }^{121}$, which increases the firing potential of dopaminergic nerves in the ventral tegmental area, and thus adds to the addictive potential of the cigarette ${ }^{122}$.

Additives are substances added for specific technological purposes in the manufacture or to advance appealing of tobacco products ${ }^{123} .1$ ) Flavorings impart a specific taste, flavor or aroma to a product and give the tobacco brand its unique sensory characteristics. Moreover, it makes the cigarette attractive, may increase the consumption rate and thus enhances addiction ${ }^{20}$. Since May 2016, characterizing flavors are prohibited and since May 2020, 
menthol is not allowed anymore in the European Union. 2) Humectants increase the moisture-holding capacity of the tobacco and fillers contribute to the volume of the product without contributing significantly to odor, taste or flavor. 3) Preservatives protect the product from deterioration caused by microorganisms, and binders and strengtheners make it possible to maintain the physical state of the product. Lastly, 4) solvents are used to dissolve or dilute ingredients, without altering their function, in order to facilitate their handling and application. The different additives are used in small amounts, not expected to give short-term effects, but their combustion products can be toxic, transforming the smoke in an even more complex chemical mixture. For example, the total particulate matter (gross tar), $\mathrm{CO}$ and carbonyl compounds, especially formaldehyde, increased in smoke when additives were added ${ }^{124,125}$. Additives that make products more toxic in unburnt form, or after combustion, those resulting in a characteristic flavor or encouraging deeper and longer inhalation, increasing the amount of nicotine that gets into the body, are further assessed in order to take regulatory decisions (e.g. limit). Since 2014, the Tobacco Product Directive (TPD) 2014/40/EU prohibits tobacco products containing additives that attribute to carcinogenic, mutagenic and reproductive toxicity in unburnt form or that increase overall toxicity of the tobacco product 76. Especially, the latter is difficult to prove. Moreover, manufacturers are obliged to disclose ingredients of tobacco products on the European market to the EU common entry gate (EU-CEG) ${ }^{126}$. 


\section{References}

1. Proctor RN. The history of the discovery of the cigarette-lung cancer link: evidentiary traditions, corporate denial, global toll. Tob Control. 2012;21(2):87-91.

2. Anderson DO. Smoking and Respiratory Disease. Am J Public Health Nations Health. 1964;54:1856-1863.

3. Crotty Alexander LE, Shin S, Hwang JH. Inflammatory Diseases of the Lung Induced by Conventional Cigarette Smoke: A Review. Chest. 2015;148(5):1307-1322.

4. Rodgman A, Perfetti TA. The Chemical Components of Tobacco and Tobacco Smoke, Second Edition. Boca Raton (FL): CRC Press, Taylor and Francis Group.; 2016.

5. GBD 2017 Tobacco Collaborators. Global, regional, and national comparative risk assessment of 84 behavioural, environmental and occupational, and metabolic risks or clusters of risks for 195 countries and territories, 1990-2017: a systematic analysis for the Global Burden of Disease Study 2017. The Lancet. 2018;392(10159):1923-1994.

6. World Health Organization. Fact sheet: Tobacco. 2020. https://www.who.int/newsroom/fact-sheets/detail/tobacco. Accessed Jan 15th, 2021.

7. WHO. Report on the Global Tobacco Epidemic, 2019. Geneva: World Health Organization Licence: CC BY-NC-SA 3.0 IGO. World Health Organization; 2019.

8. Baker RR, Bishop LJ. The pyrolysis of tobacco ingredients. J Anal Appl Pyrolysis. 2004;71(1):223-311.

9. Baker R. Smoke chemistry. In: Davis DL NM, ed. Tobacco: production, chemistry and technology. Oxford, London, UK: Blackwell Science Ltd.; 1999:398-439.

10. Thielen A, Klus H, Muller L. Tobacco smoke: unraveling a controversial subject. Exp Toxicol Pathol. 2008;60(2-3):141-156.

11. Chen P. Chemistry of Cigarette Burning Processes. Beiträge zur Tabakforschung International/Contributions to Tobacco Research. 2004;21(2):105-110.

12. Liu C, G. McAdam K, A. Perfetti T. Some Recent Topics in Cigarette Smoke Science. Mini Rev Org Chem. 2011;8(4):349-359.

13. IARC. IARC Monographs on the Evaluation of Carcinogenic Risks to Humans: Tobacco Smoke and Involuntary Smoking. IARC: Lyon, France. 2004.

14. Green CR, Rodgman A. The Tobacco Chemists' Research Conference: a half century forum for advances in analytical methodology of tobacco and its products. Fifty years of tobacco science and technology. Recent Advances in Tobacco Science. 1996;22:131-336.

15. Hoffmann D, Hoffmann I, El-Bayoumy K. The less harmful cigarette: a controversial issue. a tribute to Ernst L. Wynder. Chem Res Toxicol. 2001;14(7):767-790.

16. Counts ME, Morton MJ, Laffoon SW, Cox RH, Lipowicz PJ. Smoke composition and predicting relationships for international commercial cigarettes smoked with three machine-smoking conditions. Regul Toxicol Pharmacol. 2005;41(3):185-227. 
17. Fowles J, Dybing E. Application of toxicological risk assessment principles to the chemical constituents of cigarette smoke. Tob Control. 2003;12(4):424-430.

18. Talhout R, Schulz T, Florek E, et al. Hazardous compounds in tobacco smoke. Int J Environ Res Public Health. 2011;8(2):613-628.

19. WHO Study Group on Tobacco Product Regulation. The scientific basis of tobacco product regulation; second report of a WHO study group (945). Geneva, Switserland. World Health Organization; 2007.

20. Talhout R, Richter PA, Stepanov I, Watson CV, Watson CH. Cigarette Design Features: EffectsonEmission Levels, UserPerception, and Behavior. TobRegulSci. 2018;4(1):592-604.

21. Benowitz NL. Clinical pharmacology of nicotine: implications for understanding, preventing, and treating tobacco addiction. Clin Pharmacol Ther. 2008;83(4):531-541.

22. Dickens C, McGrath C, Warren N, Biggs P, McAughey J. Puffing and inhalation behaviour in cigarette smoking: Implications for particle diameter and dose. Journal of Physics: Conference Series. 2009;151(1):012019.

23. Baker RR, Dixon M. The retention of tobacco smoke constituents in the human respiratory tract. Inhal Toxicol. 2006;18(4):255-294.

24. Gregg EO. Assessing Smoking Behaviour and Tobacco Smoke exposure definitions and methods. 2013.

25. Benowitz NL. Nicotine addiction. N Engl J Med. 2010;362(24):2295-2303.

26. Benowitz NL, Henningfield JE. Establishing a nicotine threshold for addiction. The implications for tobacco regulation. N Engl J Med. 1994;331(2):123-125.

27. Tidey JW, Cassidy RN, Miller ME. Smoking Topography Characteristics of Very Low Nicotine Content Cigarettes, With and Without Nicotine Replacement, in Smokers With Schizophrenia and Controls. Nicotine Tob Res. 2016;18(9):1807-1812.

28. Renner B, Schreiber K. Olfactory and trigeminal interaction of menthol and nicotine in humans. Exp Brain Res. 2012;219(1):13-26.

29. Alimohammadi H, Silver WL. Evidence for nicotinic acetylcholine receptors on nasal trigeminal nerve endings of the rat. Chem Senses. 2000;25(1):61-66.

30. Thuerauf N, Markovic K, Braun G, et al. The influence of mecamylamine on trigeminal and olfactory chemoreception of nicotine. Neuropsychopharmacology. 2006;31(2):450461.

31. Wickham RJ. How Menthol Alters Tobacco-Smoking Behavior: A Biological Perspective. The Yale journal of biology and medicine. 2015;88(3):279-287.

32. Lee EM, Malson JL, Waters AJ, Moolchan ET, Pickworth WB. Smoking topography: reliability and validity in dependent smokers. Nicotine Tob Res. 2003;5(5):673-679.

33. Bridges RB, Combs JG, Humble JW, et al. Puffing topography as a determinant of smoke exposure. Pharmacol Biochem Behav. 1990;37(1):29-39.

34. Marian C, O'Connor RJ, Djordjevic MV, et al. Reconciling human smoking behavior and 
machine smoking patterns: implications for understanding smoking behavior and the impact on laboratory studies. Cancer Epidemiol Biomarkers Prev. 2009;18(12):3305-3320.

35. Schorp MK. Summary of Literature Data on Smoking Topography. 2005. https://www. industrydocumentslibrary.ucsf.edu/tobacco/docs/gpxm0149. Accessed Jan 16th, 2021.

36. Liang Q, Roethig HJ, Lipowicz PJ, Jin Y, Mendes PE. The effect of cigarette burn time on exposure to nicotine and carbon monoxide in adult smokers. Regul Toxicol Pharmacol. 2008;50(1):66-74.

37. Blank MD, Disharoon S, Eissenberg T. Comparison of methods for measurement of smoking behavior: mouthpiece-based computerized devices versus direct observation. Nicotine Tob Res. 2009;11(7):896-903.

38. Strasser AA, Ashare RL, Kozlowski LT, Pickworth WB. The effect of filter vent blocking and smoking topography on carbon monoxide levels in smokers. Pharmacol Biochem Behav. 2005;82(2):320-329.

39. Norton KJ, June KM, O'Connor RJ. Initial puffing behaviors and subjective responses differ between an electronic nicotine delivery system and traditional cigarettes. Tob Induc Dis. 2014;12(1):17.

40. Chen A, Krebs NM, Zhu J, Muscat JE. Nicotine metabolite ratio predicts smoking topography: The Pennsylvania Adult Smoking Study. Drug Alcohol Depend. 2018;190:8993.

41. Farris SG, Aston ER, Abrantes AM, Zvolensky MJ. Tobacco demand, delay discounting, and smoking topography among smokers with and without psychopathology. Drug Alcohol Depend. 2017;179:247-253.

42. Kim S, Yu S. Smoking Topography among Korean Smokers: Intensive Smoking Behavior with Larger Puff Volume and Shorter Interpuff Interval. Int J Environ Res Public Health. 2018;15(5).

43. Melikian AA, Djordjevic MV, Hosey J, et al. Gender differences relative to smoking behavior and emissions of toxins from mainstream cigarette smoke. Nicotine Tob Res. 2007;9(3):377-387.

44. Kassel JD, Greenstein JE, Evatt DP, et al. Smoking topography in response to denicotinized and high-yield nicotine cigarettes in adolescent smokers. J Adolesc Health. 2007;40(1):5460.

45. Perkins KA, Karelitz JL, Giedgowd GE, Conklin CA. The reliability of puff topography and subjective responses during ad lib smoking of a single cigarette. Nicotine Tob Res. 2012;14(4):490-494.

46. Shiffman S, Paty J. Smoking patterns and dependence: contrasting chippers and heavy smokers. J Abnorm Psychol. 2006;115(3):509-523.

47. ShahabL, HammondD, O'ConnorRJ, etal.The reliabilityand validity of self-reported puffing behavior: evidence from a cross-national study. Nicotine Tob Res. 2008;10(5):867-874. 
48. Adam T, Baker RR, Zimmermann R. Characterization of puff-by-puff resolved cigarette mainstream smoke by single photon ionization-time-of-flight mass spectrometry and principal component analysis. J Agric Food Chem. 2007;55(6):2055-2061.

49. Xie JP, Sun SH, Wang HY, et al. Determination of nicotine in mainstream smoke on the single puff level by liquid-phase microextraction coupled to matrix-assisted laser desorption/ionization Fourier transform mass spectrometry. Rapid Commun Mass Spectrom. 2006;20(17):2573-2578.

50. Cahours X, Julien R, Verron T, Colard S. Assessment of Nicotine Exposure From Active Human Cigarette Smoking Time Beiträge zur Tabakforschung / Contributions to Tobacco Research. 2017.

51. Krebs NM, Chen A, Zhu J, et al. Comparison of Puff Volume With Cigarettes per Day in Predicting Nicotine Uptake Among Daily Smokers. Am J Epidemiol. 2016;184(1):48-57.

52. Mercincavage $M$, Lochbuehler K, Wileyto EP, et al. Association of Reduced Nicotine Content Cigarettes With Smoking Behaviors and Biomarkers of Exposure Among Slow and Fast Nicotine Metabolizers: A Nonrandomized Clinical Trial. JAMA Netw Open. 2018;1(4):e181346-e181346.

53. Ross KC, Dempsey DA, St Helen G, Delucchi K, Benowitz NL. The Influence of Puff Characteristics, Nicotine Dependence, and Rate of Nicotine Metabolism on Daily Nicotine Exposure in African American Smokers. Cancer Epidemiol Biomarkers Prev. 2016;25(6):936-943.

54. Strasser AA, Benowitz NL, Pinto AG, et al. Nicotine metabolite ratio predicts smoking topography and carcinogen biomarker level. Cancer Epidemiol Biomarkers Prev. 2011;20(2):234-238.

55. Williams JM, Gandhi KK, Lu SE, et al. Shorter interpuff interval is associated with higher nicotine intake in smokers with schizophrenia. Drug Alcohol Depend. 2011;118(2-3):313319.

56. Williams JM, Gandhi KK, Lu SE, Steinberg ML, Benowitz NL. Nicotine intake and smoking topography in smokers with bipolar disorder. Bipolar Disord. 2012;14(6):618-627.

57. Adam T, Mitschke S, Streibel T, Baker RR, Zimmermann R. Quantitative puff-by-puffresolved characterization of selected toxic compounds in cigarette mainstream smoke. Chem Res Toxicol. 2006;19(4):511-520.

58. Adam T, Mitschke S, Baker RR. Investigation of Tobacco Pyrolysis Gases and Puff-bypuff Resolved Cigarette Smoke by Single Photon Ionisation (SPI) - Time-of-flight Mass Spectrometry (TOFMS). Beiträge zur Tabakforschung International/Contributions to Tobacco Research. 2009;23(4):203-226.

59. Adam T, McAughey J, McGrath C, Mocker C, Zimmermann R. Simultaneous on-line size and chemical analysis of gas phase and particulate phase of cigarette mainstream smoke. Anal Bioanal Chem. 2009;394(4):1193-1203. 
60. Counts ME, Hsu FS, Laffoon SW, Dwyer RW, Cox RH. Mainstream smoke constituent yields and predicting relationships from a worldwide market sample of cigarette brands: ISO smoking conditions. Regul Toxicol Pharmacol. 2004;39(2):111-134.

61. Counts ME, Hsu FS, Tewes FJ. Development of a commercial cigarette "market map" comparison methodology for evaluating new or non-conventional cigarettes. Regul Toxicol Pharmacol. 2006;46(3):225-242.

62. Doll R. Chapter 1 Evolution of knowledge of the smoking epidemic. Tobacco: Science, policy and public health: Oxford University Press; 2010.

63. Podraza KF. Basic Principles of Cigarette Design and Function. http://www.Isro.org/ presentation_files/air/m_011029/podraza_102901.pdf. Accessed Jan 16th, 2021.

64. Song MA, Benowitz NL, Berman M, et al. Cigarette Filter Ventilation and its Relationship to Increasing Rates of Lung Adenocarcinoma. J Natl Cancer Inst. 2017;109(12).

65. Stratton K, Shetty P, Wallace R, Bondurant S. Clearing the smoke: the science base for tobacco harm reduction--executive summary. Tob Control. 2001;10(2):189-195.

66. Kozlowski LT, O'Connor RJ, Sweeney CT. Cigarette design. In: U.S. Department of Health and Human Services NloH, National Cancer Institute, ed. Risks associated with smoking cigarettes having low machine-measured levels of tar and nicotine. Smoking and Tobacco Control Monograph, No 13. Bethesda, MD2001.

67. Benowitz NL. Compensatory smoking of low-yield cigarettes. In: U.S. Department of Health and Human Services NloH, National Cancer Institute, ed. Risks associated with smoking cigarettes having low machine-measured levels of tar and nicotine. Smoking and Tobacco Control Monograph, No 13. Bethesda, MD2001.

68. Harris JE. Incomplete compensation does not imply reduced harm: yields of 40 smoke toxicants per milligram nicotine in regular filter versus low-tar cigarettes in the 1999 Massachusetts Benchmark Study. Nicotine Tob Res. 2004;6(5):797-807.

69. Battig K, Buzzi R, Nil R. Smoke yield of cigarettes and puffing behavior in men and women. Psychopharmacology (Berl). 1982;76(2):139-148.

70. Hammond D, Fong GT, Cummings KM, Hyland A. Smoking topography, brand switching, and nicotine delivery: results from an in vivo study. Cancer Epidemiol Biomarkers Prev. 2005;14(6):1370-1375.

71. Adam T, McAughey J, Mocker C, McGrath C, Zimmermann R. Influence of filter ventilation on the chemical composition of cigarette mainstream smoke. Anal Chim Acta. 2010;657(1):36-44.

72. CORESTA. Recommended Method No. 10: Machine smoking of cigarettes, determination of crude and dry smoke condensate. CORESTA; 1969.

73. Deutsches Institut für Normung. Analysis of tobacco and tobacco products - Machine smoking of cigarettes and determination of smoke condensate: requirements for an analytical smoking machine. 1978. 
74. Baker R. The Development and Significance of Standards for Smoking-Machine Methodology. Beiträge zur Tabakforschung International/Contributions to Tobacco Research. 2002;20(1):23-41.

75. ISO 3308:2012. Routine analytical cigarette-smoking machine -definitions and standard conditions. Geneva, Switzerland: International Organization for Standardization; 2012.

76. European Union. Tobacco Products Directive (2014/40/EU). Brussels, Belgium: Offical Journal of the European Union; 2014.

77. Hammond D, Fong GT, Cummings KM, et al. Cigarette yields and human exposure: a comparison of alternative testing regimens. Cancer Epidemiol Biomarkers Prev. 2006;15(8):1495-1501.

78. Hammond D, Wiebel F, Kozlowski LT, et al. Revising the machine smoking regime for cigarette emissions: implications for tobacco control policy. Tob Control. 2007;16(1):8-14.

79. Bernert JT, Jr., McGuffey JE, Morrison MA, Pirkle JL. Comparison of serum and salivary cotinine measurements by a sensitive high-performance liquid chromatography-tandem mass spectrometry method as an indicator of exposure to tobacco smoke among smokers and nonsmokers. J Anal Toxicol. 2000;24(5):333-339.

80. St Charles FK, Krautter GR, Dixon M, Mariner DC. A comparison of nicotine dose estimates in smokers between filter analysis, salivary cotinine, and urinary excretion of nicotine metabolites. Psychopharmacology (Berl). 2006;189(3):345-354.

81. Yuki D, Kikuchi A, Miura N, Kakehi A, Onozawa M. Good relationship between saliva cotinine kinetics and plasma cotinine kinetics after smoking one cigarette. Regul Toxicol Pharmacol. 2013;67(2):240-245.

82. Paiano V, Maertens L, Guidolin V, et al. Quantitative Liquid ChromatographyNanoelectrospray Ionization-High Resolution Tandem Mass Spectrometry Analysis of Acrolein-DNA Adducts and Etheno-DNA Adducts in Oral Cells from Cigarette Smokers and Non-smokers. Chem Res Toxicol. 2020.

83. Brugnone F, Perbellini L, Faccini GB, et al. Breath and blood levels of benzene, toluene, cumene and styrene in non-occupational exposure. Int Arch Occup Environ Health. 1989;61(5):303-311.

84. Blount BC, Kobelski RJ, McElprang DO, et al. Quantification of 31 volatile organic compounds in whole blood using solid-phase microextraction and gas chromatographymass spectrometry. J Chromatogr B Analyt Technol Biomed Life Sci. 2006;832(2):292-301.

85. Chambers DM, Ocariz JM, McGuirk MF, Blount BC. Impact of cigarette smoking on volatile organic compound (VOC) blood levels in the U.S. population: NHANES 20032004. Environ Int. 2011;37(8):1321-1328.

86. Benowitz NL, Jacob P, 3rd, Herrera B. Nicotine intake and dose response when smoking reduced-nicotine content cigarettes. Clin Pharmacol Ther. 2006;80(6):703-714.

87. Benowitz NL, Hukkanen J, Jacob P, 3rd. Nicotine chemistry, metabolism, kinetics and 
biomarkers. Handb Exp Pharmacol. 2009(192):29-60.

88. Yuan JM, Butler LM, Stepanov I, Hecht SS. Urinary tobacco smoke-constituent biomarkers for assessing risk of lung cancer. Cancer Res. 2014;74(2):401-411.

89. Chen X, Wang F, Lin L, et al. Association of Smoking with Metabolic Volatile Organic Compounds in Exhaled Breath. Int J Mol Sci. 2017;18(11):2235.

90. Hoffmann D, Djordjevic MV, Hoffmann I. The changing cigarette. Prev Med. 1997;26(4):427-434.

91. Hoffmann D, Hoffmann I. Letters to the Editor - Tobacco smoke components. Beiträge zur Tabakforschung International/Contributions to Tobacco Research. 1998;18(1):49-52.

92. Hammond D, O'Connor RJ. Constituents in tobacco and smoke emissions from Canadian cigarettes. Tob Control. 2008;17 Suppl 1:i24-31.

93. Rodgman A, Green CR. Toxic Chemicals in Cigarette Mainstream Smoke - Hazard and Hoopla. Beiträge zur Tabakforschung International/Contributions to Tobacco Research. 2003;20(8):481-545.

94. Vorhees DJ DR. Estimating risk to cigarette smokers from smoke constituents in proposed "Testing and Reporting of Constituents of Cigarette Smoke" Regulations. Boston (MA): Menzie-Cura \& Associates, Inc. 1999.

95. Fowles J, Bates M, Noiton D. The Chemical Constituents in Cigarettes and Cigarette Smoke: Priorities for Harm Reduction. A report to the New Zealand Ministery of Health. 2000.

96. Pankow JF, Watanabe KH, Toccalino PL, Luo W, Austin DF. Calculated cancer risks for conventional and "potentially reduced exposure product" cigarettes. Cancer Epidemiol Biomarkers Prev. 2007;16(3):584-592.

97. WHO Study Group on Tobacco Product Regulation (TobReg). Report on the Scientific Basis of Tobacco Product Regulation; second report. WHO Technical Report Series 951. Geneva, Switserland: World Health Organization; 2008.

98. WHO Conference of the Parties (COP) to the Framework Convention on Tobacco Control (FCTC). Partial guidelines for the implementation of Articles 9 and 10 of the WHO FCTC (FCTC/COP/4/10). Moscow, Russian Federation. World Health Organization; 2010.

99. WHO Conference of the Parties (COP) to the Framework Convention on Tobacco Control (FCTC). Work in progress in relation to Articles 9 and 10 of the WHO FCTC (FCTC/ COP/6/14). Moscow, Russian Federation. World Health Organization; 2014.

100. U.S. Food and Drug Administration. Harmful and potentially harmful constituents in tobacco products and tobacco smoke; established list. Vol Federal Register Vol. 77, No. 64. Washington, US: Department of Health and Human Services; 2012.

101. U.S. Food and Drug Administration. Harmful and Potentially Harmful Constituents in Tobacco Products and Tobacco Smoke; Request for Comments. Washington, US. Department of Health and Human Services; 2011.

102. Marano KM, Liu C, Fuller W, Gentry PR. Quantitative risk assessment of tobacco 
products: A potentially useful component of substantial equivalence evaluations. Regul Toxicol Pharmacol. 2018;95:371-384.

103. Baumung C, Rehm J, Franke H, Lachenmeier DW. Comparative risk assessment of tobacco smoke constituents using the margin of exposure approach: the neglected contribution of nicotine. Sci Rep. 2016;6:35577.

104. Lachenmeier DW, Rehm J. Comparative risk assessment of alcohol, tobacco, cannabis and other illicit drugs using the margin of exposure approach. Sci Rep. 2015;5:8126.

105. Marano KM, Naufal ZS, Kathman SJ, et al. Cadmium exposure and tobacco consumption: Biomarkers and risk assessment. Regul Toxicol Pharmacol. 2012;64(2):243-252.

106. Marano KM, Naufal ZS, Kathman SJ, et al. Arsenic exposure and tobacco consumption: Biomarkers and risk assessment. Regul Toxicol Pharmacol. 2012;64(2):225-232.

107. Soeteman-Hernandez LG, Bos PM, Talhout R. Tobacco smoke-related health effects induced by 1,3-butadiene and strategies for risk reduction. Toxicol Sci. 2013;136(2):566580.

108. Xie J, Marano KM, Wilson CL, et al. A probabilistic risk assessment approach used to prioritize chemical constituents in mainstream smoke of cigarettes sold in China. Regul Toxicol Pharmacol. 2012;62(2):355-362.

109. Hossain MT, Hassi U, Imamul Huq SM. Assessment of concentration and toxicological (Cancer) risk of lead, cadmium and chromium in tobacco products commonly available in Bangladesh. Toxicol Rep. 2018;5:897-902.

110. Cunningham FH, Fiebelkorn S, Johnson M, Meredith C. A novel application of the Margin of Exposure approach: segregation of tobacco smoke toxicants. Food Chem Toxicol. 2011;49(11):2921-2933.

111. Watanabe KH, Djordjevic MV, Stellman SD, et al. Incremental lifetime cancer risks computed for benzo[a]pyrene and two tobacco-specific N-nitrosamines in mainstream cigarette smoke compared with lung cancer risks derived from epidemiologic data. Regul Toxicol Pharmacol. 2009;55(2):123-133.

112. Djordjevic MV, Stellman SD, Zang E. Doses of nicotine and lung carcinogens delivered to cigarette smokers. J Natl Cancer Inst. 2000;92(2):106-111.

113. Pack EC, Kim HS, Jang DY, et al. Risk assessment of toxicants on WHO TobReg priority list in mainstream cigarette smoke using human-smoked yields of Korean smokers. Environ Res. 2019;169:206-219.

114. Corley RA, Kabilan S, Kuprat AP, et al. Comparative Risks of Aldehyde Constituents in Cigarette Smoke Using Transient Computational Fluid Dynamics/Physiologically Based Pharmacokinetic Models of the Rat and Human Respiratory Tracts. Toxicol Sci. 2015;146(1):65-88.

115. Connor SA. Smoking will 'kill up to a billion people worldwide this century. The Independent. October 28th 2012. 
116. World Health Organisation. Framework Convention on Tobacco Control. Geneva, Switzerland 2003 updated reprint 2004, 2005.

117. Burns DM, Dybing E, Gray N, et al. Mandated lowering of toxicants in cigarette smoke: a description of the World Health Organization TobReg proposal. Tob Control. 2008;17(2):132-141.

118. Willems EW, Rambali B, Vleeming W, Opperhuizen A, van Amsterdam JG. Significance of ammonium compounds on nicotine exposure to cigarette smokers. Food Chem Toxicol. 2006;44(5):678-688.

119. Wayne GF, Carpenter CM. Tobacco Industry Manipulation of Nicotine Dosing. In: Henningfield J.E. LED, Pogun S. (eds), ed. Nicotine Psychopharmacology. Handbook of Experimental Pharmacology. Berlin, Heidelberg, Germany: Springer; 2009.

120. Jarvis MJ, Boreham R, Primatesta P, Feyerabend C, Bryant A. Nicotine yield from machinesmoked cigarettes and nicotine intakes in smokers: evidence from a representative population survey. J Natl Cancer Inst. 2001;93(2):134-138.

121. Pennings JLA, Cremers J, Becker MJA, Klerx WNM, Talhout R. Aldehyde and Volatile Organic Compound Yields in Commercial Cigarette Mainstream Smoke Are Mutually Related and Depend on the Sugar and Humectant Content in Tobacco. Nicotine Tob Res. 2020;22(10):1748-1756.

122. Paschke T, Scherer G, Heller WD. Effects of Ingredients on Cigarette Smoke Composition and Biological Activity: A Literature Overview. Beiträge zur Tabakforschung International/ Contributions to Tobacco Research. 2002;20(3):107-247.

123. Wertz MS, Kyriss T, Paranjape S, Glantz SA. The toxic effects of cigarette additives. Philip Morris' project mix reconsidered: an analysis of documents released through litigation. PLoS Med. 2011;8(12):e1001145.

124. Baker RR, Pereira da Silva JR, Smith G. The effect of tobacco ingredients on smoke chemistry. Part I: Flavourings and additives. Food Chem Toxicol. 2004;42 Suppl:S3-37.

125. Hahn J, Schaub J. Influence of Tobacco Additives on the Chemical Composition of Mainstream Smoke. Beiträge zur Tabakforschung / Contributions to Tobacco Research. Vol 242014:100.

126. European Union. EU common entry gate (EU-CEG). 2016. https://ec.europa.eu/health/ euceg/introduction_nl. Accessed Jan 16th, 2021. 




\section{Chapter 2. Cigarette filter}

\section{ventilation and smoking}

\section{protocol influence aldehyde}

\section{smoke yields}

Charlotte G.G.M. Pauwels, Walther N.M. Klerx, Jeroen L.A. Pennings, Agnes W. Boots, Frederik J. van Schooten, Antoon Opperhuizen, Reinskje Talhout. 


\begin{abstract}
The WHO study group on tobacco product regulation (TobReg) advised regulating and lowering toxicant levels in cigarette smoke. Aldehydes are one of the chemical classes on the TobReg smoke toxicants priority list. To provide insight in factors determining aldehyde yields, the levels of 12 aldehydes in mainstream cigarette smoke of 11 Dutch brands were quantified. Variations in smoking behavior and cigarette design affecting human exposure to aldehydes were studied by using four different machine testing protocols. Machine smoking was based on the International Standardization Organization (ISO) and Health Canada Intense $(\mathrm{HCl})$ regime, both with and without taping the filter vents. The 11 cigarette brands differed in (i) design and blend characteristics; (ii) tar, nicotine, and carbon monoxide (TNCO) levels; (iii) popularity; and (iv) manufacturer. Cigarette smoke was trapped on a Cambridge filter pad and carboxen cartridge. After being dissolved in methanol/CS2 and derivatization with DNPH, the aldehyde yields were determined using HPLC-DAD. Using an intense smoking regime (increased puff volume, shorter puff interval) significantly increased aldehyde yields, following the pattern: ISO $<$ ISO-taped $<\mathrm{HCl}$-untaped $<\mathrm{HCl}$. For all of the regimes, acetaldehyde and acrolein yields were strongly correlated $(r=0.804)$. The difference in TNCO and aldehyde levels between regular and highly ventilated low-TNCO cigarettes (as measured using ISO) diminished when smoking intensely; this effect is stronger when combined with taping filter vents. The highly ventilated low-TNCO brands showed six times more aldehyde production per mg nicotine for the intense smoking regimes. In conclusion, acetaldehyde and acrolein can be used as representatives for the class of volatile aldehydes for the different brands and smoking regimes. The aldehyde-to-nicotine ratio increased when highly ventilated cigarettes were smoked intensely, similar to real smokers. Thus, a smoker of highly ventilated low-TNCO cigarettes has an increased potential for higher aldehyde exposures compared to a smoker of regular cigarettes.
\end{abstract}




\section{Introduction}

During the Framework Convention on Tobacco Control (FCTC), parties started to develop guidelines for the regulation of contents and emissions of tobacco products in order to reduce tobacco-related morbidity and mortality ${ }^{1}$. As part of this, the WHO Study Group on Tobacco Product Regulation (TobReg) advised regulating and lowering toxicant yields in cigarette smoke ${ }^{2}$. Due to the complex composition of cigarette smoke and the wide variety of tobacco-related diseases, TobReg proposed beginning regulation with a limited set of high-priority toxic emissions. To this end, priority lists of smoke toxicants were compiled based on toxicity indices in combination with other information of products. This indicates that regulation is feasible, for example the considerable differences in emission levels between brands under similar smoking conditions ${ }^{2-6}$. One of the chemical classes identified by TobReg, as well as others, as priority due to their impact on human health is the volatile aldehydes ${ }^{1,2,4,7,8}$. In order to study their adverse health effects, modelled human exposures to cigarette-derived aldehydes were compared to No Observed Adverse Effect Levels (NOAELs) or Lowest Observed Adverse Effect Levels (LOAELs) derived from animal experimental data, which was translated to human risks using safety factors. Risk assessors concluded that exposure to individual aldehydes leads to adverse acute and chronic health effects ${ }^{6,9-11}$. Burns et al. showed that for all brand characteristics and human smoking behaviors ${ }^{2}$, the chemical class of aldehydes present in cigarette smoke may be represented by only three compounds, i.e. acetaldehyde, formaldehyde and acrolein. These three were selected because of similarities in structures, precursors or mechanisms of formation ${ }^{2}$. It is suggested to express the toxicant yields per mg of nicotine, since smokers titrate the nicotine need.

Since smoking behavior varies between individuals, it is important to study the influence of smoking behavior on individual exposure to cigarette mainstream smoke (MSS) constituents. Machine smoking with standardized settings for puff volume, puff duration and interpuff intervals can be used to create a range of mimicked smoking intensities that cover exposure for all human smokers. For this purpose, the International Organization for Standardization (ISO) smoking regime (puff volume $35 \mathrm{~mL}$, puff duration $2 \mathrm{~s}$, puff interval $60 \mathrm{~s}$ ) and Health Canada Intense $(\mathrm{HCl})$, (puff volume $55 \mathrm{~mL}$, puff duration $2 \mathrm{~s}$, puff interval $30 \mathrm{~s}$ ) smoking regimes are often applied. In addition to the Health Canada Intense smoking regime being more intense, another difference with the ISO smoking regime is that the cigarette filters are taped to block filter vents. Industry uses cigarette filter ventilation and cigarette 
paper porosity as a major design feature, resulting in reduced yields of tar, nicotine, and carbon monoxide (CO) as measured using the ISO regime ${ }^{12}$. This is explained by the dilution of the emissions produced in the burning tip, with ambient air invading via filter vents before the emissions are collected at the mouth end. The influence of cigarette filter ventilation is determined by combining the smoking regimes and blocking filter vents with tape ${ }^{13,14}$. It has been shown that machine-smoked cigarettes produce significantly lower yields per puff and per cigarette when ISO regimes are applied rather than $\mathrm{HCl}$ conditions ${ }^{15}$. On the one hand, filter ventilation is responsible for large differences in aldehyde yields under machine smoking conditions ${ }^{16}$, explained by a changed burning process ${ }^{17,18}$. On the other hand, due to the increased puff parameters, additional smoke is produced. The combination of filter ventilation and puff parameters is investigated in four smoking conditions. The industry aims at increasing product elasticity to facilitate the ability of smokers to extract desirable levels of nicotine ${ }^{19}$. A good example is the low-TNCO cigarette which smokers unconsciously manipulate in such a way that they extract enough nicotine to satisfy their needs ${ }^{20-22}$. In addition to smoking behavior and filter ventilation, other brand characteristics also influence smoke constituent yields, such as aldehyde yields. A cigarette brand is unique because of agricultural practices, plant characteristics, tobacco blending and cigarette design ${ }^{23}$. The curing process and the type and blend of tobacco, i.e. Virginia/Bright, Oriental, and Burley tobacco, are important contributors to the aldehyde yields in cigarette smoke ${ }^{3,16}$. Natural sugars in tobacco leaves are thought to be a significant source of aldehydes ${ }^{11,24}$. In addition, sugar is added by the manufacturer to improve the flavor and taste of the smoke ${ }^{25-27}$. It has already been shown that lowering sugar content is promising for reducing aldehydes in smoke $\mathrm{e}^{11,28}$.

The objectives of the present study are:

1. to quantify aldehyde levels in cigarette MSS for four different smoking regimes and 11 different brands;

2. to study whether acrolein, acetaldehyde and formaldehyde levels correlate well with the other aldehyde levels, and are thus representative of the class of volatile aldehydes;

3. to quantify TNCO levels for quality assurance purposes and to be able to estimate nicotine exposure;

4. to estimate the influence of the smoking regime, especially filter ventilation, and brand characteristics on the aldehyde yields in cigarette smoke;

5. to estimate the aldehyde exposure of a smoker for different brands and smoking regimes. 


\section{Experimental procedures}

Eleven cigarette brands, available on the Dutch market in 2015, were selected based on different TNCO levels, popularity, tobacco blend, and cigarette manufacturer (Table 1). According to the website of the tobacco company, the selected cigarettes in the main study typically contain the three main tobacco types in different ratios: Virginia/Bright, Burley and Oriental. All brands used were bought at a tobacconist and have the same batch code on the package. Cigarettes were conditioned and marked as described in ISO 3402:1999 and ISO 438729,30. In addition, two reference cigarettes $3 \mathrm{R} 4 \mathrm{~F}$ and $1 \mathrm{R} 5 \mathrm{~F}$, with a high and low TNCO level respectively, were purchased from the College of Agriculture Reference Cigarette Program, University of Kentucky (Lexington, KY 40546, USA).

\section{Study design}

Cigarettes were machine-smoked on a 20-port linear smoking machine (Cerulean SM450, Milton Keynes, UK), according to the ISO and $\mathrm{HCl}$ smoking regimes as described by ISO 3308:2012 and WHO TobLabNet SOP 0131,32. The ISO smoking regime is based on a $35 \mathrm{~mL}$ puff volume, $2 \mathrm{~s}$ puff duration, $60 \mathrm{~s}$ puff interval and no vent blocking. The $\mathrm{HCl}$ smoking regime is described as $55 \mathrm{~mL}$ puff volume, $2 \mathrm{~s}$ puff duration and 30 s puff interval. A $100 \%$ vent blocking is achieved by taping the vents with $19 \mathrm{~mm}$ width Scotch Magic TM tape (cat no: 810, 3M, USA). Two extra smoking regime variations on the conventional methods were included: the ISO method with filter vent blocking by taping (ISO-taped) and the $\mathrm{HCl}$ method without taping the filter vents ( $\mathrm{HCl}$-untaped).

\section{Aldehyde measurements}

The $85.2 \mathrm{mmol} / \mathrm{L}$ 2,4-dinitrophenylhydrazine hydrochloride (DNPH) reagent was composed of hydrochloride, phosphoric acid (85\%) (Merck) and acetonitrile (>99\%) (Biosolve). Calibration standards were made for formaldehyde-DNPH (97\%) (SigmaAldrich), acetaldehyde-DNPH (Sigma-Aldrich), acrolein-DNPH (Sigma-Aldrich), including $0,0.1,0.2,0.5,1.0$ and $2.0 \mu \mathrm{g} / \mathrm{mL}$, and aldehyde/ketone-DNPH mix (ERA020, Sigma-Aldrich) including 0, 0.15, 0.45, 0.901 .80 and $3.0 \mu \mathrm{g} / \mathrm{mL}$.

For the aldehyde measurement, cigarette smoke was trapped on a holder containing a Cambridge filter pad (CFP) and a CX 572 20/45 cartridge (cat no: 11072-U, Sigma) $300 \mathrm{mg}$ in a $3 \mathrm{~mL}$ SPE tube (cat no:57241, Sigma). Extraction was done as described in the WHO SOPO ${ }^{33}$. In short, CFP and carboxen were extracted by $10 \mathrm{~mL}$ carbon disulfide/methanol (20/80) while shaken for 10 minutes at $120 \mathrm{rpm} .0 .5 \mathrm{~mL}$ was taken 
to derivate with $0.2 \mathrm{mLDNPH}$ solution for 10 minutes followed by dilution with $4.3 \mathrm{~mL}$ ethanol. The aldehydes were quantified by HPLC LC-10Ai (Shimadzu), including SIL-20AC autosampler and a SPD-M20A photo diode array detector, quantified at wavelength $360 \mathrm{~nm}$, and verification of identity wavelength scan was done between 250 and 450nm. As mobile phase, a gradient of water (A) and acetonitrile (B) was used, starting with A55\% and B 45\%, after 25minutes changed to B 100\%, with a change back to $A 55 \%$ and $45 \%$ after 31 minutes, ending the run at 45 minutes. The individual aldehydes were measured in five replicates per cigarette brand, using four smoking conditions. Aldehydes of interest were acetaldehyde, acrolein, formaldehyde, acetone, propionaldehyde, crotonaldehyde, butyraldehyde, benzaldehyde, isovaleraldehyde, hexaldehyde and 2,5-dimethylbenzaldehyde, with $o^{-}, \mathrm{m}$ - and $p$-tolualdehyde combined. The latter compound has been determined as a single compound since the chromatographic method did not separate the three isomers.

\section{TNCO measurements}

TNCO in cigarette smoke was measured under the same conditions as the aldehyde measurements. A 44-mm diameter CFP (product no: 9703-9654, Whatman, GE Healthcare UK Limited) was used to trap the mainstream cigarette smoke constituents and was immediately extracted with isopropanol (>99.8\%) (CAS 67-63-0, Merck), containing heptadecane (99.6\%) (CAS 629-78-7, Sigma-Aldrich) as internal standard for nicotine (Art18142, Across). Ethanol (Merck) was used as an internal standard for water. Smoke extracts were analyzed by GC flame ionization and thermal conductivity detectors, with the use of WCOT Fused Silica coated with CP-WAX 51 for Amines 25m x 0.25mm ID (part CP7405, Agilent Technologies) and PoraBond Q, $25 \mathrm{~m} \times 0.32 \mathrm{~m}$ ID, $5 \mu \mathrm{m}$ (part CP7351I5, Agilent Technologies). Tar, nicotine and CO concentrations were determined as described in ISO 4387:2000, ISO 10315:2014 and ISO 8454:2007, with as modification for the tar and nicotine measurements one cigarette per CFP and for the CO measurements three cigarettes per smoking session, five and three replicates for four smoking conditions respectively ${ }^{34-36}$.

\section{Filter ventilation}

Filter tip ventilation is the percentage of smoke that is diluted by air when a smoker takes a puff. The KC-3 apparatus (Borgwaldt-KC, Richmond, Virginia, USA) was used to measure the filter tip ventilation at a flow rate of $17.5 \mathrm{~mL} / \mathrm{s}$ for five cigarettes per brand $^{37}$. 


\section{Statistical analysis}

Aldehyde yields in cigarette smoke were calculated as $\mu \mathrm{g}$ per cigarette, and TNCO as mg per cigarette. Mean yields and standard deviations were given for all components per cigarette brand and smoking condition. To compare the degree of variation between samples, the coefficient of variance was calculated for TNCO. Values for smoke components were compared using ANOVA statistics. For comparison between brands within each single smoking condition, one-way ANOVA was used. For comparison between brands and smoking conditions, two-way ANOVA was used, with brands and smoking condition as factors. Differences were considered significantly different when $p<0.05$. Correlations were determined between the individual aldehydes as the Pearson correlation coefficient.

\section{Results}

\section{Aldehyde levels in cigarette mainstream smoke}

The smoke emissions of several aldehydes from different cigarette brands were measured using the machine smoking regimes ISO and $\mathrm{HCl}$, both with and without the ventilation holes taped (Figure 1, Table S2). The different brands, the manufacturer, the claimed and measured TNCO values, and the tobacco blend are listed in Table 1. For both regimes, fewer puffs were taken per cigarette when the ventilation holes were taped, but the number of puffs per cigarette increased when ISO is compared to $\mathrm{HCl}$.

Significantly different yields of individual aldehyde emissions were produced for both different cigarette brand characteristics and different smoking conditions ( $p<1 \mathrm{E}-09$ in all cases) (Table S3). Within one of the four smoking conditions, taking the cigarette brands as the only variable into account, the individual aldehydes show significant differences in yield when compared to each other $(p<0.02)$. 


\begin{tabular}{|c|c|c|c|c|c|c|c|}
\hline \multirow[b]{2}{*}{ Brand } & \multirow[b]{2}{*}{ Manufacturer } & \multirow[b]{2}{*}{ Tobacco blend } & \multicolumn{5}{|c|}{$\operatorname{Tar}$ (mg/cigarette) } \\
\hline & & & $\frac{\frac{\varepsilon}{\sigma}}{U}$ & 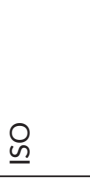 & 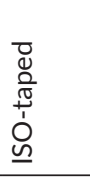 & 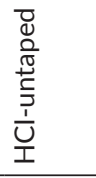 & 㐫 \\
\hline Camel filter & JT International & $\begin{array}{l}\text { Mainly Virginia and } \\
\text { Turkish tobacco }\end{array}$ & 10 & 12.24 & 17.04 & 24.06 & 29.65 \\
\hline Gauloises & Imperial tobacco & Dark tobaccos from & & & & & \\
\hline Blondes Blue & Nederland & $\begin{array}{l}\text { Syria/Turkey (strong } \\
\text { distinctive aroma) }\end{array}$ & 10 & 12.02 & 14.71 & 25.28 & 28.94 \\
\hline Dunhill red & $\begin{array}{l}\text { British American } \\
\text { Tobacco }\end{array}$ & Mainly Virginia & 10 & 10.64 & 12.52 & 22.21 & 28.62 \\
\hline Lucky Strike red & $\begin{array}{l}\text { British American } \\
\text { Tobacco }\end{array}$ & $\begin{array}{l}\text { Virginia, Burley, } \\
\text { Oriental tobacco }\end{array}$ & 10 & 11.17 & 18.94 & 24.56 & 36.5 \\
\hline $\begin{array}{l}\text { Lucky Strike } \\
\text { additive free }\end{array}$ & $\begin{array}{l}\text { British American } \\
\text { Tobacco }\end{array}$ & $\begin{array}{l}\text { Virginia, Burley, } \\
\text { Oriental tobacco }\end{array}$ & 10 & 10.69 & 14.01 & 24.21 & 39.3 \\
\hline Kent surround & $\begin{array}{l}\text { British American } \\
\text { Tobacco }\end{array}$ & $\begin{array}{l}\text { Virginia, Burley, } \\
\text { Oriental tobacco }\end{array}$ & 4 & 5.8 & 10.28 & 12.36 & 22.84 \\
\hline L\&M red & Philip Morris & $\begin{array}{l}\text { Virginia, Burley, } \\
\text { Oriental tobacco }\end{array}$ & 10 & 8.36 & 16.22 & 23.05 & 34.01 \\
\hline Marlboro Red & Philip Morris & $\begin{array}{l}\text { Virginia, Burley, } \\
\text { Oriental tobacco }\end{array}$ & 10 & 10.37 & 15.4 & 25.01 & 34.03 \\
\hline $\begin{array}{l}\text { Marlboro } \\
\text { Menthol }\end{array}$ & Philip Morris & $\begin{array}{l}\text { Virginia, Burley, } \\
\text { Oriental tobacco }\end{array}$ & 10 & 10.94 & 17.36 & 24.53 & 33.83 \\
\hline Marlboro gold & Philip Morris & $\begin{array}{l}\text { Virginia, Burley, } \\
\text { Oriental tobacco }\end{array}$ & 8 & 8.63 & 12.69 & 19.37 & 20.32 \\
\hline $\begin{array}{l}\text { Philip Morris } \\
\text { One }\end{array}$ & Philip Morris & $\begin{array}{l}\text { Virginia, Burley, } \\
\text { Oriental tobacco }\end{array}$ & 1 & 0.9 & 9.35 & 3.36 & 17.23 \\
\hline $\begin{array}{l}\text { Reference } \\
\text { cigarette 3R4F }\end{array}$ & $\begin{array}{l}\text { Kentucky Tobacco } \\
\text { Research \& } \\
\text { Development } \\
\text { Center }\end{array}$ & $\begin{array}{l}\text { Virginia, Burley, } \\
\text { Maryland, Oriental }\end{array}$ & 9.4 & 7.77 & 13.35 & 21.53 & 30.83 \\
\hline \multirow[t]{2}{*}{$\begin{array}{l}\text { Reference } \\
\text { cigarette 1R5F }\end{array}$} & $\begin{array}{l}\text { Kentucky Tobacco } \\
\text { Research \& } \\
\text { Development } \\
\text { Center }\end{array}$ & $\begin{array}{l}\text { Virginia, Burley, } \\
\text { Maryland, Oriental }\end{array}$ & 1.67 & 2.56 & 8.34 & 6.98 & 21.11 \\
\hline & & $\mathrm{CV}<$ & & 0.012 & 0.006 & 0.004 & 0.005 \\
\hline
\end{tabular}

$\$=$ failed measurement

Table 1: Dutch cigarette brands and reference cigarettes with manufacturer, TNCO values and tobacco blend. Tobacco blends as mentioned on the websites of the tobacco company. Dutch market cigarette brands and reference cigarettes $1 \mathrm{R} 5 \mathrm{~F}$ and 3R4F, with claimed yields of TNCO on the package (measured with ISO), and the mean measured TNCO and puff number when machine-smoked following the ISO or $\mathrm{HCl}$ regime, both with and without taped filter. The tip ventilation is shown as a percentage. Tar and nicotine content were from five replicates, while for $\mathrm{CO}$ three replicates of three cigarettes are shown (mg/cigarette). The coefficient of variance $(\mathrm{CV})$ for all brands is smaller than the mentioned percentage within the smoking condition. 


\begin{tabular}{|c|c|c|c|c|c|c|c|c|c|c|c|c|c|c|}
\hline \multicolumn{5}{|c|}{ Nicotine (mg/cigarette) } & \multicolumn{5}{|c|}{ Carbon monoxide (mg/cigarette) } & \multirow{2}{*}{$\begin{array}{l}\begin{array}{l}\text { Venti- } \\
\text { lation }\end{array} \\
\\
\text { ১ং }\end{array}$} & \multicolumn{4}{|c|}{ Puff number } \\
\hline$\frac{\xi}{\frac{E}{\sigma}}$ & $\begin{array}{l}\text { 으 } \\
\underline{n}\end{array}$ & 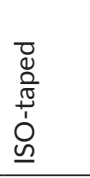 & 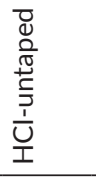 & 포 & $\frac{\frac{\varepsilon}{\sigma}}{U}$ & 은 & 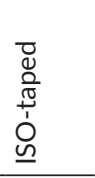 & 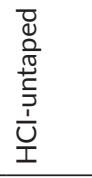 & ত্য & & 음 & 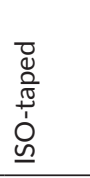 & 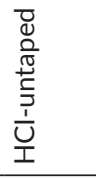 & $\begin{array}{l}\bar{I} \\
\text { İ }\end{array}$ \\
\hline 0.8 & 1.01 & 1.06 & 2.08 & 1.97 & 10 & 9.95 & 13.34 & 23.83 & 27.54 & 32.60 & 7.84 & 6.86 & 10.1 & 8.82 \\
\hline 0.8 & 0.89 & 0.87 & 2.03 & 1.89 & 10 & 9.71 & 13.74 & 20.89 & 25.32 & 22.90 & 6.52 & 5.7 & 8.7 & 7.78 \\
\hline 0.9 & 0.8 & 0.79 & 1.84 & 1.79 & 10 & 9.99 & 13.78 & 20.99 & 24.75 & 18.88 & 6.18 & 5.82 & 8.12 & 7.52 \\
\hline 0.8 & 0.9 & 1.07 & 2.02 & 2.11 & 10 & 10.11 & 13.3 & 22.04 & 28.91 & 32.90 & 8.74 & 8.16 & 12.18 & 10.48 \\
\hline 0.8 & 0.83 & 0.83 & 1.85 & 1.86 & 10 & 9.59 & 15.31 & 20.71 & 23.72 & 26.54 & 6.74 & 6.14 & 9.16 & 8.68 \\
\hline 0.4 & 0.54 & 0.71 & 1.27 & 1.51 & 5 & 6.7 & 12.41 & 17.59 & 24.19 & 77.38 & 6.68 & 5.66 & 10.46 & 8.16 \\
\hline 0.8 & 0.78 & 0.94 & 1.88 & 2.02 & 10 & 9.17 & 13.84 & 21.85 & 28.07 & 37.80 & 8.28 & 7.32 & 11.14 & 9.14 \\
\hline 0.8 & 0.8 & 0.9 & 1.93 & 1.97 & 10 & 8.51 & 15.12 & 20.7 & 26.27 & 42.72 & 7.92 & 6.94 & 10.92 & 8.9 \\
\hline 0.8 & 0.8 & 0.84 & 1.65 & 1.72 & 10 & 9.85 & 17.68 & 21.28 & 29.4 & 32.66 & 8.08 & 7.18 & 10.32 & 8.7 \\
\hline 0.6 & 0.67 & 0.77 & 1.64 & 1.67 & 9 & 8.25 & 13.97 & 19.41 & 25.45 & 33.50 & 6.76 & 6.24 & 9.32 & 8.2 \\
\hline 0.1 & 0.21 & 0.52 & 0.56 & 1.17 & 2 & 1.6 & 13.29 & 7.41 & 27 & $\$$ & 7.8 & 5.98 & 11.74 & 7.44 \\
\hline 0.73 & 0.71 & 0.85 & 1.76 & 1.9 & 12 & 10.64 & 15.76 & 25.44 & 27.65 & 29.00 & 8.4 & 7.52 & 11.88 & 10.3 \\
\hline 0.16 & 0.27 & 0.45 & 0.72 & 1.01 & 2.95 & 3.6 & 17.27 & 17.45 & 36.97 & 70.00 & 7 & 4.92 & 10.1 & 6.7 \\
\hline & 0.007 & 0.001 & 0.001 & 0.001 & & 0.002 & 0.003 & 0.001 & 0.001 & & 0.001 & 0.003 & 0.001 & 0.001 \\
\hline
\end{tabular}




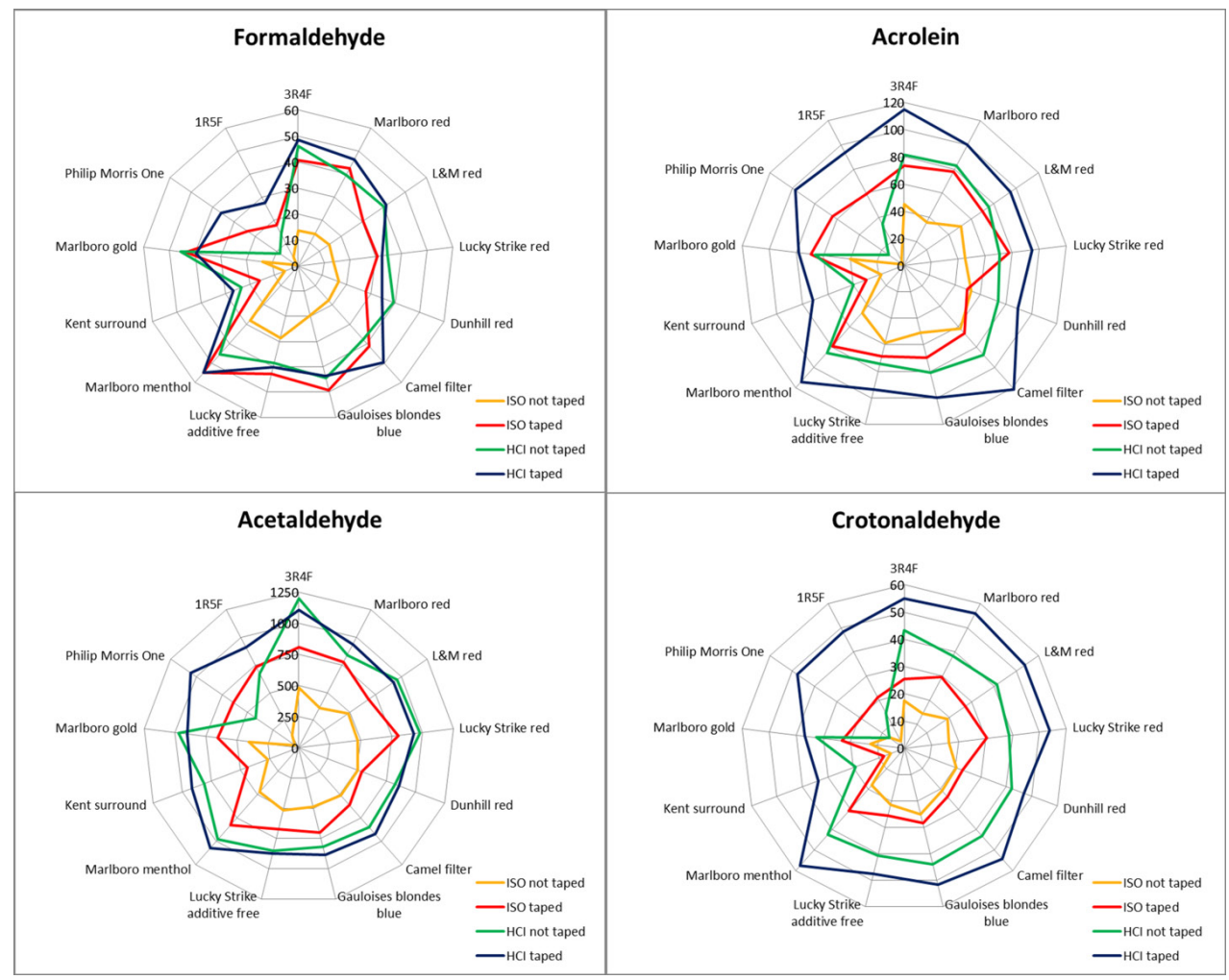

Figure 1: The radar chart shows cigarette smoke emissions of formaldehyde, acrolein, acetaldehyde and crotonaldehyde (mean $\mu \mathrm{g} /$ cigarette) of 13 different cigarette brands when machine-smoked according to the four different smoking conditions $(n=5)$.

Aldehyde yields significantly increased when the smoking regime was intensified (increasing puff volume and puff interval) (Table S3). Nearly all cigarette smoke emissions of aldehydes showed the same pattern, as illustrated in Figure 1: ISO< ISO-taped < $\mathrm{HCl}$-untaped < $\mathrm{HCl}$. Apart from the highly ventilated cigarettes Philip Morris One and 1R5F, this pattern is not observed for formaldehyde. While differences between ISO on the one hand and ISO-taped, $\mathrm{HCl}$-untaped, and $\mathrm{HCl}$ on the other are clearly noticeable, differences between ISO-taped, $\mathrm{HCl}$-untaped and $\mathrm{HCl}$ are not so clear. To a lesser extent, this is also the case for acetaldehyde, where differences between $\mathrm{HCl}$-untaped, and $\mathrm{HCl}$ are absent for most brands.

The other individual aldehydes show comparable increases in yield due to intensifying the smoking regime or taping the filter vents (Table S2). There were exceptions for acetone when ISO-taped, and for hexaldehyde and o-, $m$-, $p$-tolualdehyde for $\mathrm{HCl}$. 
In summary, the individual aldehyde yields increase as a result of the smoking regime and the filter vents being taped.
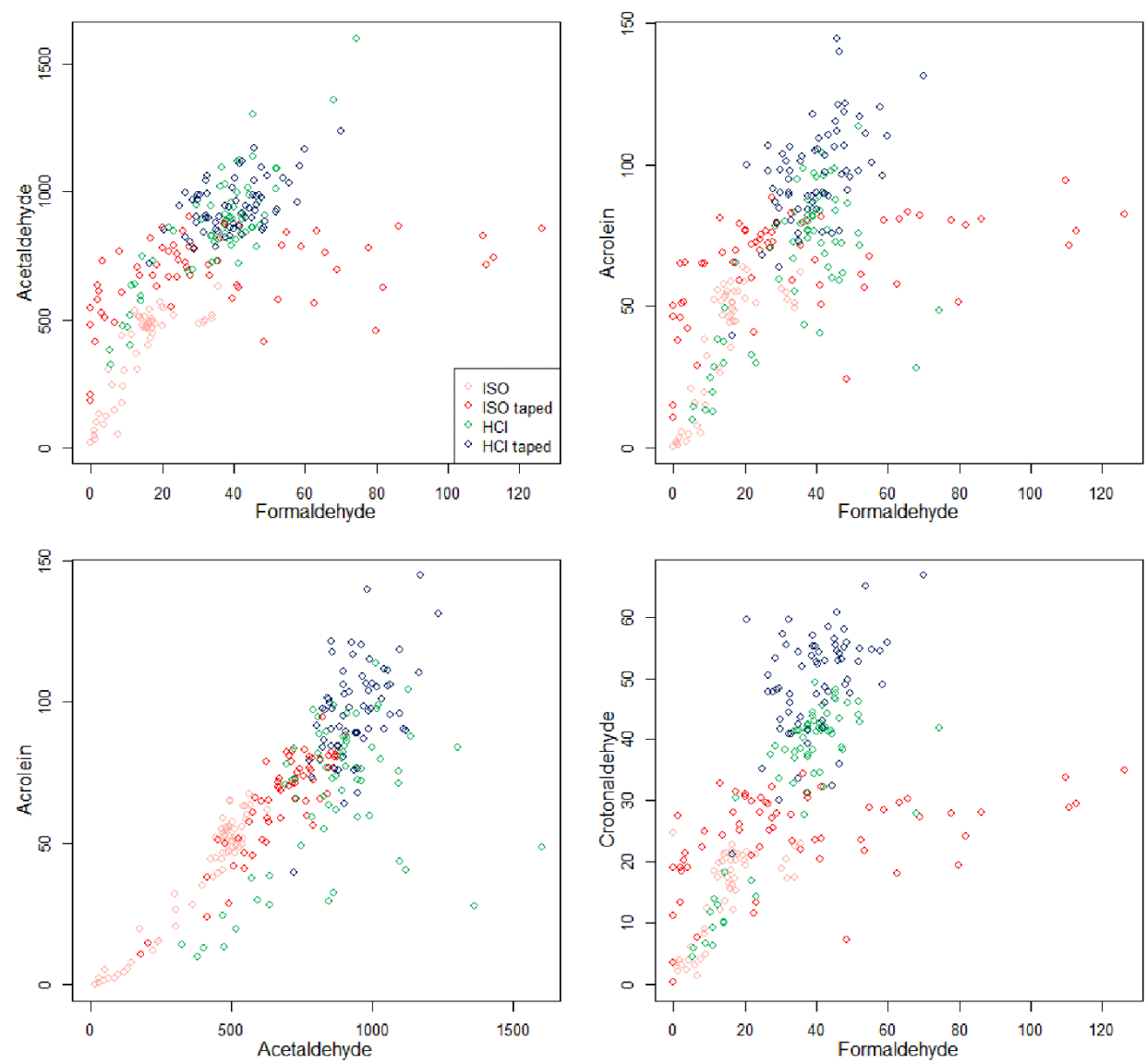

Figure 2: Correlation plots show the comparison of acetaldehyde vs. formaldehyde (top left), acrolein vs. formaldehyde (top right), acrolein vs. acetaldehyde (bottom left), crotonaldehyde vs. formaldehyde (bottom right) (mean $\mu \mathrm{g} / \mathrm{cig}$ ). The replicates $(n=5)$ of the 13 cigarette brands are represented by dots in four different colors representing the four different smoking conditions. ISO regime is orange, ISO-taped is red, $\mathrm{HCl}$-untaped is green and $\mathrm{HCl}$ is blue.

\section{Correlation between aldehyde levels}

Additionally, the relation between the different aldehydes that are present in the cigarette smoke was investigated (Table 2, Figure 2). It was found that the different aldehydes produced in different cigarette brands correlate well within a particular 
smoking regime (Figure 2, Table S3). More specifically, acetaldehyde and acrolein show a strong correlation $(r=0.804)$ with each other and with the other aldehydes. The weakest correlation is seen for formaldehyde, with acetaldehyde $(p=0.614)$ and acrolein ( $p=0.57$ ), and even lower with the other aldehydes (Figure 2, Table S4).

Table 2: Correlation coefficients of individual aldehyde emissions produced by 13 cigarette brands (five replicates) across the combined smoking conditions.

\begin{tabular}{|c|c|c|c|c|c|c|c|c|c|c|c|c|c|}
\hline $\begin{array}{l}\text { Pearson } \\
\text { correlation }\end{array}$ & 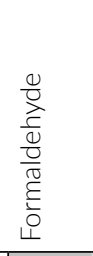 & $\begin{array}{l}\frac{0}{0} \\
\frac{1}{c} \\
\frac{0}{0} \\
\frac{0}{0} \\
\frac{0}{0} \\
\dot{4}\end{array}$ & $\begin{array}{l}\frac{.}{0} \\
\frac{0}{0} \\
\frac{0}{4}\end{array}$ & $\begin{array}{l}0 \\
\stackrel{0}{0} \\
\stackrel{0}{0} \\
\stackrel{0}{4}\end{array}$ & $\begin{array}{l}\bar{\pi} \\
\frac{\pi}{\pi} \\
\frac{0}{0} \\
\frac{0}{2}\end{array}$ & $\begin{array}{l}\frac{0}{0} \\
\frac{1}{0} \\
\frac{0}{0} \\
\frac{0}{0} \\
\frac{0}{0} \\
0 \\
\frac{0}{U}\end{array}$ & 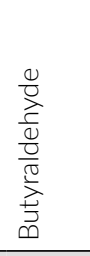 & $\begin{array}{l}\frac{0}{0} \\
\frac{\lambda}{c} \\
\frac{0}{0} \\
\frac{0}{0} \\
\frac{1}{0} \\
\infty \\
\end{array}$ & $\begin{array}{l}\frac{0}{0} \\
\frac{0}{0} \\
\frac{0}{0} \\
\frac{0}{\pi} \\
\frac{0}{\pi} \\
\underline{0} \\
\underline{0} \\
\end{array}$ & $\begin{array}{l}\frac{0}{0} \\
\frac{1}{d} \\
\frac{0}{0} \\
\frac{0}{0} \\
\frac{0}{0} \\
0 \\
\frac{1}{1} \\
\frac{1}{2} \\
0\end{array}$ & $\begin{array}{l}\overline{\widetilde{T}} \\
\widetilde{\widetilde{T}} \\
\widetilde{\widetilde{U}} \\
\text { I) } \\
\end{array}$ & 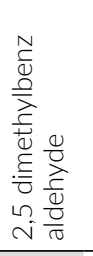 & $\begin{array}{l}\frac{0}{\bar{U}} \\
\tilde{U} \\
\overline{0} \\
\frac{0}{0}\end{array}$ \\
\hline Formaldehyde & - & 0.614 & 0.576 & 0.438 & 0.530 & 0.553 & 0.566 & 0.506 & 0.507 & 0.594 & 0.579 & 0.591 & \\
\hline Acetaldehyde & 0.614 & - & 0.804 & 0.775 & 0.868 & 0.831 & 0.909 & 0.818 & 0.874 & 0.786 & 0.698 & 0.849 & 0.0 \\
\hline Acrolein & 0.576 & 0.804 & - & 0.807 & 0.921 & 0.896 & 0.886 & 0.734 & 0.850 & 0.744 & 0.564 & 0.768 & 0.1 \\
\hline Acet & +38 & 0.775 & 0.807 & - & 0.863 & 0.832 & 0.851 & 0.740 & 0.847 & 0.669 & 0.500 & 0.780 & 0.2 \\
\hline Prop & 530 & 0.868 & 0.921 & 0.863 & - & 0.965 & 0.977 & 0.902 & 0.968 & 0.840 & 0.678 & 0.880 & 0.3 \\
\hline $\begin{array}{l}\text { Crotc } \\
\text { hyde }\end{array}$ & 0.553 & 0.831 & 0.896 & 0.832 & 0.965 & - & 0.958 & 0.903 & 0.964 & 0.803 & 0.666 & 0.908 & \\
\hline Butyr & .566 & 0.909 & 0.886 & 0.851 & 0.977 & 0.958 & - & 0.927 & 0.977 & 0.857 & 0.751 & 0.923 & 0.5 \\
\hline Benzaldehyde & 0.506 & 0.818 & 0.734 & 0.740 & 0.902 & 0.903 & 0.927 & - & 0.935 & 0.816 & 0.770 & 0.911 & 0.6 \\
\hline $\begin{array}{l}\text { Isovaleralde } \\
\text { hyde }\end{array}$ & 507 & 0.874 & 0.850 & 0.847 & 0.968 & 0.964 & 0.977 & 0.935 & & 0.842 & 0.704 & 0.923 & 0.7 \\
\hline $\begin{array}{l}o-m-p \text {-tolual- } \\
\text { dehyde }\end{array}$ & 594 & 0.786 & 0.744 & 0.669 & 0.840 & 0.803 & 0.857 & 0.816 & 0.842 & - & 0.875 & 0.798 & 0.8 \\
\hline Hexanal & 0.579 & 0.698 & 0.564 & 0.500 & 0.678 & 0.666 & 0.751 & 0.770 & 0.704 & 0.875 & - & 0.741 & 0.9 \\
\hline $\begin{array}{l}2,5 \text { dimethyl- } \\
\text { benz } \\
\text { aldehyde }\end{array}$ & 591 & 0.849 & 0.768 & 0.780 & 0.880 & 0.908 & 0.923 & 0.911 & 0.923 & 0.798 & 0.741 & & 1. \\
\hline
\end{tabular}

\section{TNCO levels in cigarette mainstream smoke}

The same experimental set-up was used to measure TNCO yields in the smoke of the different brands (Table 1, Table S1). The yields of TNCO measured with ISO differed with a maximum of $20 \%$ from the claimed TNCO levels printed on the cigarette package. In addition to the standard ISO regime, taping the cigarette filter resulted in an increase in TNCO yields (ISO-taped). The yields of tar increased between 18 - 939\%, nicotine yields between 0 - 148\%, and CO between 32 - 731\% (ISO vs. ISO-taped). When smoked with a higher puff volume and more frequent puffs using $\mathrm{HCl}$-untaped, the TNCO yields at least doubled, compared to ISO. Using $\mathrm{HCl}$ resulted in higher tar and CO yields, respectively; varying between 5 - 413\% and 9 $264 \%$, compared to the $\mathrm{HCl}$-untaped emissions. For nicotine, no clear increase was 
detected, with some brands even showing a decrease in nicotine values when $\mathrm{HCl}$ was used ( $\mathrm{HCl}$-untaped vs. $\mathrm{HCl}$ ).

\section{Influence of smoking protocol and brand characteristics, especially filter ventilation.}

The filter tip ventilation differs between the brands in the range of 18.9 to $77.4 \%$. Taping the filter vents, thereby eliminating the tip filter ventilation to $0 \%$, as well as increasing puff volume and having a smaller puff interval, both lead to an increase in aldehyde yields in cigarette smoke. More specifically, for most aldehydes, the impact of an intense smoking regime is at least two times larger compared to taping filter vents, except in the low-TNCO cigarettes, as shown in Figure 1. The low-TNCO brands Kent, Marlboro Gold, Philip Morris One and 1R5F have filter tip ventilation in the range of 33.5 to $77.4 \%$. It is only for these highly ventilated low-TNCO cigarettes that closing ventilation holes for the ISO regime (ISO-taped) leads to a more increased aldehyde yield than using an intense smoking regime $(\mathrm{HCl})$. For the most intense smoking condition ( $\mathrm{HCl}$ with taped ventilation holes), the aldehyde yields even reached the levels of the other brands. This was observed in the cases of acrolein, acetaldehyde, acetone, crotonaldehyde, propionaldehyde, benzaldehyde and 2,5-methylbenzaldehyde (Figure 1, Appendix B).

\section{Toxicants per nicotine ratio per brand}

The difference in aldehyde yields per mg of nicotine per cigarette for the different cigarette brands under different smoking conditions is shown in Figure 3. The acrolein and acetaldehyde per nicotine ratio is larger in low-TNCO cigarettes. This trend observed for acetaldehyde, acrolein, formaldehyde, crotonaldehyde, butyraldehyde and acetone (Figure 3 ) is also seen for the other aldehydes (not shown in Figure 3; propanal, butanal, isovaleraldehyde, $o^{-}, \mathrm{m}-, \mathrm{p}$-tolualdehyde, hexanal and 2,5 dimethylbenzaldehyde)). When smoking intensely $(\mathrm{HCl})$, regular cigarettes $(0.5-1.0$ $\mathrm{mg} / \mathrm{cig}$ according to the standard ISO regime), have comparable yields of aldehyde per mg of nicotine produced. In this case, taping has no increasing effect on the aldehyde production per mg of nicotine. The highest yields of aldehydes produced per mg of nicotine in smoke were measured in taped cigarettes when smoked with the ISO regime (ISO-taped). The largest difference is seen in low-TNCO cigarettes (ISO nicotine around $0.2 \mathrm{mg} / \mathrm{cig}$ ). In these low-TNCO cigarettes, up to six times more aldehyde production per mg nicotine is measured when comparing the least intense (ISO regime) with the most intense regime $(\mathrm{HCl})$. 

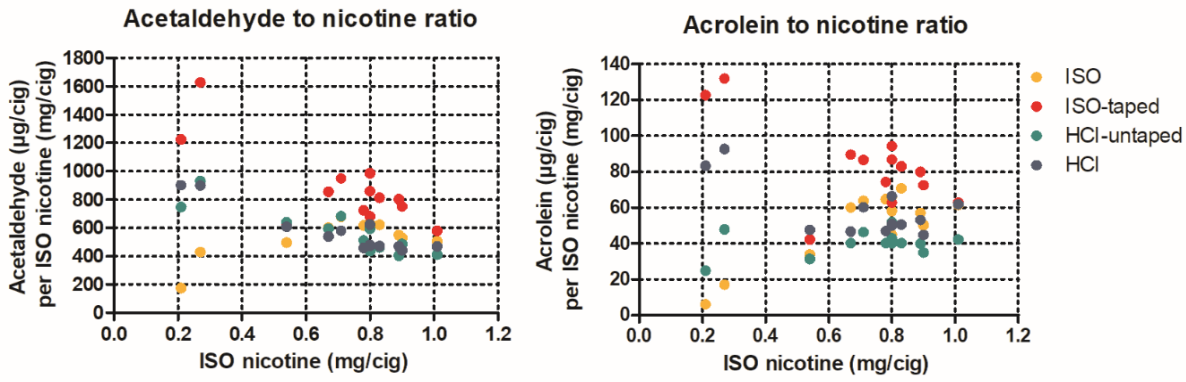

Formaldehyde to nicotine ratio
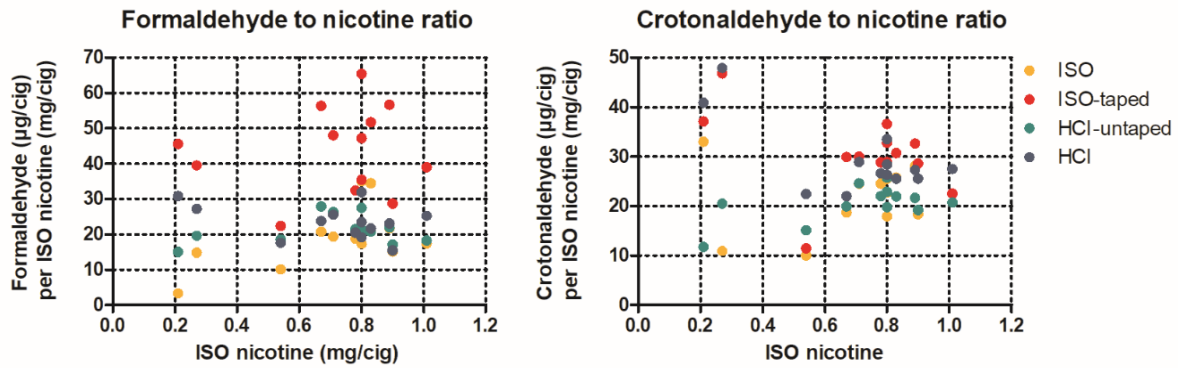

Butyraldehyde to nicotine ratio
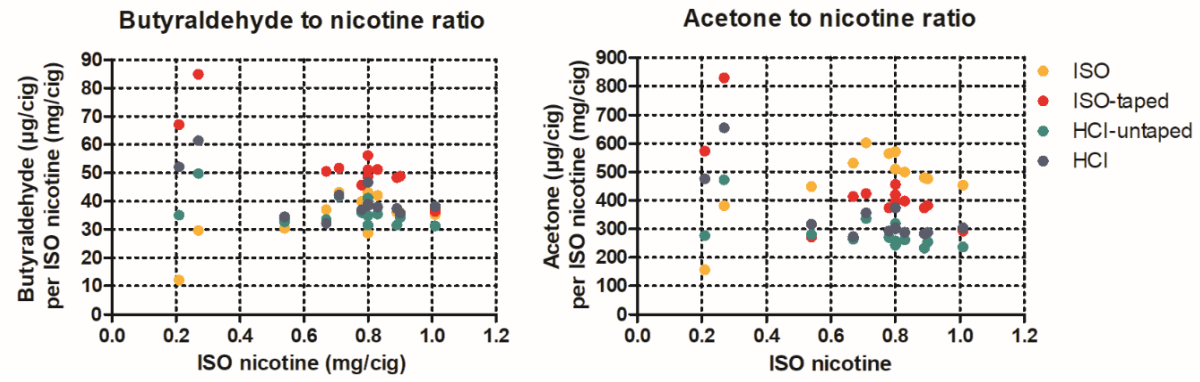

Figure 3: Toxicant-to-nicotine ratio. Acetaldehyde, acrolein, formaldehyde, crotonaldehyde, butyraldehyde and acetone yields divided by nicotine $(\mathrm{mg} / \mathrm{cig}$ ) measured using the four smoking conditions. On the X-axis, the nicotine $(\mathrm{mg} / \mathrm{cig})$ yields measured using the ISO method is shown to differentiate between the brands.

\section{Discussion}

Aldehydes are an important class of toxicants in smoke ${ }^{4,38}$, as has been recognized by WHO TobReg in their advice for mandating lower levels ${ }^{2}$. While aldehyde levels in MSS have been studied before in several brands ${ }^{11,16,39,40}$, this is the first study that systematically studies the influence of the smoking protocol on these levels. By using four different smoking protocols, ISO (standard without taping filter ventilation holes), ISO-taped, $\mathrm{HCl}$-untaped, and $\mathrm{HCl}$ (standard with taping filter ventilation 
holes), and 11 brands, the effect of puff topography and filter ventilation can be compared. Furthermore, it was tested whether aldehyde levels correlate well with each other in order to test the hypothesis of Burns et al. that one or two components in a class can serve as indicator components. Finally, based on the findings, it was estimated whether brand differences impact a smoker's exposure to aldehydes.

\section{Aldehyde levels in cigarette mainstream smoke}

The method developed by the WHO TobLabNet, which is based on the work of Uchiyama et $\mathrm{al}^{41}$, was used to measure aldehydes in 11 Dutch brands and two reference cigarettes in mainstream smoke generated using four different smoking protocols. Using the TobLabNet method, it was possible to measure aldehyde yields $(\mathrm{CV}<35.7 \%)$ comparable with previous studies of Counts et al., Uchiyama et al., Bodnar et al., Cheah et al., Reilly et al. and the CORESTA report 70+7411,16,39-41. Despite the difference in smoking regime and cigarette brands, nearly all aldehyde yields showed comparable patterns regarding their relative ratios. Individual aldehyde levels were highly correlated with each other except for formaldehyde ${ }^{40}$. More specifically, the cigarette smoke yields of acrolein and acetaldehyde strongly correlated with a larger set of different aldehyde yields ${ }^{42}$. This supports the proposal of Burns et al. to use a few aldehydes to represent the full class of aldehydes under different smoking conditions ${ }^{2}$.

A notable exception to this pattern is formaldehyde. Because formaldehyde is classified as class 1 carcinogen by the IARC ${ }^{43}$, there is no doubt about the wish to regulate this compound. However, the method used is not the most suitable one to measure formaldehyde. There are several differences between formaldehyde and the other aldehydes. Uchiyama et al. indicated that formaldehyde shows a wide analytical variation and problems with trapping ${ }^{41}$. Our results also showed wide standard deviations, especially when the ISO regime was used. A more sophisticated method is therefore needed to measure formaldehyde. In particular, formaldehyde shows a different emission pattern under different smoking conditions and for different brands than the other 12 aldehydes. In addition, formaldehyde showed the poorest association with the other aldehydes ${ }^{40}$ and therefore seems less suitable as representative of the aldehyde class.

\section{Influence of smoking protocol}

To test the effect of the smoking regime on the aldehyde yields, in combination with the cigarette design feature filter ventilation, both ISO and $\mathrm{HCl}$ regimes are used with and without taped filter ventilation holes. 
The puff parameters of ISO and $\mathrm{HCl}$ differ in puff volume and interpuff interval, leading to additional smoke produced for $\mathrm{HCl}$. In the present study, these two conditions were tested with and without accounting for the influence of filter ventilation. Thus, ISOcan be compared with $\mathrm{HCl}$-untaped, and ISO-taped can be compared with $\mathrm{HCl}$, allowing the effect of filter ventilation to be studied separately from the smoking topography. For both situations, the higher puff volume in combination with a shorter puff interval in $\mathrm{HCl}$ leads to a higher total puff volume and more puffs taken, when compared with ISO. Aldehyde yields in all cigarette brands increased when smoked according to $\mathrm{HCl}$. Reilly et al. investigated the effect of puff parameters on the aldehyde yields in cigarette smoke and concluded that increased puff volume is the primary factor leading to higher aldehyde yields for the total volume per cigarette ${ }^{40}$. As they found a similar influence of interpuff interval, puff flow, puff shape and puff duration, they suggest that temperature changes play a minor role.

\section{Influence of filter ventilation}

In all cigarette brands, the highest yields of aldehydes in the cigarette smoke are measured when the filter ventilation holes of the cigarettes are taped during machine smoking. In addition to preventing dilution by sidestream air via filter vents, closing filter vents causes an increased burn rate of the cigarette, leading to more of the tobacco rod being consumed with every puff, thereby reducing the total burn time of the cigarette, as well as the number of puffs needed to completely smoke the cigarette ${ }^{15}$. Aldehyde yields are increased during harsh burning conditions, gained by increasing puff volume or blocking ventilation. This explains why the effect of blocking ventilation holes is more pronounced for the ISO regime than the $\mathrm{HCl}$ regime. For the $\mathrm{HCl}$ regime, the harsh burning conditions due to intense smoking already lead to an increase in aldehyde yields. The addition of blocking ventilation for the $\mathrm{HCl}$ regime leads to a less distinct increase in aldehyde yields, compared with the ISO regime. This also explains why the impact of ventilation blocking on aldehyde yields was largest for those cigarettes with highest initial ventilation (1R5F, Phillip Morris One), as was also found by Counts et $\mathrm{al}^{16}$.

\section{Aldehyde-to-nicotine ratio per brand}

Brands show different aldehyde yields for the different smoking regimes when calculated as ratio to nicotine. In regular cigarettes, taping filter vents in ISO conditions (ISO-taped) lead to the highest aldehyde-to-nicotine ratio. The increase in aldehyde-to-nicotine ratio is less distinct for the $\mathrm{HCl}$ regime when taping regular cigarettes. Thus intensifying the smoking protocol by taking a puff more often and 
with a larger volume influences the aldehyde-to-nicotine ratio more than taping the filter vents. For the low-TNCO brands, the differences are even more prominent; these brands have a six times higher aldehyde production per mg nicotine for the intense smoking regimes, when compared to ISO. That the aldehyde-to-nicotine ratio increased when low-TNCO cigarettes are smoked more intensely, similar to real smokers, implies that a smoker of low-TNCO cigarettes has an increased potential for higher aldehyde exposures as compared to a smoker of regular cigarettes.

\section{Brand differences; filter ventilation}

Intensifying the smoking regime in combination with blocked filter ventilation substantially influences the aldehyde and TNCO yields in smoke. The filter tip ventilation is a design feature differing between brands. The filter tip ventilation for the 11 Dutch brands varied between 18 and 77\%. There is a trend that increasing filter ventilation leads to lower aldehyde yields, which is also found in literature ${ }^{44}$. Especially filter tip ventilation higher than $60 \%$ significantly lowers the yields of nicotine, tar and the aldehydes, seen for the low-TNCO cigarettes ${ }^{12}$.

\section{Aldehyde exposure estimation and risk assessment}

Based on the aldehyde-to-nicotine ratios, and a smoker's nicotine need, an estimation of aldehyde exposure when smoking according to different regimes can be made. Afternoon blood or plasma nicotine levels in smokers range from 10 to $50 \mathrm{ng} / \mathrm{mL}^{45}$. To maintain this level, a smoker needs $1 \mathrm{mg}$ of nicotine every two hours (taking a half-life of 1.5 hours into account), and thus a total amount of $12 \mathrm{mg}$ per day ${ }^{46}$. For example, based on the ISO regime, a Marlboro Red $(0.8 \mathrm{mg}$ nic/cig) smoker would need 15 cigarettes per day, compared to six cigarettes when smoking according to $\mathrm{HCl}$ (2mg nic/cig). This means a daily exposure to acetaldehyde of respectively $5.4 \mathrm{mg} /$ day (ISO $359.1 \mu \mathrm{g} / \mathrm{cig}$ ) or $5.6 \mathrm{mg} /$ day $(\mathrm{HCl} 933.4 \mu \mathrm{g} / \mathrm{cig}$ ). For the Philip Morris One, this means the smoker might need to smoke 60 cigarettes based on ISO $(0.2 \mathrm{mg} \mathrm{nic/cig)} \mathrm{and} \mathrm{ten} \mathrm{cigarettes} \mathrm{for} \mathrm{HCl}(1.2 \mathrm{mg} \mathrm{nic} / \mathrm{cig})$. The daily exposure to acetaldehyde is then $2.2 \mathrm{mg} /$ day (ISO $36.7 \mu \mathrm{g} / \mathrm{cig}$ ) and $10.6 \mathrm{mg} / \mathrm{day}(\mathrm{HCl} 1055.6$ $\mu \mathrm{g} / \mathrm{cig})$, a much larger difference between the two regimes than calculated for the Marlboro Red.

Recent risk assessment studies show large adverse effects of aldehydes on human health. These methods combine machine-generated yields with known chemical and toxicological properties. Risk assessment studies using inhalatory exposure risk factors were performed for the individual aldehydes ${ }^{4,6,9}$. These computer models show a different order of chemical hazard ranking: acrolein > formaldehyde 
$>$ acetaldehyde ${ }^{9}$ compared to acrolein $>$ acetaldehyde $>$ formaldehyde 6 . The ideal risk assessment methods in the case of cigarette smoke exposure use a mixture of aldehydes or assess a cumulative risk. The non-existence of well-functioning mixture toxicity models is partly due to lack of inhalatory exposure assessments. The accurate smoke analysis data of the present study can advance inhalatory exposure assessments and the precision of mixture toxicity models. Especially the changing levels in aldehydes due to choosing a different smoking regime may improve the accuracy of the models as designed e.g. by Corley et al. and other future comprehensive and specific risk assessments?.

\section{Regulatory implications}

The ISO smoking regime is prescribed in the European Union Directive 2014/40/ EU and used by manufacturers to declare TNCO yields ${ }^{47}$. However, the standard ISO regime produced substantially lower aldehyde yields than the $\mathrm{HCl}$ regime, thus resulting in an underestimation of smokers exposure. Specifically, when regular and low-ISO-TNCO-level cigarettes were smoked with the $\mathrm{HCl}$ regime or when filter ventilation holes were blocked (ISO-taped), overall aldehyde levels increased, as compared to the ISO regime. Since real smokers smoke more intensely than the ISO regime, the increased aldehyde levels when smoking more intensely or blocking filter vents can lead to higher aldehyde exposure. Thus, the present study results underline the need for a smoking regime that is more representative of actual human smoking behavior, like $\mathrm{HCl}$, as also proposed in literature.

It has been proposed in the literature that toxicant levels should be regulated relative to $\mathrm{mg}$ of nicotine in mainstream smoke ${ }^{2}$. The rationale for using exposures per $\mathrm{mg}$ of nicotine is that smokers need a certain amount of nicotine to sustain their addiction, and therefore adapt their smoking behavior in response to the cigarette design. The validity of this approach is demonstrated again by the present study results: for instance, the aldehyde levels that increased at least $50 \%$ more than the nicotine levels when a low-ISO-TNCO cigarette is smoked with the $\mathrm{HCl}$ regime, compared to a regular cigarette. Presuming that smokers smoke more intensely than the ISO regime, highly filter-ventilated cigarettes, often marketed as less harmful with a potentially reduced exposure claim, actually lead to a higher exposure to toxic aldehydes. An alternative to regulation with respect to $\mathrm{mg}$ of nicotine is to regulate cigarette design characteristics. For instance, regulating cigarette design characteristics is a straightforward measure to prevent the high aldehyde-to-nicotine ratios that occur in cigarette smoke of low-ISO-TNCO cigarettes. A more specific regulatory approach involves setting maximum allowed aldehyde levels in cigarette smoke or a maximum 
exposure concentration range based on scientific arguments which are in line with previous proposals ${ }^{2,48} \mathrm{As}$ stated previously, the ISO regime underestimates the smokers' exposure to cigarette smoke toxicants, including aldehydes. The $\mathrm{HCl}$ regime is a better representative of human smoking and the associated aldehyde yields in the cigarette smoke of an actual smoker. To adapt smoking machine protocols so that they better represent typical exposure levels, human studies measuring natural smoking behavior are needed. Smokers have varying puff volumes and durations, and because each puff has its own characteristic chemical composition this can lead to a complex smoke composition ${ }^{17}$. The measured human smoking profile can be mimicked on the smoking machine to determine the exact associated aldehyde exposure ${ }^{49}$. Specifically, a relevant set of aldehyde biomarkers can be measured in human fluids to link inhalatory exposure to internal dose. In the future, such data will show whether the reductions in machine-measured yields of specific constituents result in a reduction of exposure in smokers. 


\section{References}

1. WHO Study Group on Tobacco Product Regulation (TobReg). Report on the Scientific Basis of Tobacco Product Regulation; second report. WHO Technical Report Series 951. Geneva, Switserland: World Health Organization; 2008.

2. Burns DM, Dybing E, Gray N, et al. Mandated lowering of toxicants in cigarette smoke: a description of the World Health Organization TobReg proposal. Tob Control. 2008;17(2):132-141.

3. Hoffmann D, Hoffmann I, El-Bayoumy K. The less harmful cigarette: a controversial issue. a tribute to Ernst L. Wynder. Chem Res Toxicol. 2001;14(7):767-790.

4. Talhout R, Schulz T, Florek E, et al. Hazardous compounds in tobacco smoke. Int J Environ Res Public Health. 2011;8(2):613-628.

5. Rodgman A, Green CR. Toxic Chemicals in Cigarette Mainstream Smoke - Hazard and Hoopla. Beiträge zur Tabakforschung International/Contributions to Tobacco Research. 2003;20(8):481-545.

6. Fowles J, Dybing E. Application of toxicological risk assessment principles to the chemical constituents of cigarette smoke. Tob Control. 2003;12(4):424-430.

7. U.S. Food and Drug Administration. Harmful and potentially harmful constituents in tobacco products and tobacco smoke; established list. Vol Federal Register Vol. 77, No. 64. Washington, US: Department of Health and Human Services; 2012.

8. U.S. Department of Health and Human Services. The Health Consequences of Smoking: 50 Years of Progress. A Report of the Surgeon General. Atlanta, GA: Centers for Disease Control and Prevention; 2014.

9. Corley RA, Kabilan S, Kuprat AP, et al. Comparative Risks of Aldehyde Constituents in Cigarette Smoke Using Transient Computational Fluid Dynamics/Physiologically Based Pharmacokinetic Models of the Rat and Human Respiratory Tracts. Toxicol Sci. 2015;146(1):65-88.

10. Cunningham FH, Fiebelkorn S, Johnson M, Meredith C. A novel application of the Margin of Exposure approach: segregation of tobacco smoke toxicants. Food Chem Toxicol. 2011;49(11):2921-2933.

11. Cheah NP. Volatile aldehydes in tobacco smoke: source fate and risk. Vol Dissertation thesis. Maastricht, The Netherlands: Maastricht University; 2016.

12. Kozlowski LT, O'Connor RJ. Cigarette filter ventilation is a defective design because of misleading taste, bigger puffs, and blocked vents. Tob Control. 2002;11 Suppl 1:140-50.

13. Kozlowski LT, O'Connor RJ. Official cigarette tar tests are misleading: use a two-stage, compensating test. The Lancet. 2000;355(9221):2159-2161.

14. Marian C, O'Connor RJ, Djordjevic MV, et al. Reconciling human smoking behavior and machine smoking patterns: implications for understanding smoking behavior and 
the impact on laboratory studies. Cancer Epidemiol Biomarkers Prev. 2009;18(12):33053320.

15. Hammond D, Fong GT, Cummings KM, et al. Cigarette yields and human exposure: a comparison of alternative testing regimens. Cancer Epidemiol Biomarkers Prev. 2006;15(8):1495-1501.

16. Counts ME, Morton MJ, Laffoon SW, Cox RH, Lipowicz PJ. Smoke composition and predicting relationships for international commercial cigarettes smoked with three machine-smoking conditions. Regul Toxicol Pharmacol. 2005;41(3):185-227.

17. Adam T, McAughey J, Mocker C, McGrath C, Zimmermann R. Influence of filter ventilation on the chemical composition of cigarette mainstream smoke. Anal Chim Acta. 2010;657(1):36-44.

18. Torikai K, Uwano Y, Nakamori T, Tarora W, Takahashi H. Study on tobacco components involved in the pyrolytic generation of selected smoke constituents. Food Chem Toxicol. 2005;43(4):559-568.

19. Chaiton MO, Collinshaw NE, Callard AJ. Smoker preference for "elastic cigarettes" in the Canadian cigarette market. Chronic Dis Can. 2005;26(1):20-24.

20. Hecht SS, Murphy SE, Carmella SG, et al. Similar uptake of lung carcinogens by smokers of regular, light, and ultralight cigarettes. Cancer Epidemiol Biomarkers Prev. 2005;14(3):693-698.

21. Cummings KM, Hyland A, Bansal MA, Giovino GA. What do Marlboro Lights smokers know about low-tar cigarettes? Nicotine Tob Res. 2004;6 Suppl 3:S323-332.

22. Benowitz NL. Compensatory smoking of low-yield cigarettes. In: U.S. Department of Health and Human Services NIoH, National Cancer Institute, ed. Risks associated with smoking cigarettes having low machine-measured levels of tar and nicotine. Smoking and Tobacco Control Monograph, No 13. Bethesda, MD2001.

23. Kozlowski LT, O'Connor RJ, Sweeney CT. Cigarette design. In: U.S. Department of Health and Human Services NIoH, National Cancer Institute, ed. Risks associated with smoking cigarettes having low machine-measured levels of tar and nicotine. Smoking and Tobacco Control Monograph, No 13. Bethesda, MD2001.

24. Roemer E, Schorp MK, Piade JJ, et al. Scientific assessment of the use of sugars as cigarette tobacco ingredients: a review of published and other publicly available studies. Crit Rev Toxicol. 2012;42(3):244-278.

25. Adam T, Mitschke S, Streibel T, Baker RR, Zimmermann R. Quantitative puff-by-puffresolved characterization of selected toxic compounds in cigarette mainstream smoke. Chem Res Toxicol. 2006;19(4):511-520.

26. Baker RR. The generation of formaldehyde in cigarettes-Overview and recent experiments. Food Chem Toxicol. 2006;44(11):1799-1822.

27. Seeman JI, Dixon M, Haussmann HJ. Acetaldehyde in mainstream tobacco smoke: 
formation and occurrence in smoke and bioavailability in the smoker. Chem Res Toxicol. 2002;15(11):1331-1350.

28. Talhout R, Opperhuizen A, van Amsterdam JG. Sugars as tobacco ingredient: Effects on mainstream smoke composition. Food Chem Toxicol. 2006;44(11):1789-1798.

29. ISO 3402:2000. Tobacco and tobacco products - atmosphere for conditioning and testing. Geneva, Switzerland: International Organization for Standardization; 2000.

30. International Organisation for Standardisationm. ISO 4387:2000/A1:2008 Cigarettes - Determination of total and nicotine-free dry particulate matter using a routine analytical smoking machine. 2008.

31. International Organisation for Standardisation. ISO 3308:2012 Routine analytical cigarette-smoking machine -definitions and standard conditions. 2012.

32. WHO Tobacco Laboratory Network. WHO SOP 01 Standard operating procedure for intense smoking of cigarettes. Geneva, Switzerland. World Health Organization; 2012.

33. WHO Tobacco Laboratory Network. WHO SOP 08 Standard operating procedure for determination of aldehydes in mainstream cigarette smoke under ISO and intense smoking conditions. Geneva, Switzerland. World Health Organization; 2016.

34. ISO 4387:2000/A1:2008. Cigarettes - Determination of total and nicotine-free dry particulate matter using a routine analytical smoking machine. Geneva, Switzerland: International Organization for Standardization; 2008.

35. ISO 8454:2007/A1:2009. Cigarettes - Determination of carbon monoxide in the vapour phase of cigarette smoke - NDIR method. Geneva, Switzerland: International Organization for Standardization; 2009.

36. ISO 10315:2014. Cigarettes - Determination of nicotine in smoke condensates Gas-chromatographic method. Geneva, Switzerland: International Organization for Standardization; 2014.

37. Norman A. Cigarette design and materials. In: Davis DL NM, ed. Tobacco: production, chemistry, and technology. Oxford, UK: Blackwell Science; 1999:353-387.

38. Hoffmann D, Djordjevic MV, Hoffmann I. The changing cigarette. Prev Med. 1997;26(4):427-434.

39. Bodnar JA, Morgan WT, Murphy PA, Ogden MW. Mainstream smoke chemistry analysis of samples from the 2009 US cigarette market. Regul Toxicol Pharmacol. 2012;64(1):3542.

40. Reilly SM, Goel R, Trushin N, et al. Brand variation in oxidant production in mainstream cigarette smoke: Carbonyls and free radicals. Food Chem Toxicol. 2017;106(Pt A):147154.

41. Uchiyama S, Tomizawa T, Inaba Y, Kunugita N. Simultaneous determination of volatile organic compounds and carbonyls in mainstream cigarette smoke using a sorbent cartridge followed by two-step elution. J Chromatogr A. 2013;1314:31-37. 
42. Reilly SM, Goel R, Bitzer Z, et al. Effects of Topography-Related Puff Parameters on Carbonyl Delivery in Mainstream Cigarette Smoke. Chem Res Toxicol. 2017;30(7):14631469.

43. IARC Monographs on the Evaluation of Carcinogenic Risks to Humans. Chemical Agents and Related Occupations - Formaldehyde. Vol 100F. Lyon, France: International Agency for Research on Cancer; 2012.

44. Goel R, Bitzer Z, Reilly SM, et al. Variation in Free Radical Yields from U.S. Marketed Cigarettes. Chem Res Toxicol. 2017;30(4):1038-1045.

45. Benowitz NL. Pharmacology of nicotine: addiction, smoking-induced disease, and therapeutics. Annu Rev Pharmacol Toxicol. 2009;49:57-71.

46. Hukkanen J, Jacob P, 3rd, Benowitz NL. Metabolism and disposition kinetics of nicotine. Pharmacol Rev. 2005;57(1):79-115.

47. European Union. Tobacco Products Directive (2014/40/EU). Brussels, Belgium: Offical Journal of the European Union; 2014.

48. Hecht SS. Research opportunities related to establishing standards for tobacco products under the Family Smoking Prevention and Tobacco Control Act. Nicotine Tob Res. 2012;14(1):18-28.

49. Shihadeh AL, Eissenberg TE. Significance of smoking machine toxicant yields to bloodlevel exposure in water pipe tobacco smokers. Cancer Epidemiol Biomarkers Prev. 2011;20(11):2457-2460. 


\section{Supplemental information}

Table S1: The table shows the mean TNCO values for the Dutch market cigarette brands and reference cigarettes (1R5F and 3R4F) when machine smoked following the ISO or $\mathrm{HCl}$ regime (both with and without taped filter ventilation holes). Tar and nicotine content were from 5 replicates, while for CO 3 replicates of 3 cigarettes are shown (mg/cigarette (SD)).

\begin{tabular}{|c|c|c|c|c|c|c|c|c|}
\hline \multirow{3}{*}{$\begin{array}{l}\text { Brands Dutch market } \\
\text { Marlboro red }\end{array}$} & \multicolumn{8}{|c|}{ Nicotine (mg/cigarette (SD)) } \\
\hline & \multicolumn{2}{|c|}{ ISO } & \multicolumn{2}{|c|}{ ISO-taped } & \multicolumn{2}{|c|}{$\mathrm{HCl}$-untaped } & \multicolumn{2}{|l|}{$\mathrm{HCl}$} \\
\hline & 0.8 & (0.1) & 0.9 & $(0.0)$ & 1.9 & (0.1) & 2.0 & $(0.2)$ \\
\hline L\&M red & 0.8 & $(0.0)$ & 0.9 & (0.1) & 1.9 & $(0.2)$ & 2.0 & (0.1) \\
\hline Lucky Strike red & 0.9 & $(0.0)$ & 1.1 & (0.1) & 2.0 & (0.1) & 2.1 & (0.1) \\
\hline Kent surround & 0.5 & (0.1) & 0.7 & (0.1) & 1.3 & (0.1) & 1.5 & (0.1) \\
\hline Philip Morris One & 0.2 & $(0.0)$ & 0.5 & $(0.0)$ & 0.6 & (0.1) & 1.2 & (0.1) \\
\hline Marlboro gold & 0.7 & $(0.0)$ & 0.8 & $(0.0)$ & 1.6 & (0.1) & 1.7 & (0.1) \\
\hline Dunhill red & 0.8 & (0.1) & 0.8 & (0.1) & 1.8 & $(0.2)$ & 1.8 & (0.2) \\
\hline Camel filter & 1.0 & (0.1) & 1.1 & (0.1) & 2.1 & (0.1) & 2.0 & (0.1) \\
\hline Gauloises blondes blue & 0.9 & (0.1) & 0.9 & (0.1) & 2.0 & $(0.2)$ & 1.9 & (0.1) \\
\hline Lucky Strike additive free & 0.8 & (0.1) & 0.8 & (0.1) & 1.9 & (0.1) & 1.9 & (0.1) \\
\hline Marlboro menthol & 0.8 & (0.1) & 0.8 & (0.1) & 1.7 & (0.1) & 1.7 & (0.1) \\
\hline 1R5F & 0.3 & $(0.2)$ & 0.5 & $(0.0)$ & 0.7 & (0.1) & 1.0 & (0.1) \\
\hline \multirow[t]{3}{*}{$3 R 4 F$} & 0.7 & $(0.0)$ & 0.9 & (0.1) & 1.8 & $(0.2)$ & 1.9 & (0.1) \\
\hline & \multicolumn{8}{|c|}{ Carbon monoxide (mg/cigarette (SD)) } \\
\hline & \multicolumn{2}{|c|}{ ISO } & \multicolumn{2}{|c|}{ ISO-taped } & \multicolumn{2}{|c|}{ HCl-untaped } & \multicolumn{2}{|l|}{$\mathrm{HCl}$} \\
\hline Marlboro red & 8.5 & $(0.2)$ & 15.1 & $(0.2)$ & 20.7 & $(0.4)$ & 26.3 & (2.5) \\
\hline L\&M red & 9.2 & $(0.7)$ & 13.8 & (1.1) & 21.9 & (0.8) & 28.1 & (1.7) \\
\hline Lucky Strike red & 10.1 & $(0.4)$ & 13.3 & (1.1) & 22.0 & $(0.5)$ & 28.9 & (0.1) \\
\hline Kent surround & 6.7 & (1.2) & 12.4 & (1.5) & 17.6 & (0.5) & 24.2 & (2.2) \\
\hline Philip Morris One & 1.6 & (0.1) & 13.3 & (0.3) & 7.4 & (0.3) & 27.0 & (1.3) \\
\hline Marlboro gold & 8.3 & $(0.4)$ & 14.0 & (1.7) & 19.4 & (0.1) & 25.5 & (1.9) \\
\hline Dunhill red & 10.0 & $(0.3)$ & 13.8 & (2.1) & 21.0 & (0.1) & 24.8 & (1.1) \\
\hline Camel filter & 10.0 & (0.8) & 13.3 & (3.2) & 23.8 & (0.8) & 27.5 & (1.9) \\
\hline Gauloises blondes blue & 9.7 & (1.1) & 13.7 & (1.6) & 20.9 & (0.7) & 25.3 & (0.9) \\
\hline Lucky Strike additive free & 9.6 & $(0.4)$ & 15.3 & (4.9) & 20.7 & $(2.2)$ & 23.7 & (0.8) \\
\hline Marlboro menthol & 9.9 & $(0.2)$ & 17.7 & (2.3) & 21.3 & (1.7) & 29.4 & (1.4) \\
\hline $1 \mathrm{R} 5 \mathrm{~F}$ & 3.6 & $(0.0)$ & 17.3 & (3.8) & 17.5 & (0.9) & 37.0 & (0.5) \\
\hline $3 R 4 F$ & 10.6 & (0.1) & 15.8 & (1.2) & 25.4 & (2.3) & 27.7 & $(0.7)$ \\
\hline
\end{tabular}




\begin{tabular}{|c|c|c|c|c|c|c|c|}
\hline \multicolumn{8}{|c|}{$\operatorname{Tar}$ (mg/cigarette (SD)) } \\
\hline \multicolumn{2}{|c|}{ ISO } & \multicolumn{2}{|c|}{ ISO-taped } & \multicolumn{2}{|c|}{$\mathrm{HCl}$-untaped } & \multicolumn{2}{|l|}{$\mathrm{HCl}$} \\
\hline 10.4 & (1.8) & 15.4 & (1.6) & 25.0 & (1.8) & 34.0 & (4.6) \\
\hline 8.4 & (1.2) & 16.2 & (4.3) & 23.1 & (2.3) & 34.0 & (3.3) \\
\hline 11.2 & (1.3) & 18.9 & (6.5) & 24.6 & $(2.2)$ & 36.5 & (4.6) \\
\hline 5.8 & (1.9) & 10.3 & (1.9) & 12.4 & (3.2) & 22.8 & (2.5) \\
\hline 0.9 & (1.1) & 9.4 & (3.4) & 3.4 & (1.3) & 17.2 & (1.6) \\
\hline 8.6 & (0.9) & 12.7 & (2.4) & 19.4 & (1.7) & 20.3 & (9.8) \\
\hline 10.6 & (0.7) & 12.5 & (2.9) & 22.2 & $(0.5)$ & 28.6 & (3.4) \\
\hline 12.2 & (1.6) & 17.0 & (3.1) & 24.1 & (2.3) & 29.7 & (3.9) \\
\hline 12.0 & (0.8) & 14.7 & (2) & 25.3 & (1.2) & 28.9 & (1.6) \\
\hline 10.7 & (1.7) & 14.0 & (3.5) & 24.2 & (1.4) & 39.3 & (17.8) \\
\hline 10.9 & (3.3) & 17.4 & (4.3) & 24.5 & (1.7) & 33.8 & (3.3) \\
\hline 2.6 & (1.1) & 8.3 & (4.7) & 7.0 & (1.3) & 21.1 & (2.8) \\
\hline 7.8 & (1.6) & 13.4 & (2.9) & 21.5 & (1.7) & 30.8 & (4.7) \\
\hline \multicolumn{8}{|c|}{ Puffs per cigarette (SD) } \\
\hline \multicolumn{2}{|c|}{ ISO } & \multicolumn{2}{|c|}{ ISO-taped } & \multicolumn{2}{|c|}{$\mathrm{HCl}$-untaped } & \multicolumn{2}{|l|}{$\mathrm{HCl}$} \\
\hline 7.9 & $(0.2)$ & 6.9 & $(0.4)$ & 10.9 & $(0.6)$ & 8.9 & $(0.5)$ \\
\hline 8.3 & (0.3) & 7.3 & (0.6) & 11.1 & $(0.6)$ & 9.1 & $(0.6)$ \\
\hline 8.7 & (0.6) & 8.2 & (1.1) & 12.2 & $(0.4)$ & 10.5 & $(0.6)$ \\
\hline 6.7 & (0.4) & 5.7 & $(0.4)$ & 10.5 & (1.0) & 8.2 & $(0.5)$ \\
\hline 7.8 & (0.8) & 6.0 & (0.1) & 11.7 & $(0.5)$ & 7.4 & $(0.5)$ \\
\hline 6.8 & (0.3) & 6.2 & $(0.4)$ & 9.3 & $(0.4)$ & 8.2 & $(0.5)$ \\
\hline 6.2 & (0.3) & 5.8 & $(0.5)$ & 8.1 & $(0.2)$ & 7.5 & $(0.8)$ \\
\hline 7.8 & (0.4) & 6.9 & $(0.4)$ & 10.1 & $(0.3)$ & 8.8 & $(0.7)$ \\
\hline 6.5 & $(0.4)$ & 5.7 & (0.7) & 8.7 & $(0.7)$ & 7.8 & $(0.4)$ \\
\hline 6.7 & $(0.4)$ & 6.1 & $(0.5)$ & 9.2 & $(0.2)$ & 8.7 & $(0.5)$ \\
\hline 8.1 & $(0.3)$ & 7.2 & (0.8) & 10.3 & $(0.3)$ & 8.7 & $(0.6)$ \\
\hline 7.0 & $(0.0)$ & 4.9 & (1.3) & 10.1 & $(0.3)$ & 6.7 & $(0.4)$ \\
\hline 8.4 & $(0.3)$ & 7.5 & $(0.4)$ & 11.9 & $(0.2)$ & 10.3 & (1.0) \\
\hline
\end{tabular}


Table S2: The produced individual aldehyde yields of 5 replicates per individual cigarette brand per smoking condition are listed in a table ( $\mu \mathrm{g} /$ cigarette (SD))

\begin{tabular}{|c|c|c|c|c|c|c|c|c|}
\hline \multirow[b]{3}{*}{ Marlboro red } & \multicolumn{8}{|c|}{ Acrolein } \\
\hline & \multicolumn{2}{|c|}{ ISO } & \multicolumn{2}{|c|}{ ISO-taped } & \multicolumn{2}{|c|}{$\mathrm{HCl}$-untaped } & \multicolumn{2}{|l|}{$\mathrm{HCl}$} \\
\hline & 36.0 & (20.3) & 78.1 & (4.4) & 82.7 & (12.9) & 100.1 & (8.8) \\
\hline L\&M red & 50.5 & $(2.8)$ & 69.8 & (8.8) & 75.7 & $(9.5)$ & 94.9 & (12.0) \\
\hline Lucky Strike red & 45.1 & $(8.2)$ & 77.6 & (7.3) & 70.6 & $(18.7)$ & 94.5 & (9.1) \\
\hline Kent surround & 18.3 & (12.3) & 29.9 & (13.9) & 39.8 & (12.3) & 71.9 & (23.2) \\
\hline Philip Morris One & 1.3 & $(0.8)$ & 63.8 & (12.5) & 13.9 & $(3.6)$ & 97.4 & (7.5) \\
\hline Marlboro gold & 40.3 & $(12.5)$ & 69.0 & $(8.7)$ & 66.0 & $(22.9)$ & 77.9 & (6.2) \\
\hline Dunhill red & 52.9 & (11.4) & 49.6 & (11.4) & 73.8 & $(4.1)$ & 89.1 & (11.6) \\
\hline Camel filter & 62.0 & (3.3) & 66.6 & $(30.8)$ & 87.8 & (8.1) & 121.7 & (10.9) \\
\hline Gauloises blondes blue & 50.8 & (3.3) & 69.6 & $(9.3)$ & 80.9 & $(15.5)$ & 100.1 & (11.8) \\
\hline Lucky Strike additive free & 58.7 & $(6.2)$ & 68.8 & (10.6) & 74.4 & (15.5) & 93.9 & (9.1) \\
\hline Marlboro menthol & 46.4 & (18.4) & 79.2 & $(2.7)$ & 85.7 & (19.1) & 114.1 & (13.1) \\
\hline $1 \mathrm{R} 5 \mathrm{~F}$ & 4.6 & $(2.2)$ & 59.4 & (6.0) & 34.4 & $(9.6)$ & 93.6 & (9.9) \\
\hline \multirow[t]{3}{*}{$3 R 4 F$} & 45.2 & (11.4) & 73.6 & $(14.2)$ & 81.5 & $(22.3)$ & 114.7 & (18.6) \\
\hline & \multicolumn{8}{|c|}{ Formaldehyde } \\
\hline & \multicolumn{2}{|c|}{ ISO } & \multicolumn{2}{|c|}{ ISO-taped } & \multicolumn{2}{|c|}{$\mathrm{HCl}$-untaped } & $\mathrm{HCl}$ & \\
\hline Marlboro red & 13.9 & $(4.6)$ & 42.5 & $(24.8)$ & 39.6 & (4.9) & 46.3 & (6.6) \\
\hline L\&M red & 14.6 & (2.1) & 30.5 & (23.3) & 40.2 & $(2.6)$ & 41.2 & (5.0) \\
\hline Lucky Strike red & 13.6 & (3.0) & 30.7 & $(21.7)$ & 34.5 & $(10.8)$ & 32.5 & $(4.6)$ \\
\hline Kent surround & 5.5 & $(2.7)$ & 15.9 & $(20.2)$ & 23.5 & $(9.8)$ & 26.6 & (6.3) \\
\hline Philip Morris One & 0.7 & $(0.5)$ & 23.7 & $(26.1)$ & 8.4 & $(2.8)$ & 36.0 & (5.7) \\
\hline Marlboro gold & 13.9 & (3.5) & 43.4 & (26.5) & 45.7 & (13.5) & 39.7 & (5.4) \\
\hline Dunhill red & 16.7 & $(2.2)$ & 28.0 & (37.0) & 39.2 & $(4.5)$ & 34.4 & $(7.2)$ \\
\hline Camel filter & 17.6 & (1.6) & 41.4 & (41.0) & 37.9 & (5.3) & 49.6 & (5.7) \\
\hline Gauloises blondes blue & 19.4 & (2.8) & 49.3 & $(37.6)$ & 44.4 & (3.4) & 43.6 & (3.6) \\
\hline Lucky Strike additive free & 28.6 & $(5.4)$ & 42.9 & (43.3) & 38.5 & $(4.5)$ & 40.2 & (6.7) \\
\hline Marlboro menthol & 28.0 & $(12.8)$ & 54.9 & $(43.0)$ & 45.4 & $(10.7)$ & 54.8 & (10.0) \\
\hline $1 \mathrm{R} 5 \mathrm{~F}$ & 4.0 & $(2.1)$ & 17.8 & $(21.4)$ & 14.1 & $(4.6)$ & 27.5 & $(4.6)$ \\
\hline \multirow[t]{3}{*}{$3 R 4 F$} & 13.7 & (1.8) & 40.8 & (26.3) & 46.3 & $(16.4)$ & 48.5 & (7.4) \\
\hline & \multicolumn{8}{|c|}{ Acetone } \\
\hline & \multicolumn{2}{|c|}{ ISO } & \multicolumn{2}{|c|}{ ISO-taped } & \multicolumn{2}{|c|}{ HCl-untaped } & \multicolumn{2}{|l|}{$\mathrm{HCl}$} \\
\hline Marlboro red & 315.7 & (184.5) & 377.7 & (32.7) & 467.2 & (38.3) & 598.3 & (31.6) \\
\hline L\&M red & 439.5 & $(96.2)$ & 351.2 & (25.1) & 506.6 & (8.3) & 591.0 & (29.4) \\
\hline Lucky Strike red & 428.2 & (133.8) & 408.6 & (25.8) & 513.4 & $(66.4)$ & 607.1 & (32.8) \\
\hline Kent surround & 242.0 & (131.8) & 192.2 & (77.9) & 355.2 & (95.6) & 476.3 & (85.8) \\
\hline Philip Morris One & 32.7 & $(22.9)$ & 297.7 & $(46.4)$ & 154.9 & $(30.6)$ & 556.8 & (28.6) \\
\hline Marlboro gold & 355.5 & (156.4) & 318.0 & (16.4) & 431.3 & $(26.7)$ & 454.5 & (23.8) \\
\hline Dunhill red & 455.7 & (129.5) & 312.5 & $(76.1)$ & 475.3 & $(25.0)$ & 535.9 & (39.8) \\
\hline Camel filter & 457.9 & (98.8) & 310.2 & (121.9) & 491.7 & $(42.4)$ & 596.1 & (44.2) \\
\hline Gauloises blondes blue & 427.1 & (102.1) & 324.6 & $(41.4)$ & 472.4 & (34.1) & 533.8 & (28.5) \\
\hline Lucky Strike additive free & 414.6 & $(100.8)$ & 329.3 & $(27.7)$ & 483.4 & $(18.6)$ & 534.8 & (31.6) \\
\hline Marlboro menthol & 406.9 & (208.1) & 383.4 & (16.0) & 525.0 & $(47.3)$ & 642.9 & (72.2) \\
\hline $1 \mathrm{R} 5 \mathrm{~F}$ & 102.7 & $(20.0)$ & 373.3 & $(44.4)$ & 339.4 & (55.4) & 660.2 & (48.1) \\
\hline $3 R 4 F$ & 427.4 & (107.1) & 359.9 & (102.9) & 592.0 & $(48.5)$ & 675.5 & (51.7) \\
\hline
\end{tabular}




\begin{tabular}{|c|c|c|c|c|c|c|c|}
\hline \multicolumn{8}{|c|}{ Acetaldehyde } \\
\hline \multicolumn{2}{|c|}{ ISO } & \multicolumn{2}{|c|}{ ISO-taped } & \multicolumn{2}{|c|}{$\mathrm{HCl}$-untaped } & \multicolumn{2}{|l|}{$\mathrm{HCl}$} \\
\hline 359.1 & (190.4) & 773.5 & $(84.2)$ & 838.9 & $(81.2)$ & 933.4 & (86.5) \\
\hline 480.7 & $(35.7)$ & 681.1 & (54.0) & 958.8 & (39.9) & 924.8 & (68.3) \\
\hline 476.8 & (103.7) & 803.8 & $(72.0)$ & 981.6 & (171) & 928.7 & $(84.8)$ \\
\hline 268.0 & (113.4) & 442.1 & (158.8) & 811.5 & (227.7) & 916.6 & (120.5) \\
\hline 36.7 & (18.4) & 636.4 & (83.4) & 418.3 & $(76.1)$ & 1055.6 & $(62.2)$ \\
\hline 402.4 & (129.7) & 657.5 & (36.9) & 972.6 & (223.9) & 898.6 & (69.6) \\
\hline 506.0 & $(67.5)$ & 539.3 & (173.1) & 825.6 & $(62.5)$ & 858.7 & $(59.2)$ \\
\hline 511.1 & (36.4) & 612.6 & (244.3) & 851.0 & (99.7) & 924.5 & $(50.6)$ \\
\hline 488.1 & (16.2) & 697.9 & (95.1) & 817.5 & (72.8) & 884.9 & (42.7) \\
\hline 515.0 & $(36.8)$ & 673.6 & (95.1) & 853.5 & $(40.6)$ & 874.1 & (38.5) \\
\hline 475.6 & (143.4) & 827.5 & (44.1) & 980.8 & (166.2) & 1072.5 & (111.0) \\
\hline 115.7 & $(24.1)$ & 732.0 & (71.6) & 669.9 & (146.1) & 907.8 & (85.0) \\
\hline 481.3 & (74.1) & 806.9 & (109.9) & 1199.5 & (261.2) & 1103.0 & (66.0) \\
\hline \multicolumn{8}{|c|}{ Crotonaldehyde } \\
\hline \multicolumn{2}{|c|}{ ISO } & \multicolumn{2}{|c|}{ ISO-taped } & \multicolumn{2}{|c|}{$\mathrm{HCl}$-untaped } & \multicolumn{2}{|l|}{$\mathrm{HCl}$} \\
\hline 14.3 & (6.6) & 29.5 & (2.1) & 38.3 & (3.8) & 56.0 & (1.6) \\
\hline 19.1 & (2.4) & 27.1 & (3.1) & 41.3 & (1.8) & 53.8 & (1.1) \\
\hline 16.5 & (2.8) & 30.6 & (1.7) & 38.8 & (6.8) & 53.8 & (4.1) \\
\hline 5.4 & (2.5) & 8.1 & (5.0) & 19.2 & (10.9) & 33.8 & (8.4) \\
\hline 6.9 & (10.0) & 19.3 & (5.5) & 6.6 & $(1.7)$ & 47.9 & (5.4) \\
\hline 12.5 & $(2.7)$ & 23.1 & (2.0) & 32.6 & (4.0) & 36.8 & $(4.2)$ \\
\hline 20.4 & (2.4) & 22.8 & $(5.0)$ & 42.1 & (2.9) & 47.0 & (4.1) \\
\hline 20.9 & $(0.9)$ & 23.9 & (12.0) & 43.0 & (3.9) & 54.2 & (3.4) \\
\hline 25.0 & (8.5) & 28.4 & $(4.2)$ & 43.9 & (2.4) & 51.5 & (4.0) \\
\hline 21.3 & $(4.2)$ & 25.5 & (3.5) & 40.5 & (2.7) & 47.4 & (4.9) \\
\hline 18.2 & (7.7) & 30.7 & (2.8) & 42.4 & (3.2) & 57.6 & (7.8) \\
\hline 2.9 & (1.1) & 21.0 & (1.5) & 14.8 & (2.7) & 48.4 & (7.3) \\
\hline 17.4 & (1.8) & 25.5 & (7.4) & 43.3 & (3.1) & 54.9 & (4.8) \\
\hline \multicolumn{8}{|c|}{ Butyraldehyde } \\
\hline \multicolumn{2}{|c|}{ ISO } & \multicolumn{2}{|c|}{ ISO-taped } & \multicolumn{2}{|c|}{$\mathrm{HCl}$-untaped } & \multicolumn{2}{|l|}{$\mathrm{HCl}$} \\
\hline 22.9 & (11.2) & 45.9 & (3.0) & 60.7 & (4.9) & 76.4 & (4.3) \\
\hline 31.2 & $(2.3)$ & 42.8 & (3.4) & 67.5 & (2.2) & 74.7 & (4.5) \\
\hline 32.3 & (6.9) & 52.1 & (1.8) & 69.1 & (8.6) & 75.4 & (4.9) \\
\hline 16.4 & (5.4) & 23.4 & (8.6) & 41.6 & (10.2) & 51.9 & (9.2) \\
\hline 2.5 & (1.8) & 34.9 & (4.6) & 19.6 & (3.5) & 61.0 & (3.0) \\
\hline 24.8 & (7.4) & 38.9 & (2.4) & 54.9 & (4.0) & 53.6 & (3.1) \\
\hline 34.5 & (3.4) & 38.4 & (6.8) & 64.2 & (4.8) & 68.7 & (5.1) \\
\hline 35.6 & (1.8) & 38.5 & (14.2) & 64.8 & (5.6) & 75.0 & (4.2) \\
\hline 32.1 & (0.8) & 42.0 & (5.5) & 64.0 & (3.8) & 70.4 & (3.7) \\
\hline 34.8 & (3.0) & 42.5 & (3.8) & 65.6 & (2.5) & 70.4 & (5.0) \\
\hline 31.4 & (9.7) & 47.1 & (1.5) & 67.6 & (6.9) & 80.2 & (9.2) \\
\hline 8.0 & (1.0) & 38.1 & (4.6) & 35.8 & (5.0) & 62.0 & (4.2) \\
\hline 30.6 & (2.7) & 43.9 & (10.6) & 73.4 & (5.7) & 80.0 & (5.9) \\
\hline
\end{tabular}




\begin{tabular}{|c|c|c|c|c|c|c|c|c|}
\hline \multirow[b]{3}{*}{ Marlboro red } & \multicolumn{8}{|c|}{ Propionaldehyde } \\
\hline & \multicolumn{2}{|c|}{ ISO } & \multicolumn{2}{|c|}{ ISO-taped } & \multicolumn{2}{|c|}{ HCl-untaped } & \multicolumn{2}{|l|}{$\mathrm{HCl}$} \\
\hline & 38.2 & $(16.5)$ & 70.8 & $(5.2)$ & 90.9 & (9.5) & 122.0 & (6.4) \\
\hline L\&M red & 52.5 & $(2.5)$ & 68.1 & (7.5) & 96.2 & (3.8) & 117.4 & (11.3) \\
\hline Lucky Strike red & 50.8 & $(8.5)$ & 75.7 & (5.4) & 93.4 & $(12)$ & 114.9 & $(5.7)$ \\
\hline Kent surround & 25.4 & (10.5) & 31.1 & (13.3) & 53.9 & $(11.2)$ & 77.3 & (15.6) \\
\hline Philip Morris One & 5.5 & $(2.8)$ & 53.1 & (7.6) & 23.6 & $(5.2)$ & 95.0 & (9.0) \\
\hline Marlboro gold & 41.0 & $(10.0)$ & 59.4 & $(5.1)$ & 77.6 & (6.9) & 86.1 & (5.5) \\
\hline Dunhill red & 53.3 & $(7.5)$ & 55.9 & (11.9) & 84.5 & (5.3) & 98.4 & (7.9) \\
\hline Camel filter & 55.5 & $(4.5)$ & 56.3 & $(22.9)$ & 93.2 & (7.1) & 122.1 & (10.4) \\
\hline Gauloises blondes blue & 53.9 & $(4.0)$ & 66.9 & (8.9) & 94.7 & (7.8) & 114.1 & (12.7) \\
\hline Lucky Strike additive free & 54.1 & (6.3) & 59.5 & (4.9) & 87.8 & (8.4) & 102.7 & (11.6) \\
\hline Marlboro menthol & 48.7 & $(15.2)$ & 72.8 & (3.7) & 99.7 & (9.8) & 132.0 & (16.5) \\
\hline $1 \mathrm{R} 5 \mathrm{~F}$ & 13.8 & (1.8) & 59.0 & (8.5) & 51.1 & (9.5) & 94.8 & (8.1) \\
\hline \multirow[t]{3}{*}{$3 \mathrm{R} 4 \mathrm{~F}$} & 50.9 & (8.7) & 64.5 & (20) & 105.5 & (8.3) & 122.5 & (12.3) \\
\hline & \multicolumn{8}{|c|}{ Isovaleraldehyde } \\
\hline & \multicolumn{2}{|c|}{ ISO } & \multicolumn{2}{|c|}{ ISO-taped } & \multicolumn{2}{|c|}{$\mathrm{HCl}$-untaped } & \multicolumn{2}{|l|}{$\mathrm{HCl}$} \\
\hline Marlboro red & 45.1 & $(21.9)$ & 92.5 & (8.6) & 133.7 & (19.0) & 180.4 & (9.9) \\
\hline L\&M red & 60.6 & $(9.8)$ & 86.3 & (10.8) & 146.0 & $(16.2)$ & 174.4 & (9.1) \\
\hline Lucky Strike red & 58.7 & (13.7) & 103.8 & (13.5) & 142.7 & (16.8) & 184.3 & (7.8) \\
\hline Kent surround & 25.7 & (11.4) & 34.4 & (17.8) & 80.2 & (31.9) & 111.0 & (27.0) \\
\hline Philip Morris One & 6.7 & (3.8) & 60.8 & (15.1) & 30.8 & (7.7) & 140.1 & (12.7) \\
\hline Marlboro gold & 48.2 & (14.8) & 75.6 & (14.8) & 124.6 & (21.3) & 123.2 & (13.7) \\
\hline Dunhill red & 63.6 & (7.9) & 72.2 & $(22.0)$ & 132.7 & (11.1) & 146.6 & (13.9) \\
\hline Camel filter & 71.3 & (6.7) & 73.5 & (32.4) & 140.9 & $(14.2)$ & 168.4 & (18.4) \\
\hline Gauloises blondes blue & 64.2 & (4.7) & 80.9 & (13.9) & 138.8 & $(13.5)$ & 148.7 & (9.5) \\
\hline Lucky Strike additive free & 66.6 & $(5.9)$ & 75.2 & (3.8) & 134.5 & (16.1) & 144.7 & (15.8) \\
\hline Marlboro menthol & 59.2 & $(23.2)$ & 92.3 & (10.9) & 143.0 & $(10.4)$ & 177.8 & (23.2) \\
\hline $1 \mathrm{R} 5 \mathrm{~F}$ & 12.9 & $(4.7)$ & 69.4 & (7.0) & 64.4 & (12.0) & 147.0 & (13.7) \\
\hline \multirow[t]{3}{*}{$3 \mathrm{R} 4 \mathrm{~F}$} & 64.0 & (7.5) & 87.4 & $(35.8)$ & 159.6 & $(16.7)$ & 183.7 & (17.6) \\
\hline & \multicolumn{8}{|c|}{$o-, m-, p$-tolualdehyde } \\
\hline & \multicolumn{2}{|c|}{ ISO } & \multicolumn{2}{|c|}{ ISO-taped } & \multicolumn{2}{|c|}{$\mathrm{HCl}$-untaped } & \multicolumn{2}{|l|}{$\mathrm{HCl}$} \\
\hline Marlboro red & 35.7 & (7.5) & 62.1 & (4.4) & 83.1 & (5.5) & 78.6 & (7.4) \\
\hline L\&M red & 36.8 & (6.6) & 51.3 & (5.4) & 84.8 & $(2.6)$ & 73.4 & (5.3) \\
\hline Lucky Strike red & 31.3 & (3.3) & 50.1 & (4.8) & 71.6 & $(7.7)$ & 60.5 & (4.1) \\
\hline Kent surround & 10.7 & (4.4) & 17.7 & (7.5) & 35.5 & $(10.6)$ & 37.0 & (5.6) \\
\hline Philip Morris One & 2.0 & (0.7) & 27.3 & (7.4) & 16.0 & $(4.2)$ & 41.2 & (4.3) \\
\hline Marlboro gold & 34.1 & (6.4) & 51.4 & (8.3) & 80.2 & (6.9) & 64.6 & (7.0) \\
\hline Dunhill red & 31.4 & (7.5) & 37.3 & (11.3) & 63.0 & (6.2) & 51.0 & (2.9) \\
\hline Camel filter & 37.3 & (2.8) & 43.6 & (16.9) & 74.3 & (7.0) & 73.7 & (5.9) \\
\hline Gauloises blondes blue & 35.8 & (6.6) & 50.2 & $(4.2)$ & 81.8 & (4.4) & 65.1 & $(4.2)$ \\
\hline Lucky Strike additive free & 31.7 & $(9.2)$ & 38.5 & (6.0) & 69.0 & $(5.1)$ & 57.0 & (8.1) \\
\hline Marlboro menthol & 31.3 & (11.5) & 54.6 & (3.2) & 81.7 & $(10.3)$ & 76.1 & (7.3) \\
\hline $1 \mathrm{R} 5 \mathrm{~F}$ & 3.5 & $(0.9)$ & 23.7 & $(2.9)$ & 24.2 & $(3.4)$ & 31.0 & (2.4) \\
\hline $3 R 4 F$ & 28.4 & (4.5) & 42.5 & $(16.4)$ & 76.2 & $(7.5)$ & 64.2 & (6.1) \\
\hline
\end{tabular}




\begin{tabular}{|c|c|c|c|c|c|c|c|}
\hline \multicolumn{8}{|c|}{ Benzaldehyde } \\
\hline \multicolumn{2}{|c|}{ ISO } & \multicolumn{2}{|c|}{ ISO-taped } & \multicolumn{2}{|c|}{$\mathrm{HCl}$-untaped } & \multicolumn{2}{|l|}{$\mathrm{HCl}$} \\
\hline 1.6 & (1.6) & 4.4 & (0.8) & 8.4 & (1.2) & 13.4 & (2.8) \\
\hline 2.7 & (1.4) & 4.0 & (1.2) & 10.3 & (1.2) & 12.1 & (2.1) \\
\hline 2.3 & (1.1) & 4.6 & $(0.5)$ & 10.1 & (3.5) & 12.7 & (1.2) \\
\hline 0.9 & $(0.7)$ & 1.1 & (1.3) & 4.7 & (2.1) & 5.6 & (1.3) \\
\hline 0.1 & (0.1) & 1.9 & (1.4) & 1.1 & $(0.5)$ & 7.5 & (0.9) \\
\hline 2.2 & (1.5) & 3.2 & (1.2) & 8.2 & (3.4) & 7.0 & (0.4) \\
\hline 2.4 & (1.1) & 3.8 & (1.8) & 10.3 & (1.9) & 10.9 & (1.1) \\
\hline 2.4 & (1.4) & 2.7 & (1.8) & 8.8 & (1.5) & 11.7 & (1.5) \\
\hline 2.9 & (1.3) & 4.5 & (1.2) & 10.9 & (1.9) & 12.5 & (0.4) \\
\hline 3.4 & (1.7) & 4.1 & $(0.2)$ & 10.1 & (2.0) & 11.8 & (2.9) \\
\hline 2.4 & (1.7) & 4.5 & (0.6) & 10.2 & (2.3) & 14.2 & (3.0) \\
\hline 0.3 & $(0.3)$ & 3.2 & (1.1) & 3.2 & (1.0) & 8.7 & (1.0) \\
\hline 2.6 & (1.3) & 4.3 & (2.2) & 11.7 & (3.9) & 12.2 & (1.8) \\
\hline \multicolumn{8}{|c|}{ Hexaldehyde } \\
\hline \multicolumn{2}{|c|}{ ISO } & \multicolumn{2}{|c|}{ ISO-taped } & \multicolumn{2}{|c|}{$\mathrm{HCl}$-untaped } & \multicolumn{2}{|l|}{$\mathrm{HCl}$} \\
\hline 2.9 & (1.8) & 8.0 & (1.7) & 14.9 & (1.6) & 9.5 & (2.5) \\
\hline 2.4 & $(2.2)$ & 6.9 & (1.4) & 17.4 & (2.9) & 9.9 & (3.2) \\
\hline 3.6 & $(0.5)$ & 6.6 & (0.9) & 12.5 & (2.1) & 6.9 & (2.6) \\
\hline 1.4 & (0.4) & 2.1 & (0.4) & 4.7 & (2.0) & 3.1 & (1.0) \\
\hline 0.3 & (0.3) & 3.3 & (0.9) & 2.3 & $(0.7)$ & 4.7 & (1.6) \\
\hline 3.2 & (1.0) & 6.2 & (1.0) & 13.0 & (2.8) & 6.9 & (1.4) \\
\hline 3.5 & (1.4) & 6.0 & (2.7) & 15.0 & (2.8) & 8.6 & (3.6) \\
\hline 3.6 & (0.9) & 6.3 & (2.6) & 15.3 & (2.6) & 10.7 & (2.8) \\
\hline 4.4 & (1.6) & 8.4 & (2.1) & 18.1 & (1.5) & 10.6 & (1.7) \\
\hline 3.4 & (1.4) & 6.4 & (2.0) & 16.0 & (1.8) & 10.2 & (3.2) \\
\hline 3.2 & (0.8) & 8.7 & (1.1) & 19.3 & (4.1) & 12.2 & (4.7) \\
\hline 0.4 & (0.3) & 3.4 & (0.6) & 3.4 & (0.9) & 4.9 & (1.8) \\
\hline 3.0 & (0.8) & 6.4 & (2.2) & 17.4 & (3.5) & 10.6 & (3.7) \\
\hline \multicolumn{8}{|c|}{ 2,5-dimethylbenzaldehyde } \\
\hline \multicolumn{2}{|c|}{ ISO } & \multicolumn{2}{|c|}{ ISO-taped } & \multicolumn{2}{|c|}{$\mathrm{HCl}$-untaped } & \multicolumn{2}{|l|}{$\mathrm{HCl}$} \\
\hline 49.2 & (35.1) & 115.1 & (64.0) & 215.1 & $(50.4)$ & 281.7 & $(48.3)$ \\
\hline 58.5 & $(24.3)$ & 79.9 & $(37.5)$ & 262.3 & (12.2) & 272.9 & (27.9) \\
\hline 58.5 & (29.3) & 119.6 & (39.0) & 262.0 & (69.4) & 279.0 & (33.6) \\
\hline 23.7 & $(14.6)$ & 45.3 & (21.0) & 136.2 & $(79.0)$ & 207.4 & (56.7) \\
\hline 6.9 & (6.7) & 76.5 & (43.5) & 73.2 & (18.3) & 270.5 & (8.7) \\
\hline 64.1 & $(41.6)$ & 97.7 & $(9.7)$ & 229.5 & $(30.0)$ & 230.9 & (23.4) \\
\hline 83.4 & (39.9) & 95.2 & (53.6) & 262.2 & $(20.5)$ & 271.9 & (31.2) \\
\hline 85.8 & $(42.6)$ & 110.1 & (62.6) & 257.6 & $(30.0)$ & 295.7 & (26.3) \\
\hline 89.1 & (38.4) & 120.9 & $(44.0)$ & 263.2 & $(23.2)$ & 269.1 & (20.4) \\
\hline 63.8 & (39.2) & 88.7 & (48.6) & 252.6 & (27.1) & 273.8 & (30.4) \\
\hline 71.6 & $(48.5)$ & 134.9 & (31.0) & 235.9 & $(56.5)$ & 331.0 & (53.0) \\
\hline 17.0 & (11.8) & 37.5 & (15.4) & 75.7 & (16.1) & 233.3 & (38.2) \\
\hline 75.0 & (35.9) & 107.4 & (48.3) & 280.3 & $(54.5)$ & 341.8 & $(23.5)$ \\
\hline
\end{tabular}


Table S3: Statistical comparison ( $p$-values) per individual aldehyde for different smoking conditions (one-way ANOVA), and for the combined brands and smoking conditions (twoway ANOVA).

\begin{tabular}{lllllll}
\hline & $\begin{array}{l}\text { ISO - } \\
\text { brands }\end{array}$ & $\begin{array}{l}\text { ISO-taped - } \\
\text { brands }\end{array}$ & $\begin{array}{l}\mathrm{HCl}- \\
\text { untaped } \\
\text {-brands }\end{array}$ & $\begin{array}{l}\mathrm{HCl}- \\
\text { brands }\end{array}$ & $\begin{array}{l}\text { Smoking } \\
\text { conditions - } \\
\text { brands }\end{array}$ & $\begin{array}{l}\text { Smoking } \\
\text { conditions - } \\
\text { regimes }\end{array}$ \\
\hline Formaldehyde & $4.34 \mathrm{E}-10$ & 0.726718 & $3.53 \mathrm{E}-10$ & $2.79 \mathrm{E}-09$ & $1.30 \mathrm{E}-09$ & $8.17 \mathrm{E}-15$ \\
Acetaldehyde & $1.28 \mathrm{E}-12$ & $9.31 \mathrm{E}-05$ & $5.58 \mathrm{E}-08$ & $8.22 \mathrm{E}-06$ & $9.13 \mathrm{E}-15$ & $3.52 \mathrm{E}-63$ \\
Acrolein & $6.05 \mathrm{E}-14$ & $9.38 \mathrm{E}-06$ & $4.05 \mathrm{E}-11$ & $1.31 \mathrm{E}-06$ & $5.33 \mathrm{E}-26$ & $2.71 \mathrm{E}-54$ \\
Acetone & $1.69 \mathrm{E}-06$ & 0.000312 & $1.89 \mathrm{E}-18$ & $3.18 \mathrm{E}-10$ & $5.62 \mathrm{E}-18$ & $9.97 \mathrm{E}-38$ \\
Propanal & $2.35 \mathrm{E}-14$ & $2.37 \mathrm{E}-05$ & $5.68 \mathrm{E}-22$ & $7.43 \mathrm{E}-11$ & $5.00 \mathrm{E}-39$ & $4.69 \mathrm{E}-83$ \\
Crotonaldehyde & $5.55 \mathrm{E}-09$ & $6.32 \mathrm{E}-07$ & $1.46 \mathrm{E}-21$ & $1.27 \mathrm{E}-09$ & $4.48 \mathrm{E}-34$ & $4.68 \mathrm{E}-84$ \\
Butyraldehyde & $6.16 \mathrm{E}-15$ & $9.47 \mathrm{E}-06$ & $1.09 \mathrm{E}-21$ & $7.20 \mathrm{E}-13$ & $2.58 \mathrm{E}-41$ & $1.19 \mathrm{E}-91$ \\
Benzaldehyde & 0.001612 & 0.001154 & $4.61 \mathrm{E}-10$ & $1.09 \mathrm{E}-10$ & $6.00 \mathrm{E}-26$ & $2.62 \mathrm{E}-76$ \\
Isovaleraldehyde & $3.52 \mathrm{E}-13$ & 0.000111 & $1.92 \mathrm{E}-17$ & $9.30 \mathrm{E}-11$ & $1.92 \mathrm{E}-34$ & $3.60 \mathrm{E}-87$ \\
o-m-p-tolualdehyde & $1.74 \mathrm{E}-15$ & $8.12 \mathrm{E}-10$ & $1.38 \mathrm{E}-26$ & $4.30 \mathrm{E}-21$ & $4.25 \mathrm{E}-67$ & $3.82 \mathrm{E}-73$ \\
Hexanal & $4.74 \mathrm{E}-06$ & $3.37 \mathrm{E}-07$ & $1.91 \mathrm{E}-18$ & $1.89 \mathrm{E}-05$ & $2.29 \mathrm{E}-32$ & $3.48 \mathrm{E}-58$ \\
$\begin{array}{l}2,5 \text { dimethylbenz } \\
\text { aldehyde }\end{array}$ & 0.002360 & 0.022678 & $1.86 \mathrm{E}-12$ & $5.08 \mathrm{E}-06$ & $4.02 \mathrm{E}-21$ & $5.63 \mathrm{E}-86$ \\
\hline
\end{tabular}


Table S4: Correlation factors of individual aldehyde emissions produced by 13 cigarette brands ( 5 replicates) for the different smoking conditions. The lower triangle represents the taped variant of the smoking regime.

\begin{tabular}{|c|c|c|c|c|c|c|c|c|c|c|c|c|}
\hline & & & & & & & & & & & & \\
\hline Formaldehyde & $x$ & 0.789 & 0.773 & 0.718 & 0.764 & 0.688 & 0.794 & 0.618 & 0.801 & 0.732 & 0.633 & 0.657 \\
\hline Acetaldehyde & 0.367 & $\mathrm{x}$ & 0.963 & 0.866 & 0.979 & 0.777 & 0.979 & 0.736 & 0.960 & 0.869 & 0.662 & 0.672 \\
\hline Acrolein & 0.451 & 0.880 & $x$ & 0.823 & 0.975 & 0.812 & 0.964 & 0.704 & 0.941 & 0.869 & 0.666 & 0.595 \\
\hline Acetone & 0.218 & 0.850 & 0.811 & $x$ & 0.843 & 0.670 & 0.867 & 0.422 & 0.837 & 0.714 & 0.412 & 0.739 \\
\hline Propanal & 0.188 & 0.818 & 0.843 & 0.950 & $x$ & 0.807 & 0.984 & 0.687 & 0.950 & 0.877 & 0.681 & 0.591 \\
\hline Crotonaldehyde & 0.409 & 0.793 & 0.875 & 0.891 & 0.940 & $\mathrm{x}$ & 0.804 & 0.638 & 0.821 & 0.737 & 0.592 & 0.605 \\
\hline Butyraldehyde & 0.287 & 0.836 & 0.854 & 0.955 & 0.971 & 0.952 & $x$ & 0.674 & 0.969 & 0.850 & 0.645 & 0.663 \\
\hline Benzaldehyde & 0.099 & 0.662 & 0.635 & 0.807 & 0.864 & 0.822 & 0.850 & $x$ & 0.737 & 0.703 & 0.667 & 0.510 \\
\hline Isovaleraldehyde & 0.102 & 0.753 & 0.766 & 0.920 & 0.962 & 0.899 & 0.948 & 0.895 & $\mathrm{x}$ & 0.860 & 0.668 & 0.756 \\
\hline $\begin{array}{l}o-m-p \text {-tolualde- } \\
\text { hyde }\end{array}$ & 0.331 & 0.649 & 0.746 & 0.721 & 0.835 & 0.866 & 0.822 & 0.761 & 0.847 & $\mathrm{x}$ & 0.779 & 0.583 \\
\hline Hexanal & 0.581 & 0.639 & 0.686 & 0.630 & 0.706 & 0.821 & 0.743 & 30.691 & 0.680 & 0.867 & $\mathrm{x}$ & 0.404 \\
\hline $\begin{array}{l}\text { 2,5- } \\
\text { dimethylbenz } \\
\text { aldehyde }\end{array}$ & 0.643 & 0.591 & 0.585 & 0.537 & 0.527 & 0.682 & 0.621 & 0.451 & 0.522 & 0.674 & 0.839 & $\mathrm{x}$ \\
\hline
\end{tabular}

ISO-taped

$\mathrm{HCl}$

Formaldehyde

Acetaldehyde

Acrolein

Acetone

Propanal

Crotonaldehyde

Butyraldehyde

Benzaldehyde

Isovaleraldehyde

$o$-m- $p$-tolualde-

hyde

Hexanal

2,5-

dimethylbenz aldehyde

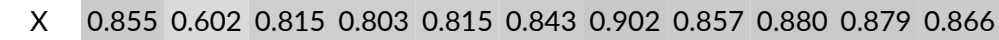

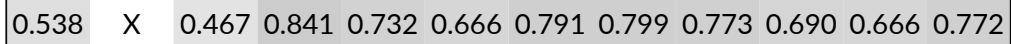
$\begin{array}{llllllllllllll}0.543 & 0.503 & \times & 0.817 & 0.894 & 0.863 & 0.822 & 0.519 & 0.747 & 0.793 & 0.714 & 0.686\end{array}$ $\begin{array}{lllllllllllll}0.280 & 0.512 & 0.731 & X & 0.959 & 0.921 & 0.975 & 0.818 & 0.931 & 0.837 & 0.816 & 0.867\end{array}$ $\begin{array}{llllllllllllllll}0.598 & 0.366 & 0.807 & 0.734 & x & 0.951 & 0.969 & 0.798 & 0.923 & 0.903 & 0.869 & 0.846\end{array}$ $\begin{array}{llllllllllllllll}0.468 & 0.330 & 0.766 & 0.815 & 0.902 & x & 0.966 & 0.830 & 0.951 & 0.901 & 0.897 & 0.921\end{array}$ $\begin{array}{llllllllllllll}0.619 & 0.433 & 0.758 & 0.754 & 0.904 & 0.881 & X & 0.875 & 0.962 & 0.890 & 0.885 & 0.920\end{array}$ $\begin{array}{lllllllllllllll}0.656 & 0.276 & 0.551 & 0.570 & 0.803 & 0.758 & 0.877 & X & 0.886 & 0.816 & 0.897 & 0.878\end{array}$ $\begin{array}{llllllllllllll}0.448 & 0.353 & 0.644 & 0.812 & 0.884 & 0.911 & 0.877 & 0.776 & x & 0.902 & 0.888 & 0.921\end{array}$

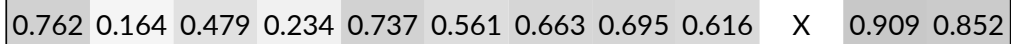
$\begin{array}{llllllllllll}0.856 & 0.342 & 0.482 & 0.268 & 0.559 & 0.460 & 0.687 & 0.776 & 0.414 & 0.681 & x & 0.848\end{array}$ $\begin{array}{llllllllllll}0.766 & 0.682 & 0.660 & 0.597 & 0.631 & 0.627 & 0.767 & 0.732 & 0.635 & 0.539 & 0.722 & x\end{array}$ 



\section{Chapter 3. Smoking regular and low-nicotine cigarettes}

results in comparable levels of volatile organic compounds in blood and exhaled breath

Charlotte G.G.M. Pauwels, Kim F.H. Hintzen, Reinskje Talhout, Hans W.J.M. Cremers, Jeroen L.A. Pennings, Agnieszka Smolinska, Antoon Opperhuizen, Frederik J. Van Schooten, Agnes W. Boots 


\begin{abstract}
Smokers are exposed to more than 6000 (toxic) smoke components including volatile organic compounds (VOCs). In this study VOCs levels in headspace of blood and exhaled breath, in the mainstream smoke of three types of cigarettes of one brand varying in declared tar, nicotine and carbon monoxide (TNCO) yields are investigated. The objective was to identify whether VOC levels correlate with TNCO yields of cigarettes smoked according to ISO 3308. Our data show that smoking regular and low-TNCO cigarettes result in comparable levels of VOCs in blood and exhaled breath. Hence, declared TNCO-yields as determined with the ISO 3308 machine smoking protocol are irrelevant for predicting VOC exposure upon human smoking. Venous blood and exhaled breath were sampled from twelve male volunteers directly before and 10 minutes after smoking cigarettes on 3 days (day 1 Marlboro Red (regular), day 2 Marlboro Prime (highly ventilated, low-TNCO), day 3 Marlboro Prime with blocked filter ventilation (taped)). Upon smoking, the levels of toluene, ethylbenzene, $\mathrm{m} / \mathrm{p}$-xylene, o-xylene, and 2,5-dimethylfuran in both headspace of venous blood and exhaled breath increase within the same range for all three cigarette types smoked. However, no strong correlation was found between VOC levels in exhaled breath and VOC levels in headspace of blood because of variations between the individual smoking volunteers. More research is required in order to use exhaled breath sampling as a non-invasive quantitative marker for volatile toxicants from cigarette smoke exposure of different brands.
\end{abstract}




\section{Introduction}

Worldwide one in every four men and one in every twenty women are daily smokers 1. These smokers are all at risk of developing smoking-related diseases, most prominently cardiovascular diseases, cancers and chronic respiratory diseases ${ }^{1}$. Smokers are exposed to more than 6000 different chemicals with varying toxicological and chemical characteristics ${ }^{2}$. The majority of the chemicals is associated with particles and aerosols in the smoke and are usually quantified as a mixture named 'tar'. Carbon monoxide (CO) and other volatile organic compounds (VOCs) are gases produced during smoldering and puffing, that are sampled and quantified separately due to their volatile characteristics. The development of smoking-related diseases is partially the consequence of exposure to toxicants associated to tar such as carcinogenic nitrosamines and polycyclic aromatic hydrocarbons. Moreover, also volatile toxic chemicals of the gas phase of cigarette smoke like acetonitrile, 1,3-butadiene, and aldehydes are associated with cancer and non-cancerous disease risks, as initially shown by risk assessments of Fowles and Dybing ${ }^{3}$ and later by WHO-IARC ${ }^{4}$. Risk assessment studies indicate that gas-phase chemicals of tobacco mainstream smoke pose very high risk towards consumers. Fowles and Dybing, for instance, noted a $6 \%$ contribution of benzene to the total cancer risk index. However, most cigarette emission studies mainly focus on the particulate phase, particularly on aromatic hydrocarbons and tobacco-specific nitrosamines ${ }^{5,6}$.

For risk and exposure assessments of smoke chemicals, usually emissions from machine smoking of cigarettes are used ${ }^{3,4}$. Initially, exposure of smokers was assessed by using smoking machine data generated with ISO 3308 settings for the smoking regime $^{7}$. In Europe, cigarettes with approximately $10 \mathrm{mg}$ tar/cig, $1 \mathrm{mg}$ nicotine/cig and $10 \mathrm{mg} \mathrm{CO} / \mathrm{cig}$ (TNCO) as determined with ISO 3308 settings, are often referred to as 'regular'. The use of the ISO-regime to determine TNCO yields in cigarettes is mandatory in many jurisdictions despite the critique that it largely underestimates human smoking topography ${ }^{8}$. It may particularly underestimate the exposure to toxic smoke gases during the consumption of highly ventilated cigarettes with such as Marlboro Prime, which show low-nicotine yields when machine smoked using ISO $3308^{9}$. However, several studies showed that smokers consuming cigarettes with reduced declared TNCO-levels (referred to as low-TNCO cigarettes) only slightly lower their exposure to tar and nicotine, according to biomarker measurements, compared to consuming regular cigarettes ${ }^{10-16}$. For example, an only $6 \%$ reduction of tar and nicotine uptake was observed when smoking reduced tar-nicotine cigarettes ( $<7 \mathrm{mg} \mathrm{tar} / \mathrm{cig})^{14}$. This contrasts with the observed $50 \%$ lower tar and nicotine yields 
in low-TNCO versus regular cigarettes as determined with a smoking machine using ISO $3308{ }^{14}$. Whereas some information is available regarding the exposure and uptake of tar-phase chemicals by smokers consuming low-TNCO cigarettes, data about the influence of cigarette ventilation on gas-phase toxicants is scarce ${ }^{10,16}$. In several studies, no reduction in human exposure of $\mathrm{CO}$ is observed when consumers switched from regular to low-TNCO products 10,12,17,18. Furthermore, for acrolein, 1,3-butadiene and benzene, exposure biomarker studies in adult smokers showed marginal to no differences in uptake levels after consumption of cigarettes with varying smoking machine determined TNCO levels ${ }^{10,11}$. These observations indicate that tar and nicotine levels determined with ISO 3308 smoking machine settings do not mimic the actual smokers' exposure to gas-phase toxicants, and are improper to use as input for risk assessment.

In order not to rely on machine smoking data, and to further improve the assessment of consumers risks associated with the exposure to volatile toxicants, it is important to quantify the actual exposure of smokers during smoking various types of cigarettes 19. However, direct measurements of exposure during human puffing of a cigarette is experimentally not feasible as it impacts the smoking topography ${ }^{20}$. Sampling after puffing is probably the best option to assess actual exposure.

During smoking a cigarette, a part of the inhaled chemicals is exhaled immediately after puffing. Another part of the inhaled chemicals is retained in the oral/nasal cavity and the lung for some period and exhaled with regular breathing, while a fraction of the inhaled compound may be metabolized in the lung ${ }^{20}$. Besides, a part of smoke toxicants, such as nicotine, diffuses through the alveoli into the circulation. VOCs circulating in the blood may diffuse from the blood back into the lungs for exhalation in either unchanged or metabolized forms. Levels of VOCs in breath and blood increase due to active cigarette smoking ${ }^{21-24}$. Former studies showed that after exposure, VOCs show peak concentrations and go rapidly back towards 'baseline' levels in blood and breath ${ }^{22,23}$. Respiration models show that remainder of tobacco smoke in the lung after puffing is rapidly exhaled during regular breathing 20. However, by measuring the presence of certain VOCs in breath and headspace of blood, previous human smoking studies could report a clear distinction between smokers and non-smokers ${ }^{25-27}$. Moreover, benzene levels in blood were shown to be 10 times higher in persons who had recently smoked, compared to nonsmokers ${ }^{24}$. It may thus be assumed that exhaled breath provides information about physiological as well as pathological processes occurring within the body, although there are limitations and difficulties interpreting actual measurements ${ }^{28-31}$. Difference in 
metabolism and pharmacokinetics (human absorption, distribution, metabolism, and excretion) may cause that the profiles of concentrations of VOCs in the inhaled smoke are not fully mimicked in the blood, nor that they are preserved in exhaled breath for extended periods. Marco et al. quantified both exposure and breath concentrations 30 minutes after smoking, thereby not reflecting acute exposure but previous uptake of the chemicals into the body ${ }^{32}$. Measuring VOCs in exhaled breath may be a noninvasive opportunity to assess previous exposure to tobacco smoke which can be used for frequent sampling, in contrast to sampling blood ${ }^{33}$.

In addition to the pharmacokinetics of VOCs, the actual concentrations of VOCs in blood may be influenced by the puffing topography of the smoker. Puffing topography of a smoker entails puff volume, puff duration, puff interval and number of puffs taken ${ }^{34}$. Previously, we have shown that individuals have characteristic puffing profiles which can generate more TNCO than ISO 3308 and Health Canada Intense $(\mathrm{HCl})$ regimes on smoking machines when the same brand is smoked ${ }^{35}$. Puffing behavior of individuals influence the smoldering and burning periods of the cigarette, as well as the burning conditions at the rod of the cigarette, all influencing actual exposure of the smoker to mainstream toxicants. Furthermore, the yields of VOCs in tobacco smoke depend on the blend and cigarette design of the cigarette brands ${ }^{36,37}$. Consequently, the amount and (VOC) composition of the smoke and smoke toxicants inhaled during puffing may be characteristic for individuals as well as for the consumed tobacco product ${ }^{34}$.

The first objective of the present study is to determine the level of VOCs in blood upon smoking three types of cigarettes of one brand with varying declared TNCO yields according to ISO 3308. Furthermore, we study the relation with VOC yields in headspace of blood to explore the potential use of exhaled breath as non-invasive biomarker of exposure to tobacco smoke of different cigarette brands. In the present study, we report about a human exposure study with active smokers of whom blood and exhaled air were sampled regularly for VOCs measurements upon smoking Marlboro Red (regular), Marlboro Prime (highly ventilated, low-TNCO), and Marlboro Prime with blocked filter ventilation (taped). Benzene ${ }^{38}$, ethylbenzene ${ }^{39}$, $o-, m$ - and $p$-xylene ${ }^{40}$ and toluene ${ }^{40}$ are studied because they are known toxicants present in cigarette smoke, exogenously sourced ${ }^{41}$ and measurable in blood samples 42. Cigarette smoke accounts for $90 \%$ of the exposure to benzene ${ }^{43}$ and benzene is often proposed as smoking biomarker ${ }^{44}$. Benzene is carcinogenic to humans (Group 1) ${ }^{38}$ and on the WHO priority list for regulation ${ }^{45}$, and styrene ${ }^{46}$, ethylbenzene ${ }^{39}$ and isopropylbenzene ${ }^{47}$ are possibly carcinogenic to human (group 2B). The different 
isoforms of xylene, $o^{-}, \mathrm{m}$ - and $p$-xylene and toluene ${ }^{40}$ are central nervous system toxicants, and at present not classifiable to their carcinogenicity to humans (Group 3) ${ }^{44}$. The volatile 2,5-dimethylfuran has been added to the measurements because it is considered a validated qualitative biomarker of smoking status ${ }^{48}$. Previously it was shown in a study with a series of brands of cigarettes in The Netherlands, that the yields of the various VOCs generated during machine smoking correlate with each other to a large extent for both ISO 3308 and $\mathrm{HCl}^{49}$.

\section{Material and methods}

\section{Human study}

\section{Cigarettes used}

The cigarette brands used in the study were Marlboro Red king-size and Marlboro Prime king-size because Marlboro is the most popular brand in the United States in $2017^{50}$ and has the largest market share in the Netherlands (35\% in 2017) ${ }^{51}$. The 'regular' cigarette Marlboro Red has ISO 3308 declared TNCO yields of 10, 0.8 and $10 \mathrm{mg} / \mathrm{cigarette}$ respectively. To cover the range of TNCO-yields available on the consumer market, we included Marlboro Prime, which is the lowest declared TNCOcigarette commercially available in The Netherlands with TNCO levels of respectively $1,0.1$ and $1 \mathrm{mg} /$ cigarette. The declared yields are based on the ISO smoking machine method 3308:2012 ${ }^{52}$. As a third cigarette type variation, the Marlboro Prime was also used in the human study with closed ventilation holes, called Marlboro Prime taped throughout this manuscript. A 100\% vent blocking was achieved by taping the vents with $19 \mathrm{~mm}$ width Scotch Magic TM tape (Cat no: 810, 3M, USA). According to ISO 3308 machine smoking measurement of the Marlboro Prime taped, TNCO levels where $9.4,0.5$, and $13.3 \mathrm{mg} / \mathrm{cig}$, respectively. Cigarette packages were bought in 2017 at a tobacconist in the Netherlands to guarantee matching batch numbers.

\section{Participant characteristics}

A recruitment company (Link2Trials) recruited smoking volunteers using advertisements via national social media. The participants had to meet the following inclusion criteria; male, Caucasian/Europe-originated, age range of 25-34 years old, and smoking 13-25 Marlboro Red cigarettes per day (CPD) ( package/day) for at least three years. Exclusion criteria were suffering from respiratory diseases or chronic illness, daily medication use, and experiencing adverse effects due to smoking. This human study was conducted upon approval of the accredited medical ethical committee (NL63420.068.17 / METC173038) in Maastricht (The Netherlands) and 
registered online at www.Clinicaltrials.gov (NCT03498053). Informed consent was signed before the experiment started and participation was rewarded with $€ 100$,per experimental day.

\section{Study protocol}

Twelve male participants were enrolled in the study and were studied during three identical experimental days of 10 hours that only differed by the type of cigarette smoked. During the first day, the smoking volunteers smoked their usual brand Marlboro Red. One week later, during the second experimental day the volunteers smoked Marlboro Prime, followed by the third study day of smoking Marlboro Prime taped. During the experimental day, participants could smoke cigarettes ad libitum. Because we included participants used to smoke 13-25 CPD, we expected >13 CPD during the study, which would comply with the study design.

The study location was an apartment with a homelike atmosphere. During the experimental days, all participants consumed the same food products for breakfast, lunch, dinner, snacks and drinks that were ad libitum at their disposal. The interval days between the first and second study day were an adjustment period of a week at home to get used to the supplied Marlboro Prime.

Participants arrived at 8 am and were instructed not to smoke before the start of the experiment. At the beginning of the first experimental day, participants signed the informed consent. Upon arrival, an intravenous peripheral canula was placed for blood sampling throughout the day (Figure 1). The baseline sampling included a venous blood sample followed by a breath sample $(t=B L)$. Directly after baseline sampling, participants were allowed to light the first cigarette of the day which was noted as the start of the experimental day. After smoking this first cigarette, blood and breath, respectively, were sampled $(\mathrm{T}=0)$. To prevent imposing the participants to smoke at a certain time point in order to maintain their natural smoking behavior, the experimental day was divided in four timeslots of $2.5 \mathrm{hrs}$ (Figure 1). Blood and breath sampling took place before and directly after (within 10 minutes) smoking the first cigarette in every timeslot ( $\mathrm{T}=\mathrm{BL}-2.5 ; \mathrm{T}=2.5-5 ; \mathrm{T}=5-7.5 ; \mathrm{T}=7.5-10)$. More specifically, first blood (duration $\sim 2 \mathrm{~min}$ ) and then breath (duration $\sim 5 \mathrm{~min}$ ) where sampled. To avoid excessive sampling, no blood and breath were sampled before and after smoking the possible additional cigarettes in a timeslot. After sampling $\mathrm{T}=10$, the peripheral venous canula was removed and participants could go home. 


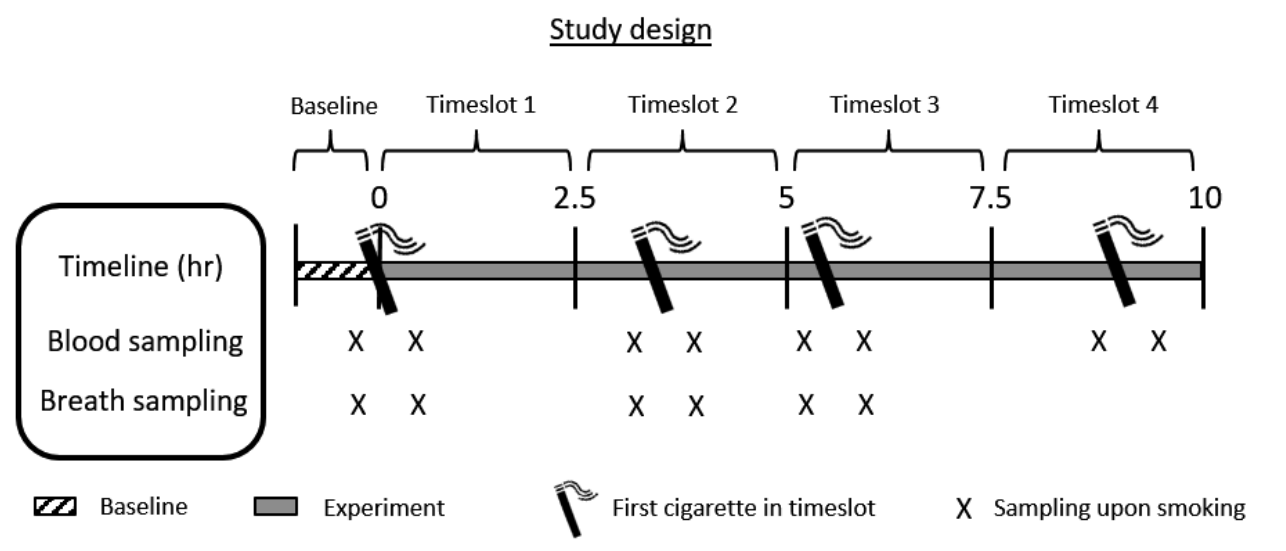

Figure 1: Schematic overview of the study design per study day. Only the hypothetical time point of smoking the first cigarette in a timeslot is depicted.

\section{VOCs analysis in blood headspace}

\section{Blood sampling}

Via the peripheral venous canula, four $\mathrm{mL}$ of venous blood was sampled into EDTA containing Vacutainers ${ }^{\circledR}$ (Beckton Dickenson; K2E (EDTA) 7.2 mg; REF 368861) after which the tubes were stored in the fridge $\left(>5^{\circ} \mathrm{C}\right)$ until analysis. In total, eight blood tubes were sampled for determination of VOCs in headspace.

\section{Standards}

A VOC mixture consisted of benzene, ethylbenzene, isopropylbenzene, $\mathrm{m} / \mathrm{p}$ xylene, o-xylene, styrene, toluene (M-502A-R2;0.2 mg/mL), 2,5-dimethylfuran (177717-25ML) and benzene-D6 (561509-10X.75ML) was acquired from SigmaAldrich (Zwijndrecht, The Netherlands). Ethylbenzene-D10 (AccuStandard, M-624-SS-08) was acquired from DaVinci Laboratory Solutions (Rotterdam, The Netherlands). The internal standard (IS) comprised of benzene-D6 (200 ng/mL) and ethylbenzene-D10 $(200 \mathrm{ng} / \mathrm{mL})$ was mixed in purge and trap grade methanol (J.T. Baker; 61009077.1000, acquired from Boom B.V. (Meppel, The Netherlands). Blood of a 41-year-old Caucasian male non-smoker was spiked with VOC mixture and IS to create a calibration curve ranging from 0 to $2000 \mathrm{pg} / \mathrm{mL}$.

\section{GC-MS-detection and quantitation of blood headspace VOCs}

Blood sample preparation was performed on ice $\left(0^{\circ} \mathrm{C}\right)$. Two $\mathrm{mL}$ of venous blood was transferred from the EDTA Vacutainers ${ }^{\circledR}$ into $20 \mathrm{~mL}$ glass headspace vials (VWR; 548-0248) and closed with a magnetic screw cap with septum (VWR; 548- 
0245), in duplicate. Solid-phase micro extraction (SPME) was used to sample VOCs in the headspace of venous blood (intermediate phase) with instrumental setup based on a published method ${ }^{42}$. Results of control experiments can be found in the Supplementary Materials. Headspace vials were transferred into a rotating agitator oven $\left(40^{\circ} \mathrm{C}\right.$ at $\left.500 \mathrm{rpm}\right)$ where after $10 \mathrm{sec}$, a $75-\mu \mathrm{m}$ SPME fiber (Carboxen ${ }^{\circledR} /$ polydimethylsiloxane (PDMS) was injected for VOC adsorption (6 min). After adsorption, the fiber was injected into the hot inlet $\left(300^{\circ} \mathrm{C}\right)$ of an Agilent Technologies 7890 GC system for 35.5 minutes. The split-splitless injector was set to use pulsed splitless mode. After the first 1.5 min pressure pulse, a laboratory-grade helium flow was kept at $1 \mathrm{~mL} / \mathrm{min}$. The DB-624 UI column (Agilent Technologies) was kept in an oven at $50^{\circ} \mathrm{C}$ for $5 \mathrm{~min}$ followed by a ramp of $5^{\circ} \mathrm{C} / \mathrm{min}$ to $200^{\circ} \mathrm{C}$ (hold time $0 \mathrm{~min}$ ) and a ramp of $30^{\circ} \mathrm{C} / \mathrm{min}$ to $260^{\circ} \mathrm{C}$ (hold time $1 \mathrm{~min}$ ). After a total run time of $38 \mathrm{~min}$, a transfer line to the Agilent Technologies 5977 Mass Selective Detector (MSD) was kept at $280^{\circ} \mathrm{C}$.

The MSD was set to scan/SIM (single ion monitoring) in high-resolution mode for masses between 35 and $200 \mathrm{~m} / \mathrm{z}$. The most abundant $\mathrm{m} / \mathrm{z}$ was used for quantification. The run was divided into timeframes of $1 \mathrm{~min}$. For the target components benzene, ethylbenzene, isopropylbenzene, $\mathrm{m} / \mathrm{p}$-xylene, o-xylene, styrene, toluene, 2,5-dimethylfuran, quantifier and qualifier masses were identified using the National Institute of Standard and Technology (NIST) library. The highest mass of each compound was used for quantification. Integration of peaks of the quantifier mass was checked manually for each compound, whereby qualifier peaks were used as a control. First, peak area of the IS was used to correct for sampling variation. Hereby was benzene-D6 used for benzene, 2,5-dimethylfuran and toluene, and ethylbenzene-D10 for all other compounds. Secondly, VOC concentrations were calculated according to their specific calibration line.

\section{VOC analysis in breath}

Breath sampling

The ReCIVA Breath Sampler (Owlstone Medical, Cambridge, UK) was used for breath sampling in combination with the 'Clean Air Supply Pump for ReCIVA' (CASPER) (Owlstone Medical, Cambridge, UK). The CASPER allowed a continuous supply of room air at a flow rate of $40 \mathrm{~L} / \mathrm{min}$, passed through a scrubber containing Airpel ${ }^{\circledR}$ (Desotec Ltd, Roeselare, Belgium) activated carbon and HEPA filter to diminish the concentration of ambient VOCs in breath samples. Before sampling, the participants breathe through the CASPER for one minute to minimize exhaling VOCs coming from inhaled ambient air. Using the ReCIVA Breath Sampler VOCs were trapped 
on two $1 / 4$ " x 3.5" stainless steel tubes with tenax TA 35/60 carbograph 5TD 40/60 sorbent (Camsco, Houston TX USA) with a sample flow of $200 \mathrm{~mL} / \mathrm{min}$. Because of continuous monitoring of pressure and $\mathrm{CO} 2$ levels within the mask during breathing, the device was able to sample $500 \mathrm{~mL}$ of the alveolar fraction of the exhaled air onto one tube. Each participant was asked to breath normally via nose-mouth mask. The inhalation took place by nose and exhalation by mouth. Each participated delivered two tubes, each filled with $500 \mathrm{~mL}$ of alveolar air. After trapping, the airtight-capped tubes were stored refrigerated $\left(4^{\circ} \mathrm{C}\right)$ until analysis.

\section{GC-TOF-MS instrumentation of breath VOCS}

VOCs were measured with thermal desorption (TD100, Markes International)-gas chromatography mass spectrometry combined with time-of-flight mass spectrometry (GC-TOF-MS), as previously described 27 with minor modifications. VOCs were released from the desorption tubes at $250^{\circ} \mathrm{C}$ under a flow of helium with the use of automated thermal desorption and divided into two parts. Half of the vaporous sample was recollected on an identical tube whereas the other half was transmitted to an electrically-cooled sorbent trap programmed at $5^{\circ} \mathrm{C}$ from which it was injected into a GC (Thermo Fischer Scientific, Austin, USA, column: Restek RTX-5ms, $30 \mathrm{~m} \times 0.25 \mathrm{~mm}$ ID, coated with $1.0 \mu \mathrm{m} \mathrm{HP}-5$ phase). The gas chromatographystarted at $40^{\circ} \mathrm{C}$ for $5 \mathrm{~min}$ and rose by $10^{\circ} \mathrm{C}$ every minute until $300^{\circ} \mathrm{C}$ was reached and kept for $5 \mathrm{~min}$. After separation by GC the compounds were identified by TOF-MS (Bench TOF-dx, Alsmco International, Llantrisant, Wales, UK). Within TOF-MS part electron ionization at $70 \mathrm{eV}$ was utilized with $5 \mathrm{~Hz}$ scanning rate over a range of m/z 35-350.

\section{Breath VOCs identification}

Benzene, ethylbenzene, isopropylbenzene, $\mathrm{m} / \mathrm{p}$-xylene, o-xylene, styrene, toluene and 2,5-dimethylfuran were first manually identified in chromatograms using retention time and a NIST database (2018). An Xcalibur 2.2 processing method was set up to extract the base peak chromatogram (BPC) for each compound. The appropriate peaks were detected and integrated using the Genesis peak detection algorithm. The base peaks of mass spectrum were used for relative quantification of the target compounds. Bromobenzene-D5 (Art. 42269, Alfa Faser, Karslruhe Germany) was used as internal standard for all compounds and for normalization of retention times.

\section{Statistical analysis}

VOCs in headspace from blood were corrected for internal standard and a mean per duplicate was calculated and depicted in pg per $\mathrm{mL}$ blood. In case of <LOD, the 
lowest measured value divided by two was used. The net increase in blood VOCs was calculated by subtracting the 'before smoking'-concentration from the 'after smoking'-concentration. The mean of four cigarettes, originating from the four different timeslots, demonstrated the average net increase per participant. Spearman correlation coefficients were calculated to show the relation between the increase of the individual VOCs in blood upon smoking (significant if $p<0.01$ ). Peak areas of VOCs in alveolar exhaled breath were corrected for the internal standard. From the raw area data, outliers were removed (values beyond 1st and 3rd quartile +/- 1.5* interquartile range). Statistical significance of differences were determined using a two-way ANOVA with participants and brands as factors, with p-value adjustment for multiple testing using the false discovery rate (FDR). Next, we calculated the Spearman correlation coefficients for the relation between the increase of individual VOCs in alveolar exhaled breath upon smoking, and deemed significant if $<0.01$. The Spearman correlation coefficients were calculated to relate increases in VOCs in blood with those in exhaled air, which were deemed significant if $p<0.01$.

\section{Results}

\section{Participants characteristics}

Twelve male participants in the age of 26 to 34 years old (mean age 29.8 years) were included. As self-reported, on average they smoked 19 cigarettes per day (15-20 cig/ day) since the age of 20 (16-28 years) old. During the study, participants smoked on average 11.7 Marlboro cigarettes (SD 2.7), 12.1 Marlboro Prime cigarettes (SD 2.4) and 12.2 Marlboro Prime taped cigarettes (SD 2.5). To adjust to the Marlboro Prime, during the period at home, participants smoked on overage 15.9 cigarettes (SD 5.4) on a daily basis. The number of cigarettes smoked per day differed between participants and the type of cigarette smoked (Figure S1). All participants smoked less cigarettes during the experiment than self-reported daily average. However, with a fluctuation of four cigarettes, most participants (except participant 11) held on their daily number of cigarettes smoked when they switched from Marlboro Red, to Prime, or Prime taped.

\section{VOCs in headspace of venous blood}

Benzene (155 pg/mL (SD 21.0)), toluene (473 pg/mL (SD 326)), styrene (128 pg/mL (SD 143)) and 2,5-dimethylfuran (62.7 pg/mL (SD 19.5)) were identified in headspace of all venous blood samples of the smokers in the morning before starting smoking. The other VOCs were inconsistently present (i.e. Day $1 \mathrm{BL}$ present, Day $2 \mathrm{BL}<\mathrm{LOD}$ ) in the early morning samples of participants after a night without smoking. After 
smoking the first cigarette of Marlboro Red, Marlboro Prime or Marlboro Prime taped, all VOCs were detected in the consecutive samples during the day. The VOC levels in blood, except for isopropylbenzene, increased substantially (1.2-fold to 5.5-fold) after smoking each cigarette (Figure 2, Figure S2, Table S2). Before the smoking in the $\mathrm{n}+1$ timeslot, the concentrations of most VOCs decreased to levels close, but not similar, to that of the start of timeslot $n$. For example, concentrations of benzene in blood were less than $200 \mathrm{pg} / \mathrm{mL}$ blood in the early morning samples of all participants (table S1). After smoking the first cigarette of Marlboro Red, the concentration increased in most cases beyond $200 \mathrm{pg} / \mathrm{mL}$, with almost $800 \mathrm{pg} / \mathrm{mL}$ as the highest for participant 5. At the start of the second timeslot concentrations of benzene in all participants had decreased to below $300 \mathrm{pg} / \mathrm{mL}$, but for the majority of the participants not below $200 \mathrm{pg} / \mathrm{mL}$. With increasing timeslot-numbers the 'before-smoking' samples had higher VOC concentrations than those of the previous timeslot. This gradual increase of 'baseline' was observed for all participants although differences were found. The 'baseline' increase was the least for benzene and 2,5-dimethylfuran. The gradual increase of 'baseline' throughout the day was observed for all three types of cigarettes smoked by the participants. Only the levels of isopropylbenzene before and after smoking do not show a 'baseline' pattern.

When the 'before-smoking' VOC levels in blood of all participants and all timeslots were averaged, and compared to the averaged 'after-smoking' levels, the increases of VOCs substantially varied between participants. VOC levels after smoking Marlboro Prime and Marlboro Prime taped are significantly higher than that of Marlboro Red for most VOCs (except styrene and isopropylbenzene) (Table S2).

The net increase of the levels of VOCs in blood (except isopropylbenzene and styrene) upon smoking one cigarette differs significantly (all $\mathrm{p}<4.5 \mathrm{E}-06, \mathrm{FDR}<1.2 \mathrm{E}-05$ ) between the individual participating smokers (Table 1). However, smokers with relatively low net increases of VOC levels in blood upon smoking Marlboro Red also show relatively low net increases upon smoking Marlboro Prime and Marlboro Prime taped. Smoking Marlboro Prime taped typically gave the largest net increases for all VOCs (except isopropylbenzene).

The net increase of levels in blood upon smoking the three cigarette types for all participants correlated well for most of the VOCs, i.e., correlation coefficient varied from 0.9 to 0.97 (all $p<1.08 E 4$ ) (Figure S3). Correlation coefficients of styrene were $>0.61$ but not significant whereas isopropylbenzene showed no correlation at all with the other VOCs (Figure S3). 

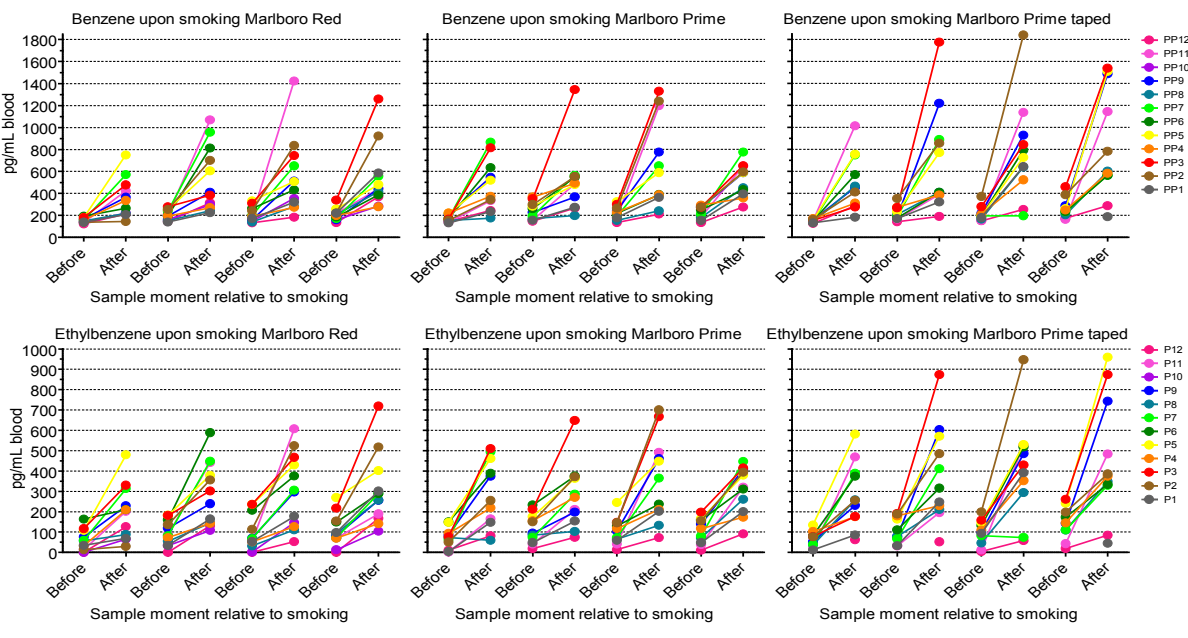

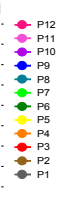
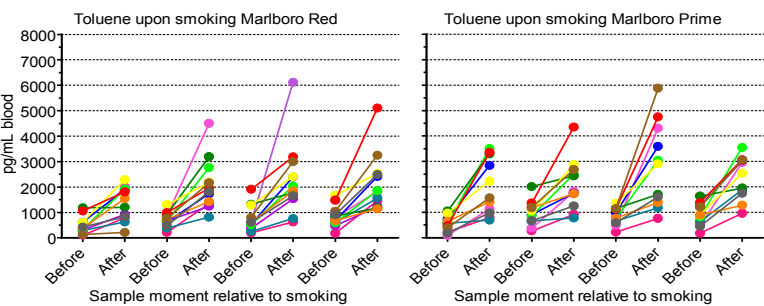

Toluene upon smoking Marlboro Prime taped
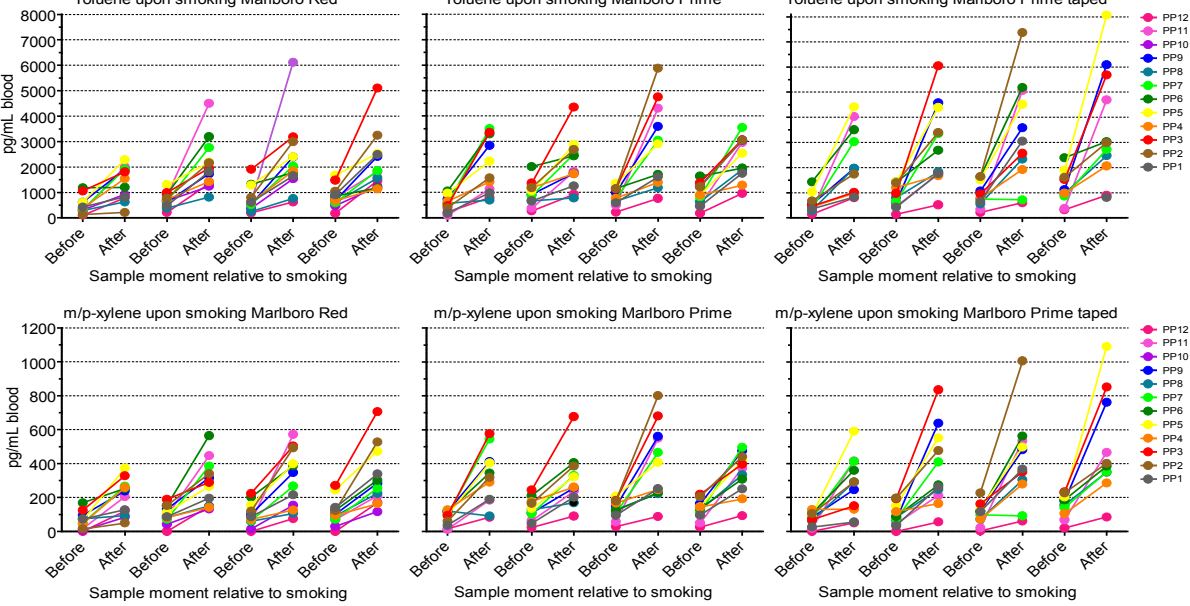

Figure 2: Benzene levels in headspace of blood $(\mathrm{pg} / \mathrm{mL})$ before and after smoking Marlboro (left), Marlboro Prime (middle) or Marlboro Prime taped (right) for the first cigarette in the four subsequent timeslots during the experimental day (left to right on $\mathrm{X}$-axis). Different colors depict the individual participants.

\section{VOCs in breath}

VOC levels could only be expressed relative to each other as no absolute concentrations can be calculated due to methodological limitations. VOCs in breath data is missing for participant 1-Marlboro and participant 10 due to analytical problems. For the other participants, benzene, ethylbenzene, m/p-xylene, o-xylene, styrene, isopropylbenzene and toluene were detected in 'baseline' breath samples 
of all participants after early morning sampling. After smoking, on average VOCs showed an increase in breath concentrations after smoking all cigarette types (Figure 3). Participants' VOC levels in exhaled breath typically increased 1.3-fold (benzene) to 4.6-fold (2,5-dimethylfuran) upon smoking Marlboro Red (Table 2). Almost similar fold-increases in exhaled breath levels were found in all smokers upon smoking Marlboro Prime. Smoking Marlboro Prime taped resulted in even larger increases of breath levels of VOCs. The highest increase in levels in exhaled breath were found for 2,5-dimethylfuran when Marlboro Prime taped was smoked (7.1-fold increase).

The individual VOC increases in breath due to smoking showed significant correlation coefficients varying from $\mathrm{R}=0.77$ to 0.90 ( $p<2.4 \mathrm{E}-3$ ) (Figure S4). Isopropylbenzene, styrene and 2,5-dimethylfuran have a weak, not significant, relationship with the other VOCs.

Table 1: Net and fold increases per VOC in headspace of blood $(\mathrm{pg} / \mathrm{mL})$ upon smoking Marlboro red, Marlboro Prime or Marlboro Prime taped

\begin{tabular}{|c|c|c|c|c|c|c|c|c|c|c|c|}
\hline \multirow[b]{2}{*}{ VOC } & \multicolumn{3}{|c|}{ Marlboro Red } & \multicolumn{3}{|c|}{ Marlboro Prime } & \multicolumn{3}{|c|}{ Marlboro Prime taped } & \multicolumn{2}{|l|}{ ANOVA } \\
\hline & $\begin{array}{l}\text { Net in- } \\
\text { crease }\end{array}$ & SD & $\begin{array}{l}\text { Fold } \\
\text { in- } \\
\text { crease }\end{array}$ & $\begin{array}{l}\text { Net in- } \\
\text { crease }\end{array}$ & SD & $\begin{array}{l}\text { Fold } \\
\text { in- } \\
\text { crease } \\
\end{array}$ & $\begin{array}{l}\text { Net in- } \\
\text { crease }\end{array}$ & SD & $\begin{array}{l}\text { Fold } \\
\text { in- } \\
\text { crease } \\
\end{array}$ & MR-MP & $\begin{array}{l}\text { MP- } \\
\text { MPT }\end{array}$ \\
\hline Benzene & 295.3 & 256.0 & 2.5 & 326.4 & 265.5 & 2.5 & 505.1 & 388.4 & 3.4 & 7.1E-01 & $4.8 \mathrm{E}-03$ \\
\hline $\begin{array}{l}\text { Ethylben- } \\
\text { zene }\end{array}$ & 183.7 & 123.4 & 3.1 & 210.2 & 134.6 & 3.1 & 290.9 & 192.1 & 3.8 & $2.9 \mathrm{E}-01$ & 7.4E-03 \\
\hline Toluene & 1274.7 & 969.9 & 2.8 & 1513.8 & 1059.2 & 2.9 & 2191.7 & 1600.9 & 3.4 & $2.8 \mathrm{E}-01$ & $8.2 \mathrm{E}-03$ \\
\hline $\begin{array}{l}\mathrm{m} / \mathrm{p}- \\
\text { Xylene }\end{array}$ & 182.3 & 113.3 & 3.0 & 226.1 & 143.6 & 2.9 & 284.1 & 207.9 & 3.6 & $5.2 \mathrm{E}-02$ & 7.6E-02 \\
\hline o-Xylene & 70.5 & 44.7 & 2.3 & 94.4 & 65.5 & 2.4 & 115.9 & 86.0 & 2.8 & $2.5 \mathrm{E}-02$ & $1.3 \mathrm{E}-01$ \\
\hline Styrene & 224.8 & 179.5 & 2.1 & 271.3 & 204.7 & 2.4 & 384.3 & 278.8 & 2.7 & $3.8 \mathrm{E}-01$ & $2.9 \mathrm{E}-02$ \\
\hline $\begin{array}{l}\text { Isopropyl- } \\
\text { benzene }\end{array}$ & 50.8 & 100.3 & 1.7 & 49.6 & 77.0 & 1.2 & 47.9 & 72.3 & 1.2 & $8.1 \mathrm{E}-01$ & $8.8 \mathrm{E}-01$ \\
\hline $\begin{array}{l}2,5- \\
\text { dimethyl- } \\
\text { furan }\end{array}$ & 356.6 & 255.7 & 4.2 & 371.6 & 254.1 & 4.0 & 513.8 & 380.9 & 5.5 & $9.3 \mathrm{E}-01$ & 2.1E-02 \\
\hline & $\mathrm{pg} / \mathrm{mL}$ & $\mathrm{pg} / \mathrm{mL}$ & & $\mathrm{pg} / \mathrm{mL}$ & $\mathrm{pg} / \mathrm{mL}$ & & $\mathrm{pg} / \mathrm{mL}$ & $\mathrm{pg} / \mathrm{mL}$ & & & \\
\hline
\end{tabular}

Net increase: mean 'after smoking' minus mean 'before smoking'. Fold increase: mean 'after smoking' divided by mean 'before smoking'. $\mathrm{n}=4$ cigarettes per participant and thus $\mathrm{n}=48$ in total per VOC. In case of a higher 'before smoking' than 'after smoking', zero was used. MR; Marlboro Red, MP; Marlboro Prime, MPT; Marlboro Prime taped. Bold; false discovery rate significant if $<0.05$ 


\section{Relation between VOCs in blood and breath}

The relations between the individual VOC-increases in blood and exhaled air upon smoking of the three types of cigarettes is shown in Figure 4. Ethylbenzene, toluene and $m / p$-xylene levels show the strongest relation between blood and breath samples (respectively $R=0.51, R=0.50, R=0.46$, all significant). The relation between blood and breath levels varies between $\mathrm{R}=0.32$ and $\mathrm{R}=0.43$ for 0 -xylene, benzene, styrene and 2,5-dimethylfuran. There is no relation between blood and breath for isopropylbenzene.

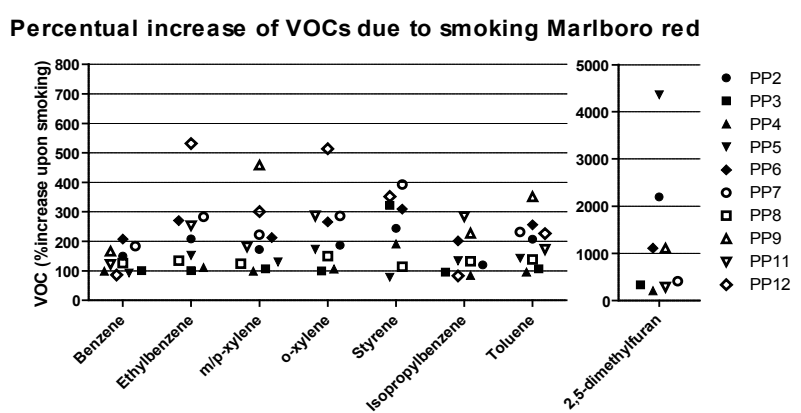

Percentual increase of VOCs due to smoking Marlboro Prime

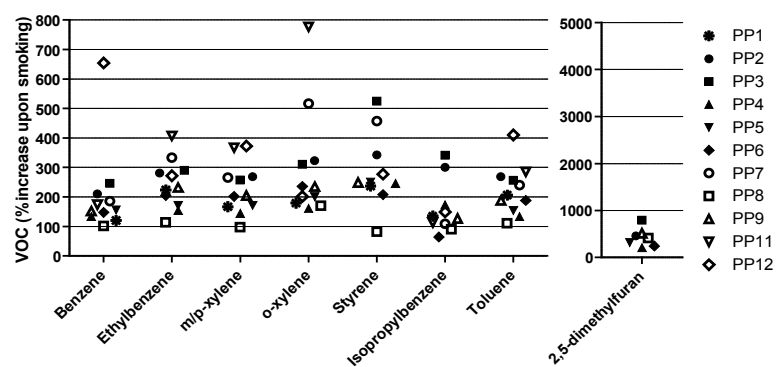

Percentual increase of VOCs due to smoking Marlboro Prime taped

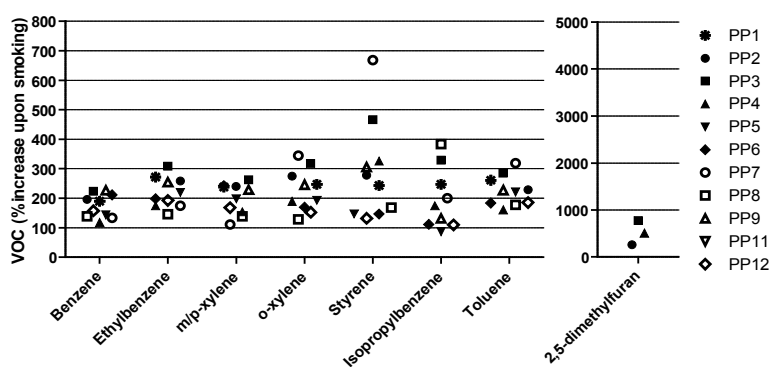

Figure 3: mean percentage increase of VOCs. Benzene, ethylbenzene, $\mathrm{m} / \mathrm{p}$-xylene, o-xylene, styrene, isopropylbenzene and toluene in alveolar exhaled breath is depicted in the left graph and 2,5-dimethylfuran in the right graph. The mean percentage increase is based on measurements in alveolar exhaled breath before and after the first cigarette in the three timeslots during the experimental day. The different symbols indicate the different participants. 
Table 2: Average fold increase of VOCs in breath upon smoking Marlboro Red, Marlboro Prime and Marlboro Prime taped.

\begin{tabular}{lccc}
\hline \multirow{2}{*}{ VOC } & \multicolumn{2}{c}{ Average fold increase per cigarette type } \\
\cline { 2 - 4 } & Marlboro Red & Marlboro Prime & Marlboro Prime taped \\
\hline Benzene & 1.3 & 1.4 & 1.6 \\
Ethylbenzene & 1.8 & 1.9 & 2.1 \\
Isopropylbenzene & 0.9 & 1.2 & 1.3 \\
m/p-Xylene & 1.6 & 1.7 & 1.9 \\
o-Xylene & 1.9 & 2.0 & 1.9 \\
Styrene & 2.3 & 2.4 & 1.8 \\
Toluene & 1.6 & 1.7 & 2.1 \\
2,5 -dimethylfuran & 4.6 & 3.4 & 7.1 \\
\hline
\end{tabular}

\section{Discussion}

The objective of the present study is to determine the level of VOCs uptake in blood upon smoking and the relation between VOCs in blood and breath upon smoking three types of Marlboro cigarettes. By including only male volunteers which are familiar Marlboro smokers we limited variations of smoking topography based on gender or brand. The study design enabled us to focus on the influence of ventilation on toxicant exposure.

Consumption of each cigarette resulted in exposure of the smoker's lung and increased concentrations of many of the VOCs in blood and breath. Elevated VOC levels in breath are considered to provide information about the presence of smoke constituents taken up into the blood and other body tissues. As exhaled breath was sampled after a few minutes of regular breathing, elevated VOC concentrations in breath are not caused by remains of mainstream smoke in the lungs ${ }^{20}$. Since VOCs are omnipresent in ambient air already, baseline levels can also be present in the blood of non-smokers. However, the average morning before smoking (=baseline) benzene levels in blood of the 12 participants in the study at hand were $155 \mathrm{pg} /$ $\mathrm{mL}$ blood, was substantially higher than levels in non-smokers, which were $<28$ $\mathrm{pg} / \mathrm{mL}^{53}$. These levels are comparable to blood levels of daily smokers measured in the National Health and Nutrition Examination Survey (NHANES) $(139 \mathrm{pg} / \mathrm{mL}$ blood) ${ }^{53}$. As expected, smokers in the present study have 2,5-dimethylfuran blood levels (321.5 pg/mL blood) far above non-smoker levels ( $<14 \mathrm{pg} / \mathrm{mL}$ blood) ${ }^{54}$. Upon inhalation, only a fraction of the VOCs is absorbed into the circulation as not all 
chemicals reach the alveoli due to depth of inhalation ${ }^{20}$. Another fraction is exhaled immediately; the mean residence time of benzene in the lungs is short ( $0.9 \mathrm{~min}$ ) with decay rate in exhaled breath of approximately $15 \mathrm{~min}^{22}$. Moreover, it was estimated that approximately $50 \%$ of the benzene exposure dose is absorbed in the body (range between 20-60\%) ${ }^{55}$. We sampled respectively blood and exhaled within 10 minutes after smoking and found substantial increases of VOC levels in exhaled breath and blood upon smoking cigarettes (except for isopropylbenzene). Others were able to use exhaled breath levels of VOCs as acute internal dose markers to quantify the systemic uptake of chemicals into the blood or the body ${ }^{56,57}$. However, in the study at hand, we observed only weak correlations with VOC levels in breath and levels determined in blood. Whereas we assumed that breath measurements can be seen as a headspace measurement of blood (depending on Henry's constant), the addition of direct exhaled residual lung VOCs are putatively hampering to show this relation 56,58. An explanation for this may be that we first sampled blood (duration of $\sim 2$ min) followed by breath (duration of $\sim 5 \mathrm{~min}$ ) in the 10 min after smoking, instead of at the same time which was not possible due to practical limitations.

The distribution of VOCs in tissues, their metabolism and their excretion via breath and urine may have been changed during these 10 minutes. Furthermore, the exhaled end-tidal breath concentrations may not equal the alveolar concentrations for VOCs, but reflect the bronchial concentrations, and hence the influence of the upper airways should be taken into account. In spite of these limitations the semi-quantitative breath VOCs markers are sensitive enough to reflect exposure to different types of cigarettes. Further research is required before exhaled breath can fully be used as an external exposure marker assessing the dose delivered to the lungs and the associated toxic burdening of pulmonary epithelium. Particularly research is needed about the impact of the timing of the sampling after smoking.

The rapid rise in VOC concentrations in blood illustrates that all VOCs (except isopropylbenzene) are rapidly taken up into the blood during smoking. The increases of various VOCs in blood are also related to each other, suggesting that despite their different chemical and physico-chemical characteristics all these VOCs reach the alveoli and are taken up into the circulation. Only the isopropylbenzene, and to some degree styrene, uptake differs which can be due to their lower boiling point and gas pressure. It is likely that these two compounds are not only present in the gas phase of tobacco smoke, but may also be part of the particulate phase and are therefore not measured with the used method ${ }^{59}$. Furthermore, the concentrations of these chemicals are low, which makes the chemical analysis sensitive for background exposure. 

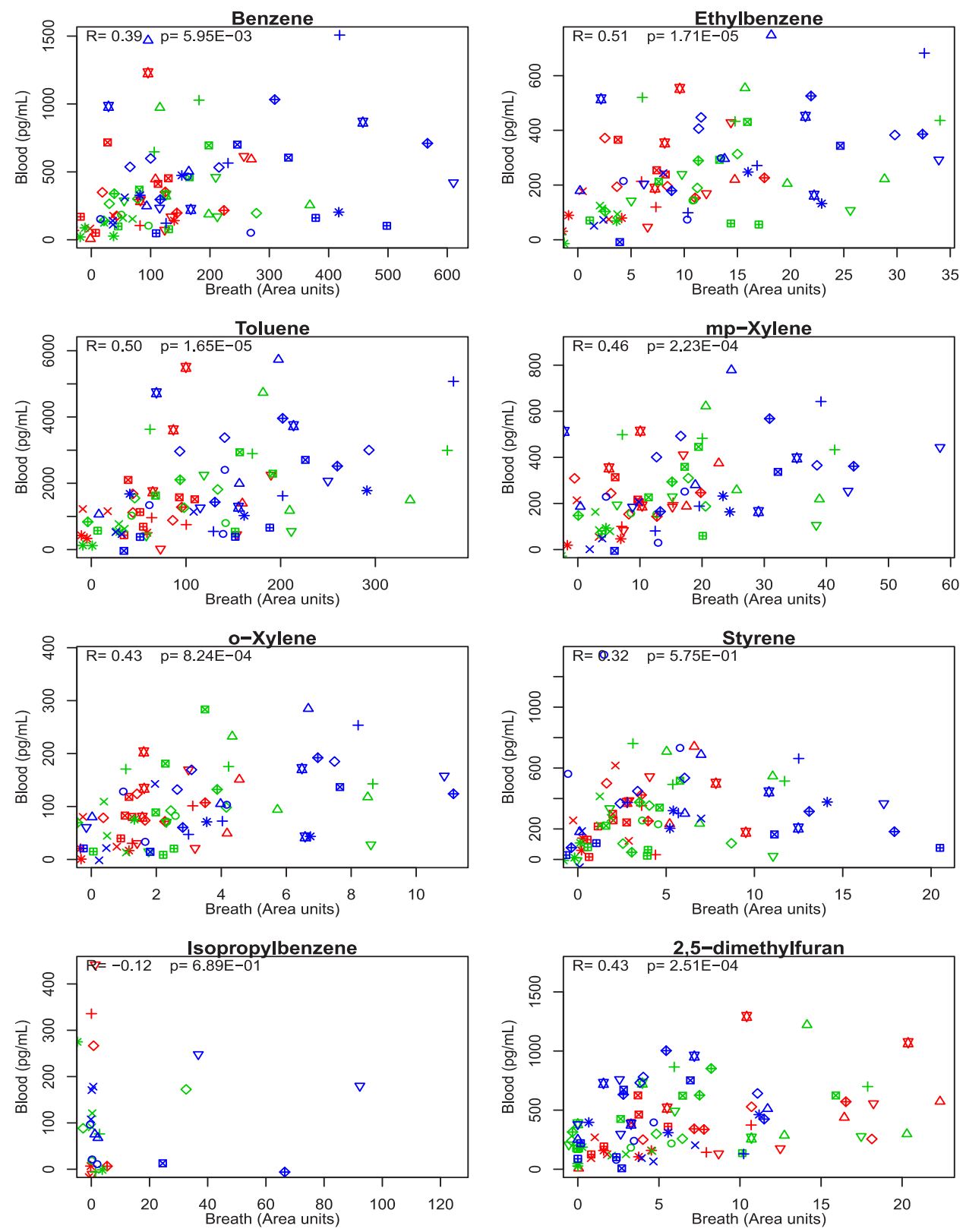

Figure 4: Scatter plots for the net increase of VOCs in blood versus exhaled breath upon smoking. Every symbol circle in the scatter plots represents per participant the mean net increase in the specific VOC upon smoking. Correlation coefficients and corresponding $\mathrm{p}$-values are depicted. significant when $\mathrm{p}<0.01$. Red is Marlboro Red, Green is Marlboro Prime and Blue is Marlboro Prime taped. 
Individual smoking puffing patterns ${ }^{35}$ influence the emission and actual uptake of chemicals after smoking a cigarette. This phenomenon, probably in combination with differences in metabolic capacity of individuals [23] is exemplified in our study, as for instance the level of benzene in blood of participant 1 smoking the first Marlboro Red cigarette of the day increased less than a factor two relative to the measurement before smoking. For participant 5 the increase was approximately a factor 4 when smoking the same type of cigarette under similar conditions. After uptake, blood concentrations drop because of xenobiotic metabolism, excretion and internal distribution of the chemicals. The analysis of blood samples in the various time slots shows that the time intervals are not sufficient to fully return to baseline levels for the VOCs ${ }^{60}$. Gradually, VOC concentrations increase during the day, with strong pulses of increase upon smoking consecutive cigarettes. This was observed for all smokers and all three types of cigarettes. Interestingly, the number of cigarettes smoked by the participants was not substantially influenced by the type of cigarettes. Only one participant (P 11) smoked substantially less Marlboro Prime taped and Marlboro Prime, than Marlboro Red. Consequently, the gradual increase of 'baseline' concentration during the day was almost absent in this subject when smoking Marlboro Prime and Marlboro Prime taped.

Blood levels of VOCs showed the highest increase for toluene and a minimal increase for isopropylbenzene for Marlboro Red as well as Marlboro Prime (toluene $>$ benzene $>$ styrene $>$ ethylbenzene $>\mathrm{m} / \mathrm{p}$-xylene $>0$-xylene $>$ isopropylbenzene). The NHANES study reported a comparable order (toluene $>m / p$-xylene $>$ benzene $>$ styrene > ethylbenzene > o-xylene) of VOCs measured in blood of daily smokers ${ }^{61}$. Moreover, smoking increased blood concentrations of VOCs on average 2.7-fold for Marlboro Red and Marlboro Prime, and even more for Marlboro Prime taped (on average 3.3-fold). For example, the average increase for all participants for benzene in blood for Marlboro Red was 295 pg/mL, for Marlboro Prime 326 pg/ $\mathrm{mL}$ and for Marlboro Prime taped $505 \mathrm{pg} / \mathrm{mL}$. Of the VOCs, toluene concentrations were the highest; an increase of $1275 \mathrm{pg} / \mathrm{mL}, 1514 \mathrm{pg} / \mathrm{mL}$ and $2192 \mathrm{pg} / \mathrm{mL}$ for the three cigarette types, respectively. When it is assumed that an adult man has approximately $5.6 \mathrm{~L}$ of blood, we can estimate that on average between 6.7 and $11.7 \mu \mathrm{g}$ of toluene is found in the blood circulation 10 minutes after smoking one cigarette for the three types of Marlboro cigarettes. There is no clear difference of VOC uptake into the circulation between Marlboro Red and Marlboro Prime, although these cigarettes have substantially different declared TNCO yields with ISO 3308. In a laboratory study with smoking machines, we measured VOC yields with different smoking regimes (unpublished data) in a similar study design as described in 
Pauwels et al. ${ }^{62}$. With the $\mathrm{HCl}$ regime $(55 \mathrm{~mL}$ per puff of 2 seconds, and 30 seconds inter-puff interval), yields were measured for toluene; $190.6 \mu \mathrm{g} / \mathrm{cig}$ for Marlboro Red (taped) and $163.2 \mu \mathrm{g} / \mathrm{cig}$ for Prime (taped), i.e. -14\% difference. For Marlboro Red (taped) and Prime (taped) under modified ISO 3308 conditions (35 mL per puff of 2 seconds, and 1 minute inter-puff interval) also -14\% difference was found. However, when the ISO 3308 regime was used without taping the cigarettes, almost a 9-fold difference in yields was determined, i.e. $50.9 \mu \mathrm{g} / \mathrm{cig}$ for Marlboro Red versus $6.1 \mathrm{\mu g} /$ cig for Marlboro Prime (unpublished data). The results shown here for toluene were also found for benzene and the other VOCs studied, except for isopropylbenzene. The ISO 3308 regime with untaped cigarettes is in many jurisdictions mandatory for measuring TNCO emissions. We previously measured $0.9 \mathrm{mg}$ tar, $0.2 \mathrm{mg}$ nicotine and $1.6 \mathrm{mg}$ CO per cigarette under ISO conditions for Marlboro Prime, and $10.4 \mathrm{mg}$ tar, $0.8 \mathrm{mg}$ nicotine and $8.5 \mathrm{mg} \mathrm{CO}$ per cigarette for Marlboro Red ${ }^{62}$. The differences between emission yields of Prime and Red disappeared when cigarettes were taped, and/or smoked with a smoking machine according to the $\mathrm{HCl}$ regime. It supports the criticism on the use of the ISO 3308 regime as a foundation for risk assessment and tobacco product regulation. The large difference in yields generated with ISO 3308 were not in line with the results in the human volunteer study at hand. Actually, in some cases the opposite is observed as indicated above. Whereas Marlboro Prime generates low yields for VOCs under ISO 3308 conditions compared to $\mathrm{HCl}$ or modified ISO 3308, like it does for TNCO, some smokers are exposed to higher concentrations of VOCs. Siu et al. compared the 'less harmful' 'super slim' cigarette with a reference cigarette and concluded increased levels of ammonia and formaldehyde in 'super slim' cigarettes, but not for CO, carbonyls, aromatic amines and volatile organics ${ }^{63}$. Another study found only $14 \%$ lower levels of uptake of a biomarker of exposure of acrolein when smokers consumed low-TNCO cigarettes, but no statistically significant differences were measured of a biomarker for 1,3 butadiene exposure ${ }^{11}$. A recent study described no increase in VOC biomarkers who switched to low-TNCO cigarettes ${ }^{64}$.

Most concentrations of VOCs in blood and breath were higher when smoking Marlboro Prime than smoking Marlboro Red within all participants, although often the difference was less than $20 \%$ between the two products. The difference between individuals for each of the VOCs was often larger. For example, VOC levels in blood differ up to 4-fold for participants 4 and 10. Similar differences could be observed in exhaled breath samples of VOCs in Figure 4. It shows that the actual exposure to smoke toxicants is to a large extent determined by the puffing topography of the individual. It also shows that different declared TNCO levels, as determined with ISO 
3308, do not indicate differences in exposure of the smoker. Cigarettes with lower declared TNCO levels may expose smokers to similar or even higher levels of smoke toxicants. The actual uptake of smoke toxicants by the smoker may not be reduced when switching to brands with lower declared TNCO levels, since the characteristic individual puffing topography dominates the inhalation and exposure. Particularly for highly ventilated cigarettes, the determination of mainstream smoke yields with ISO 3308 generates data which are irrelevant for human smoking.

\section{Conclusions and Implications}

The present study adds that ISO 3308 mainstream smoke yields of VOCs do not correspond to uptake of smoke toxicants during human smoking. Comparable biomarker concentrations of VOCs in blood and VOCs in breath resulted after smoking the three cigarette types: Marlboro Red, Marlboro Prime and Marlboro Prime taped. The study at hand reports internal doses of several VOCs upon smoking which can improve health risk assessments. Exhaled breath samples further support data of blood samples. Both blood and exhaled breath samples show that substantial differences exist between smokers. A characteristic puffing topography is more important for actual exposure to smoke toxicants than the brand smoked ${ }^{35}$. Exhaled breath can serve as a semi-quantitative non-invasive marker for external dose exposure of volatile toxicants resulting from cigarette smoke exposure. The resulting data can be used in exposure assessments to relate to health outcomes. However, further research is required to improve quantifying the exhaled breath measurements, and to link exhaled breath chemicals to the toxicokinetics and metabolism of the individual smoke chemicals. In addition, research that resolves how internal and external dose data can be used in risk assessment is eligible. 


\section{References}

1. GBD 2015 Tobacco Collaborators. Smoking prevalence and attributable disease burden in 195 countries and territories, 1990-2015: a systematic analysis from the Global Burden of Disease Study 2015. Lancet. 2017;389(10082):1885-1906.

2. Talhout R, Schulz T, Florek E, et al. Hazardous compounds in tobacco smoke. Int J Environ Res Public Health. 2011;8(2):613-628.

3. Fowles J, Dybing E. Application of toxicological risk assessment principles to the chemical constituents of cigarette smoke. Tob Control. 2003;12(4):424-430.

4. IARC. IARC Monographs on the Evaluation of Carcinogenic Risks to Humans: Tobacco Smoke and Involuntary Smoking. IARC: Lyon, France. 2004.

5. Watanabe $\mathrm{KH}$, Djordjevic MV, Stellman SD, et al. Incremental lifetime cancer risks computed for benzo[a]pyrene and two tobacco-specific $\mathrm{N}$-nitrosamines in mainstream cigarette smoke compared with lung cancer risks derived from epidemiologic data. Regul Toxicol Pharmacol. 2009;55(2):123-133.

6. Yershova K, Yuan JM, Wang R, et al. Tobacco-specific N-nitrosamines and polycyclic aromatic hydrocarbons in cigarettes smoked by the participants of the Shanghai Cohort Study. Int J Cancer. 2016;139(6):1261-1269.

7. International Organisation for Standardisation. ISO 3308:2012 Routine analytical cigarette-smoking machine -definitions and standard conditions. 2012.

8. Hammond D, Wiebel F, Kozlowski LT, et al. Revising the machine smoking regime for cigarette emissions: implications for tobacco control policy. Tob Control. 2007;16(1):814.

9. Kozlowski LT, O'Connor RJ. Cigarette filter ventilation is a defective design because of misleading taste, bigger puffs, and blocked vents. Tob Control. 2002;11 Suppl 1:140-50.

10. Mendes P, Kapur S, Wang J, Feng S, Roethig H. A randomized, controlled exposure study in adult smokers of full flavor Marlboro cigarettes switching to Marlboro Lights or Marlboro Ultra Lights cigarettes. Regul Toxicol Pharmacol. 2008;51(3):295-305.

11. Mendes $\mathrm{P}$, Liang Q, Frost-Pineda $\mathrm{K}$, et al. The relationship between smoking machine derived tar yields and biomarkers of exposure in adult cigarette smokers in the US. Regul Toxicol Pharmacol. 2009;55(1):17-27.

12. Benowitz NL, Kuyt F, Jacob P, 3rd. Circadian blood nicotine concentrations during cigarette smoking. Clin Pharmacol Ther. 1982;32(6):758-764.

13. Liang Q, Roethig HJ, Lipowicz PJ, Jin Y, Mendes PE. The effect of cigarette burn time on exposure to nicotine and carbon monoxide in adult smokers. Regul Toxicol Pharmacol. 2008;50(1):66-74.

14. Cunningham A, Sommarstrom J, Camacho OM, Sisodiya AS, Prasad K. A longitudinal study of smokers' exposure to cigarette smoke and the effects of spontaneous product 
switching. Regul Toxicol Pharmacol. 2015;72(1):8-16.

15. Lynch CJ, Benowitz NL. Spontaneous cigarette brand switching: consequences for nicotine and carbon monoxide exposure. Am J Public Health. 1987;77(9):1191-1194.

16. Feng S, Roethig HJ, Liang Q, et al. Evaluation of urinary 1-hydroxypyrene, S-phenylmercapturic acid, trans,trans-muconic acid, 3-methyladenine, 3-ethyladenine, 8-hydroxy-2'-deoxyguanosine and thioethers as biomarkers of exposure to cigarette smoke. Biomarkers. 2006;11(1):28-52.

17. Scherer G. Carboxyhemoglobin and thiocyanate as biomarkers of exposure to carbon monoxide and hydrogen cyanide in tobacco smoke. Exp Toxicol Pathol. 2006;58(2-3):101124.

18. Ueda K, Kawachi I, Nakamura M, et al. Cigarette nicotine yields and nicotine intake among Japanese male workers. Tob Control. 2002;11(1):55-60.

19. Pirkle JL, Sampson EJ, Needham LL, Patterson DG, Ashley DL. Using biological monitoring to assess human exposure to priority toxicants. Environ Health Perspect. 1995;103 Suppl 3:45-48.

20. Corley RA, Kabilan S, Kuprat AP, et al. Comparative Risks of Aldehyde Constituents in Cigarette Smoke Using Transient Computational Fluid Dynamics/Physiologically Based Pharmacokinetic Models of the Rat and Human Respiratory Tracts. Toxicol Sci. 2015;146(1):65-88.

21. Alonso M, Castellanos M, Sanchez JM. Evaluation of potential breath biomarkers for active smoking: assessment of smoking habits. Anal Bioanal Chem. 2010;396(8):29872995.

22. Gordon SM, Wallace LA, Brinkman MC, Callahan PJ, Kenny DV. Volatile organic compounds as breath biomarkers for active and passive smoking. Environ Health Perspect. 2002;110(7):689-698.

23. Jo WK, Pack KW. Utilization of breath analysis for exposure estimates of benzene associated with active smoking. Environ Res. 2000;83(2):180-187.

24. Wallace L, Pellizzari E, Hartwell TD, Perritt R, Ziegenfus R. Exposures to benzene and other volatile compounds from active and passive smoking. Arch Environ Health. 1987;42(5):272-279.

25. Capone S, Tufariello M, Forleo A, et al. Chromatographic analysis of VOC patterns in exhaled breath from smokers and nonsmokers. Biomed Chromatogr. 2018;32(4):e4132.

26. Brugnone F, Perbellini L, Faccini GB, et al. Breath and blood levels of benzene, toluene, cumene and styrene in non-occupational exposure. Int Arch Occup Environ Health. 1989;61(5):303-311.

27. Van Berkel JJ, Dallinga JW, Moller GM, et al. Development of accurate classification method based on the analysis of volatile organic compounds from human exhaled air. $J$ Chromatogr B Analyt Technol Biomed Life Sci. 2008;861(1):101-107. 
28. Ross BM, Babgi R. Volatile compounds in blood headspace and nasal breath. Journal of breath research. 2017;11(4):046001.

29. Filipiak W, Ruzsanyi V, Mochalski P, et al. Dependence of exhaled breath composition on exogenous factors, smoking habits and exposure to air pollutants. Journal of breath research. 2012;6(3):036008.

30. Boots AW, Bos LD, van der Schee MP, van Schooten FJ, Sterk PJ. Exhaled Molecular Fingerprinting in Diagnosis and Monitoring: Validating Volatile Promises. Trends Mol Med. 2015;21(10):633-644.

31. Horvath I, Barnes PJ, Loukides S, et al. A European Respiratory Society technical standard: exhaled biomarkers in lung disease. Eur Respir J. 2017;49(4):1600965.

32. Marco E, Grimalt JO. A rapid method for the chromatographic analysis of volatile organic compounds in exhaled breath of tobacco cigarette and electronic cigarette smokers. $J$ Chromatogr A. 2015;1410:51-59.

33. Beauchamp J. Inhaled today, not gone tomorrow: pharmacokinetics and environmental exposure of volatiles in exhaled breath. Journal of Breath Research. 2011;5(3):037103.

34. Baker RR, Bishop LJ. The pyrolysis of tobacco ingredients. J Anal Appl Pyrolysis. 2004;71(1):223-311.

35. Pauwels CGGM, Boots AW, Visser WF, et al. Characteristic Human Individual Puffing Profiles Can Generate More TNCO than ISO and Health Canada Regimes on Smoking Machine When the Same Brand Is Smoked. Int J Environ Res Public Health. 2020;17(9).

36. Djordjevic MV, Stellman SD, Zang E. Doses of nicotine and lung carcinogens delivered to cigarette smokers. J Natl Cancer Inst. 2000;92(2):106-111.

37. Pazo DY, Moliere F, Sampson MM, et al. Mainstream Smoke Levels of Volatile Organic Compounds in 50 U.S. Domestic Cigarette Brands Smoked With the ISO and Canadian Intense Protocols. Nicotine Tob Res. 2016;18(9):1886-1894.

38. IARC. IARC Monographs on the Evaluation of the Carcinogenic Risk of Chemicals to Humans. IARC: Lyon, France. 1982.

39. IARC. IARC Monographs on the Evaluation of the Carcinogenic Risk of Chemicals to Humans. IARC: Lyon, France. 2000.

40. IARC. IARC Monographs on the Evaluation of the Carcinogenic Risk of Chemicals to Humans. IARC: Lyon, France. 1999.

41. Buszewski B, Ulanowska A, Ligor T, Denderz N, Amann A. Analysis of exhaled breath from smokers, passive smokers and non-smokers by solid-phase microextraction gas chromatography/mass spectrometry. Biomed Chromatogr. 2009;23(5):551-556.

42. Blount BC, Kobelski RJ, McElprang DO, et al. Quantification of 31 volatile organic compounds in whole blood using solid-phase microextraction and gas chromatographymass spectrometry. J Chromatogr B Analyt Technol Biomed Life Sci. 2006;832(2):292-301.

43. Wallace L, Buckley T, Pellizzari E, Gordon S. Breath Measurements as Volatile Organic 
Compound Biomarkers. Environ Health Perspect. 1996;104:861-869.

44. Jain RB. Selected volatile organic compounds as biomarkers for exposure to tobacco smoke. Biomarkers. 2016;21(4):342-346.

45. WHO Study Group on Tobacco Product Regulation (TobReg). Report on the scientific basis of tobacco product regulation: fifth report of a WHO study group (989). Geneva, Switserland. World Health Organization; 2015.

46. IARC. IARC Monographs on the Evaluation of the Carcinogenic Risk of Chemicals to Humans. IARC: Lyon, France. 2002.

47. IARC. IARC Monographs on the Evaluation of the Carcinogenic Risk of Chemicals to Humans. IARC: Lyon, France. 2013.

48. Castellanos M, Suner R, Fernandez-Real JM, Sanchez JM. 2,5-Dimethylfuran as a Validated Biomarker of Smoking Status. Nicotine Tob Res. 2019;21(6):828-834.

49. Pennings JLA, Cremers J, Becker MJA, Klerx WNM, Talhout R. Aldehyde and Volatile Organic Compound Yields in Commercial Cigarette Mainstream Smoke Are Mutually Related and Depend on the Sugar and Humectant Content in Tobacco. Nicotine Tob Res. 2020;22(10):1748-1756.

50. Centers for Disease Control and Prevention (CDC). Tobacco Brand Preferences. Website. Available at: https://www.cdc.gov/tobacco/data_statistics/fact_sheets/tobacco_ industry/brand_preference/index.htm. Accessed August 19th 2020.

51. Statista Research. Market share of Marlboro in the Netherlands from 2012 to 2017. https://www.statista.com/statistics/822213/market-share-marlboro-in-thenetherlands/. Accessed August 19th, 2020.

52. ISO 3308:2012. Routine analytical cigarette-smoking machine -definitions and standard conditions. Geneva, Switzerland: International Organization for Standardization; 2012.

53. Centers for Disease Control and Prevention. Fourth Report on Human Exposure to Environmental Chemicals, Updated Tables. 2008. https://www.cdc.gov/exposurereport/. Accessed Jan 16th, 2021.

54. Chambers DM, Ocariz JM, McGuirk MF, Blount BC. Impact of cigarette smoking on volatile organic compound (VOC) blood levels in the U.S. population: NHANES 20032004. Environ Int. 2011;37(8):1321-1328.

55. USEPA. Toxicological review of benzene (noncancer effects) [report no. EPA/635/R-02/001F]. Washington (DC). 2002.

56. Ager C, Unterkofler K, Mochalski P, et al. Modeling-based determination of physiological parameters of systemic VOCs by breath gas analysis, part 2. Journal of breath research. 2018;12(3):036011.

57. Spanel P, Dryahina K, Smith D. A quantitative study of the influence of inhaled compounds on their concentrations in exhaled breath. Journal of breath research. 2013;7(1):017106.

58. King $\mathrm{J}$, Koc $\mathrm{H}$, Unterkofler $\mathrm{K}$, et al. Physiological modeling of isoprene dynamics in 
exhaled breath. J Theor Biol. 2010;267(4):626-637.

59. Adam T, McAughey J, McGrath C, Mocker C, Zimmermann R. Simultaneous on-line size and chemical analysis of gas phase and particulate phase of cigarette mainstream smoke. Anal Bioanal Chem. 2009;394(4):1193-1203.

60. Aylward LL, Kirman CR, Adgate JL, McKenzie LM, Hays SM. Interpreting variability in population biomonitoring data: role of elimination kinetics. J Expo Sci Environ Epidemiol. 2012;22(4):398-408.

61. Chambers DM, McElprang DO, Waterhouse MG, Blount BC. An improved approach for accurate quantitation of benzene, toluene, ethylbenzene, xylene, and styrene in blood. Anal Chem. 2006;78(15):5375-5383.

62. Pauwels CGGM, Klerx WNM, Pennings JLA, et al. Cigarette Filter Ventilation and Smoking Protocol Influence Aldehyde Smoke Yields. Chem Res Toxicol. 2018;31(6):462471.

63. Siu M, Mladjenovic N, Soo E. The analysis of mainstream smoke emissions of Canadian 'super slim' cigarettes. Tob Control. 2013;22(6):e10.

64. Smith TT, Koopmeiners JS, White CM, et al. The Impact of Exclusive Use of Very Low Nicotine Cigarettes on Compensatory Smoking: An Inpatient Crossover Clinical Trial. Cancer Epidemiol Biomarkers Prev. 2020;29(4):880-886. 


\section{Supplemental information}
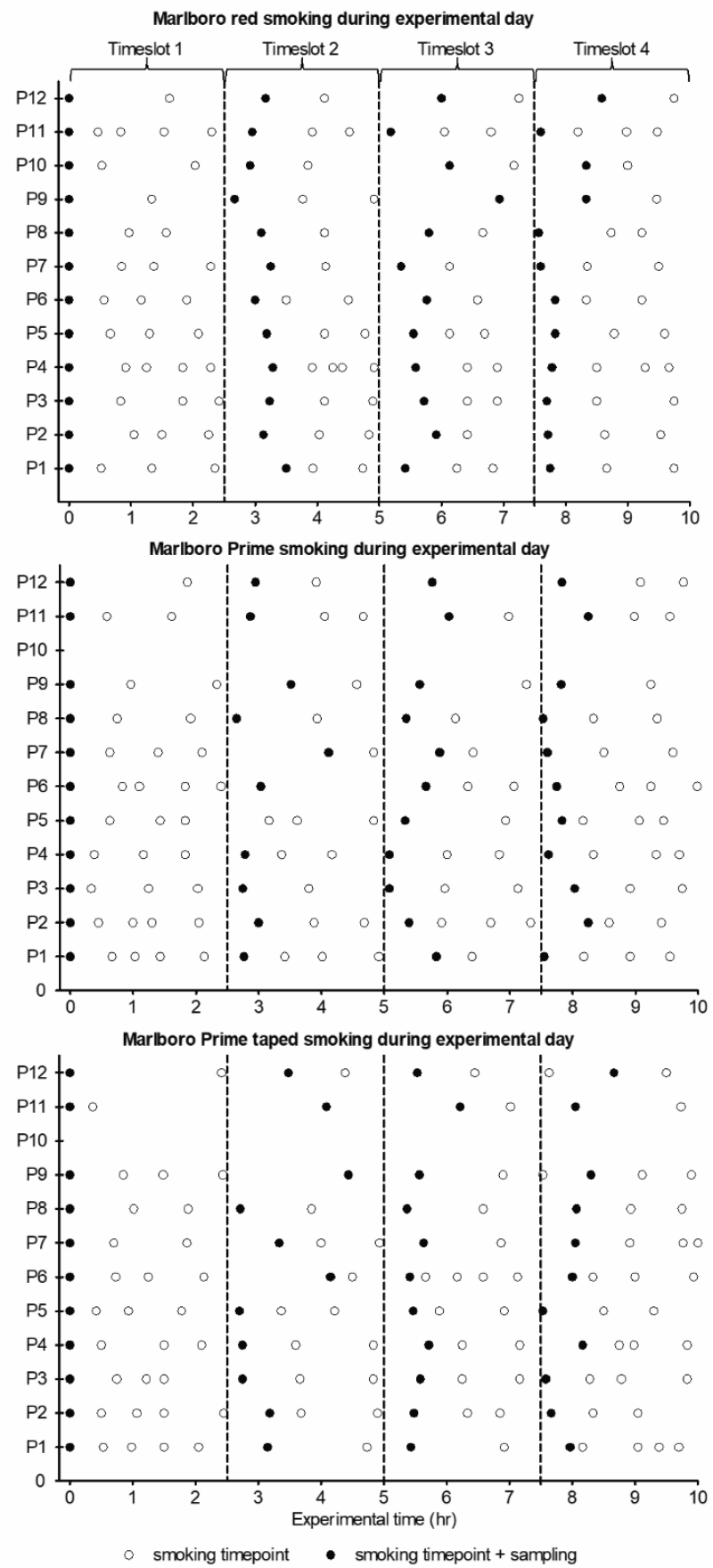

Figure S1: Time of smoking Marlboro Red, Marlboro Prime or Marlboro Prime taped per individual participant in the four timeslots (10 hours). Blood and breath was sampled upon the first smoked cigarette in a timeslot (solid circle). Lighting the first cigarette of the day was defined as $\mathrm{t}=0$. Participant 10 was a no show for experimental day 2 and 3. 

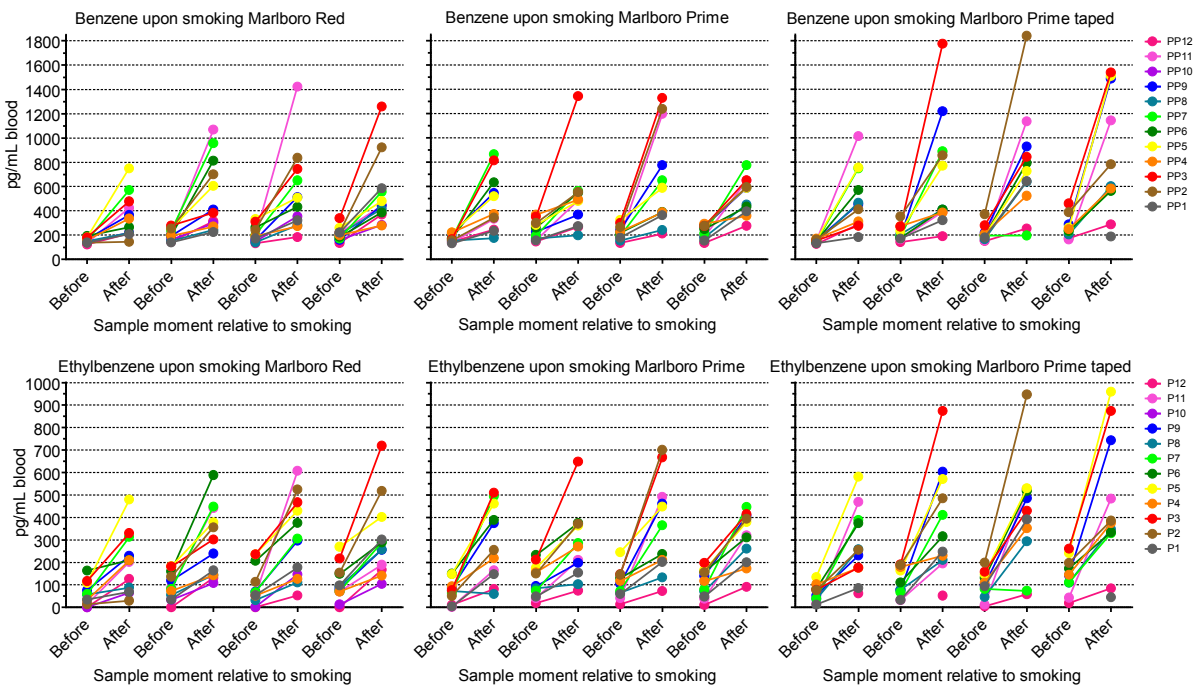

Ethylbenzene upon smoking Marlboro Prime
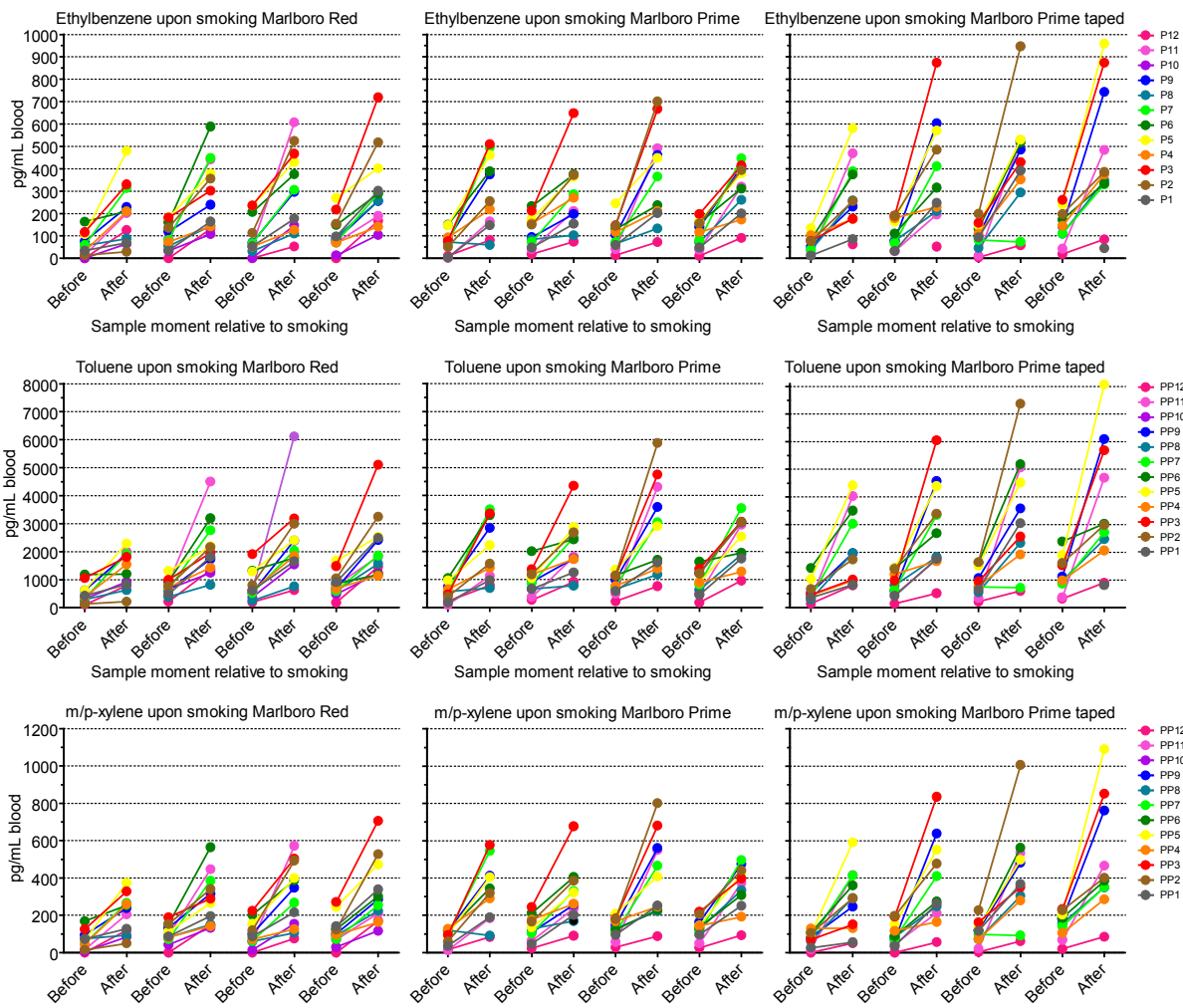

m/p-xylene upon smoking Marlboro Prime
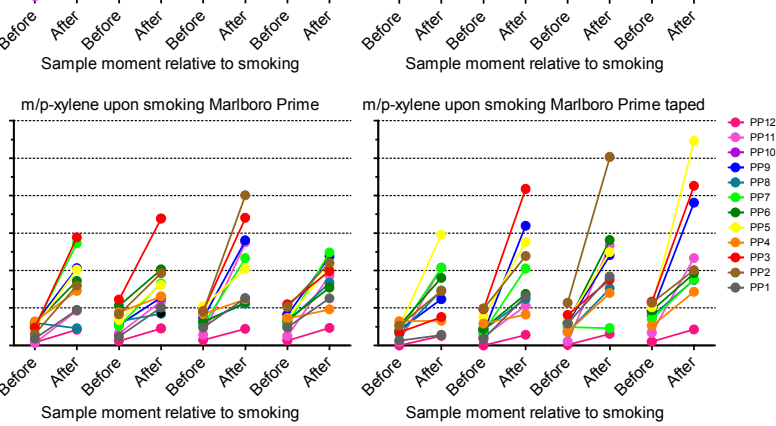

Sample moment relative to smoking 

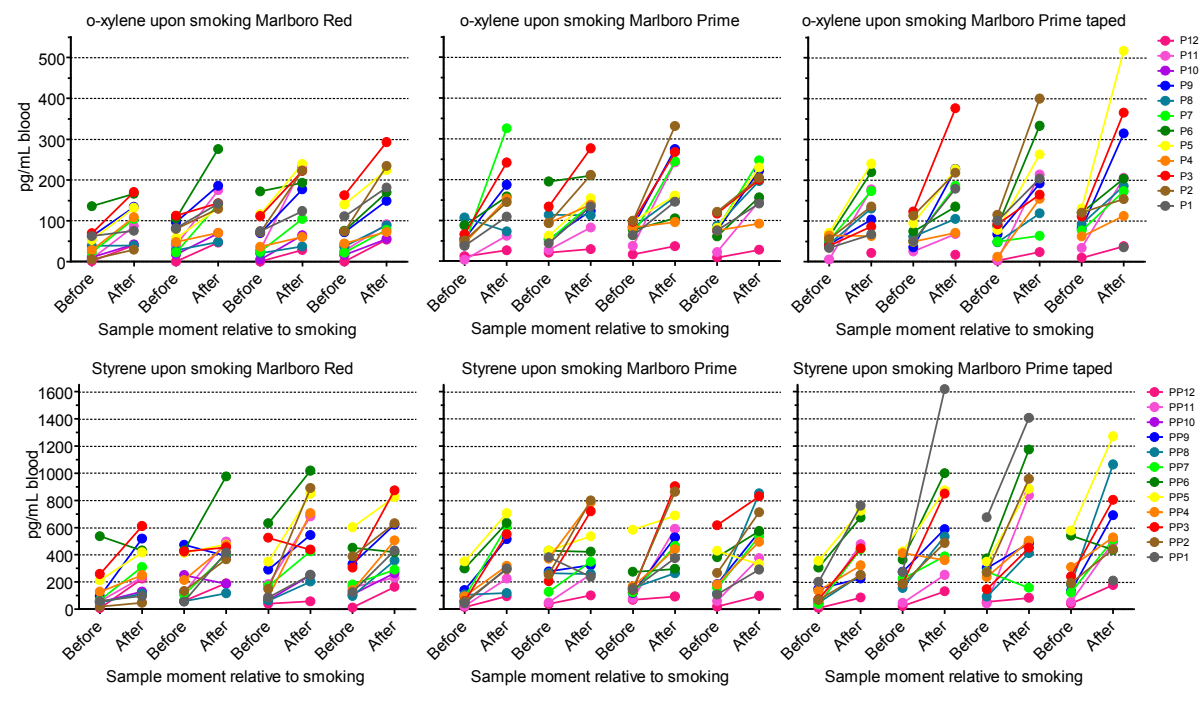

Sample moment relative to smoking

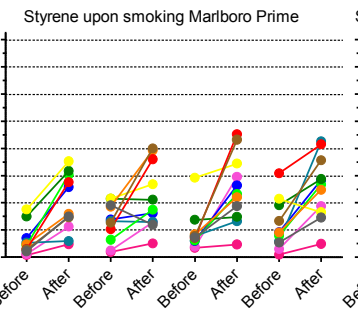

Styrene upon smoking Marlboro Prime taped

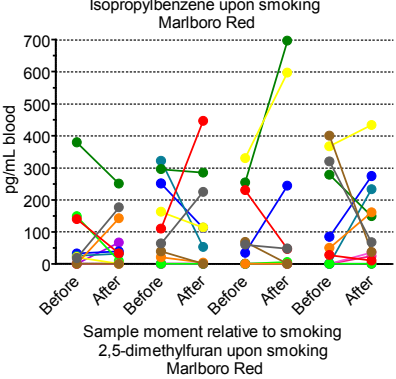

Sample moment relative to smoking

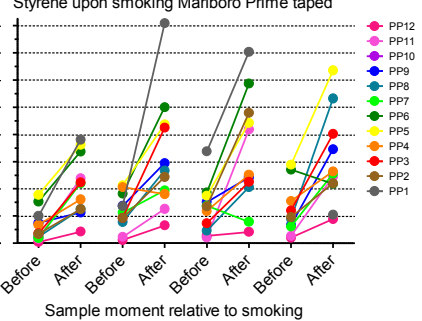

Isopropylbenzene upon smoking Marlboro Prime

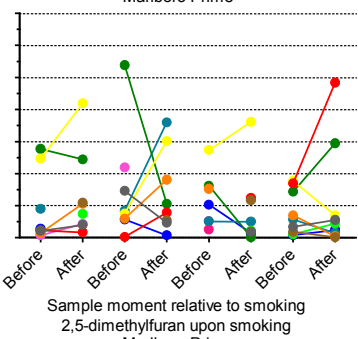

Isopropylbenzene upon smoking
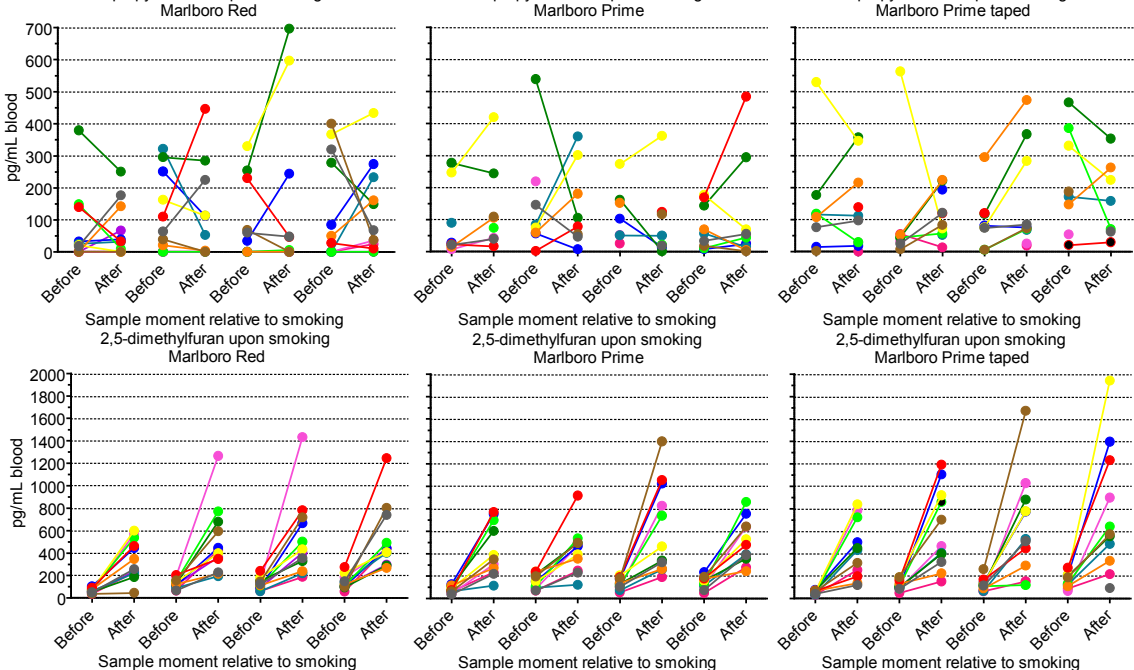

Sample moment relative to smoking 2,5-dimethylfuran upon smoking

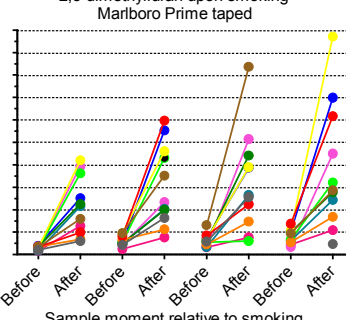

Figure S2: VOC levels in headspace of blood (pg/mL) before and after smoking Marlboro (left), Marlboro Prime (middle) or Marlboro Prime taped (right) for the first cigarette in the four subsequent timeslots during the experimental day (left to right on $\mathrm{X}$-axis). Different colors depict the individual participants. 
Table S1: Baseline levels of VOCs in blood

\begin{tabular}{lllllllllll}
\hline Brand & Baseline & Benzene & $\begin{array}{l}\text { Ethyl- } \\
\text { benzene }\end{array}$ & Toluene & $\mathrm{m} / \mathrm{p}$-Xylene o-Xylene Styrene & $\begin{array}{l}\text { Isopro- } \\
\text { pylben- } \\
\text { zene }\end{array}$ & $\begin{array}{l}2,5-\mathrm{di} \text { - } \\
\text { methyl- } \\
\text { furan }\end{array}$ \\
\hline $\begin{array}{l}\text { Marlboro } \\
\text { red }\end{array}$ & Mean & 155.0 & 56.0 & 473.2 & 61.2 & 41.2 & 127.6 & 63.6 & 62.7 \\
& SD & 21.0 & 49.3 & 325.9 & 48.8 & 36.8 & 142.4 & 107.6 & 19.5 \\
$\begin{array}{l}\text { Marlboro } \\
\text { Prime }\end{array}$ & Mean & 169.5 & 68.6 & 532.0 & 81.1 & 50.0 & 115.4 & 88.4 & 77.5 \\
& SD & 30.1 & 48.8 & 292.9 & 40.8 & 28.3 & 104.9 & 103.0 & 28.1 \\
$\begin{array}{l}\text { Marlboro } \\
\begin{array}{l}\text { Prime } \\
\text { taped }\end{array}\end{array}$ & Mean & 148.9 & 63.1 & 546.4 & 77.2 & 46.7 & 127.8 & 142.4 & 56.3 \\
& SD & 12.8 & 36.6 & 359.5 & 33.5 & 17.9 & 110.2 & 155.4 & 14.6 \\
Average & Mean & 157.8 & 62.6 & 517.2 & 73.2 & 46.0 & 123.6 & 98.1 & 65.5 \\
& SD & 8.6 & 5.2 & 31.7 & 8.6 & 3.6 & 5.8 & 32.9 & 8.9 \\
\hline
\end{tabular}

Table S2: Net increase per VOC in blood (pg/mL) upon smoking Marlboro red, Marlboro Prime or Marlboro Prime taped for the different participants including an average net increase per participant (mean (SD))

\begin{tabular}{|c|c|c|c|c|c|c|c|c|c|}
\hline & Brand & Benzene & SD & $\begin{array}{l}\text { Ethylben- } \\
\text { zene }\end{array}$ & SD & Toluene & SD & $\begin{array}{l}m / p-X y- \\
\text { lene }\end{array}$ & SD \\
\hline \multirow[t]{4}{*}{ P1 } & MR & 167.5 & 118.4 & 122.9 & 60.1 & 1088.1 & 440.3 & 123.1 & 50.6 \\
\hline & MP & 160.9 & 55.0 & 136.4 & 18.1 & 927.0 & 263.0 & 155.3 & 1.5 \\
\hline & MPT & 222.8 & 176.3 & 195.5 & 92.7 & 1406.8 & 790.5 & 170.1 & 99.8 \\
\hline & Mean & 180.2 & 123.9 & 147.6 & 68.3 & 1116.5 & 549.9 & 147.7 & 63.5 \\
\hline \multirow[t]{4}{*}{ P2 } & MR & 436.3 & 263.6 & 252.9 & 153.7 & 1469.7 & 865.4 & 250.3 & 149.4 \\
\hline & MP & 433.8 & 315.0 & 304.8 & 144.7 & 2309.4 & 1419.2 & 333.9 & 166.9 \\
\hline & MPT & 653.5 & 479.0 & 352.8 & 232.8 & 2540.6 & 1873.5 & 354.9 & 248.3 \\
\hline & Mean & 507.9 & 378.6 & 303.5 & 186.0 & 2106.6 & 1517.5 & 313.0 & 198.3 \\
\hline \multirow[t]{4}{*}{ P3 } & MR & 439.0 & 301.0 & 266.6 & 142.2 & 1654.3 & 1152.4 & 254.9 & 122.3 \\
\hline & MP & 761.7 & 267.7 & 401.6 & 112.4 & 2802.0 & 701.2 & 398.3 & 129.1 \\
\hline & MPT & 818.4 & 522.3 & 416.3 & 240.3 & 2851.9 & 1835.8 & 383.0 & 251.3 \\
\hline & Mean & 673.0 & 415.9 & 361.5 & 186.4 & 2436.1 & 1426.9 & 345.4 & 189.0 \\
\hline \multirow[t]{4}{*}{ P4 } & $\mathrm{MR}$ & 103.3 & 42.7 & 98.1 & 45.8 & 886.4 & 318.1 & 99.3 & 66.4 \\
\hline & MP & 125.7 & 37.5 & 97.2 & 26.4 & 583.6 & 139.2 & 94.0 & 42.4 \\
\hline & MPT & 224.5 & 99.6 & 149.3 & 87.8 & 804.5 & 307.3 & 109.5 & 86.9 \\
\hline & Mean & 151.2 & 84.6 & 114.9 & 64.0 & 758.2 & 296.7 & 101.0 & 68.0 \\
\hline \multirow[t]{4}{*}{ P5 } & $\mathrm{MR}$ & 328.8 & 153.1 & 223.4 & 89.5 & 1135.4 & 329.2 & 233.6 & 55.4 \\
\hline & MP & 267.0 & 43.8 & 229.9 & 48.9 & 1567.2 & 200.1 & 242.7 & 51.1 \\
\hline & MPT & 729.9 & 302.1 & 488.6 & 134.3 & 3880.8 & 1333.9 & 536.7 & 207.9 \\
\hline & Mean & 441.9 & 284.6 & 314.0 & 157.3 & 2194.5 & 1447.6 & 337.6 & 190.1 \\
\hline \multirow[t]{3}{*}{ P6 } & MR & 264.3 & 208.3 & 196.1 & 141.7 & 761.8 & 874.8 & 214.4 & 120.8 \\
\hline & MP & 275.6 & 116.4 & 160.2 & 48.6 & 885.3 & 792.6 & 175.8 & 45.0 \\
\hline & MPT & 396.7 & 135.7 & 261.2 & 86.4 & 1885.3 & 1095.5 & 270.4 & 103.4 \\
\hline
\end{tabular}




\begin{tabular}{llllllll}
\hline o-Xylene & SD & Styrene & SD & $\begin{array}{l}\text { Isopropyl- SD } \\
\text { benzene }\end{array}$ & $\begin{array}{l}\text { 2,5-di- } \\
\text { methylfu- } \\
\text { ran }\end{array}$ \\
\hline 48.3 & 21.6 & 217.6 & 126.0 & 79.8 & 79.8 & 297.8 & 171.3 \\
77.4 & 9.5 & 167.4 & 100.0 & 14.6 & 8.5 & 218.4 & 57.9 \\
88.2 & 40.3 & 879.0 & 335.9 & 42.8 & 38.0 & 238.5 & 129.2 \\
69.8 & 30.5 & 379.7 & 366.2 & 46.0 & 59.3 & 252.8 & 132.9 \\
\hline 96.1 & 60.3 & 311.2 & 262.5 & 0.0 & 0.0 & 431.0 & 261.7 \\
131.8 & 59.4 & 484.4 & 171.3 & 69.9 & 47.0 & 563.4 & 384.8 \\
125.8 & 95.4 & 354.7 & 196.9 & 35.9 & 36.0 & 639.7 & 454.8 \\
117.9 & 75.3 & 383.4 & 226.0 & 35.3 & 44.5 & 544.7 & 385.5 \\
\hline 93.2 & 37.8 & 237.7 & 235.5 & 84.0 & 145.5 & 505.9 & 301.9 \\
142.8 & 37.1 & 495.4 & 194.3 & 128.6 & 116.0 & 634.2 & 208.6 \\
157.1 & 97.7 & 475.8 & 143.5 & 2.3 & 4.0 & 599.1 & 399.3 \\
131.0 & 69.7 & 403.0 & 227.3 & 71.6 & 119.5 & 579.7 & 317.8 \\
\hline 38.6 & 24.2 & 339.9 & 181.6 & 63.5 & 64.4 & 159.3 & 66.6 \\
45.8 & 38.6 & 306.0 & 70.1 & 52.9 & 54.0 & 116.1 & 31.0 \\
53.6 & 54.4 & 155.1 & 122.4 & 143.0 & 31.9 & 147.3 & 68.5 \\
46.0 & 41.4 & 267.0 & 155.2 & 86.4 & 65.7 & 140.9 & 60.8 \\
\hline 90.0 & 19.8 & 246.9 & 159.1 & 83.1 & 109.3 & 304.7 & 132.3 \\
100.3 & 30.7 & 140.9 & 130.4 & 121.9 & 86.0 & 291.4 & 49.1 \\
218.1 & 99.1 & 511.1 & 120.9 & 51.8 & 89.7 & 970.7 & 441.4 \\
136.1 & 84.3 & 299.7 & 207.9 & 85.6 & 99.7 & 522.3 & 414.9 \\
\hline 78.8 & 59.4 & 232.9 & 239.5 & 110.5 & 191.3 & 264.4 & 170.0 \\
52.2 & 32.3 & 137.3 & 136.2 & 37.8 & 65.5 & 293.8 & 119.7 \\
136.8 & 72.3 & 450.5 & 302.5 & 151.4 & 91.9 & 448.1 & 182.4 \\
\hline & & & & & & & \\
continues
\end{tabular}




\begin{tabular}{llllllllll}
\hline & Mean & 312.2 & 169.4 & 205.8 & 108.2 & 1177.4 & 1057.2 & 220.2 & 103.0 \\
\hline P7 & MR & 491.3 & 132.6 & 269.3 & 57.0 & 1614.7 & 304.3 & 229.4 & 50.5 \\
& MP & 521.7 & 121.3 & 325.6 & 81.6 & 2396.1 & 500.9 & 354.0 & 80.0 \\
& MPT & 410.4 & 272.2 & 227.9 & 141.5 & 1804.9 & 1095.3 & 221.9 & 138.4 \\
& Mean & 474.5 & 194.1 & 274.3 & 107.6 & 1938.6 & 790.6 & 268.4 & 114.2 \\
\hline P8 & MR & 127.2 & 53.5 & 90.6 & 47.1 & 562.1 & 247.2 & 66.3 & 41.7 \\
& MP & 101.2 & 101.0 & 69.3 & 74.2 & 509.2 & 463.4 & 85.7 & 78.3 \\
& MPT & 350.0 & 99.3 & 210.0 & 45.7 & 1497.6 & 290.3 & 204.9 & 28.3 \\
& Mean & 192.8 & 141.8 & 123.3 & 84.3 & 856.3 & 571.1 & 119.0 & 81.5 \\
\hline P9 & MR & 262.4 & 60.8 & 168.1 & 38.7 & 1497.2 & 312.3 & 189.0 & 36.9 \\
& MP & 332.2 & 139.9 & 254.1 & 92.9 & 1842.6 & 647.2 & 292.0 & 94.9 \\
& MPT & 810.0 & 344.9 & 422.9 & 160.4 & 3221.6 & 1353.1 & 419.2 & 170.8 \\
& Mean & 468.2 & 326.5 & 281.7 & 152.2 & 2187.1 & 1156.4 & 300.1 & 148.5 \\
\hline P10 & MR & 137.7 & 44.6 & 93.8 & 31.1 & 774.4 & 234.4 & 98.9 & 24.2 \\
\hline P11 & MR & 649.9 & 415.8 & 303.9 & 167.3 & 2968.7 & 1739.9 & 299.5 & 146.9 \\
& MP & 501.4 & 313.4 & 266.3 & 116.5 & 2192.9 & 1076.7 & 290.2 & 132.0 \\
& MPT & 763.4 & 315.1 & 392.6 & 135.6 & 3517.8 & 1340.0 & 368.4 & 126.5 \\
& Mean & 638.2 & 367.4 & 320.9 & 150.9 & 2893.1 & 1513.1 & 319.3 & 139.8 \\
\hline P12 & MR & 136.4 & 71.2 & 119.1 & 41.5 & 884.1 & 338.8 & 128.7 & 35.1 \\
& MP & 109.2 & 23.2 & 66.5 & 9.5 & 636.6 & 92.9 & 65.1 & 3.2 \\
& MPT & 106.3 & 40.3 & 58.4 & 5.6 & 500.4 & 121.1 & 57.5 & 5.3 \\
& Mean & 117.3 & 50.9 & 81.3 & 36.6 & 673.7 & 266.9 & 83.8 & 38.0 \\
ANOVA & & & & & & & & \\
participants & $1.91 \mathrm{E}-07$ & $*$ & $3.83 \mathrm{E}-07$ & $*$ & $3.83 \mathrm{E}-07$ & $*$ & $3.83 \mathrm{E}-07$ & $*$ \\
\hline & & & & & & & \\
ANOVA brands & $1.80 \mathrm{E}-03$ & $*$ & $1.13 \mathrm{E}-03$ & $*$ & $1.13 \mathrm{E}-03$ & $*$ & $3.52 \mathrm{E}-03$ & $*$ \\
\hline
\end{tabular}

Net increase: mean 'after smoking' minus mean 'before smoking'. $n=4$ per participant per VOC and brand. In case of a higher 'before smoking' than 'after smoking', the average increase was set to zero. MR; Marlboro Red, MP; Marlboro Prime, MPT; Marlboro Prime taped. *;false discovery rate significant if $<0.05$ 


\begin{tabular}{llllllll}
\hline 89.2 & 67.2 & 273.6 & 270.2 & 99.9 & 136.6 & 335.4 & 178.8 \\
\hline 84.3 & 22.2 & 226.5 & 71.6 & 1.4 & 2.4 & 464.8 & 97.7 \\
180.5 & 69.1 & 364.0 & 105.4 & 32.0 & 26.9 & 600.7 & 110.6 \\
91.9 & 47.1 & 237.9 & 166.4 & 19.6 & 27.0 & 485.8 & 289.0 \\
118.9 & 66.3 & 276.2 & 136.1 & 17.6 & 25.3 & 517.1 & 196.6 \\
\hline 22.3 & 18.4 & 131.0 & 80.0 & 59.9 & 99.9 & 172.2 & 58.2 \\
46.2 & 47.8 & 213.8 & 304.2 & 68.8 & 119.1 & 135.7 & 103.3 \\
73.8 & 19.4 & 446.6 & 260.5 & 30.0 & 30.5 & 383.0 & 55.1 \\
47.4 & 38.0 & 263.8 & 271.0 & 52.9 & 92.9 & 230.3 & 132.6 \\
\hline 86.2 & 13.7 & 241.1 & 153.1 & 101.3 & 98.3 & 397.2 & 100.3 \\
134.6 & 43.3 & 303.5 & 148.6 & 4.0 & 6.9 & 578.0 & 193.5 \\
152.2 & 65.7 & 282.7 & 179.3 & 49.2 & 83.2 & 812.4 & 301.5 \\
124.4 & 53.9 & 275.8 & 163.0 & 51.5 & 84.4 & 595.9 & 273.9 \\
\hline 45.6 & 10.9 & 104.1 & 71.2 & 16.8 & 29.0 & 233.2 & 49.8 \\
\hline 120.5 & 54.3 & 280.8 & 167.2 & 8.8 & 15.3 & 783.0 & 416.5 \\
110.9 & 61.0 & 310.0 & 126.7 & 15.3 & 15.7 & 477.0 & 173.4 \\
148.9 & 63.3 & 470.5 & 210.1 & 0.0 & 0.0 & 723.6 & 214.0 \\
126.8 & 61.8 & 353.8 & 190.6 & 8.1 & 14.1 & 661.2 & 317.3 \\
\hline 42.2 & 9.3 & 128.3 & 72.3 & 0.0 & 0.0 & 265.5 & 109.4 \\
15.7 & 4.6 & 61.5 & 22.3 & 0.0 & 0.0 & 178.6 & 33.3 \\
21.8 & 4.2 & 87.1 & 40.3 & 0.0 & 0.0 & 134.9 & 51.3 \\
26.6 & 13.0 & 92.3 & 56.6 & 0.0 & 0.0 & 193.0 & 90.5 \\
& & & & & & & \\
$1.21 \mathrm{E}-05$ & $*$ & $7.43 \mathrm{E}-02$ & & $9.2 \mathrm{E}-01$ & & $3.83 \mathrm{E}-07$ & $*$ \\
$3.52 \mathrm{E}-03$ & $*$ & $8.94 \mathrm{E}-03$ & $*$ & $9.20 \mathrm{E}-01$ & & $1.92 \mathrm{E}-02$ & $*$ \\
\hline
\end{tabular}




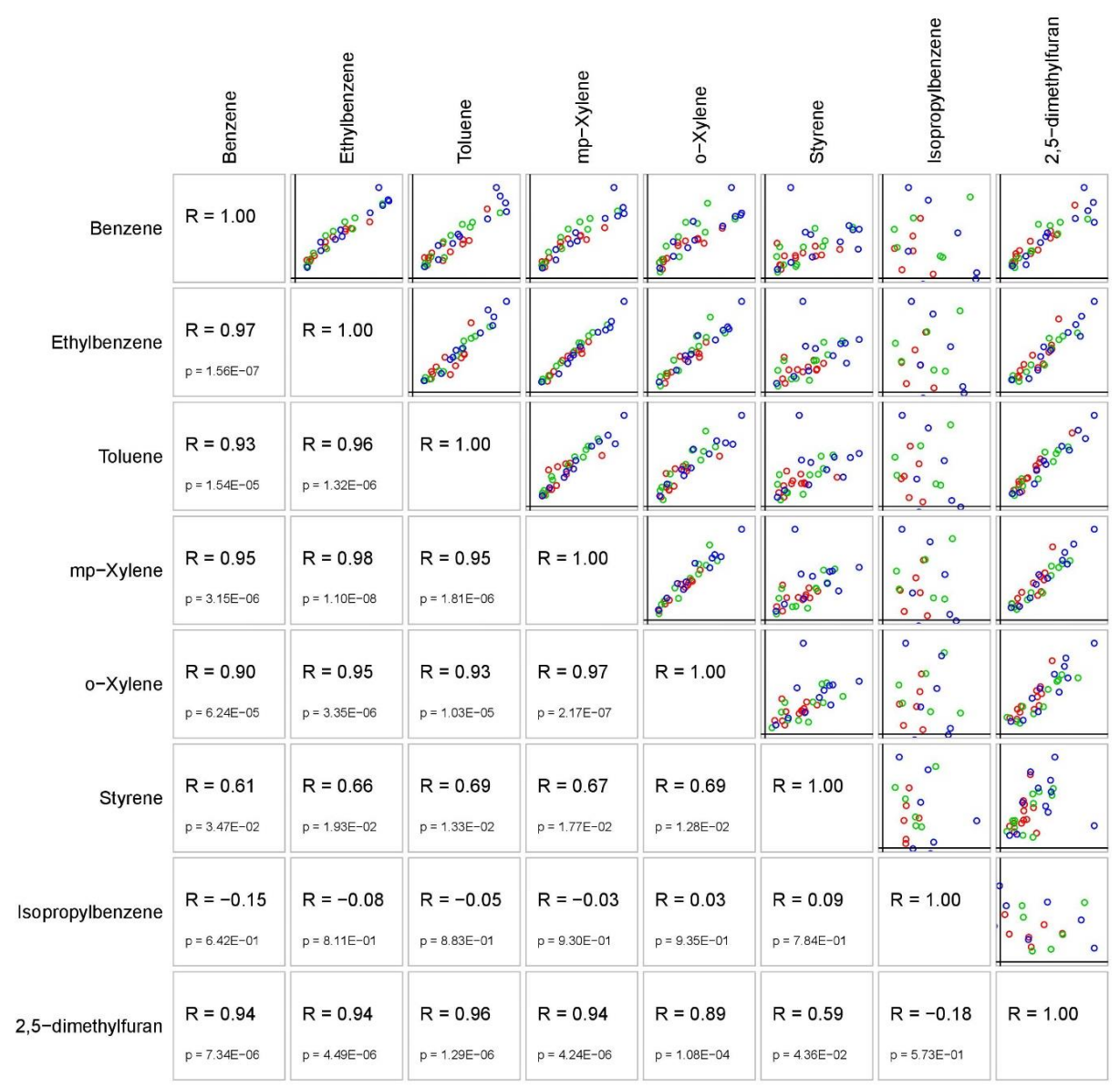

Figure S3: Spearman correlation and scatter plots for mean net increase of benzene, toluene, ethylbenzene, m/p-xylene, o-xylene and 2,5-dimethylfuran in blood upon smoking. Every open circle in the scatter plots represents per participant the mean net increase in the specific VOC upon smoking. Red is Marlboro, Green is Marlboro Prime and Blue is Marlboro Prime taped. 


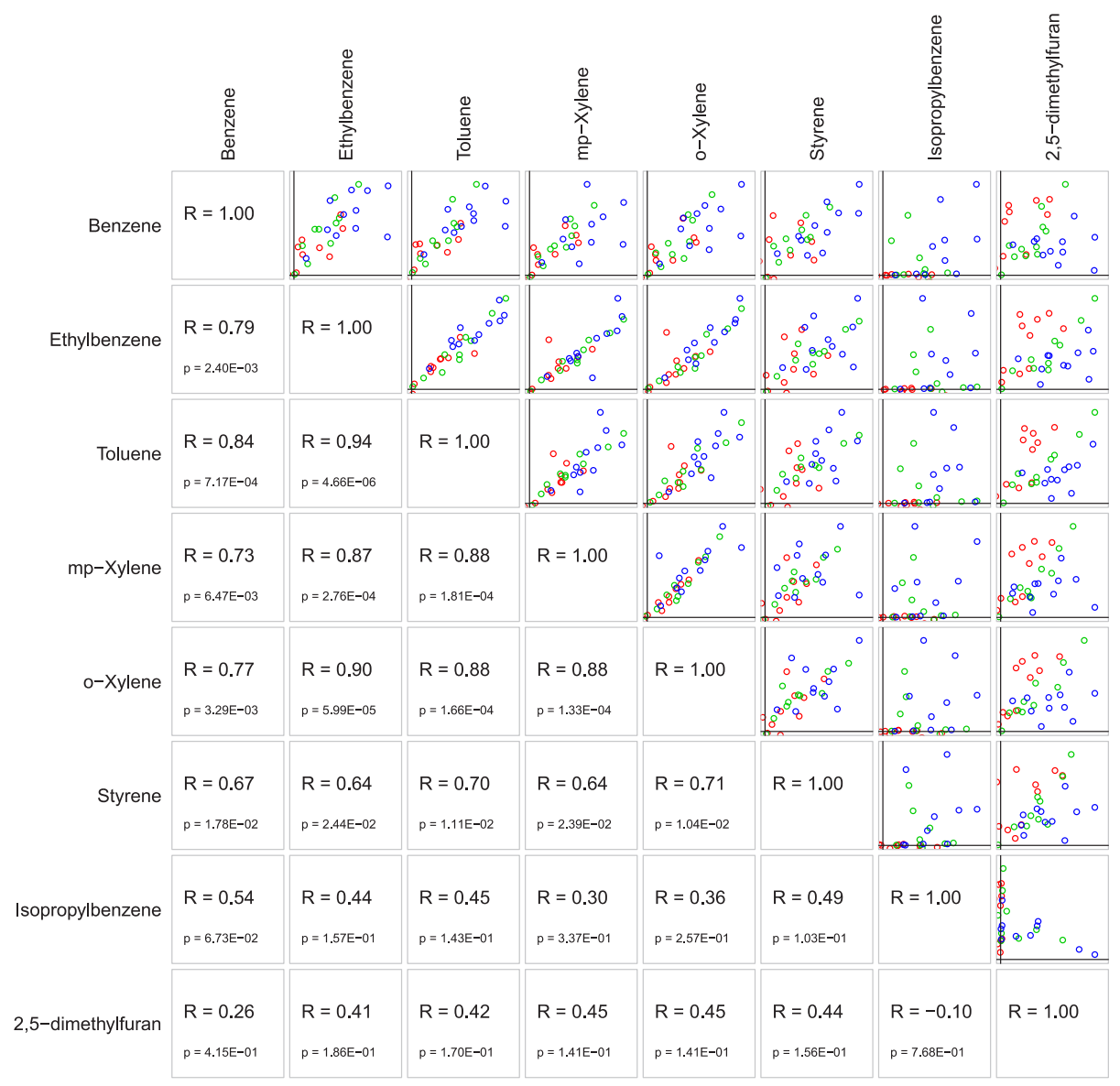

Figure S4: Spearman correlation and scatter plots for the percentage increase of VOCs in exhaled breath upon smoking. Every open circle in the scatter plots represents per participant the mean net increase in the specific VOC upon smoking. Correlation coefficients and complementary $p$-values are depicted. Significant when $p<0.01$. Red is Marlboro Red, Green is Marlboro Prime and Blue is Marlboro Prime taped. 
Supplementary information - Control and validation experiments

Table S3: calibration line data and calculated LOD and LOQ

\begin{tabular}{|c|c|c|c|c|c|c|c|c|}
\hline & Toluene & $\begin{array}{l}2,5 \text {-dimeth- } \\
\text { ylfuran }\end{array}$ & p-xylene & styrene & o-xylene & $\begin{array}{l}\text { isopropyl- } \\
\text { benzene }\end{array}$ & $\begin{array}{l}\text { ethyl- } \\
\text { benzene }\end{array}$ & benzene \\
\hline $\begin{array}{l}\text { Concentration } \\
(\mathrm{pg} / \mathrm{mL})\end{array}$ & area & area & area & area & area & area & area & area \\
\hline 0 & 2234 & 44 & 573 & 173 & 84 & 231 & 574 & 25 \\
\hline 0 & 2273 & 47 & 559 & 177 & 114 & 242 & 548 & 23 \\
\hline 31 & 2247 & 125 & 790 & 203 & 195 & 354 & 697 & 96 \\
\hline 31 & 2382 & 70 & 821 & 222 & 200 & 347 & 789 & 82 \\
\hline 31 & 2211 & 95 & 767 & 184 & 193 & 326 & 710 & 62 \\
\hline 31 & 2543 & 130 & 823 & 210 & 204 & 363 & 813 & 176 \\
\hline 62 & 2540 & 135 & 979 & 320 & 255 & 379 & 921 & 165 \\
\hline 62 & 2465 & 162 & 968 & 229 & 240 & 378 & 859 & 187 \\
\hline 62 & 2831 & 162 & 1054 & 280 & 270 & 444 & 1041 & 306 \\
\hline 62 & 2892 & 182 & 1126 & 263 & 273 & 398 & 957 & 210 \\
\hline 125 & 2959 & 303 & 1354 & 295 & 418 & 546 & 1295 & 689 \\
\hline 125 & 3142 & 353 & 1487 & 361 & 416 & 597 & 1409 & 574 \\
\hline 125 & 3124 & 343 & 1382 & 352 & 425 & 590 & 1407 & 532 \\
\hline 125 & 3318 & 359 & 1497 & 379 & 478 & 586 & 1445 & 659 \\
\hline 250 & 3668 & 668 & 2107 & 540 & 696 & 851 & 2120 & 1632 \\
\hline 250 & 3963 & 658 & 2224 & 535 & 726 & 911 & 2279 & 1761 \\
\hline 250 & 3666 & 541 & 2029 & 471 & 667 & 792 & 2022 & 1299 \\
\hline 250 & 4012 & 616 & 2222 & 488 & 716 & 797 & 2122 & 1705 \\
\hline 500 & 5174 & 1208 & 3614 & 800 & 1326 & 1345 & 3456 & 3948 \\
\hline 500 & 4745 & 1104 & 3480 & 884 & 1237 & 1336 & 3454 & 3455 \\
\hline 500 & 4985 & 1150 & 3571 & 884 & 1241 & 1357 & 3428 & 3883 \\
\hline 500 & 5071 & 1137 & 3623 & 894 & 1279 & 1417 & 3574 & 3677 \\
\hline 1000 & 7683 & 2155 & 6414 & 1518 & 2299 & 2455 & 6450 & 8827 \\
\hline 1000 & 8153 & 2350 & 6602 & 1674 & 2470 & 2614 & 6583 & 8920 \\
\hline 1000 & 7423 & 2229 & 6264 & 1502 & 2414 & 2383 & 6141 & 8487 \\
\hline 2000 & 13734 & 4615 & 13357 & 3073 & 4790 & 4891 & 12615 & 20851 \\
\hline 2000 & 14368 & 5049 & 13594 & 3120 & 4990 & 4798 & 12717 & 22780 \\
\hline $\begin{array}{l}\text { Intercept Stan- } \\
\text { dard Error }\end{array}$ & 60.68 & 22.46 & 49.23 & 10.81 & 13.27 & 12.92 & 29.36 & 187.62 \\
\hline Slope & 5.78 & 2.36 & 6.29 & 1.45 & 2.36 & 2.27 & 5.98 & 10.65 \\
\hline LOD & 34.7 & 31.5 & 25.8 & 24.6 & 18.6 & 18.8 & 16.2 & 58.1 \\
\hline LOQ & 105.0 & 95.3 & 78.3 & 74.6 & 56.2 & 56.9 & 49.1 & 176.2 \\
\hline
\end{tabular}


Previous studies report about VOC background levels in Vacutainers 1 and in the Vacutainer stoppers 2. To check for background levels of VOCs, we filled Vacutainers with water. The measurements showed no contamination and only some background noise was seen. The Vacutainers with water and spiked VOCs found the right amounts.

We checked the loss of VOCs during storage and transfer.

1. We tested that if the vacutainer were stored at $<5^{\circ} \mathrm{C}$ (fridge) and pipetting was performed on ice, it resulted in a negligible loss of VOCs.

2. A series of vacutainers filled with blood and spiked with VOCs were kept for 2 weeks. Every day, an analysis was done. If analysis was performed within 10 days, no loss of VOCs was found.

3. We tested the loss of VOCs because of open vacutainers and found that the loss of VOCs was negligible. We measured VOCs in spiked vacutainers after they were open for $15 \mathrm{sec}, 30 \mathrm{sec}, 45 \mathrm{sec}, 1 \mathrm{~min}, 2 \mathrm{~min}$ and $5 \mathrm{~min}$. The time blood is exposed to room air (open vacutainer, pipet blood to headspace vial, close vial) took $\sim 5 \mathrm{sec}$. An open vacutainer for $15 \mathrm{sec}$ resulted in a relative response of $92.7 \%$.

Table S4: Results open vacutainers

\begin{tabular}{lll}
\hline Time of open blood tube $(\mathrm{s})$ & Response & Relative response \\
\hline 0 & 0.350524 & 1 \\
15 & 0.324992 & 0.927163 \\
30 & 0.292712 & 0.83507 \\
45 & 0.220021 & 0.627692 \\
60 & 0.268008 & 0.764594 \\
120 & 0.234614 & 0.669325 \\
300 & 0.198531 & 0.566383 \\
600 & 0.176206 & 0.502694 \\
\hline
\end{tabular}


Table S5: VOCs, retention time, quantifier and qualifiers

\begin{tabular}{lllll}
\hline Compound & Retention time $(\mathrm{min})$ & Quantifier & Qualifier 1 & Qualifier 2 \\
\hline 2-butene & 1.39 & 41 & 56 & 39 \\
1,3-butadiene & 1.422 & 39 & 54 & 53 \\
2,3-dimethyl-1,3-butadiene & 5.72 & 67 & 82 & 41 \\
Benzene-D6 & 9.02 & 84 & 52 & 56 \\
Benzene & 9.15 & 78 & 77 & 51 \\
2-pentanone & 11.64 & 43 & 86 & 41 \\
2,5-dimethylfuran & 11.378 & 96 & 95 & 43 \\
Toluene & 15.03 & 91 & 92 & 65 \\
Ethylbenzeen-D10 & 19.29 & 98 & 116 & 114 \\
Ethylbenzene & 19.55 & 91 & 106 & 51 \\
m/p-xylene & 19.89 & 91 & 106 & 105 \\
o-xylene & 21.05 & 91 & 106 & 105 \\
Styrene & 21.08 & 104 & 103 & 78 \\
Isopropylbenzene / cumene & 22.17 & 105 & 120 & 77 \\
1,2,4-trimethylbenzene & 25.04 & 105 & 120 & 77 \\
Naphthalene-D8 & 32.65 & 136 & 108 & 137 \\
Naphthalene & 32.75 & 128 & 127 & 102 \\
\hline
\end{tabular}

Breath: in case of undetectable peaks (noise), the lowest AUC of the specific VOC was used and divided by 2 . This was only applicable to 2,5-dimethylfuran (AUC 12 / $2=6$ ), m,p-xylene (AUC 941.9 / 2 = 470.9) and isopropylbenzene (AUC 1.77 / 2 = 0.9).

\section{References}

1. Cardinali FL, McCraw JM, Ashley DL, Bonin M, Wooten J. Treatment of vacutainers for use in the analysis of volatile organic compounds in human blood at the low parts-pertrillion level. J Chromatogr Sci. 1995;33(10):557-560.

2. Chambers DM, McElprang DO, Waterhouse MG, Blount BC. An improved approach for accurate quantitation of benzene, toluene, ethylbenzene, xylene, and styrene in blood. Anal Chem. 2006;78(15):5375-5383. 




\section{Chapter 4. Characteristic human individual puffing profiles}

can generate more TNCO than

ISO and Health Canada regimes

on smoking machine when the same brand is smoked

Charlotte G.G.M. Pauwels, Agnes W. Boots, Wouter F. Visser, Jeroen L.A. Pennings, Reinskje Talhout, Frederik-Jan Van Schooten, Antoon Opperhuizen 


\begin{abstract}
Human smoking behavior influences exposure to smoke toxicants and is important for risk assessment. In a prospective observational study, the smoking behavior of Marlboro smokers was measured for $36 \mathrm{~h}$. Puff volume, duration, frequency, flow and inter-puff interval were recorded with the portable CReSSmicro ${ }^{\mathrm{TM}}$ device, as has often been done by other scientists. However, the use of the CReSSmicro ${ }^{T M}$ device may lead to some registration pitfalls since the method of insertion of the cigarette may influence the data collection. Participants demonstrated consistent individual characteristic puffing behavior over the course of the day, enabling the creation of a personalized puffing profile. These puffing profiles were subsequently used as settings for smoking machine experiments and tar, nicotine and carbon monoxide (TNCO) emissions were generated. The application of human puffing profiles led to TNCO exposures more in the range of Health Canada Intense ( $\mathrm{HCl}$ - $\mathrm{TNCO}$ emissions than for those of the International Standardization Organization (ISO). Compared to the ISO regime, which applies a low puff volume relative to human smokers, the generation of TNCO may be at least two times higher than when human puffing profiles were applied on the smoking machine. Human smokers showed a higher puffing intensity than $\mathrm{HCl}$ and ISO because of higher puffing frequency, which resulted in more puffs per cigarette, than both $\mathrm{HCl}$ and ISO.
\end{abstract}




\section{Introduction}

Around 6.5 million deaths are annually attributable to tobacco smoking worldwide and occur after suffering from tobacco related-diseases ${ }^{1}$. The relationship between tobacco smoking and tobacco related-diseases depends on the quantity and composition of the inhaled cigarette smoke. The adverse health impact of exposure to smoke toxicants is determined by the number of smoked cigarettes, smoking years, cigarette brands, cigarette emissions and smoking topography ${ }^{2-5}$. How these determinants influence the relationship between smoking and health effects and if they can be used to assess individual health risks require further elucidation ${ }^{6}$. For example, carcinogen intake from mainstream smoke was shown to vary by fourfold between smokers due to inter-individual differences in smoking behavior ${ }^{7}$. In general, however, literature about personal smoking behavior and actual exposure of the lungs to smoke toxicants is scarce ${ }^{6}$. The importance of these individual differences is underlined by the finding of Song et al. who demonstrated a relationship between lung adenocarcinoma and higher smoke volumes in combination with deeper inhalation of low-tar, nicotine and carbon monoxide (TNCO) cigarette smoke ${ }^{8}$. Two consecutive processes determine the individual exposure of a smoker: the generation and emission of tobacco smoke during puffing, followed by inhalation of this emission by the smoker ${ }^{3}$. These two processes interplay and determine the intake of emitted smoke into the mouth cavity and lungs of the smoker. Interestingly, experienced smokers adjust their puffing topography, consciously or not, to modulate their nicotine, flavor and carbon monoxide (CO) exposure ?

The puffing behavior relates to how a smoker smokes a cigarette and is characterized by parameters such as puff volume, puff duration, inter-puff interval and the number of puffs. Together, these puff parameters influence the airflow through the burning rod, which on its turn determines the combustion and pyrolysis rate of the tobacco and the physico-chemical processes inside the cigarette. For example, a high airflow induces higher temperatures and increases mass burn rate of the tobacco (mg/puff) ${ }^{10,11}$. Additionally, an increased puffing intensity (i.e., the product of puff volume and puff frequency) leads to more rapid burning of tobacco and less increased tar, nicotine and CO yields ${ }^{12-14}$. However, TNCO yields were shown to correlate linearly with total puff volume (i.e., the product of puff volume and puff number) ${ }^{14}$. Moreover, several studies using machine smoking have shown that varying puffing profiles lead to differences in volatile organic compounds (VOCs) ${ }^{15}$, polycyclic aromatic compounds (PAHs) ${ }^{16}$ and aldehydes ${ }^{17}$ in cigarette emissions. For machine-smoked cigarettes, emissions of TNCO and other toxicants are at least 
two times higher when a Health Canada Intense $(\mathrm{HCl})$ regime ${ }^{18}$ was applied than when International Standardization Organization (ISO) 3308 regime ${ }^{19}$ settings were used ${ }^{20}$. Among the different puff parameters, puff volume showed the greatest effect on carbonyl delivery ${ }^{4}$. Smoking behavior has been widely studied and was summarized for the last time in a report in $2000^{21}$. Since 2000 , Chen et al. published

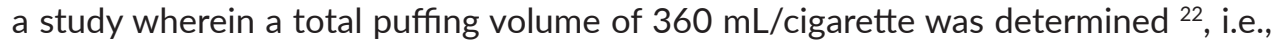
the lowest value we could identify. This is almost four times lower than the 1289 $\mathrm{mL} /$ cigarette calculated with the data from Ross et al. and Farris et al. ${ }^{23,24}$, i.e., the highest total puffing volume reported. The variation in puffing topography data published thus far may be explained by differences between cigarette brands as well as by inter-individual and intra-individual differences. Inter-individual differences in puffing topography are influenced by gender, ethnic background and type of cigarette. Indeed, it is known that women take smaller puffs of shorter duration but more puffs per cigarette than men ${ }^{7}$, Korean-Americans, for instance, smoke with higher average puff flows and shorter inter-puff intervals than White-Americans ${ }^{25}$, and that menthol and low-TNCO cigarettes are smoked with a higher puff volume and longer puff duration than regular cigarettes ${ }^{26,27}$. Furthermore, intra-individual differences are observed and smokers vary their smoking depending on the setting ${ }^{28}$, cues ${ }^{29}$, nicotine dependence, mood and emotional status ${ }^{30}$. In addition, there is variation throughout the course of the day as, for instance, the first cigarette in the morning is puffed less intensely ${ }^{31}$, whereas smokers leaving work-stations to smoke outside buildings smoke their cigarettes nearly $19 \%$ more intensely than cigarettes smoked in social settings ${ }^{32}$. The research setting also affects smoking behavior, as smokers have more intense smoking behavior during lab visits than in a private setting ${ }^{28}$. To minimize the influence of brand or experimental setting, we have performed a human volunteer study in a real world setting with 25- to 34-yearold males to determine their puffing topography, when smoking only one brand of cigarettes ad libitum. Based on the observed puffing profiles of individuals, these personal smoking profiles were mimicked on a smoking machine and mainstream smoke TNCO levels were analyzed. With the results of the study, we aim to better understand the relevance of the machine smoking emission data (generated with ISO and Health Canada regimes) in relation to exposure of human smokers.

During analysis of the individual smoking topography data, we noticed unexpected outcomes in ourstudy. Compared to the literature, a large number of puffs in combination with a high puffing volume were registered. Puffing topography was, like in many other studies, recorded with the CReSSmicro ${ }^{\mathrm{TM}}$ device. This device is described as a reliable and accurate instrument to record human smoking behavior ${ }^{33-35}$. However, we know from 
the literature that there is inconsistency in data treatment ${ }^{36}$. Moreover; malfunctions or anomalous data have been described; for example, high volumes (up to $5 \mathrm{~L}$ ) ${ }^{37}$ and a wide range of puffs (7-43 puffs) ${ }^{38}$. Furthermore, signal dropouts from unknown origin were found in the raw data of a study wherein the device was considered for measuring vaping behavior ${ }^{39}$. To investigate the origin of the unexpected data, we evaluated the CReSSmicro ${ }^{\mathrm{TM}}$ device in its performance to record human smoking behavior.

\section{Materials and methods}

\section{Literature search}

The last review listing smoking behavior originates from 1999 9. Therefore, an extensive literature search was performed for articles reporting puffing topography data that where published since 2000. The sources were the electronic databases PubMed, SCOPUS, EMBASE and WHO report series. Search terms included smoking topography, puffing topography, smoking behavior, puffing parameters, and smoker(s) or smoking in combination with human study. Reference lists were reviewed for additional references. Studies were included if puffing parameters were recorded by a desk or portable smoking topography device. Only puffing topography data of (mentally) healthy participants were included, and also when this was a control group.

\section{Recruitment of participants}

Five male participants were recruited by national social media. Only Caucasian/ Europe-originated male smokers accustomed to using Marlboro red/regular cigarettes were included. Participants had to be used to smoking 13-25 cigarettes a day for at least 3 years. Participants were excluded if suffering from respiratory diseases or chronic illnesses, daily medication use, and experience of adverse effects due to smoking. The study was approved, according to the Declaration of Helsinki, by the accredited medical ethical committee (METC 153057) in Maastricht (The Netherlands) and registered online at ToetsingOnline (NL55676.068) (i.e., Dutch internet portal for the submission, review, registration and publication of medical research involving human subjects). Informed consent was signed before the experiment started and participation was rewarded with $€ 100,-$.

\section{Study protocol}

The participants stayed in an apartment for $36 \mathrm{~h}$ to create a homelike atmosphere, where they had breakfast, lunch, dinner, snacks and drinks ad libitum at their disposal. Participants arrived at 8 p.m. to sign informed consent and receive CReSSmicro ${ }^{\mathrm{TM}}$ 
usage instructions. Hereafter, participants could settle in the apartment and were allowed to smoke freely. The next morning, lighting the first cigarette of the day was noted as the start of the experimental day $(t=0)$. During the day, participants could smoke Marlboro cigarettes ad libitum using the CReSSmicro ${ }^{\mathrm{TM}}$. The experiment ended after smoking the last cigarette of the evening before going to sleep. The next morning, participants could leave.

\section{Cigarette brand}

The cigarette type used in the study was Marlboro red/regular king-size, since Marlboro is the most popular cigarette brand in the United States ${ }^{40}$ and has the largest market share in the Netherlands, varying between $32 \%$ and 39\% during the 2012-2017 period ${ }^{41}$. The researchers bought all cigarettes at a tobacconist in The Netherlands to pursue matching batch numbers. Cigarettes in the manufacturer's unopened packaging were stored until their distribution to participants. Tar, nicotine and CO levels were 10, 0.8 and $10 \mathrm{mg} /$ cigarette, respectively, as measured by the ISO method according to the package.

\section{$\mathrm{CReSSmicro}^{\mathrm{TM}}$ analysis}

Time of smoking was noted to give an overview of the natural smoking moments during the day. Puff parameters of all cigarettes smoked during the experimental day were monitored and recorded with the handheld, portable version of the clinical research support system (CReSSmicro ${ }^{\mathrm{TM}}$ v2.0.0; Plowshare Technologies, Baltimore, MD, USA) ${ }^{34,35,42}$. The device has a sterilized flow meter mouthpiece connected to a pressure transducer, which converts pressure into a digital signal that is sampled at $50 \mathrm{~Hz}$. CReSSmicro ${ }^{\mathrm{TM}}$ computer software transforms the signal to a flow rate $(\mathrm{mL} / \mathrm{s})$ to compute puffing topography data. The three CReSSmicro ${ }^{\mathrm{TM}}$ devices used were calibrated according to procedures described in the manufacturer's user manual. The calibration was verified at the end of every experimental day. The software of the $\mathrm{CReSSmicro}^{\mathrm{TM}}$, designed by Borgwaldt, uses the $50 \mathrm{~Hz}$ raw data to show a summary of puff profiles in the viewer of the program. A puff cleanup procedure (using the CReSS CleanUp program) was followed to make correct machine-generated artefacts in the data. In the case of inter-puff interval (IPI) $<300 \mathrm{msec}$, the volume and duration were combined with the previous puff and remaining puffs with duration $<100 \mathrm{msec}$ or volume $<5 \mathrm{~mL}$ were deleted as they are most likely noise from the machine. The puff parameters according to the software were presented as descriptive statistics (frequencies, means and standard deviations) for puff duration (sec), puff volume $(\mathrm{mL})$, inter-puff interval (sec), flow per puff ( $\mathrm{mL} / \mathrm{sec})$ and the number of puffs taken per cigarette per participant. The summarized data were used to calculate a personal 
puffing profile by linear regression of puff parameters versus the puff number, using a model with an intercept and slope for the overall data, as well as a first puff-specific parameter that allows for longer first puffs when lighting the cigarette. The raw data of the CReSSmicro ${ }^{T M}$ device recordings were manually checked for anomalies such as flow rate dropouts or drops to zero (i.e., the record signal dropped to $0 \mathrm{~mL} / \mathrm{sec}$ in the middle of a puff, and then went back up to the pre-dropout flow rate).

\section{Machine smoking and chemical analysis}

The calculated personal puffing profiles were mimicked on the smoking machine. Mainstream smoke of Marlboro cigarettes was generated with a 10-port linear smoking machine (SM410RH, Cerulean, United Kingdom) with Human Puff Profile Software and a rounded sinusoidal waveform in $100 \mathrm{~Hz}$ steps. Cigarettes were smoked according to the personal puff profiles to determine tar and nicotine (in fivefold) and CO (in twofold) as described in detail in ISO 4387:2000, ISO 8454:2007, and ISO 10315:2014 21,43,44.

\section{CReSSmicro $^{\mathrm{TM}}$ device evaluation experiment}

An observatory experiment was performed to assess the impact of inserting a cigarette in the CReSSmicro ${ }^{T M}$ device on flowrate recording. Based on the user manual, the insertion was guided with a beep to inform the smoker that the device is standing by and the smoking process will be recorded. We tested three methods of insertion; slow and loose insertion, normal insertion, and tight insertion whereby the cigarette is inserted as forcefully as possible without damaging it. The cigarettes were machine smoked with the CReSSmicro ${ }^{\mathrm{TM}}$ device positioned in the smoking machine, and in the adjacent port a cigarette was directly inserted into the cigarette holder of the smoking machine. The $\mathrm{HCl}$ regime ${ }^{18}$ was set, which is a regularly used machine smoking regime (puff volume $55 \mathrm{~mL}$, puff duration $2 \mathrm{sec}$, inter puff interval $30 \mathrm{sec}$ ). A second smoking protocol derived from averaging puffing parameters in the literature included a puff volume of $65 \mathrm{~mL}$, puff duration $2 \mathrm{sec}$ and inter-puff interval $18 \mathrm{sec}$. As an accuracy check, the recorded puff parameters by the CReSSmicro ${ }^{\mathrm{TM}}$ device were compared with the set smoking machine protocol.

\section{Results}

The literature search resulted in 73 articles and reports specifying at least one or more puffing parameters. Table S1 in Supplementary Materials lists per article or report, the participants' gender, age, Fagerström index, cigarettes per day, cigarette 
type and recording device, if reported. The listed puffing parameters were puff volume, duration, flow, interval, count and total volume per cigarette and per day. If possible, missing puffing parameters were calculated.

For the human study, the selected five male participants were 26 to 29 years old (mean 27.6 years). Based on self-assessment, they started smoking on average at the age of 16 years (10-20 years old) and had smoked on average 18 cigarettes per day (15-22 cig/day) since the age of 19 years (12-23 years old) (self-reported).

\section{Smoking timepoints}

Smokers could smoke ad libitum during the experimental day, which resulted in an average of 17 cigarettes per day (10-21 cig/day) (Figure 1). Time between two cigarettes differed between 20 min and $3 \mathrm{~h}$. For all participants, the second cigarette of the day was smoked within an hour after the first cigarette and the final cigarette of the day within an hour before going to bed.

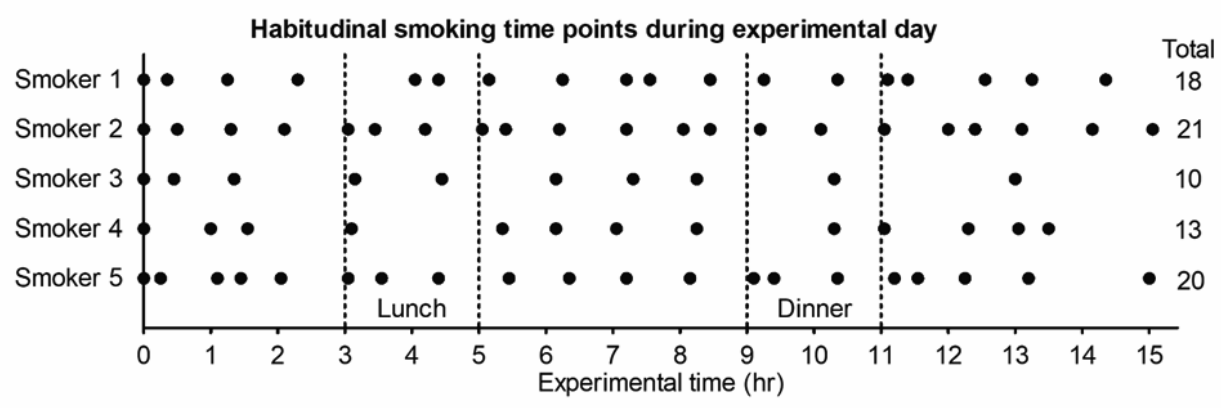

Figure 1. Smoking time points and total of cigarettes smoked by participants during the experimental day, describing their daily smoking behavior. Lighting the first cigarette of the day was defined as $t=0$.

\section{Personal puffing profile}

The smokers included in the study expressed no differences in enjoyment or satisfaction between smoking with or without the CReSSmicro ${ }^{\mathrm{TM}}$ device. The average puff parameters per participant, according to the puff profile software of the CReSSmicro ${ }^{\mathrm{TM}}$ device, are depicted in Table 1 . The number of cigarettes smoked during the day and the puff parameters (puff count, puff flow, puff duration, and inter-puff interval) per cigarette varied considerably between smokers. The average puff count ranged between 11 and 26 puffs. This is at least two puffs more than we previously 
reported for machine smoking a Marlboro cigarette with smoking regimes of ISO and $\mathrm{HCl}^{17}$. Smoker 1 had the highest puff count (26 puffs) and a high puff volume $(80 \mathrm{~mL})$, which is much higher than machine smoking under $\mathrm{ISO}$ or $\mathrm{HCl}$ regimes. Smoker 3 also had a high number of puffs (17 puffs) and the highest puff volume (93 $\mathrm{mL}$ ). Smokers 1 and 3 had a short smoldering period between two puffs (11 and 10 $\mathrm{sec})$, attributing to more puffs in total and the highest total puffing volumes. These highest total puffing volumes ( 2127 and $1582 \mathrm{~mL}$ ) are at least five times the machine smoking ISO $(280 \mathrm{~mL})$ and three times the $\mathrm{HCl}(495 \mathrm{~mL})$ total cigarette volume.

Table 1. The puff parameters per participant and smoking regime.

\begin{tabular}{|c|c|c|c|c|c|c|c|c|}
\hline $\begin{array}{l}\text { Participant } \\
\text { or } \\
\text { Smoking } \\
\text { Regime }\end{array}$ & $\begin{array}{l}\text { Ciga- } \\
\text { rette } \\
\text { Count }\end{array}$ & $\begin{array}{l}\text { Puffs per } \\
\text { Cigarette }\end{array}$ & $\begin{array}{l}\text { Puff } \\
\text { Volume } \\
\text { (mL) }\end{array}$ & $\begin{array}{l}\text { Puff } \\
\text { Flow } \\
\text { (mL/sec) }\end{array}$ & $\begin{array}{l}\text { Puff } \\
\text { Duration } \\
\text { (sec) }\end{array}$ & $\begin{array}{l}\text { Inter-Puff } \\
\text { Interval } \\
\text { (sec) }\end{array}$ & $\begin{array}{l}\text { Total Puff- } \\
\text { ing Vol- } \\
\text { ume per } \\
\text { Cigarette } \\
\text { (mL) }\end{array}$ & $\begin{array}{l}\text { Total } \\
\text { Cigarette } \\
\text { Volume } \\
\text { per Day } \\
\text { (L) \& }\end{array}$ \\
\hline & \# & Mean (SD) & $\begin{array}{l}\text { Mean } \\
\text { (SD) }\end{array}$ & $\begin{array}{l}\text { Mean } \\
\text { (SD) }\end{array}$ & Mean (SD) & Mean (SD) & Mean (SD) & \\
\hline Smoker 1 & 18 & $26(8.9)$ & $\begin{array}{l}80 \\
(11.4)\end{array}$ & $43(7.7)$ & $1.9(0.2)$ & $11(2.4)$ & $\begin{array}{l}2127 \\
(904)\end{array}$ & 38.3 \\
\hline Smoker 2 & 21 & $13(1.3)$ & $60(5.7)$ & $48(3.0)$ & $1.4(0.1)$ & $21(5.8)$ & 778 (123) & 16.3 \\
\hline Smoker 3 & 10 & $17(2.3)$ & $\begin{array}{l}93 \\
(13.9)\end{array}$ & $57(7.3)$ & $1.6(0.1)$ & $10(4.6)$ & $\begin{array}{l}1582 \\
(296)\end{array}$ & 15.8 \\
\hline Smoker 4 & 13 & $11(2.3)$ & $44(3.8)$ & $51(4.0)$ & $0.9(0.1)$ & $26(8.1)$ & 495 (125) & 6.4 \\
\hline Smoker 5 & 20 & $11(1.0)$ & $67(4.1)$ & $27(2.3)$ & $2.6(0.2)$ & $16(3.1)$ & 740 (79) & 14.8 \\
\hline ISO * & & 8 & 35 & 17.5 & 2 & 60 & $280^{\$}$ & \\
\hline $\mathrm{HCl}^{*}$ & & 9 & 55 & 27.5 & 2 & 30 & $495^{\$}$ & \\
\hline
\end{tabular}

${ }^{*}$ Data originate from Pauwels et al. ${ }^{17}$. (Marlboro red according to ISO ${ }^{19}$ and $\mathrm{HCl}{ }^{18}$ ) \# Cigarettes smoked during experiment. \$ Puff count multiplied with puff volume. \& Total cigarette volume multiplied with cigarette count. The italics represent calculated numbers.

The average puff volume $(44 \mathrm{~mL})$ of smoker 4 was in the range of the machine smoking regimes ( 35 and $55 \mathrm{~mL}$ ). He had a short puff duration of $0.9 \mathrm{sec}$, which was half of the puff duration in the smoking regimes $(2 \mathrm{sec})$. The longest puff duration was measured in smoker $5(2.6 \mathrm{sec})$. As the puff volume $(67 \mathrm{~mL})$ and puff duration $(2.6$ sec) were higher than in $\mathrm{HCl}(55 \mathrm{~mL}$ and $2 \mathrm{sec}$ ), it still led to a comparable puff flow as $\mathrm{HCl}(27 \mathrm{~mL} / \mathrm{sec})$. The average puff flow of all smokers was at least twice the puff flow of the ISO regime, except for smoker 5 . A substantial different puffing profile can still lead to a total puffing volume per day in the same range, as is seen for smokers 2,3 and 5, with, respectively, a total puffing volume per day of $16.3,15.8$ and $14.8 \mathrm{~L}$ for all the cigarettes. However, as was shown by smokers 1 and 4, respectively, more than two times higher and lower total puffing volumes per day can also be observed 


\section{Puff profile over the course of the cigarette}

The puff-by-puff pattern over the course of a cigarette smoked, averaged for all cigarettes used during the day, is shown in Figure 2. Participants smoked all cigarettes according to a characteristic puff profile that displays large differences between individuals. Smoker 1 typically inhaled almost the same volume each consecutive puff of a cigarette with limited variation between cigarettes (Figure 2, panel a). His puff flow increased slightly with consecutive puffs (Figure 2, panel b), whereas the puff duration shortened (Figure 2, panel c). Only the first puff of each cigarette of this smoker was longer than the other puffs with lower puff flow. Except for smoker 5, the other participants also increased the puff flow after the first puff. All participants, except for smoker 3 , shortened the puff duration with consecutive puffs. Smoker 3 doubled his puff volume during the course of the cigarette smoking with a stable duration of subsequent puffs and increasing puff flow during smoking cigarettes. However, this smoker showed significant differences in the way he smoked the various cigarettes, which resulted in large standard deviation of puff volumes. During the smoking process, the inter-puff interval or smoldering period was almost stable for smokers 1, 2 and 5 and slightly increased for smokers 3 and 4. However, all smokers had a deviating longer first to second puff interval. In summary, individual participants smoked all cigarettes according to personal puffing topography, allowing the generation of a characteristic profile using linear regression of the puff parameters (Figure 2, dashed line). Four randomly chosen cigarettes per participant were sufficient to calculate this personal puffing profile per participant, as adding more or different cigarettes to this calculation did not significantly modify the created profiles.

\section{Machine Smoking Puffing Profile}

The puffing parameters of the personal puffing profiles were used as input smoking regime settings (human puffing regime) for the smoking machine. The smoking machine successfully finished the human puffing regime of smokers 2,4 and 5 . The total puffing volume with machine smoking was within $10 \%$ range of the measured total puffing volumes with the CReSSmicro ${ }^{\mathrm{TM}}$ device in the human study for smokers 2, 4 and 5. The human puffing regimes of smokers 1 and 3 consisted of an excessive number of puffs that was not possible to complete with the smoking machine as the tobacco was already completely burned before the total smoking protocol could be finished. This also explains why the total cigarette volume in machine smoking is lower than the total puffing volume measured with the CReSSmicro ${ }^{\mathrm{TM}}$ device for these smokers. The different human puffing regimes led to a range of TNCO yields in the smoke produced by the smoking machine (Table 2). Only the human puffing regime of smoker 4 showed TNCO yields within the range of $\mathrm{HCl}$ and ISO. When 
human puffing regimes of the other smokers were applied on the smoking machine TNCO yields were almost twice the ISO TNCO yields. For most smokers, TNCO yields were even higher than yields produced with the $\mathrm{HCl}$ regime. The tar and nicotine yields of the human puffing regimes of smokers 1 and 3 were approximately $70 \%$ more than the yield measured with $\mathrm{HCl}$. $\mathrm{CO}$ yields were in the range between ISO and $\mathrm{HCl}$, with an exception for the human puffing regime of smoker 1 , which produced much higher yields.
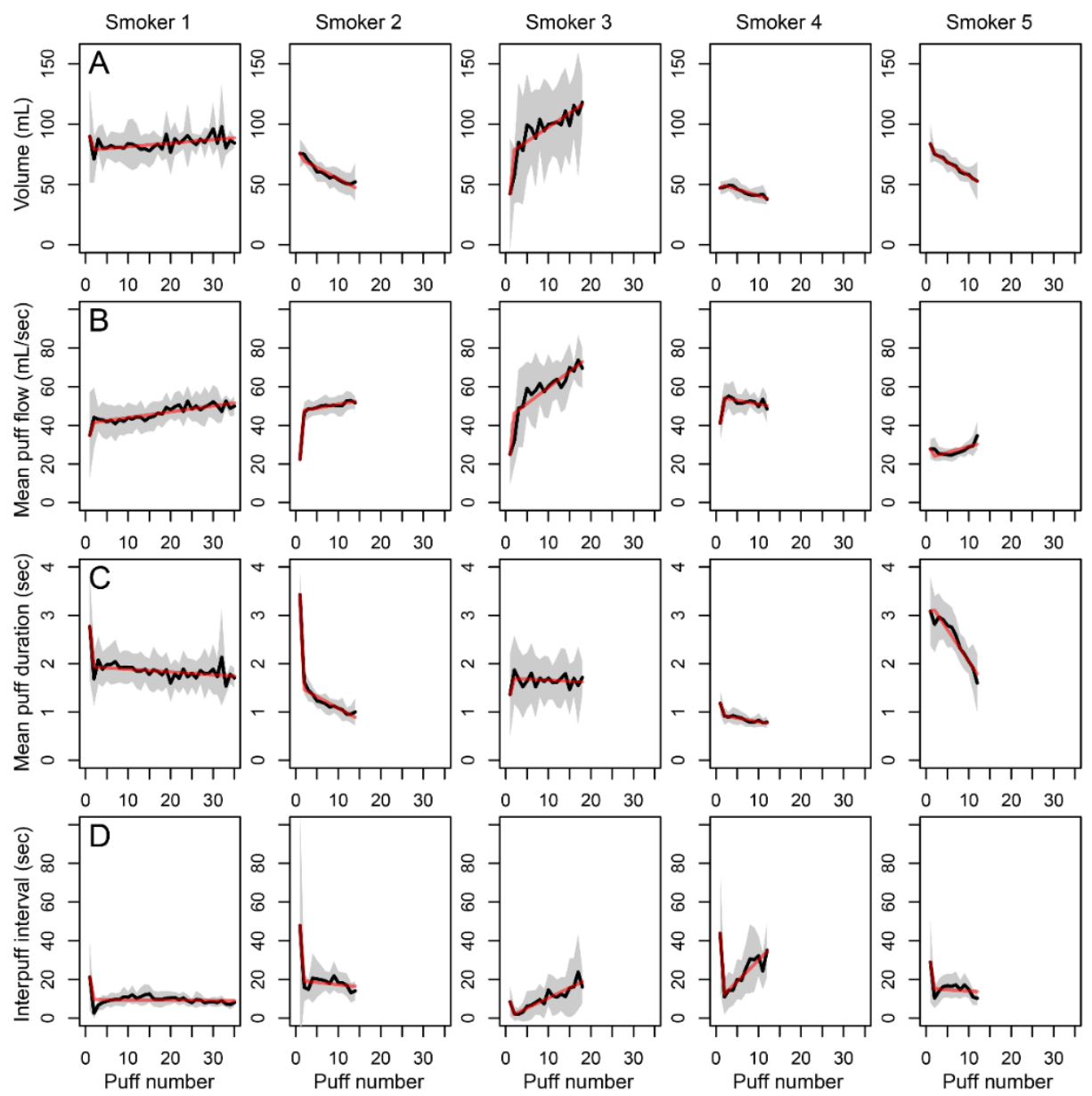

Figure 2. Individual puffing profile consisting of volume $(\mathrm{mL})$, average flow $(\mathrm{mL} / \mathrm{sec})$, duration (sec) and IPI (sec) of subsequent puffs (puff number) per smoker. Shown is the mean of all cigarettes smoked during the study day (black line) with SD (grey area), whereby the dashed line is the model fit. 
Table 2. Puff count per human puffing regime during machine smoking with associated total puffing volume, yield of TNCO (mean (SD)).

\begin{tabular}{llllll}
\hline $\begin{array}{l}\text { Participant or } \\
\text { Smoking Regime }\end{array}$ & $\begin{array}{l}\text { Puffs Smoking } \\
\text { Machine (SD) }\end{array}$ & $\begin{array}{l}\text { Total Puffing } \\
\text { Volume mL/cig } \\
\text { (SD) }\end{array}$ & $\begin{array}{l}\text { Tar mg/cig } \\
\text { (SD) }\end{array}$ & $\begin{array}{l}\text { Nicotine mg/cig } \\
\text { (SD) }\end{array}$ & CO mg/cig (SD) \\
\hline Smoker 1 & $12(1.4)$ & $1005(116)$ & $58(9.6)$ & $3.4(0.4)$ & $49(0.8)$ \\
Smoker 2 & $12(0.9)$ & $710(45)$ & $32(1.1)$ & $2.1(0.1)$ & $18(0.2)$ \\
Smoker 3 & $14(1.0)$ & $1200(108)$ & $59(8.1)$ & $3.3(0.3)$ & $27(3.3)$ \\
Smoker 4 & $12(0)$ & $530(0)$ & $21(1.4)$ & $1.5(0.1)$ & $16\left({ }^{\S}\right)$ \\
Smoker 5 & $11(0.7)$ & $754(38)$ & $38(1.5)$ & $2.4(0.1)$ & $20(0.1)$ \\
ISO $^{*}$ & 8 & $280^{\$}$ & 10.37 & 0.8 & 8.51 \\
$\mathrm{HCl}^{*}$ & 9 & $495^{\$}$ & 34.04 & 1.97 & 26.27 \\
\hline
\end{tabular}

${ }^{*}$ Data originate from Pauwels et al. ${ }^{17}$. (Marlboro red according to ISO and $\mathrm{HCI}$ ). \& failed duplicate. $\$$ calculated by puff count multiplied with puff volume.

\section{Evaluation of CReSSmicro ${ }^{\mathrm{TM}}$ device}

Marlboro cigarettes were machine smoked with the CReSSmicro ${ }^{\mathrm{TM}}$ device according to two different regime settings. The $\mathrm{HCl}$ regime settings were used, and a more intense setting with a higher puff volume $(65 \mathrm{~mL})$ and a shorter inter-puff interval (18 sec). The latter settings were close to the mean values of the five participants as listed in Table 1.

The two smoking machine regimes were combined with the three methods of insertion of the cigarette into the CReSSmicro ${ }^{\mathrm{TM}}$ device (Table 3). The CReSSmicro ${ }^{\mathrm{TM}}$ recorded the puff duration, which was similar to the smoking machine setting in all cases. However, the puff volume as well as the inter-puff interval was not similar to the machine settings in most cases. The puff volume registered by the CReSSmicro ${ }^{\mathrm{TM}}$ was higher in all cases, whereas the inter-puff interval was shorter. For example, a $\sim 10 \%$ higher volume $(59 \mathrm{~mL}$ ) was measured with $55 \mathrm{~mL}$ puff volume after normal insertion with an inter-puff interval registered of $27 \mathrm{sec}$ instead of $30 \mathrm{sec}$.

The smoking machine generated 10-12 puffs to finish the cigarette directly inserted into the machine under smoking regimes (Table 3). For the cigarettes 'tightly' inserted into the CReSSmicro ${ }^{\mathrm{TM}}$ device and smoked on the smoking machine, a comparable number of puffs was observed for the two smoking regimes. For 'normal' or 'loosely' inserted cigarettes in the CReSSmicro ${ }^{\mathrm{TM}}$ device, however, up to 16 extra puffs were required to finish the cigarette on the smoking machine. 
Higher puff count, higher puff volumes and shortened inter-puff intervals resulted in a higher total smoke volume for all experimental conditions when the CReSSmicro ${ }^{\mathrm{TM}}$ device was combined with the smoking machine.

Table 3. Puff parameters (mean) recorded by the CReSSmicro ${ }^{\mathrm{TM}}$ device while smoking via two regimes on the smoking machine. Cigarette insertion into the device in a 'normal', 'loose' and 'tight' way.

\begin{tabular}{|c|c|c|c|c|c|c|c|}
\hline \multirow[t]{3}{*}{ Puff Parameter } & \multirow{3}{*}{$\begin{array}{l}\text { Smoking Machine or } \\
\text { CReSSmicro }^{T M} \text { Device }\end{array}$} & \multicolumn{6}{|c|}{ Way of Cigarette Insertion in CReSSmicro ${ }^{T M}$ Device } \\
\hline & & \multicolumn{2}{|c|}{ Normal } & \multicolumn{2}{|c|}{ Loose } & \multicolumn{2}{|c|}{ Tight } \\
\hline & & $\begin{array}{l}\text { Regime } \\
1\end{array}$ & $\begin{array}{l}\text { Regime } \\
2\end{array}$ & $\begin{array}{l}\text { Regime } \\
1\end{array}$ & $\begin{array}{l}\text { Regime } \\
2\end{array}$ & $\begin{array}{l}\text { Regime } \\
1\end{array}$ & $\begin{array}{l}\text { Regime } \\
2\end{array}$ \\
\hline \multirow[t]{2}{*}{ Puff count } & Smoking machine & 11 & 11 & 10 & 10 & 11 & 12 \\
\hline & $\mathrm{CReSSmicro}^{\mathrm{TM}}$ device & 18 & 20 & 18 & 26 & 11 & 13 \\
\hline \multirow[t]{2}{*}{ Puff volume (ml) } & Smoking machine & 55 & 65 & 55 & 65 & 55 & 65 \\
\hline & $\mathrm{CReSSmicro}^{\mathrm{TM}}$ device & 59 & 73 & 60 & 74 & 65 & 76 \\
\hline \multirow{2}{*}{ Puff duration (sec) } & Smoking machine & 2 & 2 & 2 & 2 & 2 & 2 \\
\hline & $\mathrm{CReSSmicro}^{\mathrm{TM}}$ device & 2 & 2 & 2 & 2 & 2 & 2 \\
\hline \multirow{2}{*}{$\begin{array}{l}\text { Inter-puff interval } \\
\text { (sec) }\end{array}$} & Smoking machine & 30 & 18 & 30 & 18 & 30 & 18 \\
\hline & $\mathrm{CReSSmicro}^{\mathrm{TM}}$ device & 27 & 16 & 29 & 16 & 27 & 16 \\
\hline \multirow{2}{*}{$\begin{array}{l}\text { Total puffing } \\
\text { volume (ml) }\end{array}$} & Smoking machine & 990 & 1300 & 1008 & 1690 & 587 & 845 \\
\hline & $\mathrm{CReSSmicro}^{\mathrm{TM}}$ device & 1053 & 1453 & 1106 & 1932 & 692 & 983 \\
\hline Flow-dropouts & $\mathrm{CReSSmicro}^{\mathrm{TM}}$ device & 5 & 6 & 8 & 6 & 0 & 1 \\
\hline
\end{tabular}

Regime 1: $\mathrm{HCl}$ settings (puff volume $55 \mathrm{~mL}$, twice per minute for $2 \mathrm{sec}$ ). Regime 2: puff volume $65 \mathrm{~mL}, 18 \mathrm{sec}$ inter-puff interval and $2 \mathrm{sec}$ duration.
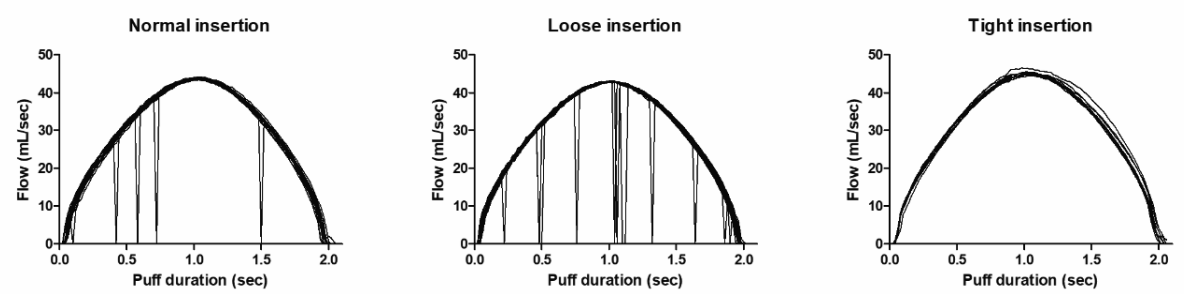

Figure 3. Example of flow-dropouts in raw data collected with the CReSSmicro ${ }^{\mathrm{TM}}$ device, when recording the smoking $(\mathrm{HCl}$ regime) of an entire cigarette after different ways of inserting the cigarette. Every line represents one puff. 


\section{Discussion}

\section{Characterizing human smoking behavior over the course of the day}

Consumer exposure to smoke toxicants varies considerably due to differences in the emissions produced by different kinds of cigarette as well as differences in human smoking behavior. We measured puffing topography with the $\mathrm{CReSSmicro}^{\mathrm{TM}}$ device in smoking volunteers in a real-world situation. The puffing parameters of the participants were used as input for smoking machine experiments to determine TNCO emissions.

Although some participants had a marginal variation in a specific puff parameter (e.g., participant 1 puff volume), overall, the puffing profiles of each cigarette smoked by the participants were not substantially different over the course of a day. This indicates that self-reported preferred cigarettes were not subject to change in puff parameters. This is in line with Hammond et al., who found a high degree of stability in puffing profile within subjects over time in three 1 -week trials ${ }^{45}$. Interestingly, a study of Grainge et al. found a slightly lower intensity of smoking of the first cigarette of the day compared to other cigarettes during the day ${ }^{31}$.

Few studies have focused on puff parameters during the course of smoking a cigarette, i.e., puff-by-puff ${ }^{46-48}$. We found a similar pattern as two other studies in adolescents, namely a decreased puff volume and duration, coupled with an increased puff flow and inter-puff interval ${ }^{49,50}$. An increased puff flow over the course of the cigarette can be explained by the draw resistance due to a reduction in the length of the cigarette after each puff. An explanation of why smokers change their puff parameters over the course of the cigarette might be that as the cigarette shortens, the delivery of nicotine and other smoke constituents, including tar and $\mathrm{CO}$, increases per puff ${ }^{47}$. A decrease in the volume and duration of puffing may in turn bring about a consistent delivery of nicotine and $\mathrm{CO}$ throughout consecutive puffs of the cigarette. For all smokers, the first puff differs from the other puffs taken with a consequent different exposure content ${ }^{51}$. This deviating first puff is referred to as the lighting puff as smokers might adapt their puffing in such a way to only light the cigarette properly, and not necessarily to dose nicotine, and therefore take a puff much shorter than the consecutive puffs. We assume that a short lighting puff is followed by a larger second puff that is fully inhaled. Furthermore, some other smokers take a large first puff (up to $3.5 \mathrm{sec}$ instead of less than $2 \mathrm{sec}$ on average), whereby we assume that a large first puff is fully inhaled in addition to lighting the cigarette. In a puff-by-puff study, the initial lighting puff and puffs between the first three and last three puffs were deleted ${ }^{49}$. We suggest including all puffs because the 
exposure estimate depends on smoking the whole cigarette.

\section{Puffing topography in literature and the use of CReSSmicro ${ }^{\mathrm{TM}}$ device}

The individual puff parameter data of smokers 2, 4 and 5 of the present study are in line with the wide range of puff parameter outcomes reported by other studies (Table S1 in Supplementary Materials), but not for smokers 1 and 3. Other studies vary in study design, setting, cigarette brand, changing cigarette characteristics over the years and study groups. Data reduction techniques and the impact of adjusting for puff count should be considered by interpreting different studies according to De Jesus et al., who systematically reviewed data produced with CReSSmicro ${ }^{\mathrm{TM}}{ }^{36}$.

In almost all studies, the puff duration is typically between 1 and $2 \mathrm{sec}$, although one study reported a shorter puff duration of $0.9^{33}$, similar to participant 4 of the study at hand $(0.9 \mathrm{sec})$, and another study reported a longer puff duration of $3 \mathrm{sec}^{52}$. Also, the lowest ( $31 \mathrm{~mL}^{33}$ ) and highest $\left(85.1 \mathrm{~mL}^{53}\right)$ puff volumes reported in the literature (Table S1 in Supplementary Materials) comprise the puff volumes in our study. The puff flow reported ranges from $25.6{ }^{54}$ to $62 \mathrm{~mL} / \mathrm{sec}^{53}$, which also comprises the puff flow in the present study $(26-58 \mathrm{~mL} / \mathrm{sec})$. The average puff count reported in the literature (Table S1 in Supplementary Materials) is between 7.6 puffs (a low-tar cigarette) ${ }^{22}$ and 20.4 puffs ${ }^{24}$.

We had a participant (smoker 1) with the extreme average puff count of 26 . It was also this participant that had an extreme total puffing volume of $2127 \mathrm{~mL}$, which is almost twice the highest total puffing volume reported in the literature $(1451 \mathrm{~mL} / \mathrm{cig})$ ${ }^{55}$. For another participant (smoker 3 ), a very high puffing volume was also registered (1582 mL/cig), although the puff count was not high. Both smokers had a short inter-puff interval and a high puff volume registered by $\mathrm{CReSSmicro}^{\mathrm{TM}}$ device. When cigarettes were smoked with a large number of registered puffs in combination with a high puffing volume, a substantial number of flow-dropouts with the CReSSmicro ${ }^{\mathrm{TM}}$ device were observed. We randomly used three CReSSmicro ${ }^{\mathrm{TM}}$ devices following the instruction of the producer, and did not observe malfunctioning of individual devices.

We experimentally checked the outcomes of the CReSSmicro ${ }^{\mathrm{TM}}$ device data under controlled experimental conditions with a smoking machine and observed substantial differences between the CReSSmicro ${ }^{\mathrm{TM}}$ device data and the smoking machine settings. As was shown in the smoking machine experiment with the $\mathrm{CReSSmicro}^{\mathrm{TM}}$ device only flow-dropouts were registered for loose and normal 
insertions, and were very limited with tight insertion (Figure 3). Tight insertion was the insertion method that produced a similar number of puffs in the smoking machine for a cigarette with and without the CReSSmicro ${ }^{\mathrm{TM}}$ device. When 'normal' insertion was applied, the number of puffs per cigarette increased, and consequently the total puffing volume. When 'loose' insertion was applied, the puff number more than doubled and puffing volume became extremely high, particularly when a high puff volume and short inter-puff interval was applied. This suggests that in the case of a loose or even normal insertion of cigarettes in the CReSSmicro ${ }^{\mathrm{TM}}$ device, in the human smoking experiment the smokers may depend on the insertion method, leading to the recording of puffing data which are a pitfall of the methodology. In our study, participants inserted the cigarettes themselves and did not indicate loose, normal or tight. However, they only followed the user manual of the device, and the researchers observed no deviating behavior. The summarized data in the software of the device gave no alert of incorrect or incomplete puff parameters, other than the flow-dropouts. Flow dropouts may, however, indicate that the device is not functioning properly. The recording of dropouts is also reported in the literature, but to the best of our knowledge no information is available whether or not data about 'high' puffing volumes, or 'high' puff numbers, have been deleted in previous studies.

During the machine smoking experiments, smoke was observed at the cigarette insertion opening in the device (Figure S1 in Supplementary Materials). During the smoking machine experiment, smoke at the mouth end of the cigarette was also observed, especially during the puff, and shortly after the puff. Human smoking with a loose insertion may lead to sidestream air entering the cigarette at the mouth end of the cigarette or air may be drawn directly into the device. In addition, as the filter (paper) is permeable at the mouth end of the cigarette, it may be possible that air is entering the device without passing or going through the cigarette, thereby diluting the smoke. On the other hand, it is also possible that smoke is leaking before entering the device. This was not mentioned by the participants nor observed by the researchers during our study. In the case of false air entering the device, we hypothesize that less tobacco is combusted with every puff, which makes it possible to take many puffs in total to finish the cigarette. If this artefact exists for a particular participant smoking a cigarette, he will try to inhale a large puff volume to satisfy his nicotine intake, probably in combination with many puffs. Due to the dilution of the smoke entering the smoker's mouth and the low amount of tobacco burnt, the nicotine intake per puff will be low. The desired effect of nicotine is not attained because of this dilution, motivating the smoker to take larger puff volumes and more puffs than he would take without the device. 


\section{TNCO yields produced by machine smoking with personal human puffing regimes, ISO regime and $\mathrm{HCl}$ regime}

There are three studies that had elements as in the present study. First, Hammond et al. recorded the puffing profile of 51 participants while smoking their usual brand; subsequently, the average puff volume and average puff frequency were used as parameters for machine smoking instead of the puff-by-puff profile as used in the study at hand ${ }^{20}$. Second, Djordjevic et al. recorded puffing profiles of 133 smokers and 72 randomly chosen puffing profiles were used for smoking machine setting for the medium-yield cigarettes ${ }^{56}$. Only averaged TNCO yields are reported and these are not linked to puffing parameters. In general, the literature data are averaged among study participants and almost no data from individuals are available. This hinders the comparison of study outcomes and identifying 'extreme' intense smoking. The third study, Dickens et al., is the only study found that reported individual puffing parameters $(n=7)$, but they were not replicated with a smoking machine ${ }^{57}$. These participants also had intense puffing profiles with puff volumes in the range of 55 to $119 \mathrm{~mL}$ per cigarette, with puff durations of 1.5 to $3.3 \mathrm{sec}^{57}$.

In our study, smoking machine experiments were used in a laboratory setting to determine cigarette smoke toxicant yields that are produced by puffing according to specified settings that were derived from the human smoking experiment. The linear regression (described in 2.5) showed that data of four cigarettes for a particular participant are sufficient to calculate the smokers' personal human puffing regime. When the human puffing profiles of smoker 1 and smoker 3 were used for machine smoking settings, the cigarette was finished before the puff profile ended. In spite of this, these two human puffing regimes generated the highest TNCO yields. Since the recording of profiles with CReSSmicro ${ }^{\mathrm{TM}}$ device may have overestimated the actual inhalation, the data of these two smokers are not further taken into account.

The least intense puffing profile (based on data of smoker 4, i.e., lowest puff volume and total cigarette volume, shortest puff duration and longest inter-puff interval) generated the smallest TNCO content. Hammond et al. reported less intense puff parameters (puff volume $53.3 \mathrm{~mL}$, inter-puff interval $33.2 \mathrm{sec}$, puff duration $1.4 \mathrm{sec}$ ) than in the present study, and this might explain why they found lower TNCO values (tar $26.7 \mathrm{mg}$, nicotine $2 \mathrm{mg}$, CO $24.6 \mathrm{mg}$ ) for comparable 'regular yield' cigarettes (9-15 mg ISO tar) ${ }^{20}$. In comparison with our puffing profiles of smokers 2, 4 and 5, the participants in the study of Djordjevic et al. had lower (total) puff volumes (523$615 \mathrm{~mL}$ versus $495-778 \mathrm{~mL}$ in our study) and a longer inter-puff interval (19-21 sec versus $16-21 \mathrm{sec}$ in our study) (similar puff duration $(1.5 \mathrm{sec}$ ) and puff count (12 or 
13 puffs)) ${ }^{56}$. Our data, as well as data collected from the literature, indicated that the inter-puff intervals applied for ISO and for $\mathrm{HCl}$ (respectively 60 and $30 \mathrm{sec}$ ) are too long to represent human smoking. This leads to long smoldering and lower puff numbers when ISO and $\mathrm{HCl}$ regimes are applied.

In our study, tar yield was on average $29 \mathrm{mg} / \mathrm{cig}$ (21-38 mg/cig), nicotine $2.39 \mathrm{mg} / \mathrm{cig}$ (1.5-2.4 mg/cig) and CO $22.5 \mathrm{mg} / \mathrm{cig}(16-20 \mathrm{mg} / \mathrm{cig})$. When TNCO yields generated according to human puffing regimes are compared to smoking machine generated emissions according to ISO and $\mathrm{HCl}$ settings (Table 2), it is clear that both ISO and $\mathrm{HCl}$ produce fewer puffs per cigarette. The $\mathrm{HCl}$ generates yields for TNCO which are in the same range yields produced with the human smoking regimes of smokers 2 , 4 and 5 . This is consistent with previous studies ${ }^{20}$. On average, the puff parameters of Hammond et al. ${ }^{20}$ are more comparable with the $\mathrm{HCl}$ regime than those of the present study. They found that their human mimic regime on the smoking machine produced slightly less nicotine ( $2 \mathrm{vs.} 2.4 \mathrm{mg} / \mathrm{cig}$ ), tar ( $24.7 \mathrm{vs.} 30.6 \mathrm{mg} / \mathrm{cig}$ ) and CO ( $24.6 \mathrm{vs} .28 .1 \mathrm{mg} / \mathrm{cig}$ ) than the $\mathrm{HCl}$ regime, while they observed a larger total cigarette volume $(53.3 \mathrm{~mL} \times 11.5$ puffs $=612.95 \mathrm{~mL})$ and higher puff flow $(38.6 \mathrm{~mL} / \mathrm{sec}){ }^{20}$. It was also clear that ISO regime underestimates human smoking substantially ${ }^{20}$. The TNCO yields determined when using the human puffing profile regime were at least twice as high as the yields we determined with ISO ${ }^{17}$ regimes on the same smoking machine. The total puff volume of $280 \mathrm{~mL}$ is very low compared to data reported in the literature, as well as the data generated in the study at hand. The lowest total puffing volume reported in the literature is $380 \mathrm{~mL}$, which is close to that of the ISO regime for smoking machines ${ }^{22}$. A higher volume per puff in combination with a higher puffing frequency better mimics human smoking intensity.

The proxy of number of smoked cigarettes per day is often used in risk assessment modelling when estimating the dose of exposure to toxicants in smokers ${ }^{7,58}$. However, as is shown in this study, this proxy has limitations for actual risk assessment of cigarettes since it does not correspond with total puffing volume per day. Others state that smoke volume correlates well with biochemically assessed human smoke exposure ${ }^{31,45}$ and that total puff volume and duration measured with the CReSSmicro ${ }^{\mathrm{TM}}$ device are likely to give the best approximation for toxicant exposure estimates ${ }^{36}$. Moreover, the inhalation of the cigarette smoke ultimately leads to systemic exposure. The puff parameters give an indication of total smoke volume and depth of inhalation ${ }^{26}$, which provide information on which part of the lungs is reached by the smoke toxicants. To estimate the final systemic exposure to cigarette smoke toxicants, we need to relate smoke content, puffing parameters 
and respiratory parameters, especially inhalation volume and duration. Knowledge about cigarette smoke inhalation parameters is limited and the realistic human puffing profiles and TNCO emissions from the present study can improve the predictions for (site-specific tissue dose) computer models ${ }^{59}$. Studies often focus on the influence of a single determinant, i.e., age ${ }^{49,50}$, gender ${ }^{7}$, racial background ${ }^{25,60,61}$, or cigarette brand ${ }^{27,62}$ on smoking behavior in healthy smokers ${ }^{33,63}$. The present study took place in a controlled, but not entirely artificial, real-world environment that accommodates the smoking experience ${ }^{48,61,64}$. In the small but homogenous group, of smokers' inter-individual differences in the number of cigarettes smoked, the time points of smoking, and the mean and total puff parameters were registered. This suggests that estimating overall exposure based on smokers' characteristics is not sufficient and that variations of smoking topography contribute to the smoker's risk. The limitation of the study at hand is that the current sample of smokers and cigarette brand is not representative for all smokers or cigarette brand. Moreover, other determinants might cause even more variations in cigarette emissions and exposures of the smokers.

\section{Conclusions}

Smokers smoke their cigarettes with consistent, individually characteristic puffing topography. These characteristic human puffing profiles show differences between smokers. The variety in puffing profiles within the homogenous study group of the present study was also seen in the compiled literature data of puffing topography studies since 2000 (Table S1 in Supplementary Materials). When the different characteristic human puffing regimes are mimicked on the smoking machine, differences in TNCO yields are generated. Comparison with machine smoking data shows that smokers are likely to be exposed to at least twice the TNCO yields as measured with ISO regimes on a smoking machine. This observation indicates that the ISO 3308 regime largely underestimates human exposure due to low puffing intensity. Smokers' exposure to TNCO can probably be better estimated with machine smoking set on the $\mathrm{HCl}$ regime. However, the present study shows that the smoking machine with the $\mathrm{HCl}$ regime may also underestimate actual smokers' exposure, because inter-puff intervals are shorter for human smokers than in the $\mathrm{HCl}$ regime. 


\section{References}

1. GBD 2015 Tobacco Collaborators. Smoking prevalence and attributable disease burden in 195 countries and territories, 1990-2015: a systematic analysis from the Global Burden of Disease Study 2015. Lancet. 2017;389(10082):1885-1906.

2. Hammond D, Wiebel F, Kozlowski LT, et al. Revising the machine smoking regime for cigarette emissions: implications for tobacco control policy. Tob Control. 2007;16(1):814.

3. Marian C, O'Connor RJ, Djordjevic MV, et al. Reconciling human smoking behavior and machine smoking patterns: implications for understanding smoking behavior and the impact on laboratory studies. Cancer Epidemiol Biomarkers Prev. 2009;18(12):3305-3320.

4. Reilly SM, Goel R, Bitzer Z, et al. Effects of Topography-Related Puff Parameters on Carbonyl Delivery in Mainstream Cigarette Smoke. Chem Res Toxicol. 2017;30(7):14631469.

5. Talhout R, Richter PA, Stepanov I, Watson CV, Watson CH. Cigarette Design Features: Effects on Emission Levels, User Perception, and Behavior. Tob Regul Sci. 2018;4(1):592604.

6. WHO Study Group on Tobacco Product Regulation (TobReg). Report on the scientific basis of tobacco product regulation: fifth report of a WHO study group (989). Geneva, Switserland. World Health Organization; 2015.

7. Melikian AA, Djordjevic MV, Hosey J, et al. Gender differences relative to smoking behavior and emissions of toxins from mainstream cigarette smoke. Nicotine Tob Res. 2007;9(3):377-387.

8. Song MA, Benowitz NL, Berman M, et al. Cigarette Filter Ventilation and its Relationship to Increasing Rates of Lung Adenocarcinoma. J Natl Cancer Inst. 2017;109(12).

9. Scherer G. Smoking behaviour and compensation: a review of the literature. Psychopharmacology (Berl). 1999;145(1):1-20.

10. Saidi MS, Mhaisekar A, Hajaligol MR, Subbiah M. Mathematical Modeling of a LitEnd Cigarette: Puffing Cycle and Effects of Puff Counts. Beiträge zur Tabakforschung International/Contributions to Tobacco Research. 2008;23(1):46-62.

11. Li B, Zhao LC, Wang L, et al. Gas-phase pressure and flow velocity fields inside a burning cigarette during a puff. Thermochim Acta. 2016;623:22-28.

12. Baker RR, Bishop LJ. The pyrolysis of tobacco ingredients. J Anal Appl Pyrolysis. 2004;71(1):223-311.

13. Liang Q, Roethig HJ, Lipowicz PJ, Jin Y, Mendes PE. The effect of cigarette burn time on exposure to nicotine and carbon monoxide in adult smokers. Regul Toxicol Pharmacol. 2008;50(1):66-74.

14. Purkis SW, Troude V, Hill CA. Effect of puffing intensity on cigarette smoke yields. Regul 
Toxicol Pharmacol. 2013;66(1):72-82.

15. Pazo DY, Moliere F, Sampson MM, et al. Mainstream Smoke Levels of Volatile Organic Compounds in 50 U.S. Domestic Cigarette Brands Smoked With the ISO and Canadian Intense Protocols. Nicotine Tob Res. 2016;18(9):1886-1894.

16. Vu AT, Taylor KM, Holman MR, et al. Polycyclic Aromatic Hydrocarbons in the Mainstream Smoke of Popular U.S. Cigarettes. Chem Res Toxicol. 2015;28(8):1616-1626.

17. Pauwels CGGM, Klerx WNM, Pennings JLA, et al. Cigarette Filter Ventilation and Smoking Protocol Influence Aldehyde Smoke Yields. Chem Res Toxicol. 2018;31(6):462471.

18. WHO Tobacco Laboratory Network. WHO SOP 01 Standard operating procedure for intense smoking of cigarettes. Geneva, Switzerland. World Health Organization; 2012.

19. ISO 3308:2012. Routine analytical cigarette-smoking machine -definitions and standard conditions. Geneva, Switzerland: International Organization for Standardization; 2012.

20. Hammond D, Fong GT, Cummings KM, et al. Cigarette yields and human exposure: a comparison of alternative testing regimens. Cancer Epidemiol Biomarkers Prev. 2006;15(8):1495-1501.

21. ISO 10315:2014. Cigarettes - Determination of nicotine in smoke condensates Gas-chromatographic method. Geneva, Switzerland: International Organization for Standardization; 2014.

22. Chen A, Krebs NM, Zhu J, Muscat JE. Nicotine metabolite ratio predicts smoking topography: The Pennsylvania Adult Smoking Study. Drug Alcohol Depend. 2018;190:8993.

23. Ross KC, Dempsey DA, St Helen G, Delucchi K, Benowitz NL. The Influence of Puff Characteristics, Nicotine Dependence, and Rate of Nicotine Metabolism on Daily Nicotine Exposure in African American Smokers. Cancer Epidemiol Biomarkers Prev. 2016;25(6):936-943.

24. Farris SG, Aston ER, Abrantes AM, Zvolensky MJ. Tobacco demand, delay discounting, and smoking topography among smokers with and without psychopathology. Drug Alcohol Depend. 2017;179:247-253.

25. Chung S, Kim SS, Kini N, et al. Smoking topography in Korean American and white men: preliminary findings. J Immigr Minor Health. 2015;17(3):860-866.

26. Appleton S, Liu J, Lipowicz PJ, Sarkar M. Effect of cigarette design on biomarkers of exposure, puffing topography and respiratory parameters. Inhal Toxicol. 2015;27(3):174180.

27. Watson CV, Richter P, de Castro BR, et al. Smoking Behavior and Exposure: Results of a Menthol Cigarette Cross-over Study. Am J Health Behav. 2017;41(3):309-319.

28. June KM, Norton KJ, Rees VW, O'Connor RJ. Influence of measurement setting and home smoking policy on smoking topography. Addict Behav. 2012;37(1):42-46. 
29. Ferguson SG, Frandsen M, Dunbar MS, Shiffman S. Gender and stimulus control of smoking behavior. Nicotine Tob Res. 2015;17(4):431-437.

30. Piasecki TM, Hedeker D, Dierker LC, Mermelstein RJ. Progression of nicotine dependence, mood level, and mood variability in adolescent smokers. Psychol Addict Behav. 2016;30(4):484-493.

31. Grainge MJ, Shahab L, Hammond D, O'Connor RJ, McNeill A. First cigarette on waking and time of day as predictors of puffing behaviour in UK adult smokers. Drug Alcohol Depend. 2009;101(3):191-195.

32. Chapman S, Haddad S, Sindhusake D. Do work-place smoking bans cause smokers to smoke "harder"? Results from a naturalistic observational study. Addiction (Abingdon, England). 1997;92(5):607-610.

33. Lee EM, Malson JL, Waters AJ, Moolchan ET, Pickworth WB. Smoking topography: reliability and validity in dependent smokers. Nicotine Tob Res. 2003;5(5):673-679.

34. Blank MD, Disharoon S, Eissenberg T. Comparison of methods for measurement of smoking behavior: mouthpiece-based computerized devices versus direct observation. Nicotine Tob Res. 2009;11(7):896-903.

35. Perkins KA, Karelitz JL, Giedgowd GE, Conklin CA. The reliability of puff topography and subjective responses during ad lib smoking of a single cigarette. Nicotine Tob Res. 2012;14(4):490-494.

36. De Jesus S, Hsin A, Faulkner G, Prapavessis H. A systematic review and analysis of data reduction techniques for the CReSS smoking topography device. Journal of Smoking Cessation. 2013;10(1):12-28.

37. Shiffman S, Scholl S. Increases in Cigarette Consumption and Decreases in Smoking Intensity When Nondaily Smokers Are Provided With Free Cigarettes. Nicotine Tob Res. 2018;20(10):1237-1242.

38. Borges AM, Leyro TM, Rosen RL, Zvolensky MJ, Farris SG. Negative urgency and adlibitum smoking topography. Drug Alcohol Depend. 2019;201:220-226.

39. Mikheev VB, Buehler SS, Brinkman MC, et al. The application of commercially available mobile cigarette topography devices for e-cigarette vaping behavior measurements. Nicotine Tob Res. 2018.

40. Centers for Disease Control and Prevention (CDC). Tobacco Brand Preferences. Website. Available at: https://www.cdc.gov/tobacco/data_statistics/fact_sheets/tobacco_ industry/brand_preference/index.htm. Accessed August 19th 2020.

41. Statista Research. Market share of Marlboro in the Netherlands from 2012 to 2017. https://www.statista.com/statistics/822213/market-share-marlboro-in-thenetherlands/. Accessed April 9th 2020.

42. Oldham MJ, Plunkett SE, Fisher MT, Shafer KH, Morton MJ. Laboratory Evaluation of the CReSSmicro ${ }^{\mathrm{TM}}$ Portable Topography Device: Implications for Clinical Research. 
Contributions to Tobacco Research. 2014;26(1).

43. ISO 4387:2000/A1:2008. Cigarettes - Determination of total and nicotine-free dry particulate matter using a routine analytical smoking machine. Geneva, Switzerland: International Organization for Standardization; 2008.

44. ISO 8454:2007/A1:2009. Cigarettes - Determination of carbon monoxide in the vapour phase of cigarette smoke - NDIR method. Geneva, Switzerland: International Organization for Standardization; 2009.

45. Hammond D, Fong GT, Cummings KM, Hyland A. Smoking topography, brand switching, and nicotine delivery: results from an in vivo study. Cancer Epidemiol Biomarkers Prev. 2005;14(6):1370-1375.

46. Brinkman MC, Kim H, Chuang JC, et al. Comparison of True and Smoothed Puff Profile Replication on Smoking Behavior and Mainstream Smoke Emissions. Chem Res Toxicol. 2015;28(2):182-190.

47. Guyatt AR, Kirkham AJ, Baldry AG, Dixon M, Cumming G. How does puffing behavior alter during the smoking of a single cigarette? Pharmacol Biochem Behav. 1989;33(1):189195.

48. Kolonen S, Tuomisto J, Puustinen P, Airaksinen MM. Puffing behavior during the smoking of a single cigarette in a naturalistic environment. Pharmacol Biochem Behav. 1992;41(4):701-706.

49. Collins CC, Epstein DH, Parzynski CS, et al. Puffing behavior during the smoking of a single cigarette in tobacco-dependent adolescents. Nicotine Tob Res. 2010;12(2):164167.

50. Veilleux JC, Kassel JD, Heinz AJ, et al. Predictors and sequelae of smoking topography over the course of a single cigarette in adolescent light smokers. J Adolesc Health. 2011;48(2):176-181.

51. Wagner KA, Higby R, Stutt K. Puff-by-Puff Analysis of Selected Mainstream Smoke Constituents in The Kentucky Reference 2R4F Cigarette. Beiträge zur Tabakforschung International/Contributions to Tobacco Research. 2005;21(5):273-279.

52. Norton KJ, June KM, O'Connor RJ. Initial puffing behaviors and subjective responses differ between an electronic nicotine delivery system and traditional cigarettes. Tob Induc Dis. 2014;12(1):17.

53. Strasser AA, Ashare RL, Kozlowski LT, Pickworth WB. The effect of filter vent blocking and smoking topography on carbon monoxide levels in smokers. Pharmacol Biochem Behav. 2005;82(2):320-329.

54. Brinkman MC, Chuang JC, Gordon SM, et al. Exposure to and deposition of fine and ultrafine particles in smokers of menthol and nonmenthol cigarettes. Inhal Toxicol. 2012;24(5):255-269.

55. Tidey JW, Cassidy RN, Miller ME. Smoking Topography Characteristics of Very Low 
Nicotine Content Cigarettes, With and Without Nicotine Replacement, in Smokers With Schizophrenia and Controls. Nicotine Tob Res. 2016;18(9):1807-1812.

56. Djordjevic MV, Stellman SD, Zang E. Doses of nicotine and lung carcinogens delivered to cigarette smokers. J NatI Cancer Inst. 2000;92(2):106-111.

57. Dickens C, McGrath C, Warren N, Biggs P, McAughey J. Puffing and inhalation behaviour in cigarette smoking: Implications for particle diameter and dose. Journal of Physics: Conference Series. 2009;151(1):012019.

58. Rostron BL, Corey CG, Chang JT, et al. Associations of Cigarettes Smoked Per Day with Biomarkers of Exposure Among U.S. Adult Cigarette Smokers in the Population Assessment of Tobacco and Health (PATH) Study Wave 1 (2013-2014). Cancer Epidemiol Biomarkers Prev. 2019;28(9):1443-1453.

59. Corley RA, Kabilan S, Kuprat AP, et al. Comparative Risks of Aldehyde Constituents in Cigarette Smoke Using Transient Computational Fluid Dynamics/Physiologically Based Pharmacokinetic Models of the Rat and Human Respiratory Tracts. Toxicol Sci. 2015;146(1):65-88.

60. Kim S, Yu S. Smoking Topography among Korean Smokers: Intensive Smoking Behavior with Larger Puff Volume and Shorter Interpuff Interval. Int J Environ Res Public Health. 2018;15(5).

61. Matsumoto M, Inaba Y, Yamaguchi I, et al. Smoking topography and biomarkers of exposure among Japanese smokers: associations with cigarette emissions obtained using machine smoking protocols. Environ Health Prev Med. 2013;18(2):95-103.

62. Breland AB, Kleykamp BA, Eissenberg T. Clinical laboratory evaluation of potential reduced exposure products for smokers. Nicotine Tob Res. 2006;8(6):727-738.

63. Dixon M, Kochhar N, Prasad K, Shepperd J, Warburton DM. The influence of changing nicotine to tar ratios on human puffing behaviour and perceived sensory response. Psychopharmacology (Berl). 2003;170(4):434-442.

64. Hatsukami D, Morgan SF, Pickens RW, Hughes JR. Smoking topography in a nonlaboratory environment. Int J Addict. 1987;22(8):719-725. 


\section{Supplemental information}

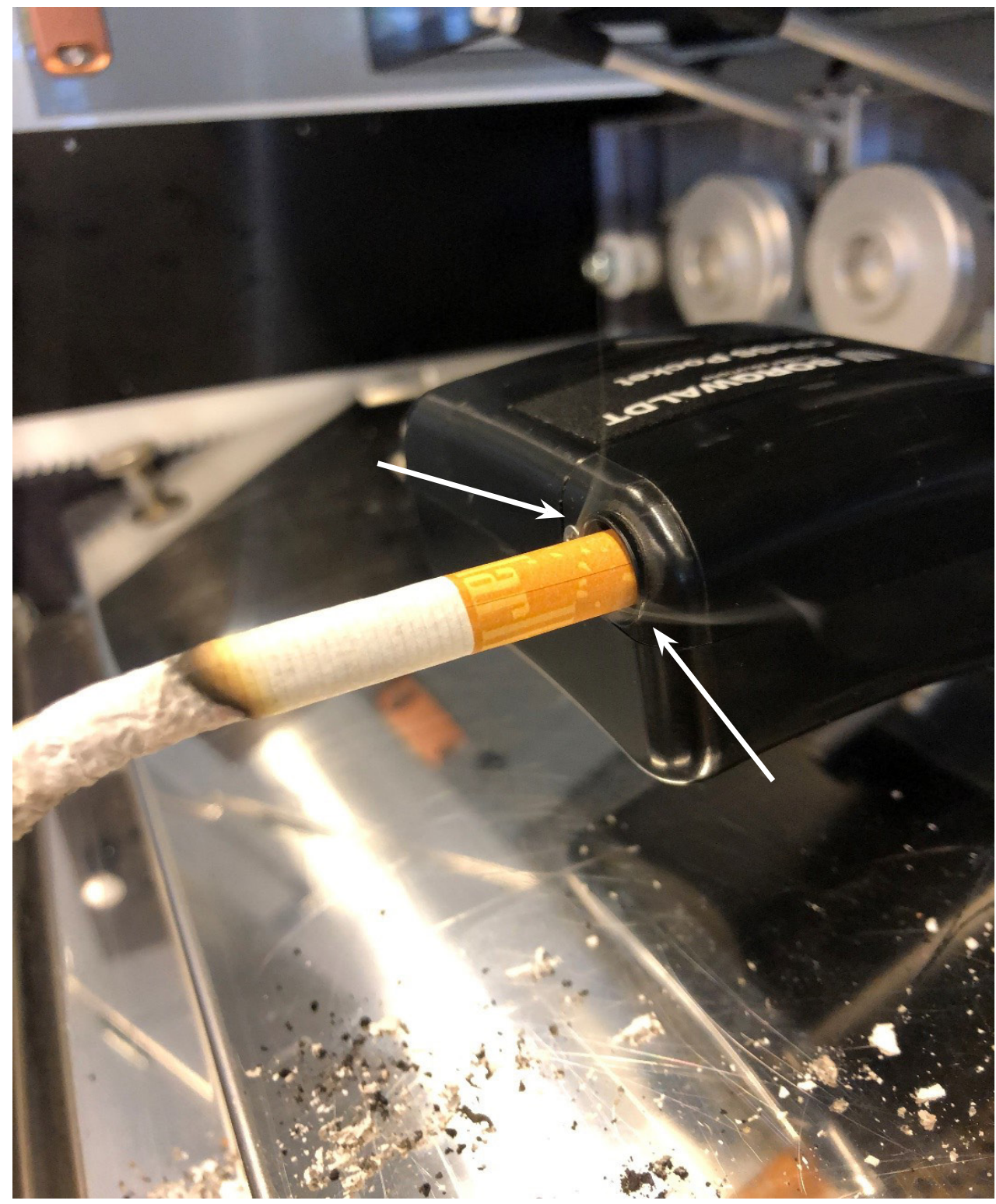

Figure S1: Smoke is escaping (arrow) during the smoking with a smoking machine. The cigarette was loosely inserted in the CReSSmicro ${ }^{\mathrm{TM}}$ device. 
Table S1: Literature reporting puffing parameters in chronological order since 2000

\begin{tabular}{|c|c|c|c|c|c|c|c|c|c|c|c|c|}
\hline Author & Year & Sort & $\mathrm{n}$ & $\begin{array}{l}\text { Gen- } \\
\text { der }\end{array}$ & Age & SD & $\begin{array}{l}\text { No of } \\
\text { cig/ } \\
\text { day }\end{array}$ & SD & $\begin{array}{l}\text { Puff } \\
\text { volume } \\
\text { (ml) }\end{array}$ & SD & $\begin{array}{l}\text { Puff } \\
\text { duration } \\
\text { (sec) }\end{array}$ & SD \\
\hline $\begin{array}{l}\text { Buchhalter } \\
\text { et al }{ }^{1}\end{array}$ & 2000 & $\begin{array}{l}\text { own brand } \\
\text { (9,5 mg tar, } \\
0.73 \mathrm{mg} \\
\text { nicotine) }\end{array}$ & 10 & $\hat{o} / q$ & 23.2 & 3.4 & 15.3 & 4.1 & 38.4 & 11.7 & 1.2 & 0.4 \\
\hline \multirow[t]{2}{*}{$\begin{array}{l}\text { Djordjevic } \\
\text { et } a^{2}\end{array}$} & 2000 & $\begin{array}{l}\text { own brand } \\
\text { ( } 8.5 \mathrm{mg} \\
\text { tar, } 0.7 \mathrm{mg} \\
\text { nicotine) }\end{array}$ & 56 & $3 / 9$ & 34.1 & $\begin{array}{l}\mathrm{Cl} 31.3- \\
37.2\end{array}$ & 14.9 & $\begin{array}{l}\text { Cl 13.1- } \\
16.9\end{array}$ & 48.6 & $\begin{array}{l}\text { Cl } 45.2 \\
-25.3\end{array}$ & 1.5 & $\begin{array}{l}\mathrm{Cl} 1.4- \\
1.7\end{array}$ \\
\hline & & $\begin{array}{l}\text { own brand } \\
\text { (15.4 mg } \\
\text { tar, } 1.11 \mathrm{mg} \\
\text { nicotine) }\end{array}$ & 77 & $\hat{\sigma} / q$ & 34.7 & $\begin{array}{l}\mathrm{Cl} 32.5- \\
37.1\end{array}$ & 15.9 & $\begin{array}{l}\mathrm{Cl} 14.3- \\
17.8\end{array}$ & 44.1 & $\begin{array}{l}\text { Cl } 40.8- \\
46.8\end{array}$ & 1.5 & $\begin{array}{l}\text { Cl 1.4- } \\
1.6\end{array}$ \\
\hline $\begin{array}{l}\text { Breland et } \\
a^{3}\end{array}$ & 2002 & $\begin{array}{l}\text { own brand } \\
(10,2 \mathrm{mg} \\
\text { tar, } 0.8 \mathrm{mg} \\
\text { nicotine) }\end{array}$ & 20 & $\hat{o} / q$ & 21.6 & $\begin{array}{l}\text { SEM } \\
1.1\end{array}$ & 18.9 & $\begin{array}{l}\text { SEM } \\
0.7\end{array}$ & 49.8 & $\begin{array}{l}\text { SEM } \\
3.3\end{array}$ & 1.7 & $\begin{array}{l}\text { SEM } \\
0.1\end{array}$ \\
\hline $\begin{array}{l}\text { Breland et } \\
\text { al }^{4}\end{array}$ & 2002 & $\begin{array}{l}\text { own brand } \\
\text { ( } 9,4 \mathrm{mg} \text { tar, } \\
0.73 \mathrm{mg} \\
\text { nicotine) }\end{array}$ & 18 & $0 / 9$ & 25.8 & 6.0 & 20.7 & 4.7 & 56.5 & 11.2 & 1.8 & 0.1 \\
\hline \multirow[t]{5}{*}{ Dixon et al } & 2003 & $\begin{array}{l}\text { test cigarette } \\
\text { ( } 9.5 \mathrm{mg} \text { tar, } \\
0.77 \mathrm{mg} \\
\text { nicotine) }\end{array}$ & 13 & & & & & & 55.4 & 12.4 & 1.8 & 0.8 \\
\hline & & $\begin{array}{l}\text { test cigarette } \\
\text { (8.8 mg tar, } \\
0.48 \mathrm{mg} \\
\text { nicotine) }\end{array}$ & 13 & & & & & & 56.7 & 11.6 & 1.8 & 0.8 \\
\hline & & $\begin{array}{l}\text { test cigarette } \\
\text { (8.7 mg tar, } \\
0.81 \mathrm{mg} \\
\text { nicotine) }\end{array}$ & 13 & & & & & & 53.6 & 13.3 & 1.7 & 0.8 \\
\hline & & $\begin{array}{l}\text { test cigarette } \\
8.1 \mathrm{mg} \text { tar, } \\
0.10 \mathrm{mg} \\
\text { nicotine) }\end{array}$ & 13 & & & & & & 55.6 & 11.5 & 1.8 & 0.7 \\
\hline & & $\begin{array}{l}\text { test cigarette } \\
(7.7 \mathrm{mg} \text { tar, } \\
0.22 \mathrm{mg} \\
\text { nicotine) }\end{array}$ & 13 & & & & & & 55.8 & 13.0 & 1.8 & 0.8 \\
\hline \multirow[t]{2}{*}{ Lee et al ${ }^{6}$} & 2003 & $\begin{array}{l}\text { own brand } \\
(16.7 \mathrm{mg} \\
\text { tar, } 1.2 \mathrm{mg} \\
\text { nicotine) }\end{array}$ & 7 & $\hat{o} / q$ & 37.0 & $25-44$ & 25.0 & $10-38$ & 30.8 & SE 3.5 & 0.9 & SE 0.1 \\
\hline & & $\begin{array}{l}\text { own brand } \\
(12.8 \mathrm{mg} \\
\text { tar, } 1.0 \mathrm{mg} \\
\text { nicotine) }\end{array}$ & 10 & ol/ & 24.5 & $20-37$ & 25.0 & $17-40$ & 45.1 & SE 4.9 & 1.2 & SE 0.1 \\
\hline
\end{tabular}




\begin{tabular}{|c|c|c|c|c|c|c|c|c|c|c|c|c|}
\hline $\begin{array}{l}\text { Puff } \\
\text { flow }\end{array}$ & SD & $\begin{array}{l}\text { Puff } \\
\text { interval } \\
\text { (sec) }\end{array}$ & SD & $\begin{array}{l}\text { Puff } \\
\text { count }\end{array}$ & SD & $\begin{array}{l}\text { Total } \\
\text { volume } \\
\text { (ml/cig) }\end{array}$ & SD & $\begin{array}{l}\text { Total } \\
\text { volume/ } \\
\text { day }\end{array}$ & $\begin{array}{l}\text { Fagerström } \\
\text { index }\end{array}$ & SD & Device & Comments \\
\hline 32.0 & & 35.0 & 17.9 & 10.3 & 2.1 & 395.5 & & 6.1 & 4.0 & 1.2 & CRSSPT & \\
\hline 32.4 & & 21.3 & $\begin{array}{l}\mathrm{Cl} 19- \\
23.8\end{array}$ & 12.7 & $\begin{array}{l}\mathrm{Cl} \\
11.8- \\
13.6\end{array}$ & 615.0 & $\begin{array}{l}\mathrm{Cl} 566- \\
668\end{array}$ & 9.5 & 3.3 & $\begin{array}{l}\mathrm{Cl} \\
2.3- \\
4.8\end{array}$ & $\begin{array}{l}\text { Tobacco } \\
\text { Smoke } \\
\text { Inhalation } \\
\text { Testing } \\
\text { System }\end{array}$ & \\
\hline 29.4 & & 18.5 & $\begin{array}{l}\text { Cl 16.5- } \\
20.6\end{array}$ & 12.1 & $\begin{array}{l}\mathrm{Cl} \\
11.3- \\
12.9\end{array}$ & 523.0 & $\begin{array}{l}\mathrm{Cl} 487- \\
561\end{array}$ & 8.2 & 3.8 & $\begin{array}{l}\mathrm{Cl} \\
2.7- \\
5.3\end{array}$ & $\begin{array}{l}\text { Tobacco } \\
\text { Smoke } \\
\text { Inhalation } \\
\text { Testing } \\
\text { System }\end{array}$ & \\
\hline 29.3 & & & & 8 & & 398.4 & & 7.5 & 5.6 & $\begin{array}{l}\text { SEM } \\
0.3\end{array}$ & $\begin{array}{l}\text { Tobacco } \\
\text { Smoke } \\
\text { Inhalation } \\
\text { Testing } \\
\text { System } \\
\text { Tobacco }\end{array}$ & $\begin{array}{l}\text { Fixed puff } \\
\text { count }\end{array}$ \\
\hline 31.4 & & 33.9 & 23.6 & 8 & & 452.0 & & 9.4 & 5.3 & 1.6 & $\begin{array}{l}\text { Smoke } \\
\text { Inhalation } \\
\text { Testing } \\
\text { System }\end{array}$ & $\begin{array}{l}\text { Fixed puff } \\
\text { count }\end{array}$ \\
\hline 31.7 & & 20.9 & 4.4 & 16.0 & 2.6 & 877.0 & 197.0 & & & & $\begin{array}{l}\text { Orifice-type } \\
\text { holder/ } \\
\text { flowmeter } \\
\text { (design of } \\
\text { Creighton et } \\
\text { al. 1978) }\end{array}$ & \\
\hline 31.5 & & 20.8 & 3.6 & 16.1 & 3.0 & 890.0 & 152.0 & & & & $\begin{array}{l}\text { Orifice-type } \\
\text { holder/ } \\
\text { flowmeter } \\
\text { (design of } \\
\text { Creighton et } \\
\text { al. 1978) }\end{array}$ & \\
\hline 31.7 & & 21.4 & 5.3 & 14.4 & 2.3 & 755.0 & 166.0 & & & & $\begin{array}{l}\text { Orifice-type } \\
\text { holder/ } \\
\text { flowmeter } \\
\text { (design of } \\
\text { Creighton et } \\
\text { al. 1978) }\end{array}$ & \\
\hline 31.4 & & 21.1 & 4.5 & 14.4 & 2.3 & 766.0 & 141.0 & & & & $\begin{array}{l}\text { Orifice-type } \\
\text { holder/ } \\
\text { flowmeter } \\
\text { (design of } \\
\text { Creighton et } \\
\text { al. 1978) }\end{array}$ & \\
\hline 30.3 & & 20.0 & 3.7 & 15.6 & 3.3 & 870.0 & 136.0 & & & & $\begin{array}{l}\text { Orifice-type } \\
\text { holder/ } \\
\text { flowmeter } \\
\text { (design of } \\
\text { Creighton et } \\
\text { al. 1978) }\end{array}$ & \\
\hline 44.6 & SE 3.4 & 19.9 & SE 3.5 & 9.3 & & 284.9 & & 7.1 & 6.8 & $4-10$ & CRSSPT & $\begin{array}{l}8,8,11 \\
10 \text { puffs }\end{array}$ \\
\hline 54.4 & SE 4.8 & 23.2 & SE 3.0 & 10.0 & & 451.0 & & 11.3 & 6.0 & $3-9$ & CRSSPT & \\
\hline
\end{tabular}




\begin{tabular}{|c|c|c|c|c|c|c|c|c|c|c|c|c|}
\hline Author & Year & Sort & $\mathrm{n}$ & $\begin{array}{l}\text { Gen- } \\
\text { der }\end{array}$ & Age & SD & $\begin{array}{l}\text { No of } \\
\text { cig/ } \\
\text { day }\end{array}$ & SD & $\begin{array}{l}\text { Puff } \\
\text { volume } \\
\text { (ml) }\end{array}$ & SD & $\begin{array}{l}\text { Puff } \\
\text { duration } \\
\text { (sec) }\end{array}$ & SD \\
\hline \multirow[t]{2}{*}{ Aung et $a^{7}$} & 2004 & own brand & & & & & & & & & & \\
\hline & & & 56 & $\hat{o} / 9$ & 15.4 & 1.3 & 19.6 & 8.93 & 38.1 & 14.5 & 1.1 & 0.4 \\
\hline \multirow[t]{4}{*}{ Dixon $^{\$}$} & 2004 & $\begin{array}{l}10 \text { mg tar, } 1 \\
\text { mg nicotine }\end{array}$ & 100 & $3 / 9$ & & & & & 46.2 & & 1.9 & \\
\hline & & $\begin{array}{l}4,8 \mathrm{mg} \text { tar, } \\
0.5 \mathrm{mg} \\
\text { nicotine }\end{array}$ & 100 & $3 / 9$ & & & & & 58.6 & & 1.9 & \\
\hline & & $\begin{array}{l}2,8 \mathrm{mg} \text { tar, } \\
0.3 \mathrm{mg} \\
\text { nicotine }\end{array}$ & 100 & $\hat{\sigma} / q$ & & & & & 57.6 & & 1.9 & \\
\hline & & $\begin{array}{l}1,2 \mathrm{mg} \text { tar, } \\
0.1 \mathrm{mg} \\
\text { nicotine }\end{array}$ & 100 & $3 / q$ & & & & & 63.4 & & 1.9 & \\
\hline \multirow[t]{2}{*}{ Dixon $\$$} & 2004 & $\begin{array}{l}5,6 \mathrm{mg} \text { tar, } \\
0.5 \mathrm{mg} \\
\text { nicotine }\end{array}$ & 50 & $\hat{\sigma} / q$ & & & & & 52.8 & & 1.7 & \\
\hline & & $\begin{array}{l}1 \mathrm{mg} \text { tar, } 0.1 \\
\text { mg nicotine }\end{array}$ & 50 & $3 / q$ & & & & & 63.2 & & 1.7 & \\
\hline \multirow[t]{3}{*}{$\begin{array}{l}\text { Hughes et } \\
a l^{8}\end{array}$} & 2004 & $\begin{array}{l}\text { own brand } \\
\text { (Light, } \\
\text { ultralight, } \\
\text { regular) }\end{array}$ & 34 & $3 / 9$ & 48.0 & & 30.0 & SEM 2 & 50.0 & SEM 2 & & \\
\hline & & $\begin{array}{l}\text { Omni light } \\
\text { (12 mg } \\
\text { tar, } 0.8 \mathrm{mg} \\
\text { nicotine) }\end{array}$ & & & & & & & & & & \\
\hline & & $\begin{array}{l}\text { or Omni } \\
\text { Full flavor } \\
\text { King/100's } \\
\text { (15 mg } \\
\text { tar, } 1.0 \mathrm{mg} \\
\text { nicotine) }\end{array}$ & 34 & $\hat{o} / 9$ & 48.0 & & 31.0 & SEM 2 & 49.0 & SEM 2 & & \\
\hline \multirow[t]{2}{*}{ Lee et $a^{9}{ }^{9}$} & 2004 & own brand & & & & & & & & & & \\
\hline & & $\begin{array}{l}\text { (14.5 mg } \\
\text { tar, } 1.1 \mathrm{mg} \\
\text { nicotine) }\end{array}$ & 10 & $\delta / q$ & 30.3 & $19-46$ & 21.3 & $13-30$ & 60.1 & 4.0 & 1.1 & \\
\hline \multirow[t]{2}{*}{$\begin{array}{l}\text { Strasser et } \\
\text { al }{ }^{10}\end{array}$} & 2004 & $\begin{array}{l}\text { own brand } \\
\text { (mean }\end{array}$ & 113 & $1 / 9$ & 458 & 107 & 212 & 78 & 548 & 160 & 16 & 0 \\
\hline & & $\begin{array}{l}0.93 \mathrm{mg} \\
\text { nicotine) }\end{array}$ & 113 & $6 / 7$ & 45.8 & 10.1 & & 1.8 & & & & \\
\hline \multirow{2}{*}{$\begin{array}{l}\text { Wood et } \\
\text { al }{ }^{11}\end{array}$} & 2004 & own brand & 24 & 우 & 16.3 & 1.5 & 15.0 & $1-25$ & 38.5 & 12.2 & 1.1 & 0.3 \\
\hline & & own brand & 25 & $\hat{o}$ & 16.4 & 1.4 & 15.0 & $1-25$ & 45.8 & 14.6 & 1.2 & 0.3 \\
\hline $\begin{array}{l}\text { Zimmerman } \\
\text { et al }{ }^{12}\end{array}$ & 2004 & own brand & 92 & $\delta / q$ & 15.2 & 1.5 & & & 38.2 & 12.5 & 1.1 & 0.4 \\
\hline \multirow[t]{3}{*}{$\begin{array}{l}\text { Hammond } \\
\text { et al }{ }^{13}\end{array}$} & 2005 & $\begin{array}{l}\text { own brand } \\
\text { (10-14 mg } \\
\text { tar) }\end{array}$ & 58 & $\hat{o} / 9$ & 37.1 & 11.1 & 19.3 & 8.0 & 54.2 & 10.3 & 1.5 & 0.2 \\
\hline & & $\begin{array}{l}\text { own brand } \\
\text { (10-14 mg } \\
\text { tar) } \\
\text { Matinee }\end{array}$ & 58 & $\hat{o} / 9$ & 37.1 & 11.1 & 19.3 & 8.0 & 52.3 & 12.4 & 1.4 & 0.3 \\
\hline & & $\begin{array}{l}\text { Extra Mild (4 } \\
\text { mg tar, } 0.8 \\
\text { mg nicotine) }\end{array}$ & 24 & $\delta / 9$ & 37.1 & 11.1 & 19.3 & 8.0 & 58.3 & 16.1 & & \\
\hline $\begin{array}{l}\text { Hitsman et } \\
\text { al }{ }^{14}\end{array}$ & 2005 & $\begin{array}{l}\text { own brand } \\
\text { (mean } 0.8 \mathrm{mg} \\
\text { nicotine) }\end{array}$ & 8 & $\delta / q$ & 35.5 & 16.9 & 18.8 & 2.3 & & & 2.4 & 0.7 \\
\hline
\end{tabular}




\begin{tabular}{|c|c|c|c|c|c|c|c|c|c|c|c|c|}
\hline $\begin{array}{l}\text { Puff } \\
\text { flow }\end{array}$ & SD & $\begin{array}{l}\text { Puff } \\
\text { interval } \\
\text { (sec) }\end{array}$ & SD & $\begin{array}{l}\text { Puff } \\
\text { count }\end{array}$ & SD & $\begin{array}{l}\text { Total } \\
\text { volume } \\
\text { (ml/cig) }\end{array}$ & SD & $\begin{array}{l}\text { Total } \\
\text { volume/ } \\
\text { day }\end{array}$ & $\begin{array}{l}\text { Fagerström } \\
\text { index }\end{array}$ & SD & Device & Comments \\
\hline 52.0 & 19.3 & 15.5 & 8.6 & 14.0 & 3.9 & 534.0 & & 10.5 & 7.4 & 1.4 & CRSSPT & $\begin{array}{l}\text { Current } \\
\text { non-mar- } \\
\text { ijua- } \\
\text { na-smok- } \\
\text { ing teens }\end{array}$ \\
\hline 24.2 & & 24.7 & & 12.6 & & 558.0 & & & & & & \\
\hline 31.7 & & 21.7 & & 16.6 & & 939.0 & & & & & & \\
\hline 30.6 & & 19.7 & & 15.0 & & 844.0 & & & & & & \\
\hline 33.2 & & 18.7 & & 18.8 & & 1135.0 & & & & & & \\
\hline 30.3 & & & & 12.5 & & 644.0 & & & & & & \\
\hline \multirow[t]{3}{*}{36.3} & & & & 15.1 & & 901.0 & & & & & & \\
\hline & & & & 12.7 & $\begin{array}{l}\text { SEM } \\
0.7\end{array}$ & 612.0 & SEM 34 & 18.4 & 6.4 & 2.0 & CRSSPT & \\
\hline & & & & 11.6 & $\begin{array}{l}\text { SEM } \\
0.5\end{array}$ & 547.0 & SEM 25 & 17.0 & 6.4 & 2.0 & CRSSPT & \\
\hline 57.1 & 3.5 & & & 11.5 & 0.7 & 691.2 & & 14.7 & 5.4 & $3-9$ & CRSSPT & \\
\hline 34.3 & 8.2 & 24.8 & 11.9 & 12.7 & 4.0 & 675.7 & 244.7 & 14.3 & 5.5 & 2.1 & CRSSPT & \\
\hline 35.0 & & 24.1 & 9.9 & 12.7 & 6.2 & 504.4 & 312.1 & 7.6 & 4.2 & 1.6 & CRSSPT & \\
\hline 38.2 & & 19.1 & 10.9 & 15.6 & 6.1 & 729.0 & 393.5 & 10.9 & 4.6 & 1.7 & CRSSPT & \\
\hline 51.1 & 16.0 & 16.8 & 10.9 & & & & & & & & CRSSPT & $\begin{array}{l}\text { cessation } \\
\text { trial NIDA }\end{array}$ \\
\hline 38.1 & 5.6 & 33.5 & 17.6 & 11.3 & 3.4 & 612.0 & 195.7 & 11.8 & & & CRSSPT & trial 1 \\
\hline \multirow[t]{3}{*}{37.9} & 6.1 & 35.6 & 18.4 & 11.1 & 3.3 & 580.5 & 206.9 & 11.2 & & & CRSSPT & trial 2 \\
\hline & & & & 13.4 & & 779.2 & 331.0 & 15.0 & & & CRSSPT & trial 3 \\
\hline & & 36.8 & 17.2 & 10.8 & 3.6 & & & & 5.6 & 1.7 & $\begin{array}{l}\text { Videotaping } \\
+ \\
\text { handtiming }\end{array}$ & \\
\hline
\end{tabular}




\begin{tabular}{|c|c|c|c|c|c|c|c|c|c|c|c|c|}
\hline Author & Year & Sort & $\mathrm{n}$ & $\begin{array}{l}\text { Gen- } \\
\text { der }\end{array}$ & Age & SD & $\begin{array}{l}\text { No of } \\
\text { cig/ } \\
\text { day }\end{array}$ & SD & $\begin{array}{l}\begin{array}{l}\text { Puff } \\
\text { volume } \\
\text { (ml) }\end{array} \\
\end{array}$ & SD & $\begin{array}{l}\begin{array}{l}\text { Puff } \\
\text { duration } \\
\text { (sec) }\end{array} \\
\end{array}$ & SD \\
\hline \multirow[t]{3}{*}{$\begin{array}{l}\text { Strasser et } \\
\text { al }{ }^{15}\end{array}$} & 2005 & $\begin{array}{l}\text { Marlboro } \\
\text { Light } 100 \\
\text { HP (10 mg } \\
\text { tar, } 0.8 \mathrm{mg} \\
\text { nicotine) }\end{array}$ & 12 & o/q & 21.6 & 4.5 & 17.5 & 12.5 & 63.4 & SE 8.4 & 1.6 & SE 0.2 \\
\hline & & $\begin{array}{l}\text { Carlton } 100 \\
\mathrm{HP}(1 \mathrm{mg} \\
\text { tar, } 0.1 \mathrm{mg} \\
\text { nicotine) }\end{array}$ & 12 & o/q & 21.6 & 4.5 & 18.0 & 12.5 & 85.1 & SE 10.9 & 2.0 & SE 0.3 \\
\hline & & $\begin{array}{l}\text { Carlton } 100 \\
\mathrm{HP}(1 \mathrm{mg} \\
\text { tar, } 0.1 \mathrm{mg} \\
\text { nicotine) }\end{array}$ & 12 & $\hat{\jmath}$ & 41.6 & 15.3 & 19.4 & 9.5 & 83.9 & & 1.9 & \\
\hline $\begin{array}{l}\text { Tidey et } \\
\text { al }{ }^{16}\end{array}$ & 2005 & $\begin{array}{l}\text { own brand } \\
\text { (mean } 1.1 \mathrm{mg} \\
\text { nicotine) }\end{array}$ & 20 & s/o & 51.0 & 12.0 & 29.0 & 11 & 47.5 & 10.4 & 1.3 & 0.2 \\
\hline $\begin{array}{l}\text { Breland et } \\
\text { al }{ }^{17}\end{array}$ & 2006 & $\begin{array}{l}\text { own brand } \\
\text { ( } 9.89 \mathrm{mg} \\
\text { tar, } 0.74 \mathrm{mg} \\
\text { nicotine) }\end{array}$ & 35 & olq & 22.4 & $\begin{array}{l}\mathrm{Cl} \\
21.19- \\
23.55\end{array}$ & 21.0 & $\begin{array}{l}\mathrm{Cl} 3.46- \\
5.55\end{array}$ & 51.0 & $\begin{array}{l}\mathrm{Cl} \\
45.70- \\
56.24\end{array}$ & 1.4 & $\begin{array}{l}\mathrm{Cl} 1.24- \\
1.52\end{array}$ \\
\hline $\begin{array}{l}\text { Franken et } \\
\text { al }{ }^{18}\end{array}$ & 2006 & own brand & 66 & $3 / 9$ & 15.1 & 1.3 & 19.0 & 8.4 & 36.0 & 13.5 & 1.1 & 0.4 \\
\hline \multirow[t]{2}{*}{$\begin{array}{l}\text { Hammond } \\
\text { et al }{ }^{19}\end{array}$} & 2006 & $\begin{array}{l}\text { own brand } \\
\text { (9-15 mg tar) }\end{array}$ & 51 & $3 / q$ & 37.1 & & $>5$ & & 53.3 & 11.9 & 1.4 & 0.3 \\
\hline & & $\begin{array}{l}\text { Matinee } \\
\text { Extra Mild (4 } \\
\text { mg tar, } 0.4 \\
\text { mg nicotine) }\end{array}$ & 21 & $3 / 9$ & 37.1 & & $>5$ & & 60.7 & 15.6 & 1.6 & 0.4 \\
\hline $\begin{array}{l}\text { Kassel et } \\
\text { al }{ }^{20}\end{array}$ & 2007 & $\begin{array}{l}\text { Research } \\
\text { cigarette } \\
(15.9 \mathrm{mg} \\
\text { tar, } 1.14 \mathrm{mg} \\
\text { nicotine) } \\
\text { Research } \\
\text { cigarette } \\
(17.9 \mathrm{mg} \\
\text { tar, } 0.06 \mathrm{mg} \\
\text { nicotine) }\end{array}$ & 19 & $\hat{o} / 9$ & 17.5 & 1.1 & 3.8 & 1.2 & 40.1 & 22.2 & 1.0 & 0.4 \\
\hline $\begin{array}{l}\text { Melikian et } \\
\text { al }^{21}\end{array}$ & 2007 & $\begin{array}{l}\text { own brand } \\
\text { (10.1 mg } \\
\text { tar, } 1.92 \mathrm{mg} \\
\text { nicotine) } \\
\text { own brand } \\
\text { (12.4 } \mathrm{mg} \\
\text { tar, } 2.2 \mathrm{mg} \\
\text { nicotine) }\end{array}$ & 128 & $\widehat{0}$ & 35.0 & $\begin{array}{l}\mathrm{Cl} 31.2- \\
35\end{array}$ & 16.8 & $\begin{array}{l}\mathrm{Cl} 14.7- \\
17.1\end{array}$ & 45.8 & & 1.5 & \\
\hline \multirow[t]{4}{*}{$\begin{array}{l}\text { Strasser et } \\
a l^{23}\end{array}$} & 2007 & $\begin{array}{l}\text { own brand } \\
\text { (mean } 12,9 \\
\text { mg tar, } 0.94 \\
\text { mg nicotine) }\end{array}$ & 50 & $3 / 9$ & 44.5 & 12.1 & 21.3 & 8.1 & 60.5 & $\begin{array}{l}\text { Cl 55.2- } \\
65.7\end{array}$ & 1.8 & $\begin{array}{l}\mathrm{Cl} 1.6- \\
1.9\end{array}$ \\
\hline & & $\begin{array}{l}\text { Quest (10 mg } \\
\text { tar, } 0.6 \mathrm{mg} \\
\text { nicotine) }\end{array}$ & 50 & $3 / q$ & 44.5 & 12.1 & 21.3 & 8.1 & 58.1 & $\begin{array}{l}\text { CI 53.3- } \\
62.8\end{array}$ & 1.8 & $\begin{array}{l}\mathrm{Cl} 1.6- \\
1.9\end{array}$ \\
\hline & & $\begin{array}{l}\text { Quest (10 mg } \\
\text { tar, } 0.3 \mathrm{mg} \\
\text { nicotine) }\end{array}$ & 50 & $\hat{o} / q$ & 44.5 & 12.1 & 21.3 & 8.1 & 55.9 & $\begin{array}{l}\text { Cl 51.0- } \\
60.8\end{array}$ & 1.7 & $\begin{array}{l}\mathrm{Cl} 1.5- \\
1.8\end{array}$ \\
\hline & & $\begin{array}{l}\text { Quest (10 mg } \\
\text { tar, } 0.05 \mathrm{mg} \\
\text { nicotine) }\end{array}$ & 50 & $3 / 9$ & 44.5 & 12.1 & 21.3 & 8.1 & 59.4 & $\begin{array}{l}\mathrm{Cl} 54.6- \\
64.3\end{array}$ & 1.8 & $\begin{array}{l}\mathrm{Cl} 1.6- \\
1.9\end{array}$ \\
\hline
\end{tabular}




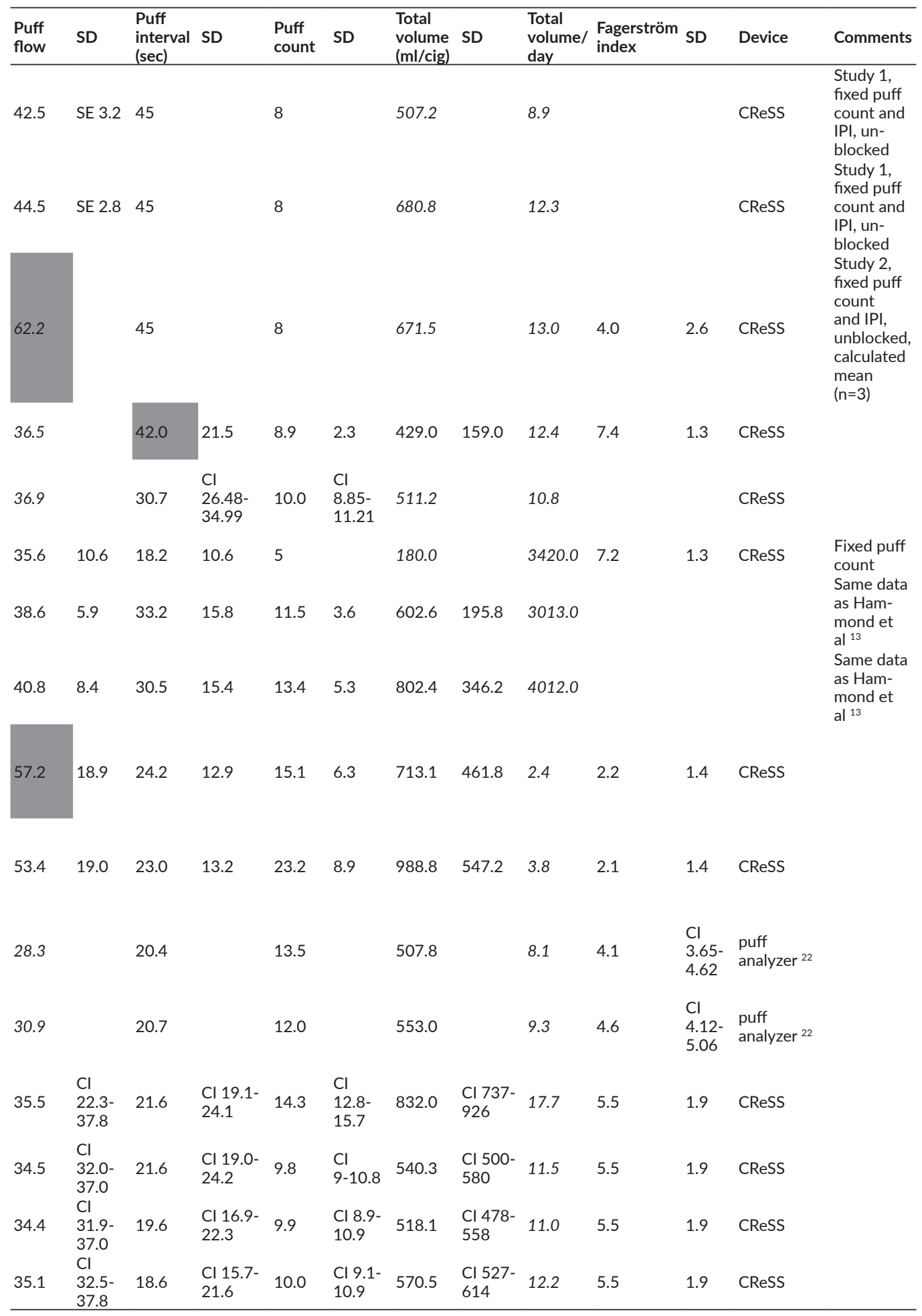




\begin{tabular}{|c|c|c|c|c|c|c|c|c|c|c|c|c|}
\hline Author & Year & Sort & $\mathrm{n}$ & $\begin{array}{l}\text { Gen- } \\
\text { der }\end{array}$ & Age & SD & $\begin{array}{l}\text { No of } \\
\text { cig/ } \\
\text { day }\end{array}$ & SD & $\begin{array}{l}\text { Puff } \\
\text { volume } \\
\text { (ml) }\end{array}$ & SD & $\begin{array}{l}\text { Puff } \\
\text { duration } \\
\text { (sec) }\end{array}$ & SD \\
\hline $\begin{array}{l}\text { Strasser et } \\
\text { al } 24\end{array}$ & 2007 & own brand & 119 & j/q & 45.8 & 10.8 & 21.2 & 8.1 & 55.1 & 16.9 & & \\
\hline $\begin{array}{l}\text { Attwood et } \\
\text { al } 25\end{array}$ & 2008 & own brand & 55 & $3 / 9$ & 22.0 & 4.0 & 11.0 & 5 & 49.0 & 12.0 & 1.6 & 0.4 \\
\hline $\begin{array}{l}\text { Collins et } \\
\text { al }^{26}\end{array}$ & 2008 & own brand & 67 & $\hat{0} / 9$ & 15.3 & 1.3 & $>10$ & & 38.7 & & 1.1 & \\
\hline \multirow[t]{13}{*}{ Rees et al ${ }^{27}$} & 2008 & Marlboro & & & & & & & & & & \\
\hline & & $\begin{array}{l}\text { Light (11 mg } \\
\text { tar, } 0.8 \mathrm{mg} \\
\text { nicotine) }\end{array}$ & 17 & $\hat{b} / 9$ & 27.7 & $\begin{array}{l}\text { Cl 24.3- } \\
31.0\end{array}$ & 15.7 & $\begin{array}{l}\mathrm{Cl} 12.0- \\
19.3\end{array}$ & 50.7 & 19.6 & 1.4 & 0.5 \\
\hline & & $\begin{array}{l}\text { Marlboro } \\
\text { Light (11 mg } \\
\text { tar, } 0.8 \mathrm{mg} \\
\text { nicotine) } \\
\text { Marlboro }\end{array}$ & 17 & J/P & 27.7 & $\begin{array}{l}\mathrm{Cl} 24.3- \\
31.0\end{array}$ & 15.7 & $\begin{array}{l}\mathrm{Cl} 12.0- \\
19.3\end{array}$ & 51.2 & 17.3 & 1.4 & 0.5 \\
\hline & & $\begin{array}{l}\text { Light (11 mg } \\
\text { tar, } 0.8 \mathrm{mg} \\
\text { nicotine) } \\
\text { Marlboro }\end{array}$ & 15 & 3/9 & 27.8 & $\begin{array}{l}\mathrm{Cl} 35.5- \\
32.1\end{array}$ & 15.9 & $\begin{array}{l}\mathrm{Cl} 9.5- \\
22.2\end{array}$ & 47.4 & 16.9 & 1.3 & 0.4 \\
\hline & & $\begin{array}{l}\text { Light (11 mg } \\
\text { tar, } 0.8 \mathrm{mg} \\
\text { nicotine) }\end{array}$ & 15 & $3 / 9$ & 27.8 & $\begin{array}{l}\mathrm{Cl} 35.5- \\
32.1\end{array}$ & 15.9 & $\begin{array}{l}\mathrm{Cl} 9.5- \\
22.2\end{array}$ & 41.0 & 18.0 & 1.3 & 0.5 \\
\hline & & $\begin{array}{l}\text { Marlboro } \\
\text { ultraLight (6 } \\
\text { mg tar, } 0.5 \\
\text { mg nicotine) }\end{array}$ & 17 & $3 / 9$ & 27.7 & $\begin{array}{l}\text { Cl 24.3- } \\
31.0\end{array}$ & 15.7 & $\begin{array}{l}\mathrm{Cl} 12.0- \\
19.3\end{array}$ & 51.4 & 19.0 & 1.3 & 0.4 \\
\hline & & $\begin{array}{l}\text { Marlboro } \\
\text { ultraLight (6 } \\
\text { mg tar, } 0.5 \\
\text { mg nicotine) }\end{array}$ & 17 & $\hat{o} / q$ & 27.7 & $\begin{array}{l}\mathrm{Cl} 24.3- \\
31.0\end{array}$ & 15.7 & $\begin{array}{l}\mathrm{Cl} 12.0- \\
19.3\end{array}$ & 49.9 & 18.3 & 1.4 & 0.5 \\
\hline & & $\begin{array}{l}\text { Marlboro } \\
\text { ultraLight (6 } \\
\text { mg tar, } 0.5 \\
\text { mg nicotine) }\end{array}$ & 15 & $\hat{o} / q$ & 27.8 & $\begin{array}{l}\text { Cl 35.5- } \\
32.1\end{array}$ & 15.9 & $\begin{array}{l}\mathrm{Cl} 9.5- \\
22.2\end{array}$ & 50.1 & 15.6 & 1.4 & 0.4 \\
\hline & & $\begin{array}{l}\text { Marlboro } \\
\text { ultraLight (6 } \\
\text { mg tar, } 0.5 \\
\text { mg nicotine) }\end{array}$ & 15 & $3 / 9$ & 27.8 & $\begin{array}{l}\text { Cl 35.5- } \\
32.1\end{array}$ & 15.9 & $\begin{array}{l}\mathrm{Cl} 9.5- \\
22.2\end{array}$ & 52.2 & 15.7 & 1.5 & 0.5 \\
\hline & & $\begin{array}{l}\text { Marlboro } \\
\text { UltraSmooth } \\
\text { (5 mg tar, } 0.4 \\
\text { mg nicotine) }\end{array}$ & 17 & $\delta / 9$ & 27.7 & $\begin{array}{l}\text { Cl 24.3- } \\
31.0\end{array}$ & 15.7 & $\begin{array}{l}\mathrm{Cl} 12.0- \\
19.3\end{array}$ & 54.2 & 19.4 & 1.4 & 0.4 \\
\hline & & $\begin{array}{l}\text { Marlboro } \\
\text { UltraSmooth } \\
\text { (5 mg tar, } 0.4 \\
\text { mg nicotine) }\end{array}$ & 17 & $\hat{3} / 9$ & 27.7 & $\begin{array}{l}\text { Cl 24.3- } \\
31.0\end{array}$ & 15.7 & $\begin{array}{l}\mathrm{Cl} 12.0- \\
19.3\end{array}$ & 53.5 & 19.2 & 1.4 & 0.5 \\
\hline & & $\begin{array}{l}\text { Marlboro } \\
\text { UltraSmooth } \\
\text { ( } 5 \text { mg tar, } 0.4 \\
\text { mg nicotine) }\end{array}$ & 15 & $3 / 9$ & 27.8 & $\begin{array}{l}\mathrm{Cl} 35.5- \\
32.1\end{array}$ & 15.9 & $\begin{array}{l}\mathrm{Cl} 9.5- \\
22.2\end{array}$ & 56.7 & 15.2 & 1.5 & 0.4 \\
\hline & & $\begin{array}{l}\text { Marlboro } \\
\text { UltraSmooth } \\
\text { ( } 5 \text { mg tar, } 0.4 \\
\text { mg nicotine) }\end{array}$ & 15 & o/9 & 27.8 & $\begin{array}{l}\text { Cl 35.5- } \\
32.1\end{array}$ & 15.9 & $\begin{array}{l}\mathrm{Cl} 9.5- \\
22.2\end{array}$ & 54.6 & 19.4 & 1.5 & 0.5 \\
\hline $\begin{array}{l}\text { Shahab et } \\
\text { al }{ }^{28}\end{array}$ & 2008 & own brand & 131 & o/9 & 31.4 & 10.4 & 13.4 & 5.7 & 54.2 & 14.0 & 1.5 & 0.5 \\
\hline
\end{tabular}




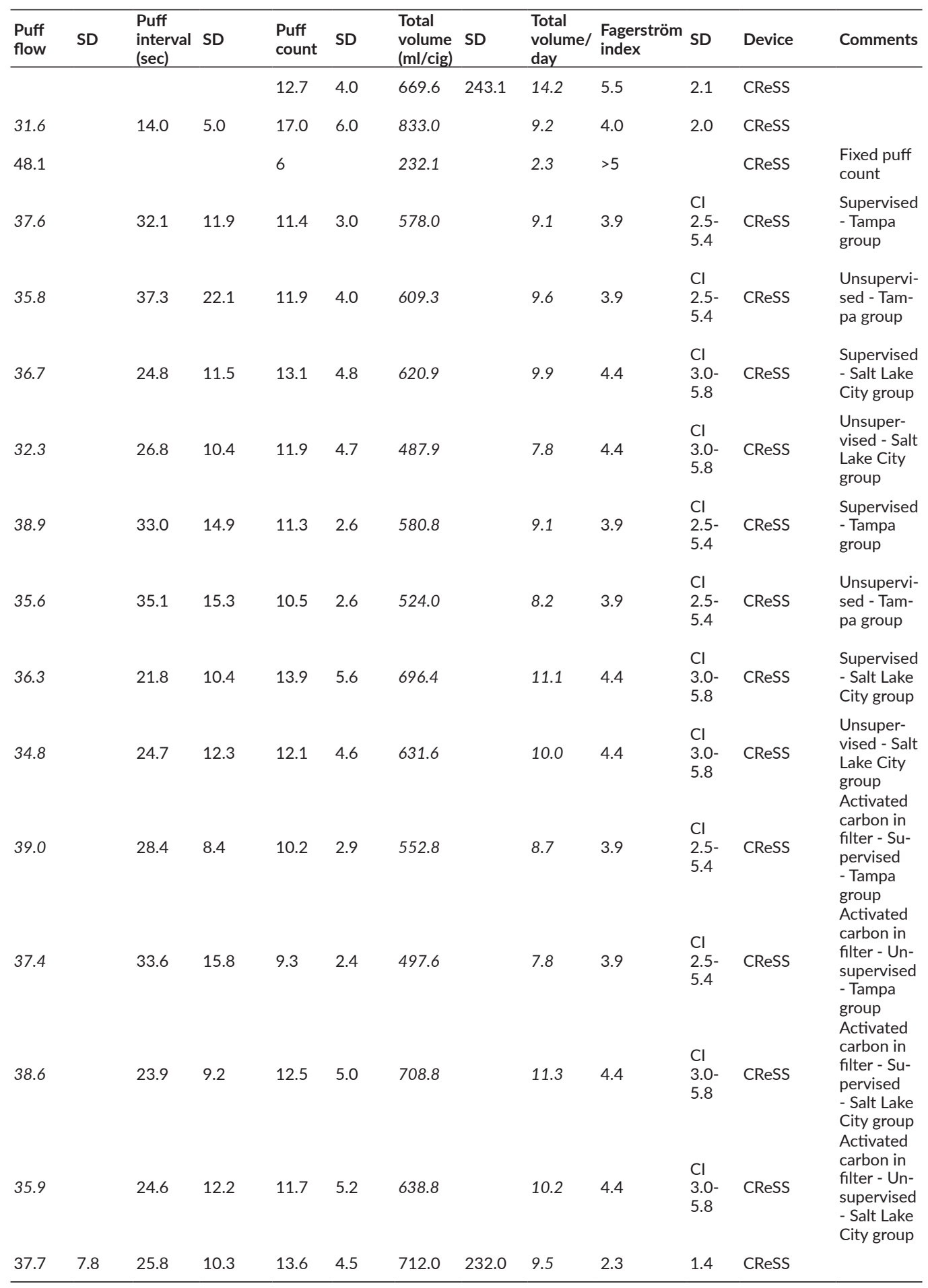




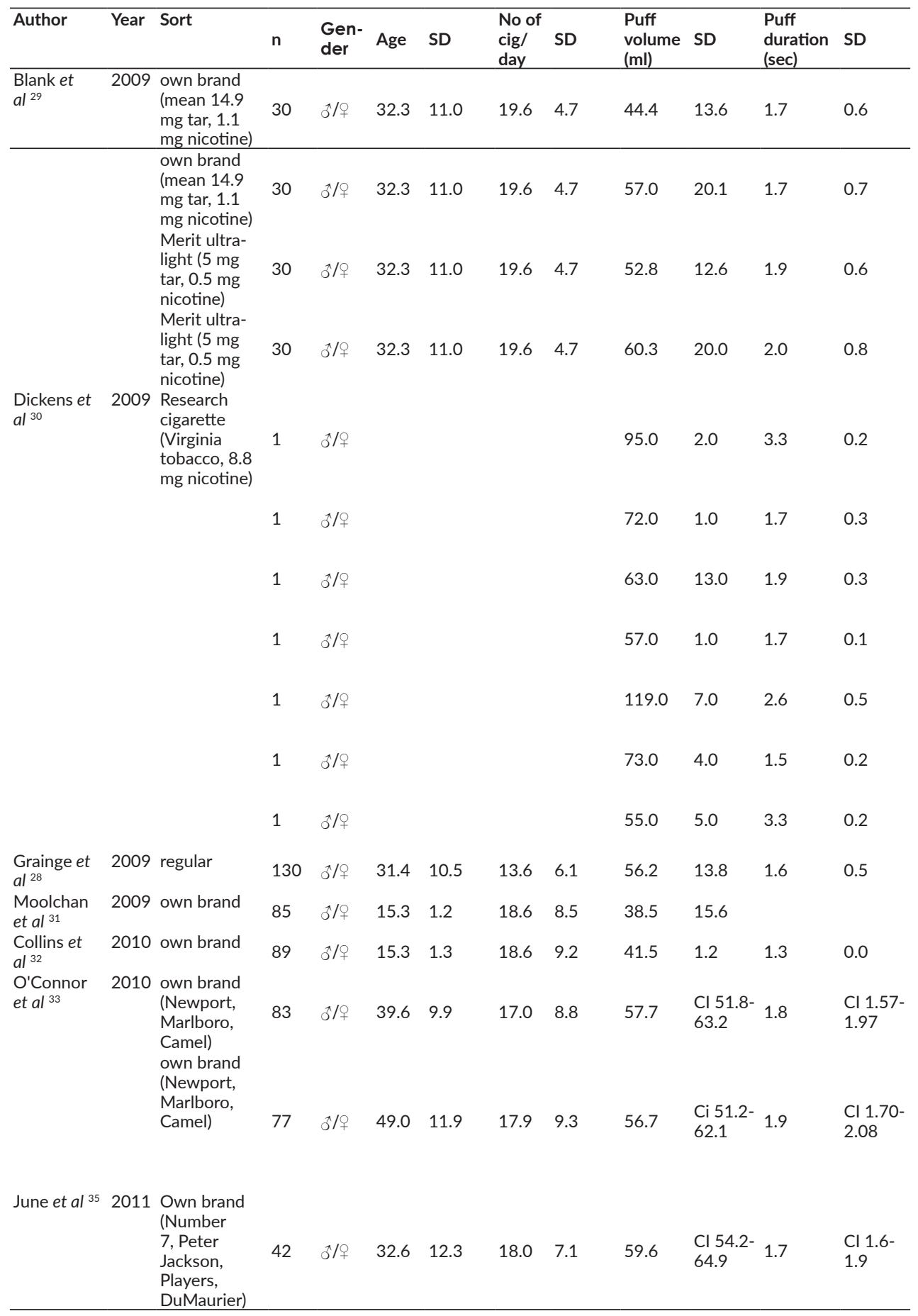




\begin{tabular}{|c|c|c|c|c|c|c|c|c|c|c|c|c|}
\hline $\begin{array}{l}\text { Puff } \\
\text { flow }\end{array}$ & SD & $\begin{array}{l}\text { Puff } \\
\text { interval } \\
\text { (sec) }\end{array}$ & SD & $\begin{array}{l}\text { Puff } \\
\text { count }\end{array}$ & SD & $\begin{array}{l}\text { Total } \\
\text { volume } \\
\text { (ml/cig) }\end{array}$ & SD & $\begin{array}{l}\text { Total } \\
\text { volume/ } \\
\text { day }\end{array}$ & $\begin{array}{l}\text { Fagerström } \\
\text { index }\end{array}$ & SD & Device & Comments \\
\hline 26.1 & & 18.2 & 7.6 & 9.4 & 3.0 & 411.4 & 170.7 & 8.1 & 6.0 & 2.0 & $\begin{array}{l}\text { Portable } \\
\text { CReSS }\end{array}$ & \\
\hline 33.5 & & 18.1 & 8.8 & 9.7 & 3.3 & 578.7 & 327.2 & 8.1 & 6.0 & 2.0 & $\begin{array}{l}\text { Desktop } \\
\text { CReSS }\end{array}$ & \\
\hline 27.8 & & 16.7 & 7.7 & 10.1 & 3.4 & 528.5 & 207.2 & 10.4 & 6.0 & 2.0 & $\begin{array}{l}\text { Portable } \\
\text { CReSS }\end{array}$ & \\
\hline 30.2 & & 15.2 & 7.2 & 10.2 & 3.1 & 614.2 & 301.1 & 8.1 & 6.0 & 2.0 & $\begin{array}{l}\text { Desktop } \\
\text { CReSS }\end{array}$ & \\
\hline 29.5 & 2.4 & & & & & 572.0 & & & & & $\begin{array}{l}\text { Smoker } \\
\text { Analyser } \\
\text { (SA7) }\end{array}$ & \\
\hline 40.7 & 1.7 & & & & & 573.0 & & & & & $\begin{array}{l}\text { Smoker } \\
\text { Analyser } \\
\text { (SA7) } \\
\text { Smoker }\end{array}$ & \\
\hline 35.0 & 2.9 & & & & & 376.0 & & & & & $\begin{array}{l}\text { Analyser } \\
\text { (SA7) } \\
\text { Smoker }\end{array}$ & \\
\hline 34.5 & 1.1 & & & & & 400.0 & & & & & $\begin{array}{l}\text { Analyser } \\
\text { (SA7) } \\
\text { Smoker }\end{array}$ & \\
\hline 27.5 & 3.0 & & & & & 717.0 & & & & & $\begin{array}{l}\text { Analyser } \\
\text { (SA7) } \\
\text { Smoker }\end{array}$ & \\
\hline 35.0 & 0.9 & & & & & 440.0 & & & & & $\begin{array}{l}\text { Analyser } \\
\text { (SA7) } \\
\text { Smoker }\end{array}$ & \\
\hline 29.5 & 2.4 & & & & & 441.0 & & & & & $\begin{array}{l}\text { Analyser } \\
\text { (SA7) }\end{array}$ & \\
\hline \multirow[t]{2}{*}{35.6} & & 26.6 & 10.5 & 13.2 & 4.1 & 711.7 & 208.3 & 9.7 & & & $\begin{array}{l}\text { Portable } \\
\text { CReSS }\end{array}$ & \\
\hline & & & & 5 & & 599.5 & 201.6 & 11.1 & 7.0 & 1.2 & CReSS & $\begin{array}{l}\text { Fixed puff } \\
\text { count }\end{array}$ \\
\hline 53.9 & 2.0 & 14.5 & 0.7 & 15.2 & & 630.8 & & 11.7 & 7.3 & 1.3 & CReSS & \\
\hline 36.5 & $\begin{array}{l}\mathrm{Cl} \\
33.4- \\
39.7\end{array}$ & 17.6 & $\begin{array}{l}\mathrm{Cl} 14.8- \\
20.5\end{array}$ & 14.4 & $\begin{array}{l}\mathrm{Cl} \\
13.1- \\
15.7\end{array}$ & 828.0 & $\begin{array}{l}\mathrm{Cl} 750- \\
905\end{array}$ & 14.1 & & & $\begin{array}{l}\text { Portable } \\
\text { CReSS }\end{array}$ & $\begin{array}{l}\text { Same data } \\
\text { as June et } \\
\text { al }^{34}\end{array}$ \\
\hline 31.5 & $\begin{array}{l}\mathrm{Cl} \\
28.5- \\
34.6\end{array}$ & 21.3 & $\begin{array}{l}\text { Cl 18.6- } \\
24.0\end{array}$ & 13.7 & $\begin{array}{l}\mathrm{Cl} \\
12.5- \\
15.0\end{array}$ & 611.0 & $\begin{array}{l}\text { Cl 539- } \\
682\end{array}$ & 10.9 & & & $\begin{array}{l}\text { Portable } \\
\text { CReSS }\end{array}$ & $\begin{array}{l}\text { Same data } \\
\text { as June } \\
\text { et al }{ }^{34} \text {, } \\
\text { Reduced } \\
\text { Ignition } \\
\text { Propensity } \\
\text { type }\end{array}$ \\
\hline 36.8 & $\begin{array}{l}\mathrm{Cl} \\
33.8- \\
39.8\end{array}$ & 19.2 & $\begin{array}{l}\mathrm{Cl} 17.0- \\
21.4\end{array}$ & 14.1 & $\begin{array}{l}\mathrm{Cl} \\
12.7- \\
15.5\end{array}$ & 834.9 & $\begin{array}{l}\mathrm{Cl} \\
733.1- \\
936.7\end{array}$ & 15.0 & & & $\begin{array}{l}\text { Portable } \\
\text { CReSS }\end{array}$ & \\
\hline
\end{tabular}




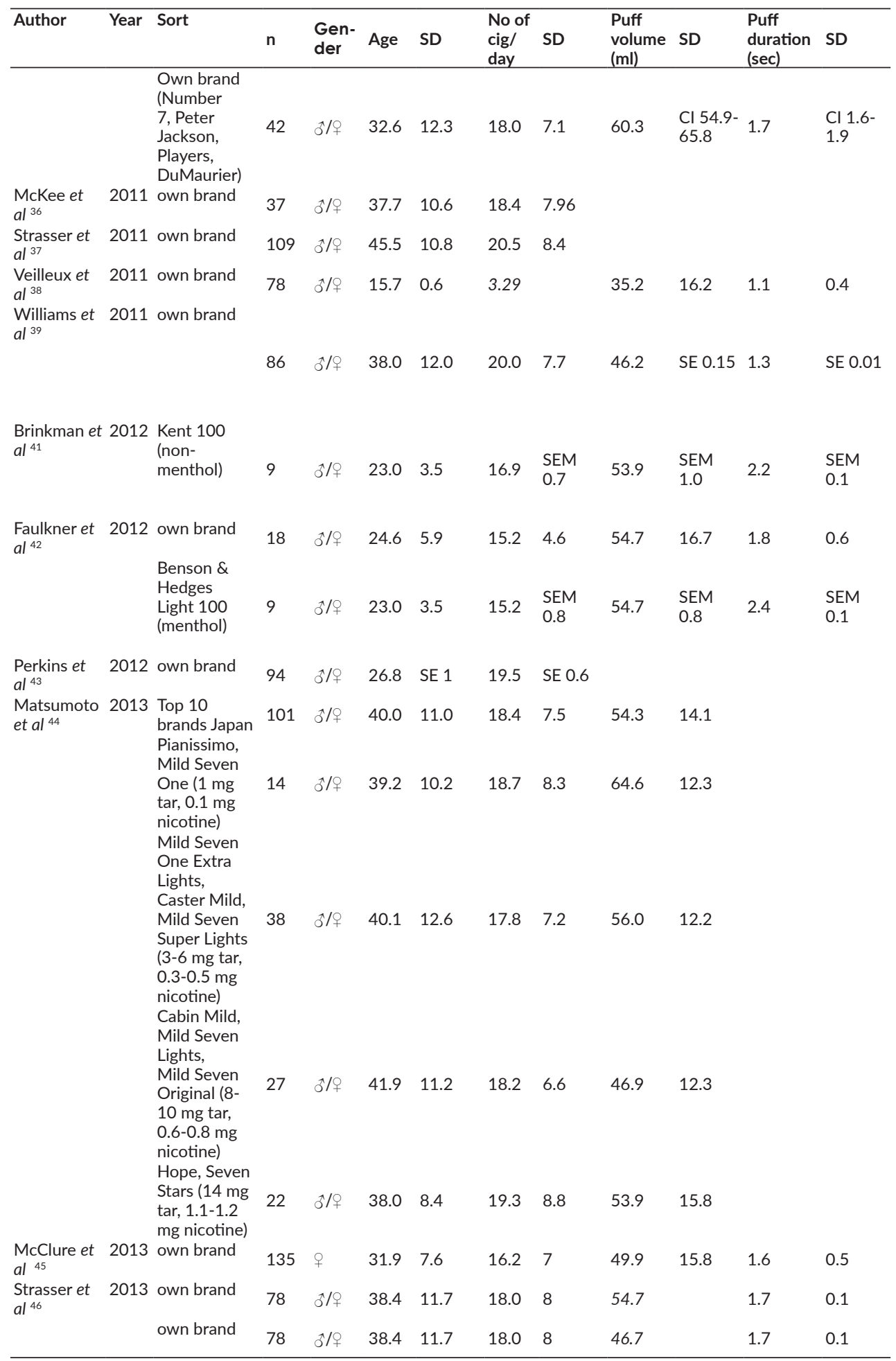




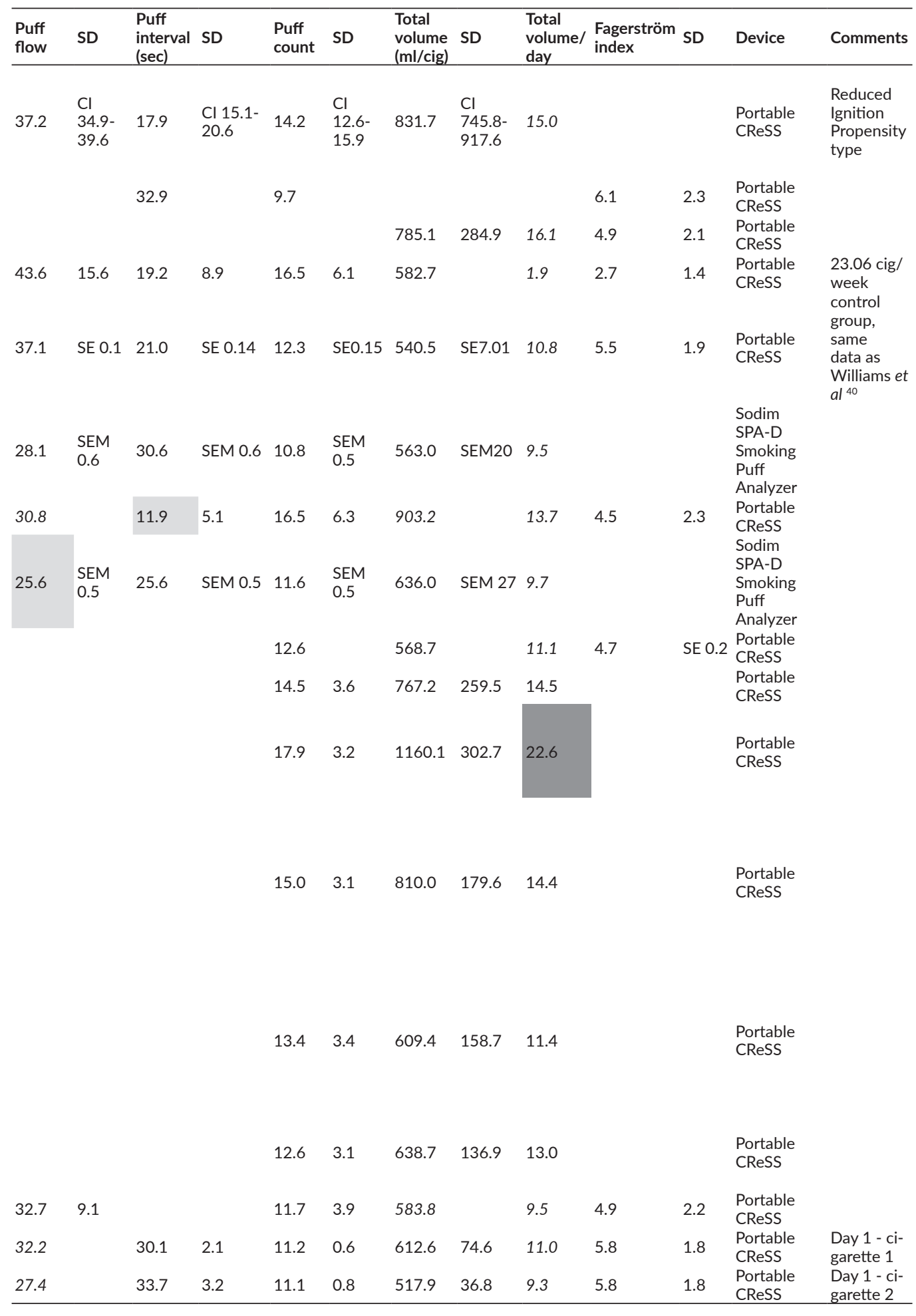




\begin{tabular}{|c|c|c|c|c|c|c|c|c|c|c|c|c|}
\hline Author & Year & Sort & $\mathrm{n}$ & $\begin{array}{l}\text { Gen- } \\
\text { der }\end{array}$ & Age & SD & $\begin{array}{l}\text { No of } \\
\text { cig/ } \\
\text { day }\end{array}$ & SD & $\begin{array}{l}\text { Puff } \\
\text { volume } \\
\text { (ml) }\end{array}$ & SD & $\begin{array}{l}\text { Puff } \\
\text { duration } \\
\text { (sec) }\end{array}$ & SD \\
\hline & & own brand & 78 & $3 / 9$ & 38.4 & 11.7 & 18.0 & 8 & 44.5 & & 1.6 & 0.1 \\
\hline $\begin{array}{l}\text { Tidey et } \\
\text { al } 47\end{array}$ & 2013 & own brand & 26 & $3 / q$ & 44.5 & 10.9 & 23.5 & 6.5 & & & & \\
\hline \multirow[t]{4}{*}{$\begin{array}{l}\text { Hammond } \\
\text { et al } 48\end{array}$} & 2014 & own brand & 72 & $\delta / q$ & 37.2 & 11.9 & 16.1 & 6.3 & 63.5 & 22.4 & & \\
\hline & & $\begin{array}{l}\text { Quest } 1 \text { (0.6 } \\
\text { mg nicotine) }\end{array}$ & 71 & $3 / q$ & 37.2 & 11.9 & 14.5 & 4.6 & 64.3 & 22.3 & & \\
\hline & & $\begin{array}{l}\text { Quest } 2 \text { (0.3 } \\
\text { mg nicotine) }\end{array}$ & 71 & $\hat{s} / 9$ & 37.2 & 11.9 & 13.8 & 4.3 & 64.2 & 17.2 & & \\
\hline & & $\begin{array}{l}\text { Quest } 3 \text { (0.05 } \\
\text { mg nicotine) }\end{array}$ & 72 & $3 / 9$ & 37.2 & 11.9 & 13.2 & 4.5 & 69.3 & 18.8 & & \\
\hline $\begin{array}{l}\text { Norton et } \\
\text { al }^{49}\end{array}$ & 2014 & own brand & 16 & $\hat{J} / 9$ & 45.5 & SE 3.5 & 16.1 & SE 1.4 & 67.5 & SE 6.3 & 3.0 & SE 1 \\
\hline \multirow[t]{4}{*}{$\begin{array}{l}\text { Schneider } \\
\text { et al }{ }^{50}\end{array}$} & 2014 & own brand & 25 & $3 / q$ & 45.9 & 12.4 & 16.7 & 4.6 & 62.2 & 18.5 & 1.7 & 0.5 \\
\hline & & own brand & 25 & $3 / 9$ & 45.9 & 12.4 & 16.7 & 4.6 & 58.8 & 18.3 & 1.6 & 0.4 \\
\hline & & own brand & 23 & $3 / 9$ & 39.1 & 13.8 & 15.6 & 4.22 & 55.3 & 18.5 & 1.7 & 0.4 \\
\hline & & own brand & 23 & $3 / 9$ & 39.1 & 13.8 & 15.6 & 4.22 & 54.8 & 16.9 & 1.7 & 0.5 \\
\hline \multirow[t]{3}{*}{$\begin{array}{l}\text { Appleton et } \\
\text { al }{ }^{51}\end{array}$} & 2015 & $\begin{array}{l}\text { own brand } \\
\text { (>13 mg tar) }\end{array}$ & 20 & $\hat{\sigma}$ & 35.3 & 6.1 & $10-30$ & & 69.7 & 18.6 & 2.3 & 0.6 \\
\hline & & $\begin{array}{l}\text { Test cigarette } \\
\text { High Tar }(\sim 15 \\
\text { mg tar })\end{array}$ & 20 & $\hat{0}$ & 35.4 & 6.4 & $\begin{array}{l}22.4- \\
24.0\end{array}$ & & 59.4 & 18.3 & 2.0 & 0.6 \\
\hline & & $\begin{array}{l}\text { Test Cigarette } \\
\text { Low tar }(\sim 7 \\
\text { mg tar) }\end{array}$ & 19 & $\hat{0}$ & 35.1 & 6.2 & $\begin{array}{l}20.5- \\
22.6\end{array}$ & & 69.3 & 19.2 & 2.4 & 0.7 \\
\hline \multirow[t]{3}{*}{$\begin{array}{l}\text { Brinkman et } \\
\text { al }{ }^{52}\end{array}$} & 2015 & $\begin{array}{l}\text { GPC Full } \\
\text { flavor and } \\
\text { GPC Ultra } \\
\text { Light }\end{array}$ & 24 & $3 / q$ & $\begin{array}{l}18- \\
30\end{array}$ & & $>20$ & & 55.6 & $\begin{array}{l}\mathrm{Cl} \\
53.71- \\
57.49\end{array}$ & 2.1 & $\begin{array}{l}\mathrm{Cl} \\
2.042- \\
2.198\end{array}$ \\
\hline & & $\begin{array}{l}\text { GPC Full } \\
\text { flavor (15.2 } \\
\text { mg tar, } 0.97 \\
\text { mg nicotine) }\end{array}$ & 24 & $3 / 9$ & $\begin{array}{l}18- \\
30\end{array}$ & & $>20$ & & 51.9 & $\begin{array}{l}\mathrm{Cl} \\
49.42- \\
54.45\end{array}$ & 2.0 & $\begin{array}{l}\mathrm{Cl} 1.9- \\
2.13\end{array}$ \\
\hline & & $\begin{array}{l}\text { GPC Ultra } \\
\text { Light }(5.8 \mathrm{mg} \\
\text { tar, } 0.51 \mathrm{mg} \\
\text { nicotine) }\end{array}$ & 24 & $3 / 9$ & $\begin{array}{l}18- \\
30\end{array}$ & & $>20$ & & 59.6 & $\begin{array}{l}\mathrm{Cl} \\
56.94- \\
62.37\end{array}$ & 2.2 & $\begin{array}{l}\text { Cl 2.14- } \\
2.34\end{array}$ \\
\hline \multirow[t]{2}{*}{$\begin{array}{l}\text { Chung et } \\
\text { al } 53\end{array}$} & 2015 & $\begin{array}{l}\text { own brand - } \\
\text { white }\end{array}$ & 26 & $\hat{0}$ & 39.2 & 10.1 & $>12$ & & 57.2 & SE 2.69 & 1.6 & SE 0.06 \\
\hline & & $\begin{array}{l}\text { own brand- } \\
\text { korean }\end{array}$ & 27 & $\hat{\sigma}$ & 37.3 & 9.7 & 12.0 & 1.82 & 59.6 & SE 3 & 1.5 & SE 0.07 \\
\hline Gass et al ${ }^{54}$ & 2016 & own brand & 107 & $\hat{o} / q$ & 25.0 & 5.9 & 2.7 & 2.2 & 31.4 & 13.0 & 1.2 & 0.5 \\
\hline \multirow[t]{2}{*}{$\begin{array}{l}\text { Krebs et } \\
\text { al }^{55}\end{array}$} & 2016 & own brand & & & & & & & & & & \\
\hline & & & 332 & $3 / q$ & 37.6 & 11.6 & 16.5 & 6.2 & 48.2 & 14.9 & 1.6 & 0.4 \\
\hline
\end{tabular}




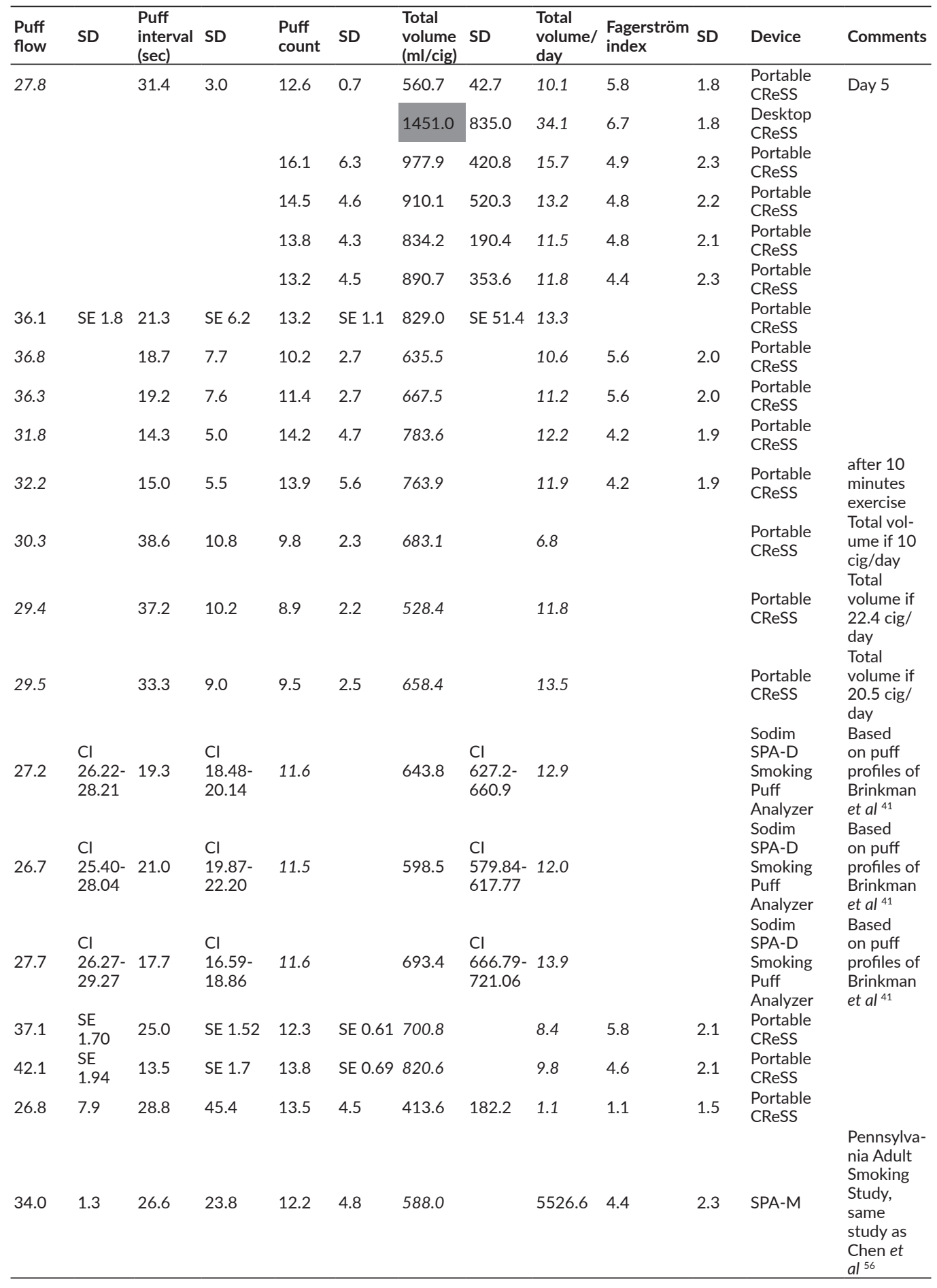




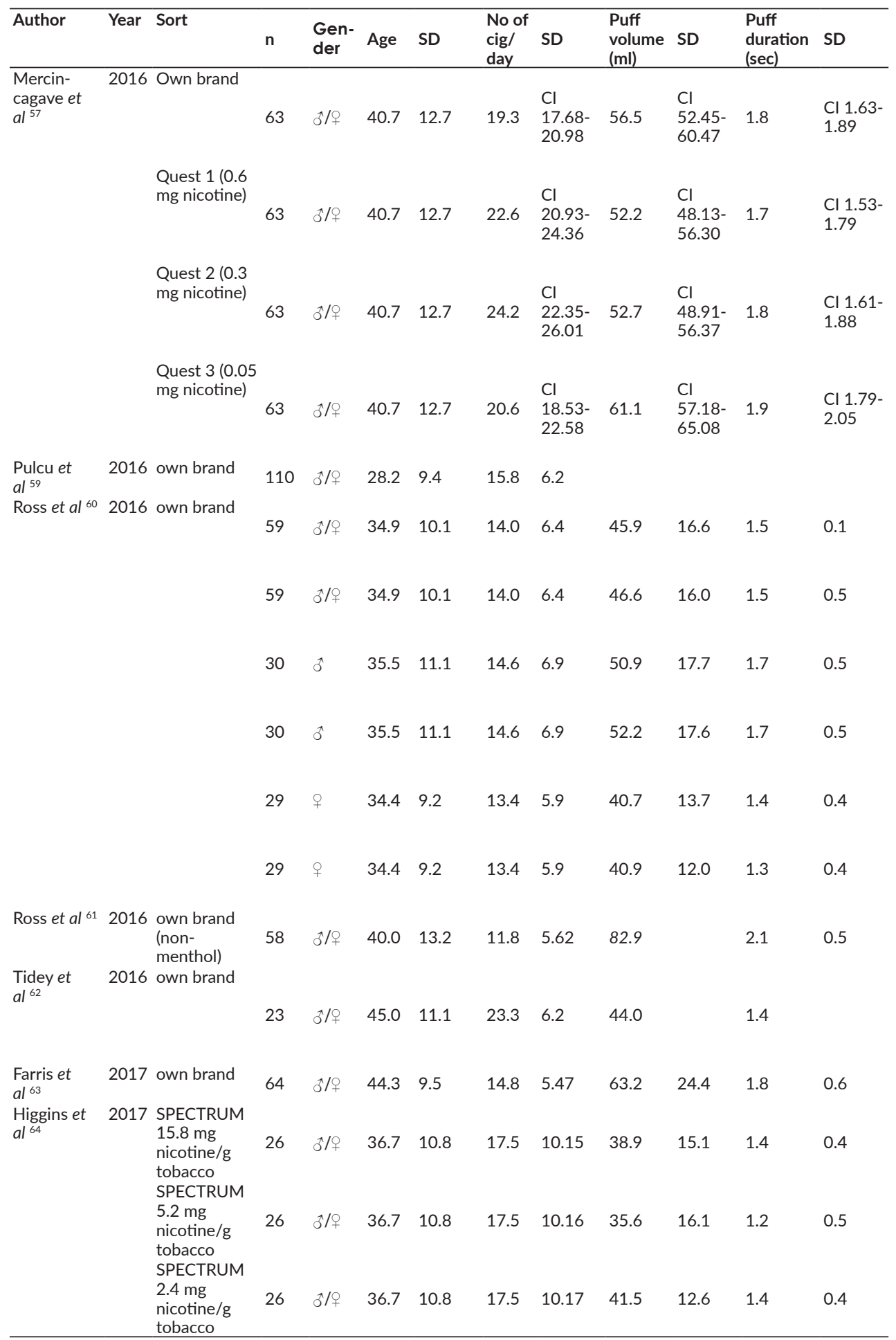




\begin{tabular}{|c|c|c|c|c|c|c|c|c|c|c|c|c|}
\hline $\begin{array}{l}\text { Puff } \\
\text { flow }\end{array}$ & SD & $\begin{array}{l}\text { Puff } \\
\text { interval } \\
\text { (sec) }\end{array}$ & SD & $\begin{array}{l}\text { Puff } \\
\text { count }\end{array}$ & SD & $\begin{array}{l}\text { Total } \\
\text { volume } \\
\text { (ml/cig) }\end{array}$ & SD & $\begin{array}{l}\text { Total } \\
\text { volume/ } \\
\text { day }\end{array}$ & $\begin{array}{l}\text { Fagerström } \\
\text { index }\end{array}$ & SD & Device & Comments \\
\hline 32.1 & & 24.4 & $\begin{array}{l}21.34- \\
27.40\end{array}$ & 13.8 & $\begin{array}{l}\mathrm{Cl} \\
12.63- \\
14.88\end{array}$ & 756.0 & $\begin{array}{l}\mathrm{Cl} \\
690.68- \\
821.34\end{array}$ & 14.6 & 5.6 & 1.9 & $\begin{array}{l}\text { Portable } \\
\text { CReSS }\end{array}$ & $\begin{array}{l}\text { same } \\
\text { study as } \\
\text { Mercin- } \\
\text { cagave et } \\
\text { al }^{58}\end{array}$ \\
\hline 31.5 & & 20.9 & $\begin{array}{l}\mathrm{Cl} \\
18.36- \\
23.46\end{array}$ & 10.8 & $\begin{array}{l}\mathrm{Cl} \\
9.87- \\
11.81\end{array}$ & 541.0 & $\begin{array}{l}\mathrm{Cl} \\
489.42- \\
592.51\end{array}$ & 12.2 & 5.6 & 1.9 & $\begin{array}{l}\text { Portable } \\
\text { CReSS }\end{array}$ & $\begin{array}{l}\text { same } \\
\text { study as } \\
\text { Mercin- } \\
\text { cagave et } \\
\text { al }^{58}\end{array}$ \\
\hline 30.1 & & 19.1 & $\begin{array}{l}\mathrm{Cl} \\
16.51- \\
21.58\end{array}$ & 10.9 & $\begin{array}{l}\mathrm{Cl} \\
9.92- \\
11.91\end{array}$ & 545.1 & $\begin{array}{l}\mathrm{Cl} \\
499.34- \\
590.86\end{array}$ & 13.2 & 5.6 & 1.9 & $\begin{array}{l}\text { Portable } \\
\text { CReSS }\end{array}$ & $\begin{array}{l}\text { same } \\
\text { study as } \\
\text { Mercin- } \\
\text { cagave et } \\
\text { al }^{58}\end{array}$ \\
\hline \multirow[t]{2}{*}{31.8} & & 17.5 & $\begin{array}{l}\mathrm{Cl} \\
15.04- \\
19.91\end{array}$ & 11.8 & $\begin{array}{l}\mathrm{Cl} \\
10.63- \\
12.88\end{array}$ & 691.1 & $\begin{array}{l}\mathrm{Cl} \\
632.34- \\
749.91\end{array}$ & 14.2 & 5.6 & 1.9 & $\begin{array}{l}\text { Portable } \\
\text { CReSS }\end{array}$ & $\begin{array}{l}\text { same } \\
\text { study as } \\
\text { Mercin- } \\
\text { cagave et } \\
\text { al }^{58}\end{array}$ \\
\hline & & 26.6 & 11.4 & 14.4 & 4.0 & & & & & & $\begin{array}{l}\text { Portable } \\
\text { CReSS }\end{array}$ & \\
\hline 31.3 & 8.4 & 21.4 & 9.4 & 12.4 & 3.9 & 536.4 & 117.0 & 7.5 & 5.1 & 2.0 & $\begin{array}{l}\text { Portable } \\
\text { CReSS }\end{array}$ & $\begin{array}{l}\text { first cig- } \\
\text { arette of } \\
\text { the day } \\
\text { after } 4\end{array}$ \\
\hline 32.1 & 8.8 & 19.4 & 8.4 & 12.9 & 4.0 & 554.5 & 164.7 & 7.8 & 5.1 & 2.0 & $\begin{array}{l}\text { Portable } \\
\text { CReSS }\end{array}$ & $\begin{array}{l}\text { hours ad } \\
\text { libitum } \\
\text { smoking }\end{array}$ \\
\hline 31.4 & 10.5 & 21.2 & 7.3 & 11.4 & 2.8 & 559.5 & 200.9 & 8.2 & 4.5 & 2.0 & $\begin{array}{l}\text { Portable } \\
\text { CReSS }\end{array}$ & $\begin{array}{l}\text { first cig- } \\
\text { arette of } \\
\text { the day } \\
\text { after } 4\end{array}$ \\
\hline 31.9 & 11.0 & 18.7 & 8.4 & 12.2 & 3.2 & 582.2 & 171.8 & 8.5 & 4.5 & 2.0 & $\begin{array}{l}\text { Portable } \\
\text { CReSS }\end{array}$ & $\begin{array}{l}\text { hours ad } \\
\text { libitum } \\
\text { smoking }\end{array}$ \\
\hline 31.1 & 5.8 & 21.6 & 11.3 & 13.4 & 4.6 & 512.5 & 148.1 & 6.9 & 5.7 & 1.8 & $\begin{array}{l}\text { Portable } \\
\text { CReSS }\end{array}$ & $\begin{array}{l}\text { first cig- } \\
\text { arette of } \\
\text { the day } \\
\text { after } 4\end{array}$ \\
\hline 32.2 & 5.9 & 20.0 & 8.4 & 13.7 & 4.7 & 526.7 & 155.3 & 7.1 & 5.7 & 1.8 & $\begin{array}{l}\text { Portable } \\
\text { CReSS }\end{array}$ & $\begin{array}{l}\text { hours ad } \\
\text { libitum } \\
\text { smoking }\end{array}$ \\
\hline 39.9 & 8.3 & & & 14.6 & 4.6 & 1213.3 & & 14.4 & 4.0 & 2.3 & $\begin{array}{l}\text { Portable } \\
\text { CReSS }\end{array}$ & \\
\hline 31.4 & & 35.0 & & 11.0 & & 500.0 & & 11.7 & & & $\begin{array}{l}\text { Portable } \\
\text { CReSS }\end{array}$ & $\begin{array}{l}\text { Graph } \\
\text { data, origi- } \\
\text { nates from } \\
\text { Tidey et } \\
\text { al }^{47}\end{array}$ \\
\hline 35.9 & & 14.3 & 5.4 & 20.4 & 7.4 & 1290.1 & & 19.1 & 4.6 & 1.5 & $\begin{array}{l}\text { Portable } \\
\text { CReSS }\end{array}$ & \\
\hline 28.8 & & 19.9 & 9.3 & 15.0 & 8.3 & 463.8 & 211.9 & 8.1 & 5.2 & 2.7 & $\begin{array}{l}\text { Desktop } \\
\text { CReSS }\end{array}$ & \\
\hline 28.9 & & 27.8 & 24.2 & 12.0 & 5.0 & 370.7 & 212.2 & 6.5 & 5.2 & 2.7 & $\begin{array}{l}\text { Desktop } \\
\text { CReSS }\end{array}$ & \\
\hline 29.9 & & 21.0 & 8.2 & 11.3 & 3.2 & 444.4 & 200.1 & 7.8 & 5.2 & 2.7 & $\begin{array}{l}\text { Desktop } \\
\text { CReSS }\end{array}$ & \\
\hline
\end{tabular}




\begin{tabular}{|c|c|c|c|c|c|c|c|c|c|c|c|c|}
\hline Author & Year & Sort & $\mathrm{n}$ & $\begin{array}{l}\text { Gen- } \\
\text { der }\end{array}$ & Age & SD & $\begin{array}{l}\text { No of } \\
\text { cig/ } \\
\text { day }\end{array}$ & $\mathrm{SD}$ & $\begin{array}{l}\text { Puff } \\
\text { volume } \\
\text { (ml) }\end{array}$ & SD & $\begin{array}{l}\text { Puff } \\
\text { duration } \\
\text { (sec) }\end{array}$ & SD \\
\hline & & SPECTRUM & & & & & & & & & & \\
\hline & & $\begin{array}{l}0.4 \mathrm{mg} \\
\text { nicotine/g } \\
\text { tobacco }\end{array}$ & 26 & $3 / 9$ & 36.7 & 10.8 & 17.5 & 10.18 & 38.6 & 12.5 & 1.4 & 0.4 \\
\hline \multirow[t]{2}{*}{ Hsu et al ${ }^{65}$} & 2017 & $\begin{array}{l}\text { own brand } \\
\text { (non- } \\
\text { menthol) }\end{array}$ & 34 & J/9 & 41.4 & 10.9 & $>10$ & & 52.7 & 18.0 & 1.6 & 0.8 \\
\hline & & $\begin{array}{l}\text { own brand } \\
\text { (menthol) }\end{array}$ & 71 & $3 / q$ & 43.8 & 9.3 & $>10$ & & 55.7 & 18.5 & 1.8 & 0.6 \\
\hline \multirow[t]{2}{*}{$\begin{array}{l}\text { Watson et } \\
\text { al } 66\end{array}$} & 2017 & $\begin{array}{l}\text { Kent } 100 \\
\text { (non- } \\
\text { menthol) }\end{array}$ & 42 & $\delta / 9$ & 35.0 & & 23.0 & & 47.7 & $\begin{array}{l}\text { SEM } \\
1.5\end{array}$ & 1.2 & $\begin{array}{l}\text { SEM } \\
0.03\end{array}$ \\
\hline & & $\begin{array}{l}\text { Benson \& } \\
\text { Hedges } \\
\text { Light } 100 \\
\text { (menthol) }\end{array}$ & 42 & o/q & 35.0 & & 22.0 & & 52.2 & $\begin{array}{l}\text { SEM } \\
2.7\end{array}$ & 1.2 & $\begin{array}{l}\text { SEM } \\
0.03\end{array}$ \\
\hline \multirow[t]{2}{*}{$\begin{array}{l}\text { Bergeria et } \\
\text { al } 67\end{array}$} & 2018 & own brand & 89 & q & 29.7 & 6.4 & 15.3 & 6.1 & 48.3 & 2.9 & 1.3 & 0.1 \\
\hline & & own brand & 20 & 우 & 30.3 & 4.9 & 12.6 & 5.4 & 48.2 & 5.0 & 1.3 & 0.1 \\
\hline \multirow{2}{*}{$\begin{array}{l}\text { Chen et } \\
\text { al }^{56}\end{array}$} & 2018 & own brand & & & & & & & & & & \\
\hline & & & 326 & o/9 & 37.6 & 11.6 & 16.5 & 8.1 & 48.3 & 14.9 & 1.6 & 0.4 \\
\hline \multirow[t]{3}{*}{ Kim et al 68} & 2018 & own brand & 300 & $3 / 9$ & $\sim 30$ & & $0->20$ & & $\begin{array}{l}\text { median } \\
60.6\end{array}$ & $\begin{array}{l}\text { IQR } \\
49.9- \\
73.9\end{array}$ & $\begin{array}{l}\text { median } \\
1.5528\end{array}$ & $\begin{array}{l}\text { IQR } \\
1.243- \\
1.923\end{array}$ \\
\hline & & & 250 & $\hat{0}$ & $\sim 30$ & & $0->20$ & & $\begin{array}{l}\text { median } \\
32.7\end{array}$ & $\begin{array}{l}\text { IQR } \\
52.7- \\
75.5\end{array}$ & $\begin{array}{l}\text { median } \\
1.6\end{array}$ & $1.2-1.9$ \\
\hline & & & 50 & 우 & $\sim 30$ & & $0->20$ & & $\begin{array}{l}\text { median } \\
53.5\end{array}$ & $\begin{array}{l}\text { IQR 42- } \\
64.2\end{array}$ & $\begin{array}{l}\text { median } \\
1.4\end{array}$ & $1.2-1.8$ \\
\hline \multirow[t]{3}{*}{$\begin{array}{l}\text { Mercincag- } \\
\text { ave et al }{ }^{58}\end{array}$} & 2018 & $\begin{array}{l}\text { own brand } \\
\text { (non menthol) }\end{array}$ & 84 & $\delta / 9$ & 43.0 & 12.1 & 13.9 & $\begin{array}{l}\mathrm{Cl} 12.5- \\
15.2\end{array}$ & 52.7 & $\begin{array}{l}\text { Cl 48.1- } \\
57.4\end{array}$ & 1.7 & $\begin{array}{l}\mathrm{Cl} 1.6- \\
1.8\end{array}$ \\
\hline & & $\begin{array}{l}\text { SPECTRUM } \\
400(9 \mathrm{mg} \\
\text { tar, } 0.26 \mathrm{mg}\end{array}$ & & & & & & & & & & \\
\hline & & & 84 & j/q & 43.0 & 12.1 & 16.5 & $\begin{array}{l}\mathrm{Cl} 14.9- \\
18.1\end{array}$ & 49.4 & $\begin{array}{l}\mathrm{Cl} 44.4- \\
54.3\end{array}$ & 1.7 & $\begin{array}{l}\mathrm{Cl} 1.5- \\
1.8\end{array}$ \\
\hline
\end{tabular}

SPECTRUM

$20019 \mathrm{mg}$

tar, $0.07 \mathrm{mg}$

nicotine)

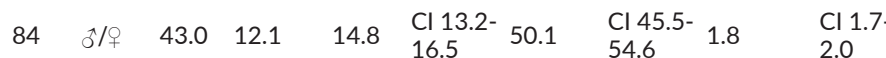

Shiffman et 2018 own brand al ${ }^{69}$

$\begin{array}{llll}190 & 3 / 9 & 38.0 & 13.8 \quad 2.0\end{array}$

39.6

1.5

own brand

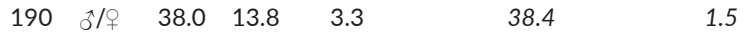




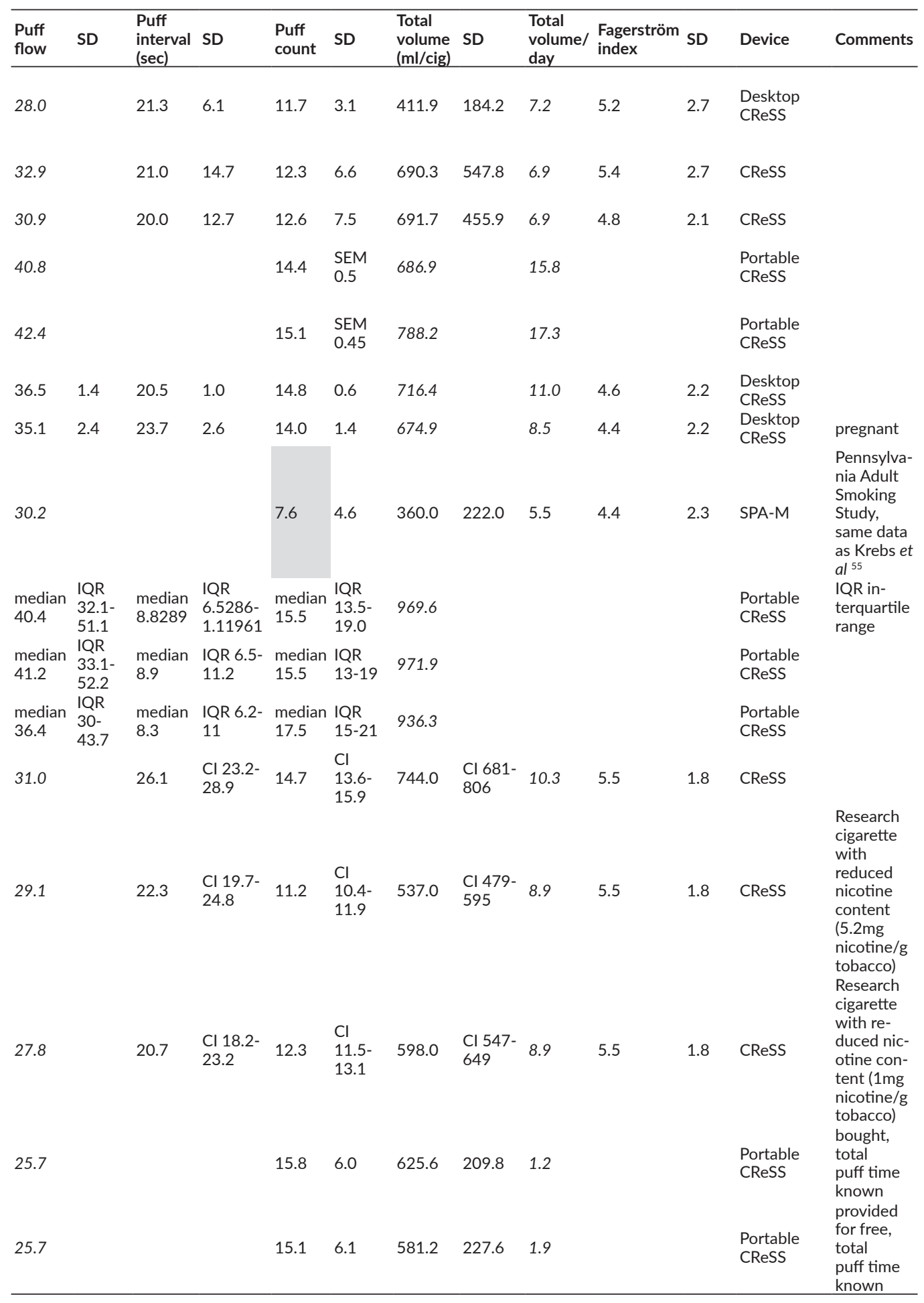




\begin{tabular}{|c|c|c|c|c|c|c|c|c|c|c|c|c|}
\hline Author & Year & Sort & $\mathrm{n}$ & $\begin{array}{l}\text { Gen- } \\
\text { der }\end{array}$ & Age & SD & $\begin{array}{l}\text { No of } \\
\text { cig/ } \\
\text { day }\end{array}$ & SD & $\begin{array}{l}\text { Puff } \\
\text { volume } \\
\text { (ml) }\end{array}$ & $S D$ & $\begin{array}{l}\text { Puff } \\
\text { duration } \\
\text { (sec) }\end{array}$ & SD \\
\hline \multirow[t]{2}{*}{$\begin{array}{l}\text { Vansickel et } \\
\text { al }{ }^{70}\end{array}$} & 2018 & own brand & & & & & & & & & & \\
\hline & & & 13 & $\hat{\sigma} / 9$ & 45.0 & 11.0 & 15.4 & 4 & 44.1 & 10.5 & 1.7 & 0.4 \\
\hline \multirow[t]{4}{*}{ Yuki et al ${ }^{71}$} & 2018 & $\begin{array}{l}\text { own brand } \\
\text { ( 6.5 mg tar) }\end{array}$ & 20 & $3 / 9$ & 30.9 & 12.5 & 17.3 & 6.6 & 58.5 & 20.2 & 1.6 & 0.4 \\
\hline & & $\begin{array}{l}\text { own brand } \\
\text { ( 6.5 mg tar) }\end{array}$ & 20 & d/9 & 30.9 & 12.5 & 17.3 & 6.6 & 58.8 & 19.0 & 1.8 & 0.7 \\
\hline & & $\begin{array}{l}\text { own brand } \\
\text { ( 6.5 mg tar) }\end{array}$ & 20 & $3 / 9$ & 30.9 & 12.5 & 17.3 & 6.6 & 62.8 & 19.2 & 1.8 & 0.5 \\
\hline & & $\begin{array}{l}\text { own brand } \\
\text { ( 6.5 mg tar) }\end{array}$ & 20 & $\delta / q$ & 30.9 & 12.5 & 17.3 & 6.6 & 56.0 & 14.4 & 1.6 & 0.4 \\
\hline \multirow[t]{2}{*}{$\begin{array}{l}\text { Watson et } \\
\text { al } 72\end{array}$} & 2019 & own brand & 163 & ôto & 42.4 & $18-66$ & 16.1 & $6-40$ & 54.1 & $\begin{array}{l}\text { Cl 51.5- } \\
56.7\end{array}$ & 1.5 & $\begin{array}{l}\mathrm{Cl} 1.48- \\
1.59\end{array}$ \\
\hline & & own brand & 163 & J/o & 42.4 & $18-66$ & 16.1 & $6-40$ & 53.6 & $\begin{array}{l}\text { Cl 51.1- } \\
56.1\end{array}$ & 1.5 & $\begin{array}{l}\mathrm{Cl} 1.47- \\
1.58\end{array}$ \\
\hline
\end{tabular}

Calculated values in italic. SD = standard deviation, $\mathrm{Cl}=95 \%$ Confidence interval, SEM = Standard error of the mean, SE = Standard error, $q$ female, $₫$ male, CRSSPT = Clinical Research Support System, Plowshare Technologies, CReSS $=$ CReSSmicro $^{\mathrm{TM}}$ (Clinical Research Support System), Plowshare Technologies. Dark grey: highest value. Light grey: lowest value. \$ Data originates from ISO/TR 17219:2013 (stated as personal communication) [73] 
Characteristic puffing profiles generate more TNCO than ISO and $\mathrm{HCl} \mid 157$

\begin{tabular}{|c|c|c|c|c|c|c|c|c|c|c|c|c|}
\hline $\begin{array}{l}\text { Puff } \\
\text { flow }\end{array}$ & SD & $\begin{array}{l}\text { Puff } \\
\text { interval } \\
\text { (sec) }\end{array}$ & SD & $\begin{array}{l}\text { Puff } \\
\text { count }\end{array}$ & SD & $\begin{array}{l}\text { Total } \\
\text { volume } \\
\text { (ml/cig) }\end{array}$ & SD & $\begin{array}{l}\text { Total } \\
\text { volume/ } \\
\text { day }\end{array}$ & $\begin{array}{l}\text { Fagerström } \\
\text { index }\end{array}$ & SD & Device & Comments \\
\hline 28.6 & 6.1 & & & & & & & & & & $\begin{array}{l}\text { Sodim } \\
\text { SPA-D } \\
\text { Smoking } \\
\text { Puff } \\
\text { Analyzer }\end{array}$ & \\
\hline 36.1 & & & & 14.6 & 4.2 & 858.0 & 369.0 & 14.8 & 4.3 & 1.7 & $\begin{array}{l}\text { Portable } \\
\text { CReSS }\end{array}$ & Baseline \\
\hline 32.3 & & & & 14.6 & 3.8 & 857.0 & 296.0 & 14.8 & 4.3 & 1.7 & $\begin{array}{l}\text { Portable } \\
\text { CReSS }\end{array}$ & day 1 \\
\hline 35.3 & & & & 15.2 & 3.4 & 989.0 & 425.0 & 17.1 & 4.3 & 1.7 & $\begin{array}{l}\text { Portable } \\
\text { CReSS }\end{array}$ & day 3 \\
\hline 34.6 & & & & 14.2 & 3.4 & 847.0 & 292.0 & 14.7 & 4.3 & 1.7 & $\begin{array}{l}\text { Portable } \\
\text { CReSS }\end{array}$ & day 5 \\
\hline 35.4 & & 16.8 & $\begin{array}{l}\mathrm{Cl} 15.2- \\
18.5\end{array}$ & 11.0 & $\begin{array}{l}\mathrm{Cl} 9.8- \\
12.1\end{array}$ & 595.1 & & 9.6 & & & CReSS & day 1 \\
\hline 35.3 & & 16.3 & $\begin{array}{l}\mathrm{Cl} 14.7- \\
17.9\end{array}$ & 14.9 & $\begin{array}{l}\mathrm{Cl} \\
13.4- \\
16.5\end{array}$ & 798.6 & & 12.9 & & & CReSS & day 2 \\
\hline
\end{tabular}




\section{References}

1. Buchhalter AR, Eissenberg T. Preliminary evaluation of a novel smoking system: effects on subjective and physiological measures and on smoking behavior. Nicotine Tob Res. 2000;2(1):39-43.

2. Djordjevic MV, Stellman SD, Zang E. Doses of nicotine and lung carcinogens delivered to cigarette smokers. J Natl Cancer Inst. 2000;92(2):106-111.

3. Breland AB, Buchhalter AR, Evans SE, Eissenberg T. Evaluating acute effects of potential reduced-exposure products for smokers: clinical laboratory methodology. Nicotine Tob Res. 2002;4 Suppl 2:S131-140.

4. Breland AB, Evans SE, Buchhalter AR, Eissenberg T. Acute effects of Advance: a potential reduced exposure product for smokers. Tob Control. 2002;11(4):376-378.

5. Dixon M, Kochhar N, Prasad K, Shepperd J, Warburton DM. The influence of changing nicotine to tar ratios on human puffing behaviour and perceived sensory response. Psychopharmacology (Berl). 2003;170(4):434-442.

6. Lee EM, Malson JL, Waters AJ, Moolchan ET, Pickworth WB. Smoking topography: reliability and validity in dependent smokers. Nicotine Tob Res. 2003;5(5):673-679.

7. Aung AT, Pickworth WB, Moolchan ET. History of marijuana use and tobacco smoking topography in tobacco-dependent adolescents. Addict Behav. 2004;29(4):699-706.

8. Hughes JR, Hecht SS, Carmella SG, Murphy SE, Callas P. Smoking behaviour and toxin exposure during six weeks use of a potential reduced exposure product: Omni. Tob Control. 2004;13(2):175-179.

9. Lee EM, Malson JL, Moolchan ET, Pickworth WB. Quantitative comparisons between a nicotine delivery device (Eclipse) and conventional cigarette smoking. Nicotine Tob Res. 2004;6(1):95-102.

10. Strasser AA, Pickworth WB, Patterson F, Lerman C. Smoking topography predicts abstinence following treatment with nicotine replacement therapy. Cancer Epidemiol Biomarkers Prev. 2004;13(11 Pt 1):1800-1804.

11. Wood T, Wewers ME, Groner J, Ahijevych K. Smoke constituent exposure and smoking topography of adolescent daily cigarette smokers. Nicotine Tob Res. 2004;6(5):853-862.

12. Zimmerman DM, Sehnert SS, Epstein DH, et al. Smoking topography and trajectory of asthmatic adolescents requesting cessation treatment. Prev Med. 2004;39(5):940-942.

13. Hammond D, Fong GT, Cummings KM, Hyland A. Smoking topography, brand switching, and nicotine delivery: results from an in vivo study. Cancer Epidemiol Biomarkers Prev. 2005;14(6):1370-1375.

14. Hitsman B, Spring B, Wolf W, et al. Effects of acute tryptophan depletion on negative symptoms and smoking topography in nicotine-dependent schizophrenics and nonpsychiatric controls. Neuropsychopharmacology. 2005;30(3):640-648. 
15. Strasser AA, Ashare RL, Kozlowski LT, Pickworth WB. The effect of filter vent blocking and smoking topography on carbon monoxide levels in smokers. Pharmacol Biochem Behav. 2005;82(2):320-329.

16. Tidey JW, Rohsenow DJ, Kaplan GB, Swift RM. Cigarette smoking topography in smokers with schizophrenia and matched non-psychiatric controls. Drug Alcohol Depend. 2005;80(2):259-265.

17. Breland $A B$, Kleykamp BA, Eissenberg T. Clinical laboratory evaluation of potential reduced exposure products for smokers. Nicotine Tob Res. 2006;8(6):727-738.

18. Franken FH, Pickworth WB, Epstein DH, Moolchan ET. Smoking rates and topography predict adolescent smoking cessation following treatment with nicotine replacement therapy. Cancer Epidemiol Biomarkers Prev. 2006;15(1):154-157.

19. Hammond D, Fong GT, Cummings KM, et al. Cigarette yields and human exposure: a comparison of alternative testing regimens. Cancer Epidemiol Biomarkers Prev. 2006;15(8):1495-1501.

20. KasselJD,GreensteinJE,EvattDP,etal.Smokingtopographyinresponsetodenicotinizedand high-yield nicotine cigarettes in adolescent smokers. J Adolesc Health. 2007;40(1):54-60.

21. Melikian AA, Djordjevic MV, Hosey J, et al. Gender differences relative to smoking behavior and emissions of toxins from mainstream cigarette smoke. Nicotine Tob Res. 2007;9(3):377-387.

22. Djordjevic MV, Fan J, Ferguson S, Hoffmann D. Self-regulation of smoking intensity. Smoke yields of the low-nicotine, low-'tar' cigarettes. Carcinogenesis. 1995;16(9):2015-2021.

23. Strasser AA, Lerman C, Sanborn PM, Pickworth WB, Feldman EA. New lower nicotine cigarettes can produce compensatory smoking and increased carbon monoxide exposure. Drug Alcohol Depend. 2007;86(2-3):294-300.

24. Strasser AA, Malaiyandi V, Hoffmann E, Tyndale RF, Lerman C. An association of CYP2A6 genotype and smoking topography. Nicotine Tob Res. 2007;9(4):511-518.

25. Attwood AS, O'Sullivan H, Leonards U, Mackintosh B, Munafo MR. Attentional bias training and cue reactivity in cigarette smokers. Addiction. 2008;103(11):1875-1882.

26. Collins CC, Lippmann BM, Lo SJ, Moolchan ET. Time spent with smoking parents and smoking topography in adolescents. Addict Behav. 2008;33(12):1594-1597.

27. Rees VW, Wayne GF, Connolly GN. Puffing style and human exposure minimally altered by switching to a carbon-filtered cigarette. Cancer Epidemiol Biomarkers Prev. 2008;17(11):2995-3003.

28. Grainge MJ, Shahab L, Hammond D, O'Connor RJ, McNeill A. First cigarette on waking and time of day as predictors of puffing behaviour in UK adult smokers. Drug Alcohol Depend. 2009;101(3):191-195.

29. Blank MD, Disharoon S, Eissenberg T. Comparison of methods for measurement of smoking behavior: mouthpiece-based computerized devices versus direct observation. 
Nicotine Tob Res. 2009;11(7):896-903.

30. Dickens C, McGrath C, Warren N, Biggs P, McAughey J. Puffing and inhalation behaviour in cigarette smoking: Implications for particle diameter and dose. Journal of Physics: Conference Series. 2009;151(1):012019.

31. Moolchan ET, Parzynski CS, Jaszyna-Gasior M, et al. A link between adolescent nicotine metabolismandsmokingtopography.CancerEpidemiolBiomarkersPrev.2009;18(5):1578-1583.

32. Collins CC, Epstein DH, Parzynski CS, et al. Puffing behavior during the smoking of a single cigarette in tobacco-dependent adolescents. Nicotine Tob Res. 2010;12(2):164-167.

33. O'Connor RJ, Rees VW, Norton KJ, et al. Does switching to reduced ignition propensity cigarettes alter smoking behavior or exposure to tobacco smoke constituents? Nicotine Tob Res. 2010;12(10):1011-1018.

34. June KM, Norton KJ, Rees VW, O'Connor RJ. Influence of measurement setting and home smoking policy on smoking topography. Addict Behav. 2012;37(1):42-46.

35. June KM, Hammond D, Sjodin A, et al. Cigarette ignition propensity, smoking behavior, and toxicant exposure: A natural experiment in Canada. Tob Induc Dis. 2011;9(1):13.

36. McKee SA, Sinha R, Weinberger AH, et al. Stress decreases the ability to resist smoking and potentiates smoking intensity and reward. J Psychopharmacol. 2011;25(4):490-502.

37. Strasser AA, Benowitz NL, Pinto AG, et al. Nicotine metabolite ratio predicts smoking topography and carcinogen biomarker level. Cancer Epidemiol Biomarkers Prev. 2011;20(2):234-238.

38. Veilleux JC, Kassel JD, Heinz AJ, et al. Predictors and sequelae of smoking topography over the course of a single cigarette in adolescent light smokers. J Adolesc Health. 2011;48(2):176-181.

39. WilliamsJM,GandhiKK,LuSE,etal.Shorterinterpuffintervalisassociatedwithhighernicotine intake in smokers with schizophrenia. Drug Alcohol Depend. 2011;118(2-3):313-319.

40. Williams JM, Gandhi KK, Lu SE, Steinberg ML, Benowitz NL. Nicotine intake and smoking topography in smokers with bipolar disorder. Bipolar Disord. 2012;14(6):618-627.

41. Brinkman MC, Chuang JC, Gordon SM, et al. Exposure to and deposition of fine and ultrafine particles in smokers of menthol and nonmenthol cigarettes. Inhal Toxicol. 2012;24(5):255-269.

42. Faulkner GE, Arbour-Nicitopoulos KP, Hsin A. Cutting Down One Puff at a Time: The Acute Effects of Exercise on Smoking Behaviour. Journal of Smoking Cessation. 2012;5(2):130-135.

43. Perkins KA, Karelitz JL, Giedgowd GE, Conklin CA. The reliability of puff topography and subjective responses during ad lib smoking of a single cigarette. Nicotine Tob Res. 2012;14(4):490-494.

44. Matsumoto M, Inaba Y, Yamaguchi I, et al. Smoking topography and biomarkers of exposure among Japanese smokers: associations with cigarette emissions obtained 
using machine smoking protocols. Environ Health Prev Med. 2013;18(2):95-103.

45. McClure EA, Saladin ME, Baker NL, Carpenter MJ, Gray KM. Smoking topography and abstinence in adult female smokers. Addict Behav. 2013;38(12):2833-2836.

46. Strasser AA, Ashare RL, Kaufman M, et al. The effect of menthol on cigarette smoking behaviors, biomarkers and subjective responses. Cancer Epidemiol Biomarkers Prev. 2013;22(3):382-389.

47. Tidey JW, Rohsenow DJ, Kaplan GB, Swift RM, Ahnallen CG. Separate and combined effects of very low nicotine cigarettes and nicotine replacement in smokers with schizophrenia and controls. Nicotine Tob Res. 2013;15(1):121-129.

48. Hammond D, O'Connor RJ. Reduced nicotine cigarettes: smoking behavior and biomarkers of exposure among smokers not intending to quit. Cancer Epidemiol Biomarkers Prev. 2014;23(10):2032-2040.

49. Norton KJ, June KM, O'Connor RJ. Initial puffing behaviors and subjective responses differ between an electronic nicotine delivery system and traditional cigarettes. Tob Induc Dis. 2014;12(1):17.

50. Schneider T, De Jesus S, Prapavessis H. The Effect of Acute Exercise on Smoking Topography: No Evidence for Cutting Down One Puff at a Time. Journal of Smoking Cessation. 2014;10(2):146-153.

51. AppletonS, LiuJ, LipowiczPJ,SarkarM. Effect of cigarettedesign on biomarkers of exposure, puffing topography and respiratory parameters. Inhal Toxicol. 2015;27(3):174-180.

52. Brinkman MC, Kim H, Chuang JC, et al. Comparison of True and Smoothed Puff Profile Replication on Smoking Behavior and Mainstream Smoke Emissions. Chem Res Toxicol. 2015;28(2):182-190.

53. Chung S, Kim SS, Kini N, et al. Smoking topography in Korean American and white men: preliminary findings. J Immigr Minor Health. 2015;17(3):860-866.

54. Gass JC, Germeroth LJ, Wray JM, Tiffany ST. The Reliability and Stability of Puff Topography Variables in Non-Daily Smokers Assessed in the Laboratory. Nicotine Tob Res. 2016;18(4):484-490.

55. Krebs NM, Chen A, Zhu J, et al. Comparison of Puff Volume With Cigarettes per Day in Predicting Nicotine Uptake Among Daily Smokers. Am J Epidemiol. 2016;184(1):48-57.

56. Chen A, Krebs NM, Zhu J, Muscat JE. Nicotine metabolite ratio predicts smoking topography:ThePennsylvaniaAdultSmokingStudy.DrugAlcoholDepend.2018;190:89-93.

57. Mercincavage M, Souprountchouk V, Tang KZ, et al. A Randomized Controlled Trial of Progressively Reduced Nicotine Content Cigarettes on Smoking Behaviors, Biomarkers of Exposure,andSubjectiveRatings.CancerEpidemiolBiomarkersPrev.2016;25(7):1125-1133.

58. Mercincavage M, Lochbuehler K, Wileyto EP, et al. Association of Reduced Nicotine Content Cigarettes With Smoking Behaviors and Biomarkers of Exposure Among Slow and Fast Nicotine Metabolizers: A Nonrandomized Clinical Trial. JAMA Netw Open. 
2018;1(4):e181346-e181346.

59. Pulcu E. Self-report distortions of puffing topography in daily smokers. J Health Psychol. 2016;21(8):1644-1654.

60. Ross KC, Dempsey DA, St Helen G, Delucchi K, Benowitz NL. The Influence of Puff Characteristics, Nicotine Dependence, and Rate of Nicotine Metabolism on Daily Nicotine Exposure inAfricanAmerican Smokers. CancerEpidemiolBiomarkers Prev. 2016;25(6):936-943.

61. Ross KC, Juliano LM. Smoking Through a Topography Device Diminishes Some of the Acute Rewarding Effects of Smoking. Nicotine Tob Res. 2016;18(5):564-571.

62. Tidey JW, Cassidy RN, Miller ME. Smoking Topography Characteristics of Very Low Nicotine Content Cigarettes, With and Without Nicotine Replacement, in Smokers With Schizophrenia and Controls. Nicotine Tob Res. 2016;18(9):1807-1812.

63. Farris SG, Aston ER, Abrantes AM, Zvolensky MJ. Tobacco demand, delay discounting, and smoking topography among smokers with and without psychopathology. Drug Alcohol Depend. 2017;179:247-253.

64. Higgins ST, Heil SH, Sigmon SC, et al. Response to varying the nicotine content of cigarettes in vulnerable populations: an initial experimental examination of acute effects. Psychopharmacology (Berl). 2017;234(1):89-98.

65. Hsu PC, Lan RS, Brasky TM, et al. Menthol Smokers: Metabolomic Profiling and Smoking Behavior. Cancer Epidemiol Biomarkers Prev. 2017;26(1):51-60.

66. Watson CV, Richter P, de Castro BR, et al. Smoking Behavior and Exposure: Results of a Menthol Cigarette Cross-over Study. Am J Health Behav. 2017;41(3):309-319.

67. Bergeria CL, Heil SH, Bunn JY, Sigmon SC, Higgins ST. Comparing Smoking Topography and Subjective Measures of Usual Brand Cigarettes Between Pregnant and NonPregnant Smokers. Nicotine Tob Res. 2018;20(10):1243-1249.

68. Kim S, Yu S. Smoking Topographyamong Korean Smokers: Intensive Smoking Behaviorwith Larger PuffVolume and Shorter Interpuff Interval. Int J Environ Res Public Health. 2018;15(5).

69. Shiffman S, Scholl S. Increases in Cigarette Consumption and Decreases in Smoking Intensity When Nondaily Smokers Are Provided With Free Cigarettes. Nicotine Tob Res. 2018;20(10):1237-1242.

70. Vansickel AR, Edmiston JS, Liang Q, et al. Characterization of puff topography of a prototype electronic cigarette in adult exclusive cigarette smokers and adult exclusive electronic cigarette users. Regul Toxicol Pharmacol. 2018;98:250-256.

71. Yuki D, Takeshige Y, Nakaya K, Futamura Y. Assessment of the exposure to harmful and potentially harmful constituents in healthy Japanese smokers using a novel tobacco vapor product compared with conventional cigarettes and smoking abstinence. Regul Toxicol Pharmacol. 2018;96:127-134.

72. Watson CV, Richter P, Li Y, et al. Mouth Level Nicotine in a Clinical Setting versus Nonclinical Setting. Tobacco Regulatory Science. 2019;5(3):229-241. 




\section{Chapter 5. Characteristic}

\section{puffing topography versus}

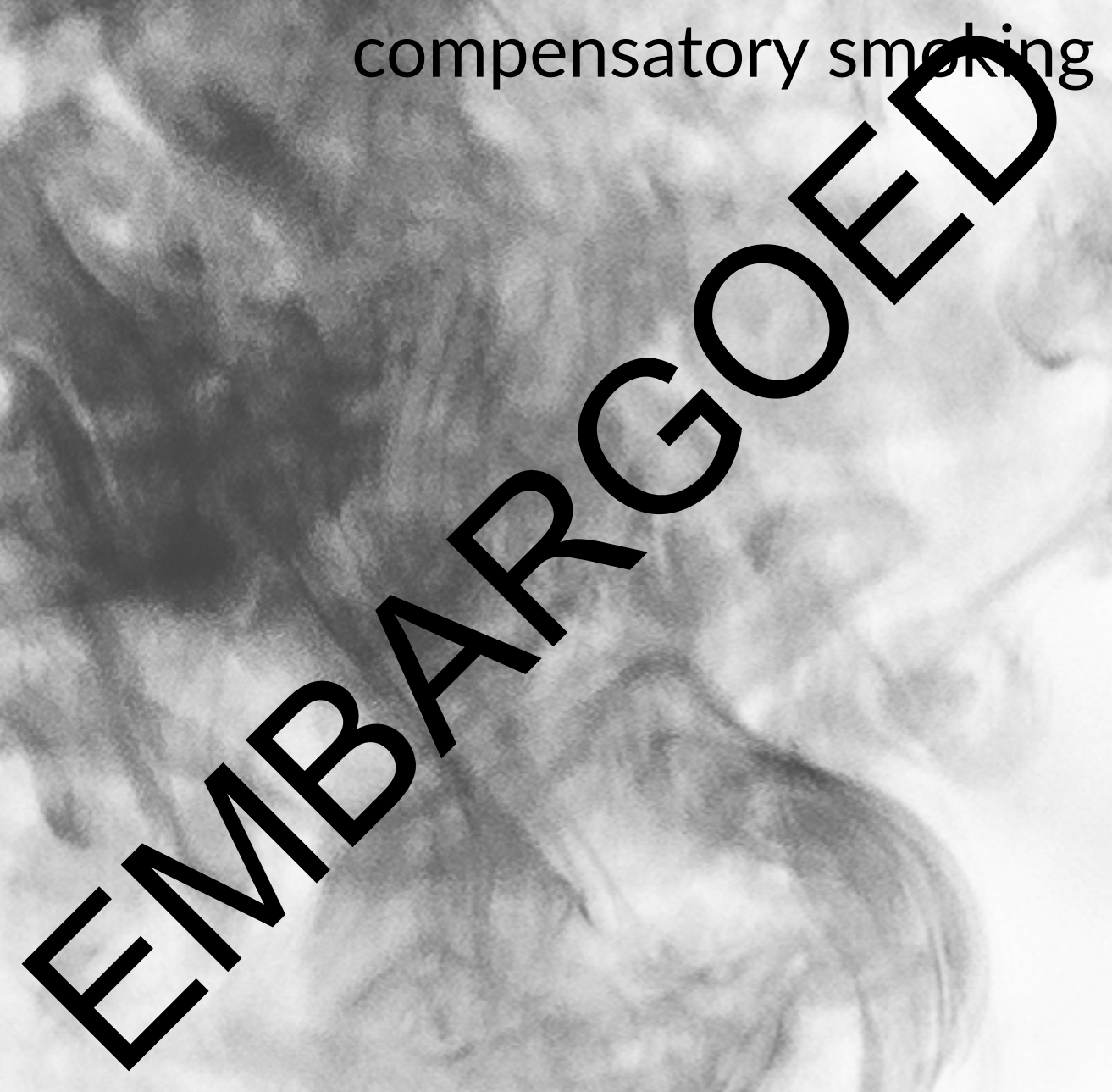

Charlotte G.G.M Pauwels, Agnes W. Boots, Wouter F. Visser, Jeroen L.A. Pennings, Reinskje Talhout, Frederik J. Van Schooten, Antoon Opperhuizen 


\section{Chapter 6. Summary}

\section{and general discussion}





\section{Worldwide tobacco pandemic}

Worldwide, many far-reaching economic and social measures are taken in the fight against the COVID-19 pandemic in 2020, during which, according to the Johns Hopkins University, more than 1.8 million people died in that year ${ }^{1}$. However, based on annual mortality rates in 2020 , at least three times more world citizens (>7 million) died due to tobacco consumption ${ }^{2}$, and this will continue every year in the near future. In the fight against COVID-19, governments worldwide dramatically restricted freedom and liberty of all citizens and took dramatic measures to save lives and reduce virus-related morbidity in society. The measures did not only affect the subpopulation at high risk, but also low risk subpopulations such as children and adolescents, in an attempt to protect citizens against the virus, and to mitigate the COVID-19 pandemic by vaccination when exposure could not be prevented. To solve the worldwide tobacco pandemic, ideally producing and selling tobacco products should be banned and consumption stopped worldwide to prevent exposure of citizens to these toxic products. With such a full ban, nobody would be exposed legally. However, maintaining a tobacco products prohibition is a political, regulatory and societal challenge susceptible for failure ${ }^{3}$. It might lead to a rise in illegal practices) in tobacco products, including illegal production, smuggling or growing for personal use. In The Netherlands and many other countries, smokers will argue that they will be robbed of their 'freedom and liberty' to consume the addictive tobacco products. However, ideas have been raised to gradually expand regulatory measures with respect to smoking, making it effectively illegal for the generation born after 2004 as already proposed in New Zealand.

Besides measures to fully prevent tobacco use, also risk mitigation approaches help to fight the smoking pandemic. Such measures are mainly based on taxation, de-normalization, cessation-aid, and 'smoke-free' legislation focusing on actual smokers and potential smokers. These risk mitigation approaches have led to a substantially lower prevalence in most countries, but it did, and does, eliminate use of cigarettes and other tobacco products. Nevertheless, governments already consider experienced smokers switching to Electronic Nicotine Delivery Devices (ENDs) such as e-cigarettes, or to dual use, as a successful tobacco policy ${ }^{4}$. Even though ENDS and other more recently developed tobacco products (such as heated tobacco products (HTP)) by tobacco industry may help quitting regular cigarette use, the new products are also addictive and harmful 5,6. Although they are less harmful with regard to cancer risk, there are disappointing signals with regard to the risk of developing cardiovascular diseases and chronic obstructive pulmonary disease. Moreover, dual use is not quitting smoking and there are concerns about ENDS and HTP as gateway to smoking regular tobacco products. 
Tobacco policies can be strengthened by regulating the traditional tobacco products such as cigarettes, which are still dominantly present on the consumers' market and contribute to the high mortality and morbidity rates. One of the authorities who has assembled a harm reduction approach is the World Health Organization (WHO) Framework Convention on Tobacco Control (FCTC). Within the FCTC, various guidelines have been adopted and implemented in many countries and regions to reduce tobacco use. However, little progress has been made concerning Article 9 Regulation of the content of tobacco products. This Article reads "The Conference of the Parties, in combination with competent international bodies, should propose Guidelines for testing and measuring the contents and emissions of tobacco products, and for the regulation of these contents and emissions. Each Party shall, approved by competent authorities, adopt and implement, effective legislative, executive and administrative or other measures for such testing and measuring, and for such regulation" 7. Although FCTC went into force in 2005, hitherto no full set of Guidelines for Parties have been provided by the Conference of the Parties. In 2010, partial Guidelines for the Article 9 and 10 (about the regulation of disclosure of information about tobacco products) have been adopted which have been amended in 2014 and $2016^{8}$. However, in these partial Guidelines paragraph 3.2 about Content and 3.3 about Emissions anno 2021 still reads "(this section is intentionally left blank to indicate that guidance will be proposed at a later stage)". It illustrates that in the political arena no consensus has been found about the scientific foundation for guidance about regulation of emissions. In other words, regulators struggle with the fact that smoking is still harmful and if they agree on emission regulation, it looks like they approve continuing tobacco use. In addition, regulators find the health beneficial effects of lowering smoke components unclear. In the 2018 meeting of the Conference of the Parties (COP), the concern about filter ventilation has been addressed ". The WHO was tasked to provide "the latest scientific evidence on the impact of cigarette ventilation on cigarette use" and to report to the COP before the ninth meeting that will be held in The Netherlands in November 2021.

Although no guidance has been provided by FCTC, The European Union (EU) (also a Party which adopted FCTC) regulates tar, nicotine and carbon monoxide (CO) (TNCO) of cigarettes in the European Tobacco Product Directive (ETPD/2014/40/ EU) ${ }^{10}$. The ETPD has limits of respectively $10 \mathrm{mg}, 1 \mathrm{mg}$ and $10 \mathrm{mg}$ per cigarette set as maximum emissions allowed in cigarettes smoke ${ }^{10}$. Interestingly, the ETPD/2014/40/EU contains only a reference to the analytical technique of the International Organization of Standardization (ISO) method and not to the ISO 3308 protocol itself that describes the smoke generation. It is known already for decades 
that cigarette smoke emission is determined by the way the smoke is generated. Moreover, emission of toxicants other than TNCO is not regulated at all. Before the revision of the ETPD, the ISO 3308 protocol for smoking machines was prescribed for the determination of TNCO in the EU. In daily practice, all countries in the EU still interpret that this method is the required standardized testing protocol for machine smoking experiments. However, setting standards for tobacco smoke without indicating how the standard can be endorsed and controlled is questionable. Regulating smoke emission based on ISO 3308 alone is not scientifically suitable according to WHO Study Group on Tobacco Product Regulation (WHO-TobReg) (2008), and could play an important role in what is called 'a deceptive policy of tobacco industry' to promote highly filter-ventilated cigarettes as 'light' or 'mild' or even 'healthier' ${ }^{11}$. However, evidence-based tobacco regulation needs to be furthered and therefore the following aim was formulated for this thesis.

This thesis aims to:

Relate, for the purpose of risk assessment and cigarette product regulation, the emissions of nicotine, carbon monoxide, and volatile organic compounds produced with smoking machines to emissions produced during human smoking, as well as to the actual uptake of smoke constituents in the body of smokers, taking into account the smokers' daily use of cigarettes and their personal puff topography.

\section{Methodology}

Tobacco smoke contains over 6,000 chemicals with different chemical and toxicological properties ${ }^{12}$. For obvious reasons not all of these chemicals can be studied for the purpose of tobacco smoking related diseases. Furthermore, neither all potential variations between exposure of smokers can be taken into account, nor the many differences between brands. In this thesis, we used the work of WHOTobReg (2008) ${ }^{13}$ and focused only on nicotine, CO and aldehydes (Chapter 2) and other volatile organic compounds (VOCs) (Chapter 3). A comprehensive discussion of tar is intentionally left out, as it is a mixture of thousands of individual and potentially toxic chemicals.

Two types of experiments were carried out for this thesis, i.e. smoking studies with either machines or volunteers. First, cigarette smoke was generated with smoking machines (according to ISO 3308 and Health Canada Intense (HCI)), the smoke constituents were quantified and the yields (per cigarette) and concentration (per $\mathrm{mL}$ ) were related to human smoking topography. With smoking machines, cigarettes are smoked under controlled conditions with selected and fixed regimes for puff 
topography, meaning a fixed puff volume, puff duration and inter-puff period. Dependent on the specific profile, the smoking machine will 'consume' the cigarette with a specific number of puffs. The total puff volume of a cigarette depends on the number of puffs and the puff volume set at the specific smoking machine regime. Second, experiments with volunteers were carried out in order to determine their individual smoking topography and to determine the uptake of tobacco smoke constituents into the body. Human volunteers usually apply puff topographies that are person specific, different from other smokers and which may be brand dependent or specific. The rationale behind these experiments is that the human uptake of smoke constituents will vary based on the smoker's topography and the type of (filter-ventilated) cigarette. By comparing the smoker's topography to machine smoking settings, human topography standardized machine-smoking settings could have the potential to deliver data that aid to set limits for product regulation of cigarettes. It is agreed already for decades that machine smoking is different from human smoking, but in-depth studies about the nature of the difference has been scarce, particularly when it concerns highly filter-ventilated cigarettes testing.

Chapter 2 is focused on smoking machine data using two types of smoking regimes and compares TNCO and aldehydes emissions of various brands of the Dutch consumers market. The cigarettes studied are brands with low as well as very high filter ventilation levels. In Chapter 4, another approach is presented in which three variants of one brand, i.e. Marlboro, are used to study the influence of variation of (human) puffing topography profiles on emissions and uptake. In Chapter 3 and 5, the two kinds of experiments are combined in order to study similarities and differences between smoking machine emissions and emissions of smoke constituents during human smoking as reflected by biomarkers. In Chapter 3 , it was investigated whether or not exhaled breath can be used as a non-invasive tool to assess exposure of constituents by analyzing volatile biomarkers. Additionally, the uptake of smoke constituents in blood was analyzed.

\section{Summary and answers to the research questions}

Research question 1 - Do smokers have characteristic puffing topography profiles?

Volunteers in our study did not increase the number of cigarettes per day (CPD) upon switching from Marlboro Red to Marlboro Prime, which is consistent with previous findings ${ }^{14,15}$. Smoking behavior of smokers is generally studied with a flowmeter device, such as the CReSSmicro ${ }^{\mathrm{TM}}$ device. Interestingly, in Chapter 4 we describe that the use of the CReSSmicro ${ }^{\mathrm{TM}}$ device to record smoking behavior may lead to some 
registration pitfalls, since the method of insertion of the cigarette may influence the data collection. Consequently, we concluded that the device is not as robust as previously assumed ${ }^{16-18}$ and care should be taken when applying it. Differences in puffing topography between studies, including ours, may thus be partially the result of technical complications of the device, as experienced by us and others, particularly when 'high' puff numbers and 'high' puff volumes are reported 16-18. However, because other, more reliable, devices are lacking, and we were able to identify an origin for the deviating data (i.e. the way of insertion), it can be concluded that the CReSSmicro ${ }^{\mathrm{TM}}$ device is useful with the proviso that the raw data need to be critically checked for anomalies (e.g. flow-rate dropouts) ${ }^{16}$. Furthermore, the investigator should correctly insert the cigarette or give detailed instructions to the participants in future research.

In our small prospective observational study, the smoking behavior of Marlboro smokers was measured for 36 hours in a home-like atmosphere. Puff volume, duration, frequency, flow and inter-puff interval were recorded with the portable $\mathrm{CReSSmicro}^{\mathrm{TM}}$ device. We found significant differences in puffing topography between participants, although consistent individual characteristic puffing behavior over the course of the day was demonstrated for each participant. In other words, smokers did not smoke their first cigarettes of the day, after a night of abstinence, significantly different from any other cigarette smoked later on. This observation is particularly important for Chapter 5 where the uptake of nicotine and $\mathrm{CO}$ throughout the day was studied in relationship to smoking topography. In Chapter 4, personalized puffing profile characteristics for the individual smokers were created based on topographic data of volunteers smoking their usual brand of cigarettes. In Chapter 5, we show that most, but not all, smokers maintain this characteristic profile when they switch to highly filter-ventilated cigarettes and even to cigarettes with completely blocked filter ventilation. That a few smokers do use a different puff topography upon switching brands will be discussed later. In conclusion, experienced smokers display a characteristic puffing topography per cigarette and do not change the number of CPD when they switch to other brands.

Research question 2 - How do the puffing regimes ISO 3308 and $\mathrm{HCl}$ used as settings for smoking machines relate to puffing topography of human smokers?

The characteristic puffing profiles of the volunteers have been used as settings for smoking machine experiments after which TNCO emissions were determined and reported in Chapter 4. The application of different human puffing profiles led 
to a variety of nicotine and $\mathrm{CO}$ yields between the different smokers' profiles. As expected, the least intense puffing profile (lowest puff volume and total cigarette volume, shortest puff duration and longest inter-puff interval) generated the lowest nicotine and $\mathrm{CO}$ yields. However, these yields were still higher than those determined with the ISO 3308 smoking regime, indicating that even the least intense smoker in our study is exposed to higher yields of toxicants as anticipated based upon the ISO 3308 method. Compared to human smokers, the ISO 3308 regime on a smoking machine applies a low puff volume $(35 \mathrm{~mL})$, which explains why the generation of nicotine and $\mathrm{CO}$ was at least two times lower than when human puffing profiles were applied on the smoking machine.

Nicotine and $\mathrm{CO}$ yields were more in the range of $\mathrm{HCl}$ than ISO 3308 generated emissions, even though smokers did probably not completely block the filter ventilation holes as is done for $\mathrm{HCl}$ by taping. Some human smokers use a more intense puff topography than $\mathrm{HCl}$, particularly because of higher puffing frequency (approximately 3 puffs per minute compared to 2 puffs for $\mathrm{HCl}$ and 1 puff for ISO), which results in more puffs per cigarette, and consequently more total puff volume of the toxic smoke. Besides, also larger puff volumes of approximately $70 \mathrm{~mL} /$ puff were recorded upon human smoking, compared to the $35 \mathrm{~mL}$ and $55 \mathrm{~mL}$ per puff for ISO 3308 and $\mathrm{HCl}$. These findings are in line with previous studies reporting that ISO, and sometimes even $\mathrm{HCl}$, underestimates human smoking behavior 19,20. In this thesis, further support is provided that the ISO regime for smoking machines generates unrealistically low total puff volumes compared to human smoking. This is demonstrated in Figure 1 that shows the frequency distribution of total puffing volumes smoking Marlboro, Marlboro Prime and Marlboro Prime taped. Both ISO and $\mathrm{HCl}$ total puffing volume are left of the peak of distribution. The total puffing volumes of Marlboro Prime taped, the not-commercially available variant are closest to ISO and $\mathrm{HCl}$. That smokers had smaller total puffing volumes is probably because they are less appealing, which was not the scope of our studies. The figure also shows a large skew to the right in human total puffing volumes again demonstrating the large variability in human smoking behavior and thus that a single smoking machine regimes cannot represent all human smokers. $\mathrm{HCl}$ may also generate total puff volumes that are relatively low compared to humans, but particularly the puff frequency applied in $\mathrm{HCl}$ is much lower than during human smoking. The lower smoking intensity systematically results in lower yields of smoke constituents and consequently to an underestimation of human exposure, as was even shown in studies from the tobacco industry ${ }^{21}$. 
As is shown in Chapter 3, uptake of nicotine and other smoke constituents (as determined in blood) from highly filter-ventilated cigarettes is only a little lower than that from regular king size cigarettes, while most smokers apply their characteristic puffing topography that is also used for smoking low-ventilated cigarettes. Both cigarette types contain a comparable amount of nicotine in the tobacco filler. The little difference in nicotine yields between cigarette types is in contrast to a large difference in yields when tested on a smoking machine, illustrating that testing of filter-ventilated cigarettes on smoking machine impossibly reflects human smoking as filter tip ventilation is not blocked by taping. However, it is also clear from Chapter 5 , that $100 \%$ blocking of filter tips is also not a realistic situation reflecting human puffing while smoking a commercially available cigarette. Thus, neither unblocked nor fully blocked testing of highly filter-ventilated cigarette will generate yields that mimic topography of smokers. Even the previously introduced Massachusetts regime that consists of testing half-blocked cigarettes with puff parameters between the ISO and $\mathrm{HCl}$ parameters does not represent human smoking behavior ${ }^{22}$.

In conclusion, machine smoking with ISO 3308 settings generates yields of tobacco smoke constituents which cannot reasonably be used for regulatory purposes or human risk assessment, as it often underestimates exposure by at least $50 \%$ compared to human smoking. However, also emissions generated with $\mathrm{HCl}$ setting of a smoking machine should be used with due restraints, particularly because of the low puffing frequency, resulting again in an underestimation of human exposure. In addition, testing filter-ventilated cigarettes with ISO 3308 with and without blocking the ventilation holes generates unrealistically low yields of smoke constituents. Testing only filter-ventilation blocked cigarettes, as is done under $\mathrm{HCl}$ settings, produces yields that better reflect human smoking. Half-blocked cigarettes might better represent the holding of cigarettes between lips and fingers and can be achieved by applying special holders within the smoking machine. For risk assessment and regulatory purposes both (half-) blocked and unblocked testing with a slightly modified testing $\mathrm{HCl}$ regime should be further investigated. Suggested modifications are a slightly higher puff volume $(60-70 \mathrm{~mL} /$ puff) and a higher puffing frequency ( 3 puffs per minute rather than 2 puffs per minute) than the current $\mathrm{HCl}$ regime. 
Frequency distribution of total puffing volume: Marlboro

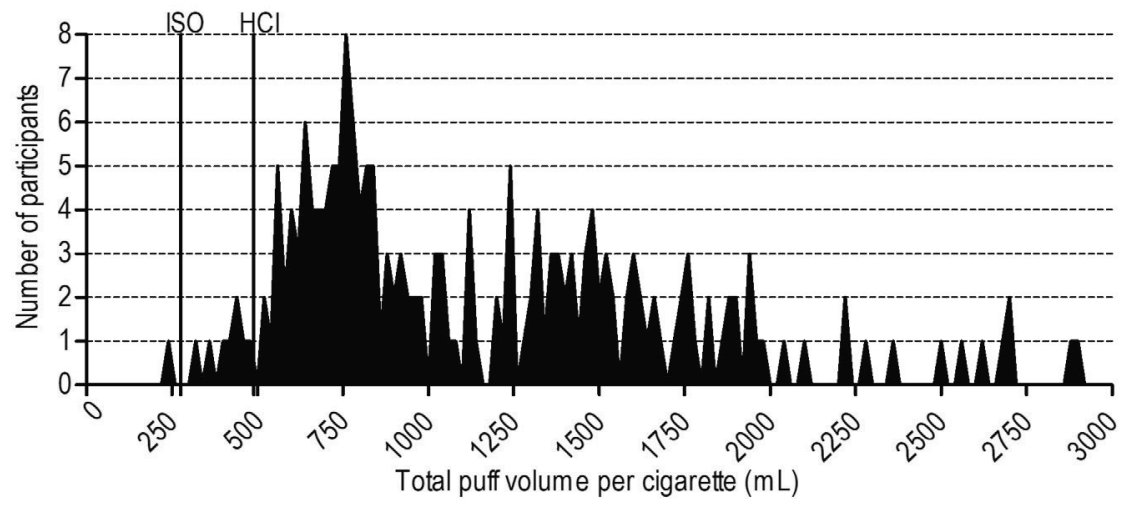

Frequency distribution of total puffing volume: Marlboro Prime

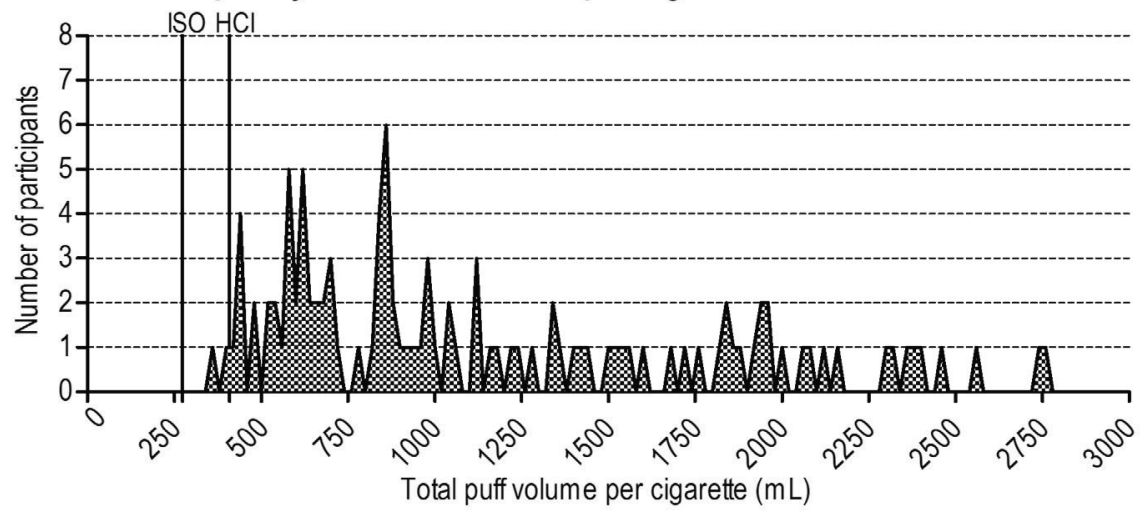

Frequency distribution of total puffing volume: Marlboro Prime taped

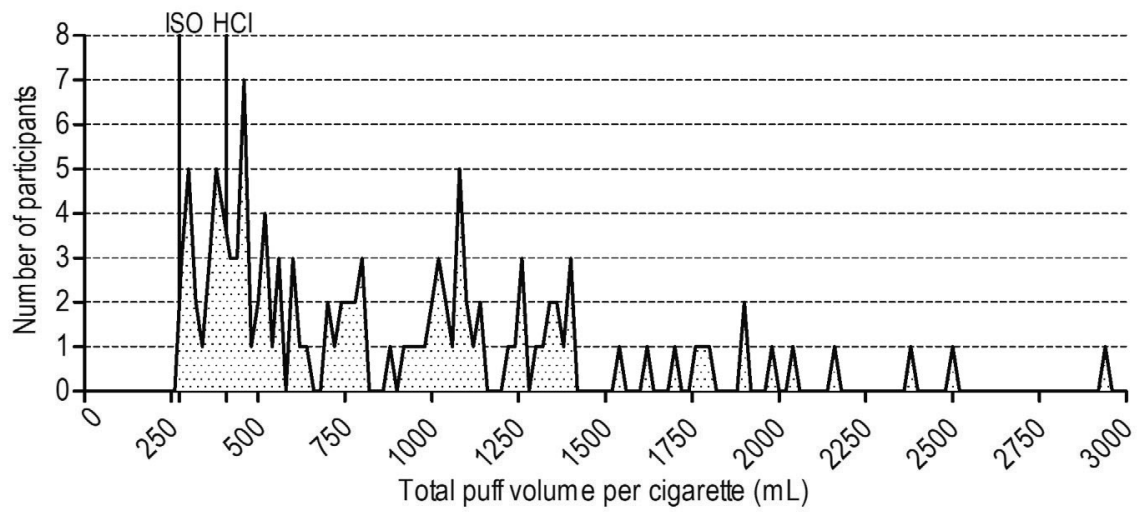

Figure 1: Graphs showing the frequency distribution (per $20 \mathrm{~mL}$ ) of the total puff volume per cigarette for Marlboro ( $n=202)$, Marlboro Prime $(n=114)$ and Marlboro Prime taped $(n=117)$ from two human studies (Chapter 4 and 5). ISO total puff volume per cigarette is $277 \mathrm{~mL}$ for 
Marlboro and $273 \mathrm{~mL}$ for Marlboro Prime. $\mathrm{HCl}$ total puff volume per cigarette is $490 \mathrm{~mL}$ for Marlboro and $409 \mathrm{~mL}$ for Marlboro Prime. ISO and $\mathrm{HCl}$ total puff volume per cigarette was calculated with the smoking machine data from Chapter 2.

Research question 3 - Is the nicotine delivery of 'very low yield' cigarettes above the threshold to initiate and sustain nicotine addiction as postulated by Benowitz and Henningfield (1994) ${ }^{23}$ ?

This thesis focused not only on cigarettes with regular yields of TNCO, generated on a smoking machine, but also on low-yield products. We take into account that the US-regular brands have higher TNCO yields than EU-regular cigarettes. Purposely, the brand with the lowest declared nicotine yield in the Dutch consumers' market was subject of the human volunteer study: Marlboro Prime (Chapter 4 and 5), previously also named Philip Morris One (Chapter 3), with the declared ISO-nicotine yield of $0.1 \mathrm{mg} / \mathrm{cig}$.

The experimental nicotine yield determined with ISO 3308 was $0.21 \mathrm{mg} / \mathrm{cig}$ (Chapter 2) which is significantly higher than the declared value. However, with $\mathrm{HCl}$, a more than 5 times higher yield $(0.56 \mathrm{mg} / \mathrm{cig})$ is determined. Smokers in the volunteers' studies described in the Chapters 3, 4 and 5 smoked at maximum 22 CPD. Based on 22 CPD, the experimental ISO 3308 yield would lead to a total exposure of $\sim 4.6$ mg maximum per day, which is a value in the range of the threshold proposed by Benowitz and Henningfield ${ }^{23}$. Because ISO 3308 underestimates real life exposure levels it would falsely suggest that by smoking fewer cigarettes, as most smokers do, threshold for addiction would not be reached. The nicotine uptake data in Chapter 5 show the opposite indicating that thresholds are easily reached, and so do the calculations based on yields determined with $\mathrm{HCl}$ on a smoking machine. Smoking Marlboro Prime reduced the cotinine concentrations after a week of smoking with approximately $50 \mu \mathrm{g} / \mathrm{mL}$ blood, from an average of $250 \mu \mathrm{g} / \mathrm{mL}$ to $200 \mu \mathrm{g} / \mathrm{mL}$ while the CPD did not change. Based on literature data, $200 \mathrm{ug} / \mathrm{mL}$ cotinine in blood corresponds to a daily nicotine exposure of $\sim 15 \mathrm{mg}$ of nicotine. Hence, it can be concluded that highly filter-ventilated cigarettes expose smokers to a sufficient amount of nicotine to initiate and sustain nicotine addiction. Based on experimentally determined $\mathrm{HCl}$ yields, consumption of 15-20 CPD would result in an exposure of 8.4 to $11.2 \mathrm{mg} / \mathrm{day}$.

Research question 4 - Does the individual's nicotine uptake change when a different type of cigarette is smoked or are smokers adapting their puffing topography to (partially) compensate for differences in nicotine yields of the cigarettes? 
In Chapters 4 and 5 it is shown that individuals have a characteristic puffing profile for regular cigarette use that is in most cases not altered when the experienced smoker switches to highly filter-ventilated products. Total number of CPD, puff volume, number of puffs and inter-puff period are person-specific, and brand independent. Even when smokers switch to a filter-ventilated blocked cigarette, which has a completely different draw resistance, most smokers maintain their characteristic puff topography. However, several volunteers smoked fewer filter-ventilation blocked cigarettes compared to the usual cigarettes of their own brand. The filter-ventilation blocked cigarette (e.g., 100\% blocked filter ventilation) was created for this study and has not been developed for the consumer's market by the manufacturer. It may have several characteristics that are not appreciated by the smokers, such as mouthfeel, harshness, taste and smell. Such unpleasant experiences were also reported by several of our volunteers but not further investigated as this was out of our scope. In general, unblocked highly filter-ventilated cigarettes may also create a different sensory sensation during puffing than regular cigarettes as well as a lower draw resistance that may facilitate larger puffs. However, in Chapter 5 we observe a nonsignificant average increase of $7 \%$ in total puff volume per cigarette. The resulting blood nicotine concentration is lower than upon smoking regular cigarettes. After smoking the filter-ventilated cigarette for a week, a $20 \%$ reduced cotinine blood concentration is found, but the daily cigarette number and puff topography remain unaltered. Hence, we conclude that the smokers did not compensate for the switch from regular to highly filter-ventilated products by increasing their CPD or smoking intensity. However, smokers may use fewer cigarettes when they switch from a highly filter-ventilated cigarette to a filter-ventilation-blocked variant, probably because they dislike such products that should be investigated in the future.

Research question 5 - Is the uptake of $\mathrm{CO}$ or other volatile toxicants in tobacco smoke linked to the nicotine uptake during smoking filter-ventilated cigarettes?

The WHO Study Group on Tobacco Product Regulation (TobReg) developed a smoke toxicants priority list including several aldehydes, VOCs and polycyclic aromatic hydrocarbons (PAHs) ${ }^{24}$. In Chapter 2, aldehydes together with nicotine and $\mathrm{CO}$ were quantified in mainstream cigarette smoke of 11 Dutch cigarette brands and two reference cigarettes. The cigarettes of interest differed in (i) design and blend characteristics; (ii) TNCO levels; (iii) popularity; and (iv) manufacturer. Variations in smoking behavior and cigarette design affecting human exposure to smoke toxicants were studied by using four different machine testing protocols based on the ISO 3308 and $\mathrm{HCl}$ regime, both with and without taping the filter vents ${ }^{25,26}$. TNCO levels were 
determined in cigarette smoke according to ISO 8454, ISO 10315 and ISO 4387, as used for regulation ${ }^{27-29}$. Using an intense smoking regime (increased puff volume, shorter puff interval) significantly increased toxicant yields were found, following the pattern ISO $<$ ISO-taped $<\mathrm{HCl}$-untaped $<\mathrm{HCl}$ for both regular- and highly filterventilated cigarettes. The difference in TNCO and aldehyde levels between regular and highly filter-ventilated low-TNCO cigarettes (as measured using ISO) diminished when smoking intensely; this effect was stronger when combined with taping filter vents. For all of the regimes and for the different cigarette brands, acetaldehyde and acrolein yields were strongly and significant correlated with each other and with the other volatile aldehydes. Previously, the WHO suggested that one, but preferably more, compounds per chemical class can be used as representative marker(s) for its chemical class ${ }^{24}$. Indeed, the obtained correlations indicate that in case of volatile aldehydes both acetaldehyde and acrolein are suitable representatives.

In Chapter 3, blood and exhaled breath samples were taken from the participants in order to determine VOCs levels directly before and maximally 10 minutes after smoking a regular, a highly filter-ventilated, and a filter-ventilation blocked Marlboro cigarette. Upon smoking, the levels of toluene, ethylbenzene, $m / p$-xylene, $o$-xylene, and 2,5-dimethylfuran in both headspace of venous blood and exhaled breath increase to a similar extent for all three cigarette types smoked. Generally, a correlation between the increase of the concentrations of the various VOCs was observed. The increases of VOCs in exhaled breath and in blood samples were not different between smoking regular and highly filter-ventilated cigarettes and only slightly higher upon smoking the taped variant of the highly filter-ventilated product. These results are consistent with the results of Chapter 5 showing a similar nicotine uptake in blood upon smoking regular, filter-ventilated and taped cigarettes. CO uptake was also similar, except for the taped variant of the highly filter-ventilated product after which the $\mathrm{CO}$ uptake was statistically higher in accordance with the VOC uptake in Chapter 3. The increased filter ventilation in our study did not reduce $\mathrm{CO}$ and $\mathrm{VOC}$ exposure of the smoker, but slightly reduced nicotine intake. The consequence of blocking the filter-ventilation is an increased exposure to $\mathrm{CO}$ and VOCs, even when smokers on average smoke such cigarettes with fewer puffs. In conclusion, the uptake of nicotine, $\mathrm{CO}$ and VOCs are dependent on the individual smoking behavior.

Research question 6 - Can toxicant yields of cigarettes produced with a smoking machine be used for human risk assessment purposes, and are there alternatives such as exhaled breath? 
During the human study in Chapter 3, it was aimed to investigate VOCs levels in headspace of blood and exhaled breath and their interrelations upon smoking three types of cigarettes. For most of the VOCs, concentrations in blood as well as in exhaled breath increased 2-3 fold upon smoking a single cigarette. Overall, the VOC levels in exhaled breath and blood were not significantly correlated, partly because of the large variations observed between the smoking topography of the individual volunteers. This lack of correlation may also be due to the moments of sampling since sampled exhaled air only at $t=10$ minutes after smoking, but did not investigate the kinetics of the VOCs over an extended period. Therefore, we conclude that more research is required in order to use exhaled breath sampling as a non-invasive quantitative tool for volatile organic toxicants from cigarette smoke exposure.

Based on the data obtained in Chapter 4 and 5 , it can be concluded that the currently used ISO regime during machine smoking is insufficiently exemplary for human smoking and that the human topography lies closer to the $\mathrm{HCl}$ regime and is even more intense. However, $\mathrm{HCl}$ deals with closed ventilation holes and thus direct comparison needs caution.

In the past, the cigarette product manufacturer positioned the filter vents on the filter where they remain open when placed in the smoking machine holder in order to mislead the smoking machine and manipulate the cigarette smoke emissions. This concept is called the cheating cigarette ('sjoemelsigaret' in Dutch) in The Netherlands. To improve the relevance of machine smoking measurements for regulation, is that either measurement methods are being used that are insensitive for filter ventilation (such as $\mathrm{HCl}$, or that filter ventilation as a design feature is prohibited. Filter ventilation enhances the palatability of the smoke and is thus an attractive design feature for smoker. Also regular brands, such as Marlboro Red have some filter ventilation. If filter ventilation is completely blocked, the cigarette smoke is less palatable. This is also demonstrated by Figure 1 where can be seen that smoking Marlboro Prime taped results in lower total puff volumes; the distribution is shifted to the left, compared to Marlboro Prime. Prohibition of filter ventilation will end this. Using puffing parameters settings on the smoking machine representative for human smoking will lead to a valid exposure estimate and is therefore interesting for regulatory purposes.

Research question 7 - What are the contributions of toxicant smoke yields resulting from (the several types of) human puffing topographies to the risk for smokers? 
As expected, levels of nicotine, carboxyhaemoglobin ( $\mathrm{COHb}$ ) and VOCs in blood increase after smoking a cigarette with the levels of increase depending on the puffing profile of the individual smoker. In Chapter 3, smokers had a similar VOC intake for the cigarette types differing in ISO-TNCO yields. In Chapter 5, it is shown that $\mathrm{COHb}$ levels in smokers are almost similar when volunteers smoke regular or highly filter-ventilated cigarettes. This observation indicates that cigarettes with lower ISO-declared TNCO levels, such as Marlboro Prime, may expose smokers to similar or even higher levels of VOCs and possibly other pyrolysis or combustion-related smoke constituents, than regular cigarettes. These observations are consistent with literature data of $\mathrm{CO}$ uptake in smokers upon smoking highly filter-ventilated cigarettes. Based on the results of the volunteers' studies in the Chapters 3 and 5 it is concluded that a characteristic puffing topography is more important for actual exposure to smoke constituents than the brand smoked. However, smoking Marlboro Prime taped resulted in higher $\mathrm{COHb}$ levels in blood compared to the other cigarette types as even when fewer puffs were taken per cigarette and fewer cigarettes were smoked, blocking filter ventilation led to significantly higher $\mathrm{CO}$ exposure over the day compared to non-blocking. An explanation for these higher $\mathrm{CO}$ yields might be a lower airflow entering the cigarettes via the flank leading to a less complete (e.g. more incomplete) combustion. Also during machine smoking experiments (Chapter 3) higher levels of $\mathrm{CO}$ and other volatile organic smoke constituents are generated with fewer puffs when cigarettes are taped, showing that pyrolysis and burning conditions during puffing substantially influence the concentrations of pyrolysis and burning products in the tobacco smoke (Chapter 2). However, the interaction between smoking topography and pyrolysis and burning products requires further study. In the 'normally distributed area' below the $1000 \mathrm{~mL}$ (Figure 1), the peak of total puffing volume lies on $750 \mathrm{~mL}$. An individual smoker is able to inhale two to three times more volume. The total puffing volume reached by smoking under ISO 3308 conditions is only a third $(277 \mathrm{~mL})$ of the $750 \mathrm{~mL}$, and for $\mathrm{HCl}(490 \mathrm{~mL})$ this is two-third. Fowles and Dybing used ISO data to calculate cancer risk indices (CRI). The calculation with ISO resulted in a 4.9 times lower CRI than the observed cancer incidence attributable to smoking in the US. The almost five times lower CRI can be explained by the underestimation of ISO towards realistic smoking as is shown in this thesis. The proposed use of $\mathrm{HCl}$ yield data instead of the now used ISO yield data by Fowles and Dybing will still not result in a comparable CRI to the observed cancer incidence as $\mathrm{HCl}$ is still underrepresenting human smoking. Moreover, our studies showed that smokers often reach higher total cigarette volumes than the 4.9 times ISO volume $(277 \mathrm{~mL}$ x $4.9=1.357 \mathrm{~mL})$, as can be seen in Figure 1 . The noncancer risk indices (NCRI) calculated with ISO yields for some compounds are above 
1 , some even above 100 . These will increase up to 1000 if $\mathrm{HCl}$ yield or human yields are used. Moreover, the NCRI that are below 1 now, and thus not of concern, will be above 1 when more representative yields are used for the calculations. The ranking of compounds will not change, but the list of compounds of concern will increase. $\mathrm{HCl}$ data or preferably human data improves the prediction of Fowles and Dybing's proposal.

\section{General discussion}

Based on the data described in this thesis, several important issues concerning cigarette regulation and risk assessment regarding emissions of toxicants are addressed (research questions 10, 11 and 12). In our studies, most smokers show no, or minimal, characteristic puffing parameter adjustments when switching to other brands. Characteristic smoking topography is significantly different between smokers, but all smokers still attained comparable nicotine, COHB and VOC blood levels independent of the type of cigarette while they smoked a similar number of CPD. In studies reported in the literature with Very Low Nicotine Cigarettes (VLNC), significantly reduced uptake of nicotine has been observed ${ }^{30-32}$ which can be explained by the fact that hardly any nicotine is present in the tobacco filler and nicotine is not produced during burning and pyrolysis. However, it was unexpected that VLNC smokers continued smoking and that only minor changes in puffing topography and CPD were observed. These observations are not consistent with the hypothesis that experienced habitual smokers only continue smoking to satisfy their need of self-administration of nicotine. However, it is consistent with the hypothesis that tobacco addiction is only partially a pharmacological addiction and more than nicotine addiction. Furthermore, in accordance with our data from the volunteers' experiments, literature also reports that with VLNC puffing topography is not controlled by direct nicotine exposure during smoking. Although each individual smoker has a characteristic puffing topography, the overall purpose of smoking is essentially to experience a brain reward. As uptake of nicotine through the lungs and transport to the brain takes more than 10 seconds ${ }^{33}$ and the puff duration is only 2 seconds or less, it is unlikely that this mechanism plays a critical role in puff topography. Nicotine uptake is more likely to be controlled in the buccal cavity by the olfactory and trigeminal neural systems ${ }^{34,35}$. Brain activity responses to exposure in the buccal cavity can be very quick ( $<4$ seconds) and require little nicotine. With each puff, a smoker inhales nicotine and other smoke constituents, which activate the quick reward response via the olfactory and trigeminal neural system. These processes occur independent of the cigarette type (light, heavy, filterventilated, etc.) as each cigarette contains sufficient amount of nicotine $(\sim 16 \mathrm{mg}$ 
in tobacco filler of one cigarette) to deliver the desired amount per puff and per cigarette. By doing so, a smoker becomes used to their cigarette brand, and develops a characteristic puffing profile. The only aspect the design of the cigarette needs to ensure is that there is not too little or too much nicotine per puff delivered, leading to respectively too little reward or a trigeminal nerve overreaction. Hence, a smoker primarily controls the nicotine intake by its puff-pulse rhythm. In addition, once the characteristic puff topography has been developed, the smoker will use this topography for other tobacco products as well. Even when nicotine concentrations in the smoke are lower, the characteristic smoking behavior will be sustained as long as other rewarding sensory elements of the tobacco smoke are delivered by the cigarette. Since high filter ventilation, as well as the use of nicotine-free tobacco, may influence the overall sensation of puffing, minor changes in puff topography may be seen when smokers switch brands. Our study suggested that 'compensation' is not due to lower nicotine yield and supports the hypothesis that if smokers change their puffing when using another brand, they probably do this because of other sensory effects in the buccal cavity.

Upon smoking VLN,C usually no reduced CO levels were found in smokers, suggesting that the actual exposure of the smoker to $\mathrm{CO}$, generated during pyrolysis and burning, is mainly determined by puffing topography and not necessarily related to nicotine exposure and intake. Instead, for $\mathrm{CO}$ as well as other smoke constituents also produced during burning and pyrolysis, the smoldering and puffing parameters such as puff duration, puff volume and puff number, determine the human exposure. For nicotine, also the amount present in the tobacco filler plays a role in human exposure during smoking, and thus exposure to burning and pyrolysis products in tobacco smoke are not always reflected by nicotine exposure.

Thus, for risk assessment and regulatory purposes, the underlying similarities and differences between the processes determining the presence of different classes of constituents in the smoke should be taken into account. However, for chemicals that are mainly released into the smoke by evaporation such as nicotine, as well as constituents that are produced during pyrolysis and burning, puffing topography has major impact on the yields. This finding indicates that when risk assessment and regulation are based on standardized machine smoking data, the smoking machine puffing profile needs to be close to human puffing profiles with regard to puff frequency, puff volume, puff duration and puff numbers. However, to use smoke toxicant-to-nicotine ratio of the yields may have limitations for low or high nicotine content cigarettes. 
Exposure assessment is an essential aspect of risk assessment as it includes the characterization of the magnitude, frequency and duration of exposure to an agent, as well as the number and characteristics of the population exposed. In the past, TNCO yields have been used as an overarching umbrella term for toxicant yields in cigarette smoke. Fortunately, more and more research is performed for chemicals with specific characteristics, such as carbonyls and VOCs that are part of cigarette smoke emissions. Measurements of different chemicals with similar physicochemical characteristics in cigarette smoke emissions produced with the smoking machine can be used as exposure estimate of a chemical class in human risk assessments. Our research shows that the puffing parameter settings of the smoking machine and the cigarette design features (especially filter-ventilation) are important determinants for the measured toxicant yields in cigarette smoke. When determining toxicant yields it is important to use more than one puffing regime and different cigarette types to assure a representative range of toxicant levels in smoke. As said, a puffing regime that requires (half-) blocked and unblocked testing with a slightly higher puff volume $(60-70 \mathrm{~mL} /$ puff) and a higher puffing frequency ( 3 puffs per minute rather than 2 puffs per minute) might be helpful.

\section{Implications and future research}

The methodology (e.g. smoking machine experiments) to determine exposure to cigarette smoke toxicants is inadequate and needs improvement to allow for a more accurate exposure assessment.

\section{Inhalation measurements}

In order to more accurately assess exposure, more knowledge is needed not only about the emission of smoke toxicants, but also about human smoking behavior. The dose of toxicants to which smokers are exposed depends on different factors such as the cigarette type, the number of cigarettes smoked, the toxicant yields delivered per cigarette and lastly the inhalation practice. The inhalation practice is defined by the inhalation parameters such as the hold time in the lungs, the in- and exhalation volumes, and the depth of inhalation. The inhalation practice, in addition to the physicochemical characteristics of the constituents, determines the location and amount of smoke constituents in the lung. The majority of the studies indicate that approximately $60-80 \%$ of particulate matter retains in the lungs after inhalation. Similarly, $90-100 \%$ of nicotine and nitric oxides, $90 \%$ of aldehydes and $55-65 \%$ of carbon monoxide retain in the lungs of smokers ${ }^{36-38}$. Accurate methodology to directly measure smoke distribution and retention in the lungs is however lacking. To date, computer modeling is used to determine the respiratory region where 
different smoke toxicants end up. However, this method often uses generalized breathing parameters instead of actual human smoking behavior ${ }^{38}$. A possible way to distinguish breathing from inhaling cigarette smoke is the use of the Respiratory Inductance Plethysmography (RIP) technology. With this technology, upper and lower respiratory movements are un-invasively measured by the use of sensors in comfortable garment such as the Hexoskin. In order to accurately determine the internal dose of the smoker, information about the inhalation parameters (by Hexoskin) in combination with the smoke toxicants formed (mimicking human puffing profile on smoking machine) under certain puffing parameter conditions (recorded puffing topography) is needed. In the past, Feng et al., who tested and controlled different inhalation patterns in their research, described that using such RIP garment is a suitable method for estimation of retention of smoke constituents in the lungs ${ }^{39}$. With their study design, the hypothesis that larger puff volumes could possibly lead to deeper inhalation and development of a specific type of cancer tumor in case of highly filter-ventilated cigarettes could be tested ${ }^{38}$. The knowledge about the inhalation practice of smokers is valuable for the use and optimization of computer modeling of respiratory exposure to smoke toxicants.

\section{In vitro systems}

An alternative for mixture risk assessment is the use of in vitro cell systems cultured in contact with air such as the air-liquid-interface (ALI) models. This cell culture system represents the pulmonary epithelial layer as the cells are cultured on airliquid inserts, prone to air stream and reacting on exposure by air. A smoking machine can be coupled to this system to expose the cells to freshly generated cigarette smoke. To specifically estimate individual lung exposure according to actual human smoking, the human puff profile of a certain individual can be used as settings to the smoking machine coupled to ALI. Parallel, the TNCO and other toxicant yields in the smoke generated under the human profile settings can be determined in a smoking machine experiment. A similar approach is the combination of a robotic smoking machine with a lung-on-a-chip technology. This is a microfluidically coupled, multicompartment platform that bidirectionally 'breathes' fresh cigarette smoke through microchannels of a human lung small airway microfluidic culture device that mimics how lung cells may experience smoke in vivo ${ }^{40}$. Results of the two described in vitro experiments inform on cigarette smoke lung damage according to human smoking conditions. A disadvantage of in vitro systems are the many different readouts possible and that the human relevance of the results is not that clear yet. 
The study results presented in this thesis help closing the gap in knowledge between reduced exposure and reduction of harmful effects. With the rise of new tobaccorelated products such as e-cigarettes and heated tobacco products, closing this gap is even more relevant. Using different nicotine delivery systems clearly results in different exposure levels, but the (especially non-cancer) effects hereof are unknown.

\section{Limitations}

As part of this thesis, two human studies were designed and performed with the main aim to study natural smoking behavior. Based on the chosen design, a few potential limitations could be raised. It can be argued that the sample size of the human studies is small, or that testing only two brands is too little. Another point of discussion is that the study population would not be representative for the human smoking population. A last debate point is the ad libitum smoking (e.g. natural behavior) instead of a controlled number of cigarettes. We are aware of the fact that these study design choices are not traditional or regular and are associated with disadvantages. Of course, we would have preferred to have an endless number of participants and tested more brands, but we had to minimize to such extent for practical reasons. From an ethical perspective it is desirable to minimize the number of volunteers ( $n$ ) who are asked to smoke. Moreover, the number of cigarettes that individuals are asked to smoke for the experiment should also be minimized. Therefore, we chose to study two different types from a cigarette brand, including the design feature filter ventilation. The multiple sampling within a participant for a single product, and also performed for the different products, is a strength of the present study. For labor-intensively reasons, we preferred to have more sampling moments per person, to outline the intake over a day, rather than single measures for more participants. As described in the introduction, there are many interindividual differences in smoking behavior as was tested in heterogenous study populations. However, these could not explain why studies find a wide range of puffing parameters. Therefore, we decided to study a homogeneous population with the hypothesis that the 'type' of smoker (male, age range, CPD) would not be the possible confounder of the puffing parameter data. The research design aim was to study natural smoking behavior, which means that we could not impose to smoke at a certain time point. Consequently, we were not able to sample directly before and

after all cigarettes. The homelike atmosphere environment enabling natural smoking behavior and thus a realistic intake of smoke compounds is a strength of the present study. 


\section{Concluding remarks}

The adverse health impact on individuals and the population of cigarette smoking is undisputed. All tobacco smoking increases the health risk and no smoking is the only healthy alternative. However, cigarettes are legally available on the consumers' market and health reduction strategies have been chosen by international governments in the fight against the tobacco pandemic. Tobacco smoke contains thousands of chemicals, many of which are available in toxicologically relevant concentrations, and none of which have been regulated so far under the FCTC. In order to support future regulation, the aim of this thesis is to

Relate, for the purpose of risk assessment and cigarette regulation, the emissions of nicotine, carbon monoxide, and volatile organic compounds produced with smoking machines to emissions produced during human smoking, as well as to the actual uptake of smoke constituents in the body of smokers, taking into account the smokers' daily use of cigarettes and their personal puff topography.

I. Experienced smokers expose themselves more than 100 times per day during 1 or 2 seconds to the chemical mixture by applying their own characteristic puffing topography. Actual puffing of experienced smokers is not regulated by nicotine uptake by the lungs, but by sensory effects in the buccal and nasal cavity, an issue that needs further investigation. Differences between the individual smoking behavior (cigarette per day and puffing topography) easily leads to a two-to-three-fold different exposure of tobacco smoke when the smokers use the same brand (Chapter 3 ). In risk assessment models variation of exposure is usually taken into account, and that this variation is often less than factor of 10 between the highest and the lowest exposure. For experienced smokers this assumption holds for nicotine, as the variation between nicotine concentrations in blood shortly after smoking between users is comparable (Chapter 5), irrespective of the brand smoked. It is also shown for carbon monoxide in various studies (Chapter 5) other tobacco smoke constituents of the gas phase, such as aldehydes and VOCs (Chapter 3 and 4). This is in spite of the different puffing topography and differences between brands. This thesis generated insufficient data to allow a full statistical analysis of the attribution of puffing topography, brand variation and actual exposure. However, based on the experiments of human smoking, actual exposure variation between individuals is not much more than a factor of 10 . Such a limited variation it is not completely unexpected, since tobacco industry probably invest much to design and manufacture cigarettes to deliver tobacco smoke within a narrow 
range of nicotine exposure.

II. Anarrow range of emission yields of gas phase constituents is found when tobacco smoke yields are determined with standardized smoking machine. However, smoking regimes used nowadays underestimate human exposure substantially as the puffing volumes and the puffing frequency are too low. In addition, this also results in too low puffing numbers compared to human smoking. When ISO 3308 data are used human exposure may easily be underestimated by a factor 2-3 for regular cigarettes and even more for highly ventilated products. Taping is critical since untaped testing generates unrealistically low yields for highly filter filter-ventilated cigarettes. A suggested modification is half-blocking with the use of holders that partially cover the filter when used in smoking machine experiment. Another option is eliminating filter ventilation to a certain extent (e.g. a maximum filter percentage allowed) as design feature. It must be noted that puff number per cigarette has major impact on yields, particularly since concentrations of smoke constituents can be higher in the last puffs of a cigarette compared to the earlier puffs. $\mathrm{HCl}$ regiments on a smoking machine should actually be modified by applying 3 rather than 2 puff per minute.

III. Based on this thesis we postulate that such a modified standardized $\mathrm{HCl}$ test on a smoking machine generates tobacco smoke with smoke constituents in concentrations $(\mu \mathrm{g} / \mathrm{mL}$ ) which can be related to smoke during human smoking, under conditions of comparable puffing topography (puff number, puff volume, puff frequency, total cigarette volume). However, even a standardized modified $\mathrm{HCl}$ test will not fully mimic human smoking completely and one testing method is prone to (adaptation) design features of products as has been shown with ISO 3308 and filter-ventilated products. Therefore, a second testing method is always required to be used in tandem with a modified $\mathrm{HCl}$ regiment. A modified ISO 3308 may be an option as second test when puffing intensity is increased with higher puff volume and higher puffing frequency. 


\section{References}

1. Center for Systems Science and Engineering (CSSE). COVID-19 Dashboard. 2020. https://gisanddata.maps.arcgis.com/apps/opsdashboard/index.html\#/ bda7594740fd40299423467b48e9ecf6. Accessed Jan 16th, 2021.

2. World Health Organization. Fact sheet: Tobacco. 2020. https://www.who.int/newsroom/fact-sheets/detail/tobacco. Accessed Jan 15th, 2021.

3. Proctor RN. Why ban the sale of cigarettes? The case for abolition. Tob Control. 2013;22 Suppl 1:i27-30.

4. Beard E, Jackson SE, West R, Kuipers MAG, Brown J. Population-level predictors of changes in success rates of smoking quit attempts in England: a time series analysis. Addiction. 2020;115(2):315-325.

5. Gotts JE, Jordt SE, McConnell R, Tarran R. What are the respiratory effects of e-cigarettes? BMJ. 2019;366:15275.

6. Ratajczak A, Jankowski P, Strus P, Feleszko W. Heat Not Burn Tobacco Product-A New Global Trend: Impact of Heat-Not-Burn Tobacco Products on Public Health, a Systematic Review. Int J Environ Res Public Health. 2020;17(2).

7. World Health Organisation. Framework Convention on Tobacco Control. Geneva, Switzerland 2003 updated reprint 2004, 2005.

8. WHO Conference of the Parties (COP) to the Framework Convention on Tobacco Control (FCTC). Partial guidelines for the implementation of Articles 9 and 10 of the WHO FCTC (FCTC/COP/4/10). Moscow, Russian Federation. World Health Organization; 2010.

9. WHO Conference of the Parties (COP) to the Framework Convention on Tobacco Control (FCTC). Implementation of Articles 9 and 10 of the WHO FCTC (Regulation of contents and disclosure of tobacco products, including water pipe, smokeless tobacco and heated tobacco products) (FCTC/COP/8(21)). Geneva, Switzerland. World Health Organization; 2018.

10. European Union. Tobacco Products Directive (2014/40/EU). Brussels, Belgium: Offical Journal of the European Union; 2014.

11. Pollay RW, Dewhirst T. The dark side of marketing seemingly "Light" cigarettes: successful images and failed fact. Tob Control. 2002;11 Suppl 1:I18-31.

12. Baker R. Smoke chemistry. In: Davis DL NM, ed. Tobacco: production, chemistry and technology. Oxford, London, UK: Blackwell Science Ltd.; 1999:398-439.

13. WHO Study Group on Tobacco Product Regulation (TobReg). Report on the Scientific Basis of Tobacco Product Regulation; second report. WHO Technical Report Series 951. Geneva, Switserland: World Health Organization; 2008.

14. Scherer G. Smoking behaviour and compensation: a review of the literature. Psychopharmacology (Berl). 1999;145(1):1-20.

15. Scherer G, Lee PN. Smoking behaviour and compensation: a review of the literature with 
meta-analysis. Regul Toxicol Pharmacol. 2014;70(3):615-628.

16. Mikheev VB, Buehler SS, Brinkman MC, et al. The application of commercially available mobile cigarette topography devices for e-cigarette vaping behavior measurements. Nicotine Tob Res. 2018.

17. Shiffman S, Scholl S. Increases in Cigarette Consumption and Decreases in Smoking Intensity When Nondaily Smokers Are Provided With Free Cigarettes. Nicotine Tob Res. 2018;20(10):1237-1242.

18. Borges AM, Leyro TM, Rosen RL, Zvolensky MJ, Farris SG. Negative urgency and adlibitum smoking topography. Drug Alcohol Depend. 2019;201:220-226.

19. Hammond D, Fong GT, Cummings KM, et al. Cigarette yields and human exposure: a comparison of alternative testing regimens. Cancer Epidemiol Biomarkers Prev. 2006;15(8):1495-1501.

20. Djordjevic MV, Stellman SD, Zang E. Doses of nicotine and lung carcinogens delivered to cigarette smokers. J Natl Cancer Inst. 2000;92(2):106-111.

21. Purkis SW, Troude V, Hill CA. Effect of puffing intensity on cigarette smoke yields. Regul Toxicol Pharmacol. 2013;66(1):72-82.

22. Hammond D, Wiebel F, Kozlowski LT, et al. Revising the machine smoking regime for cigarette emissions: implications for tobacco control policy. Tob Control. 2007;16(1):814.

23. Benowitz NL, Henningfield JE. Establishing a nicotine threshold for addiction. The implications for tobacco regulation. N Engl J Med. 1994;331(2):123-125.

24. Burns DM, Dybing E, Gray N, et al. Mandated lowering of toxicants in cigarette smoke: a description of the World Health Organization TobReg proposal. Tob Control. 2008;17(2):132-141.

25. WHO Tobacco Laboratory Network. WHO SOP 01 Standard operating procedure for intense smoking of cigarettes. Geneva, Switzerland. World Health Organization; 2012.

26. International Organisation for Standardisation. ISO 3308:2012 Routine analytical cigarette-smoking machine -definitions and standard conditions. 2012.

27. International Organisation for Standardisation. ISO 8454:2007/A1:2009 Cigarettes Determination of carbon monoxide in the vapour phase of cigarette smoke - NDIR method. 2009.

28. International Organisation for Standardisation. ISO 10315:2014 Cigarettes Determination of nicotine in smoke condensates - Gas-chromatographic method. 2014.

29. International Organisation for Standardisationm. ISO 4387:2000/A1:2008 Cigarettes Determination of total and nicotine-free dry particulate matter using a routine analytical smoking machine. 2008.

30. Donny EC, Denlinger RL, Tidey JW, et al. Randomized Trial of Reduced-Nicotine Standards for Cigarettes. N Engl J Med. 2015;373(14):1340-1349. 
31. Denlinger-Apte RL, Donny EC, Lindgren BR, et al. Smoking Topography Characteristics During a 6-Week Trial of Very Low Nicotine Content Cigarettes in Smokers With Serious Mental IIIness. Nicotine Tob Res. 2020;22(8):1414-1418.

32. Tidey JW, Rohsenow DJ, Kaplan GB, Swift RM, Ahnallen CG. Separate and combined effects of very low nicotine cigarettes and nicotine replacement in smokers with schizophrenia and controls. Nicotine Tob Res. 2013;15(1):121-129.

33. Benowitz NL. Clinical pharmacology of nicotine: implications for understanding, preventing, and treating tobacco addiction. Clin Pharmacol Ther. 2008;83(4):531-541.

34. Hummel T, Hummel C, Pauli E, Kobal G. Olfactory discrimination of nicotine-enantiomers by smokers and non-smokers. Chem Senses. 1992;17(1):13-21.

35. Albrecht J, Kopietz R, Linn J, et al. Activation of olfactory and trigeminal cortical areas following stimulation of the nasal mucosa with low concentrations of S(-)-nicotine vapor-an fMRI study on chemosensory perception. Hum Brain Mapp. 2009;30(3):699-710.

36. Baker RR, Dixon M. The retention of tobacco smoke constituents in the human respiratory tract. Inhal Toxicol. 2006;18(4):255-294.

37. Thielen A, Klus H, Muller L. Tobacco smoke: unraveling a controversial subject. Exp Toxicol Pathol. 2008;60(2-3):141-156.

38. Song MA, Benowitz NL, Berman M, et al. Cigarette Filter Ventilation and its Relationship to Increasing Rates of Lung Adenocarcinoma. J Natl Cancer Inst. 2017;109(12).

39. Feng S, Plunkett SE, Lam K, et al. A new method for estimating the retention of selected smoke constituents in the respiratory tract of smokers during cigarette smoking. Inhal Toxicol. 2007;19(2):169-179.

40. Benam KH, Novak R, Ferrante TC, Choe Y, Ingber DE. Biomimetic smoking robot for in vitro inhalation exposure compatible with microfluidic organ chips. Nat Protoc. 2020;15(2):183-206. 



\section{Impact paragraph}



Smoking is still a worldwide problem that should be taken seriously as can also be deduced from the World Health Organization (WHO) Framework Convention on Tobacco Control (FCTC). The WHO FCTC is a legal framework that entered into force in 2005 as a response on the global tobacco epidemic. While all consumer products, and especially food and nutraceuticals are tested and rated for their potentially safe use, it is known for decades that tobacco products are unsafe but allowed. Moreover, while there is all-round legislation for product safety, the unsafe tobacco products are not regulated.

This thesis subject is in agreement with Article 9 and 10 of the WHO FCTC that includes regulations of the content and disclosures of tobacco products whereby it is unclear whether lowering smoke components has a health beneficial effect. A tobacco product may be harm reducing if it lowers total tobacco related mortality and morbidity (i.e. on population level) even though the use of that product may involve continued exposure to tobacco related chemicals. Toxicity to some extent is an inherent aspect of the tobacco product, but less harmful products can still benefit the general smokers' health.

For example, in the Netherlands yearly 20.000 smokers die because of smoking. ${ }^{1}$ If this number could be halved, this would be a huge health benefit. To reach a less harmful product, the WHO Study Group on Tobacco Product Regulation (TobReg) proposed mandated lowering of harmful chemicals, or toxicants, in cigarette smoke. Such a strategy for regulation is based on product performance measures with the goal to reduce toxicant levels in mainstream cigarette smoke measured under standardized conditions. This is a challenge for which scientific data based on toxicological testing are needed. Currently, smoking machine tests under 'standardized conditions' are the golden standard to obtain such data although this approach is often criticized. No single protocol is able to give a good prediction for every smoker, with every brand, but the current International Standardization Organization (ISO) 3308 protocol definitely fails to link the actual risks for human smokers from a scientific and biologically relevant perspective. With this thesis, we aimed to improve this link and thereby decrease the gap in current knowledge about smoking topography and the assessment of exposure to cigarette smoke compounds.

\section{Impact on fundamental and applied science}

Human studies often show substantially elevated concentrations of (biomarkers of) toxicants in smokers' blood compared to those in the blood of non-smokers, indicating an increased health risk. The influence of human smoking behavior on 
blood concentration of smoke toxicants, in combination with the yields of the used products, is scarcely investigated yet. Instead of comparing non-smokers to smokers, we investigated how the actual exposure doses depend on individual variations in smoking topography. In our studies, we aimed to reflect actual human exposure to smoke toxicants, providing insights into the relevance of using machine-smoking data in risk assessment and product regulation.

In this thesis, we show that smokers have a personal smoking profile that is fairly stable but varies greatly between smokers. This indicates that personal exposure (and therefore risk) vary greatly. Additionally, we show that smokers have a more intense smoking profile than even the Health Canada Intense $(\mathrm{HCl})$ protocol. If this is taken into account, the calculations of Fowles and Dybing will yield reasonable results with epidemiological data. Ergo, the order of compounds as presented by Fowles and Dybing stay intact. Reduction of toxicant yields in smoke will therefore most likely be associated with less risk of developing smoking related diseases and thus lower total tobacco related mortality and morbidity.

In addition to the regular cigarette Marlboro red, we specifically focused on highly ventilated cigarettes of which it is assumed that these cigarettes are less harmful. The nicotine exposure of these cigarettes is very low, even below the threshold of initiating or sustaining nicotine addiction (daily dose of less than $\sim 5 \mathrm{mg}$ ). In contrast to the established theory, hardly any compensation is found for the highly ventilated cigarettes.

We showed that smoke compounds relate to each other, and that a limited set of smoke components is therefore sufficient for risk estimation. Hence, the data presented in this thesis could be used to improve the current measurement methods for toxicant exposure levels and thus consequently contribute to harm reducing measures with respect to tobacco smoking. The data presented for the different cigarette brands according to different smoking regimes can be used by risk assessors as input for their models. In addition, the puffing topography data can be used to generate more reliably model human exposure. The information from Chapter 2, 4 and 5 may lead to more reliable risk assessment models in which health effects are related to tobacco smoking. The papers that cited our articles (Chapter 2 and 4) are using our data as such.

The results in this thesis are especially relevant for other scientific researchers working in this field, because the list with human studies and the detailed data 
of puffing parameters presented in Chapter 4 give insight in worldwide puffing topography; this is especially informative because it is specified per brand smoked. Furthermore, our own puffing topography study included a thorough investigation of the CReSSmicro ${ }^{T M}$ device. The data have led to insight about the use of this device to measure smoking topography for fellow researchers and future studies. We have shown where the anomalies in the raw data possibly come from and how to deal with or prevent them.

\section{Impact on regulation}

In Chapter 2, we compared the ISO and Health Canada Intense $(\mathrm{HCl})$ method for 11 cigarette brands commercially available in The Netherlands. Our data revealed that two to three times more TNCO was measured when using $\mathrm{HCl}$ compared to ISO. This was caused, among other things, by the fact that the measured smoke is mixed with air that enters via the ventilation holes in the filter of the cigarette during machine smoking of the ISO 3308 method. This means that the current measurement method used in the EU (e.g. ISO 3308) is underestimating actual exposure levels of smokers to the harmful chemicals in cigarette smoke. Tobacco manufacturers manipulated the method by adapting their cigarette design by adding filter ventilation holes. This urges for a different measurement method for detecting toxicant levels in mainstream cigarette smoke, as for instance the $\mathrm{HCl}$ method in which the ventilation holes are taped and thus closed.

In October 2017, the State Secretary sent a letter to Brussels wherein he argued for a different measurement method than the prescribed ISO 3308 method to measure tar, nicotine and carbon monoxide (TNCO) in the European Tobacco Products Directive (EU-TPD). This letter was (partly) based on data from this thesis (Chapter 2). Subsequently to the letter of the State Secretary, the RIVM was asked to measure 100 Dutch brands using the $\mathrm{HCl}$ method and the obtained results supported our outcome that is published in Chapter 2. Despite the recommendation from different parties such as the Dutch government, to include an independent measurement method, such as the WHO TobLabNet SOP 01, this is not implemented yet in the EU-TPD. This is unfortunate because countries cannot implement these SOPs in national legislation as they have to adhere to the EU legislation.

Because we used smoking machine settings with and without taping the cigarettes, the data for the different brands are also demonstrating the effect of a design feature such as filter ventilation on smoke toxicants (and the exposure of the smoker). This information adds to the idea of limiting the allowed cigarette design features such 
as a maximum filter ventilation percentage or no filter at all.

In conclusion, $\mathrm{HCl}$ results in cigarette smoke emission that is too low to represent human smoking. In order to give a more accurate reflection of human smoking behavior, cigarettes should be machine smoked with a more realistic puffing regime that has a higher puff frequency and a higher puff volume, and with and without filter ventilation blocking. In addition, two regimes can be used to prevent that possible design features manipulate one type of regime and thus the smoke toxicant measurements.

\section{Reference}

1. Rokeninfo.nl. Hoeveel mensen overlijden er jaarlijks in Nederland aan de gevolgen van roken? https://www.rokeninfo.nl/cijfers/hoeveel-overlijden-gevolgroken\#: :text=Jaarlijks\%20overlijden\%20in\%20Nederland\%20ongeveer,aan\%20 roken\%20kan\%20worden\%20toegeschreven. Accessed May 5th, 2021. 


Nederlandse samenvatting 



\section{Wereldwijde tabak pandemie}

Wereldwijd worden veel verstrekkende economische en sociale maatregelen genomen in de strijd tegen de COVID-19-pandemie. Volgens de Johns Hopkins University stierven tijdens de pandemie in 2020 meer dan 1,8 miljoen mensen. Volgens de jaarlijkse sterftecijfers stierven in 2020 echter minstens drie keer meer wereldburgers ( $>7$ miljoen) als gevolg van tabaksgebruik en dit aantal zal in de nabije toekomst blijven groeien. In de strijd tegen COVID-19 hebben regeringen de vrijheid van alle burgers drastisch beperkt en dramatische maatregelen genomen om levens te redden en virus-gerelateerde morbiditeit te verminderen. Om de tabakspandemie op te lossen moet idealiter de productie en verkoop van tabaksproducten worden verboden. Naast maatregelen om tabaksgebruik volledig te voorkomen, helpen ook risico beperkende benaderingen om de tabakspandemie te bestrijden. Dergelijke maatregelen zijn voornamelijk gebaseerd op belastingen, de-normalisatie, hulp bij stoppen-met-roken en "rookvrije" wetgeving die gericht is op (potentiële) rokers. Deze risico beperkende benaderingen hebben in de meeste landen geleid tot een aanzienlijk lagere prevalentie van roken, maar het heeft het gebruik van sigaretten en andere tabaksproducten niet geëlimineerd.

Het tabaksbeleid kan worden verbeterd door regulatie van traditionele tabaksproducten, zoals sigaretten, die nog steeds dominant aanwezig zijn op de consumentenmarkt en leiden tot hoge sterfte- en morbiditeitspercentages door roken. Eén van de autoriteiten die een schadebeperkingsaanpak heeft voorgesteld is de Wereldgezondheidsorganisatie (WHO) Kaderverdrag inzake Tabaksontmoediging (FCTC). Binnen de FCTC zijn in veel landen en regio's verschillende richtlijnen aangenomen en geïmplementeerd om het tabaksgebruik te verminderen. $\mathrm{Er}$ is echter weinig vooruitgang geboekt met betrekking tot Artikel 9 - Regulation of the content of tobacco products. Dit artikel luidt: De Conferentie van de Partijen doet, in overleg met bevoegde internationale instanties, voorstellen voor richtlijnen voor het testen en meten van de inhoud en emissies van tabaksproducten, en voor de regulering hiervan. Elke Partij neemt, wanneer goedgekeurd door bevoegde nationale autoriteiten, doeltreffende wetgevende, uitvoerende en bestuurlijke of andere maatregelen, en voert deze uit, ten behoeve van deze tests en metingen, en ten behoeve van genoemde regulering. Hoewel de FCTC in 2005 in werking is getreden, heeft de Conferentie van de Partijen (COP) tot nu toe geen volledige Richtlijn voor Partijen verstrekt. In 2010 zijn gedeeltelijke richtlijnen voor Artikel 9 en 10 (over de verordening inzake de openbaarmaking van informatie over tabaksproducten) aangenomen, die in 2014 en 2016 zijn gewijzigd. In deze gedeeltelijke richtlijnen staat echter in paragraaf 3.2 ("Inhoud") en 3.3 ("Emissies") anno 2021 nog steeds "(dit gedeelte is 
opzettelijk blanco gelaten om aan te geven dat er in een later stadium richtlijnen zullen worden voorgesteld)". Het illustreert dat er op politiek gebied geen consensus is gevonden over de wetenschappelijke basis voor richtlijnen betreffende regulering van emissies. Met andere woorden, beleidsmakers worstelen met het feit dat roken nog steeds schadelijk is en als ze het eens worden over emissieregulering, lijkt het erop dat ze doorgaan met tabaksgebruik goedkeuren. Bovendien vinden beleidsmakers de effecten die leiden tot voordelen voor de gezondheid door het verlagen van rookcomponenten onduidelijk. De bezorgdheid over filterventilatie is genoemd in de 2018 COP meeting ${ }^{2}$. The WHO kreeg de taak om te voorzien in "het recentste wetenschappelijke bewijs over de impact van sigarettenventilatie op het gebruik van sigaretten" en dat te rapporteren aan de COP voor de negende meeting die gehouden wordt in Nederland in november 2021.

HoeweldeFCTCgeenemissierichtlijnheeftverstrekt, regelt deEuropeseUnie(EU)(ook een partij die de FCTC heeft aangenomen) de maximale gehaltes van teer, nicotine en koolmonoxide (CO) (TNCO) in sigarettenrook in de Europese tabaksproductenrichtlijn (TPD/2014/40/EU). De TPD heeft grenzen van respectievelijk 10 mg, 1 mg en 10 mg per sigaret gesteld als de maximumemissies die zijn toegestaan in sigarettenrook. De ETPD/2014/40/EU bevat alleen een verwijzing naar de analysetechniek van de ISO methode (International Organization of Standardization) en niet naar het ISO 3308-protocol zelf dat de rookmachinemethode beschrijft. Het is al tientallen jaren bekend dat de uitstoot van sigarettenrook wordt bepaald door de manier waarop de rook wordt gegenereerd. Bovendien is de emissie van andere toxische stoffen dan TNCO helemaal niet gereguleerd in de EU. Vóór de herziening van de ETPD werd het ISO 3308-protocol voor rookmachines wèl voorgeschreven voor de bepaling van TNCO in de EU. In de dagelijkse praktijk gebruiken alle landen in de EU nog steeds deze methode als het vereiste gestandaardiseerde testprotocol voor rookmachineexperimenten. Het is echter twijfelachtig om normen voor tabaksrook vast te stellen zonder aan te geven hoe deze norm kan worden goedgekeurd en gecontroleerd. Het reguleren van de rookemissie op basis van ISO 3308 alleen is volgens de WHO "Study Group on Tobacco Product Regulation" (WHO-TobReg 2008) niet wetenschappelijk geschikt en zou een belangrijke rol kunnen spelen in wat wordt genoemd "een misleidend beleid van de tabaksindustrie" om filter geventileerde sigaretten te promoten als "lichte", "milde" of zelfs "gezondere" sigaretten. Een wetenschappelijk onderbouwde tabaksregulering moet echter nog worden opgesteld en daarom is voor dit proefschrift het volgende doel geformuleerd. 
Dit proefschrift heeft als doel om met het oog op risicobeoordeling en regulering van sigaretten, de emissies van nicotine, koolmonoxide en vluchtige organische stoffen geproduceerd met rookmachines te relateren aan emissies geproduceerd tijdens humaan roken, evenals aan de daadwerkelijke opname van rookcomponenten in het lichaam van rokers, daarbij rekening houdend met het dagelijks gebruik van sigaretten door rokers en hun persoonlijke rooktopografie.

\section{Methodologie}

Tabaksrook bevat meer dan 6000 chemicaliën met verschillende chemische en toxicologische eigenschappen. Niet al deze chemische stoffen kunnen worden bestudeerd in relatie tot tabaksrook gerelateerde ziekten. Bovendien kan geen rekening worden gehouden met alle mogelijke verschillen tussen blootstelling van rokers, noch met de vele verschillen tussen sigarettenmerken. In dit proefschrift gebruikten we het werk van WHO-TobReg (2008) en richtten we ons alleen op nicotine, $\mathrm{CO}$, aldehyden (hoofdstuk 2) en andere vluchtige organische componenten (VOCs) (hoofdstuk 3). Een uitgebreide discussie over de effecten van teer wordt weloverwogen weggelaten, omdat het een mengsel is van duizenden individuele en potentieel giftige chemicaliën.

Voor dit proefschrift werden twee soorten experimenten uitgevoerd, namelijk rookstudies met rookmachines en met rokende vrijwilligers. In de rookstudies met de rookmachine werd sigarettenrook gegenereerd (volgens ISO 3308 en Health Canada Intense $(\mathrm{HCl})$ ), werden de rookcomponenten gekwantificeerd en werden de concentraties, per sigaret en per $\mathrm{mL}$, gerelateerd aan de topografie van humaan roken. Met de rookmachine worden sigaretten gerookt onder gereguleerde omstandigheden met geselecteerde en vaste protocollen voor rooktopografie, dat wil zeggen een vast trekvolume, trekduur en trekinterval. Afhankelijk van het specifieke profiel zal de rookmachine de sigaret 'roken' met een specifiek aantal trekjes. Het totale trekvolume van een sigaret is afhankelijk van het aantal trekjes en het trekvolume dat is ingesteld bij het specifieke rookmachineprotocol. Ten tweede werden metingen bij rokende vrijwilligers uitgevoerd om hun individuele rooktopografie en de opname van tabaksrookbestanddelen in het lichaam te bepalen. Een roker past meestal een unieke rooktopografie toe die verschilt van die van andere rokers en merkafhankelijk of -specifiek kan zijn. De achterliggende gedachte bij deze metingen is dat de humane opname van rookcomponenten zal variëren op basis van de rooktopografie van de roker en het type (filter geventileerde) sigaret. Door de rooktopografie van de roker te vergelijken met de huidige rookprotocollen kunnen gestandaardiseerde instellingen geoptimaliseerd worden om gegevens te 
leveren die helpen bij het vaststellen van limieten voor regulering van sigaretten.

Hoofdstuk 2 bestudeert twee soorten rookprotocollen en vergelijkt de uitstoot van TNCO en aldehyden van verschillende sigarettenmerken verkrijgbaar in Nederland. De onderzochte sigaretten zijn merken met zowel lage als zeer hoge filterventilatie. In hoofdstuk 4 wordt een andere benadering gepresenteerd waarbij drie varianten van één merk, namelijk Marlboro, worden gebruikt om de invloed van variatie van (menselijke) rooktopografie profielen op opname en emissies te bestuderen. In hoofdstuk 3 en 5 worden de twee soorten experimenten gecombineerd om overeenkomsten en verschillen te bestuderen tussen de emissies van de rookmachine en het humaan roken op basis van biomarkers. In hoofdstuk 3 wordt onderzocht of uitgeademde lucht kan worden gebruikt als een niet-invasief hulpmiddel om de blootstelling aan sigarettenrookcomponenten te beoordelen door vluchtige biomarkers te analyseren. Bovendien wordt de opname van rookcomponenten in bloed geanalyseerd.

\section{Hoofdstuk 2}

Aldehyden zijn één van de chemische klassen op de prioriteitenlijst van TobReg voor regulatie. Om inzicht te krijgen in factoren die de aldehydeconcentratie in sigarettenrook bepalen, zijn de concentraties van 12 aldehyden in sigarettenrook van 11 merken verkrijgbaar op de Nederlandse markt gekwantificeerd. Variaties in rookgedrag en sigaretontwerp die de humane blootstelling aan aldehyden beïnvloeden, werden bestudeerd met behulp van vier verschillende rookmachine protocollen. Het machineroken was gebaseerd op het protocol van de ISO en $\mathrm{HCl}$, zowel met als zonder afplakken van de filterventilatiegaatjes. De 11 sigarettenmerken verschilden in (i) ontwerp- en tabaksamenstellingskenmerken; (ii) TNCO; (iii) populariteit; en (iv) fabrikant. Het gebruik van een intensief rookprotocol (verhoogd trekvolume, korter trekinterval) verhoogde de aldehyde concentraties aanzienlijk als volgt: $\mathrm{HCl}>\mathrm{HCl}$ niet afgeplakt $>$ ISO afgeplakt $>$ ISO. Voor alle protocollen waren de opbrengsten van acetaldehyde en acroleïne sterk gecorreleerd $(r=0,804)$. Het verschil in TNCO- en aldehydegehaltes tussen gewone en sigaretten met hoge filterventilatie en een laag TNCO-gehalte (gemeten met ISO) nam af bij intensief roken; dit effect is sterker in combinatie met het afplakken van filter ventilatiegaatjes. De laag-TNCO-merken met een hoge filterventilatie vertoonden een zes keer hogere aldehydeconcentratie per mg nicotine voor de intensieve rookprotocollen. Concluderend kan gezegd worden dat acetaldehyde en acroleïne gebruikt kunnen worden als vertegenwoordigers voor de klasse van vluchtige aldehyden voor de verschillende merken en rookprotocollen. De aldehyde-tot-nicotine-verhouding 
nam toe wanneer sigaretten met een hoge filterventilatie intens werden gerookt. Een roker van sigaretten met een laag TNCO-gehalte en een hoge filterventilatie heeft dus een verhoogd risico op hogere blootstelling aan aldehyden in vergelijking met een roker van de reguliere sigaretten.

\section{Hoofdstuk 3}

Naast de aldehyden worden rokers ook blootgesteld aan VOCs. In hoofdstuk 3 wordt gefocust op VOCs in rook van drie soorten sigaretten van één merk variërend in aangegeven TNCO concentratie; een reguliere (Marlboro red), een laag-TNCO (en dus hoog filter geventileerde) (Marlboro Prime) en een laag-TNCO sigaret (Marlboro Prime) met afgeplakte filterventilatiegaatjes. De VOC concentraties werden bepaald in de lucht boven het bloed en in de uitgeademde lucht van rokers voor en na roken van één sigaret. Het doel was om vast te stellen of de VOC concentraties correleren met de TNCO concentraties van sigaretten die worden gerookt volgens rookprotocol ISO 3308. Uit onze gegevens blijkt dat het roken van reguliere sigaretten en sigaretten met een laag TNCO-gehalte vergelijkbare niveaus van VOCs in bloed en uitgeademde lucht tot gevolg heeft. Dit is een aanwijzing dat de aangegeven TNCO gehaltes zoals bepaald met het rookprotocol ISO 3308 voor machineroken niet relevant zijn voor het voorspellen van VOCs uitgescheiden na roken door mensen, omdat je met die methode wel verschillen ziet. Veneus bloed en adem werden bemonsterd bij twaalf mannelijke rokende vrijwilligers direct voor en tien minuten na het roken van een sigaret op drie onderzoeksdagen (dag 1 Marlboro Red, dag 2 Marlboro Prime, dag 3 Marlboro Prime met afgeplakte filterventilatiegaatjes). Door het roken namen de concentraties van tolueen, ethylbenzeen, m/p-xyleen, o-xyleen en 2,5-dimethylfuran vergelijkbaar toe in zowel de lucht boven bloed als de uitgeademde lucht voor alle drie de typen sigaretten. Er werd echter geen sterke correlatie gevonden tussen VOC concentraties in uitgeademde lucht en VOC concentraties in de lucht boven bloed, waarschijnlijk vanwege variaties tussen de individuele rokende vrijwilligers. Er is meer onderzoek nodig om te bepalen of uitgeademde lucht te gebruiken is als een niet-invasieve kwantitatieve marker voor vluchtige toxische stoffen voor blootstelling aan sigarettenrook van verschillende merken.

\section{Hoofdstuk 4}

Het rookgedrag van mensen beïnvloedt hun blootstelling aan toxische stoffen uit rook en dat is belangrijk voor de risicobeoordeling. In een prospectieve observationele studie werd het rookgedrag van Marlboro-rokers gedurende 36 uur gemeten. Het trekvolume, de trekduur, de trekfrequentie, de trekflow en het trekinterval werden geregistreerd met het draagbare CReSSmicro ${ }^{\mathrm{TM}}$ - 
apparaat, zoals vaak is gedaan door andere wetenschappers. Het gebruik van het $\mathrm{CReSSmicro}^{\mathrm{TM}}$-apparaat kan echter leiden tot problemen met registratie van de rooktopografie, aangezien de methode van inbrengen van de sigaret in het apparaat de gegevensverzameling kan beïnvloeden. De rokende vrijwilligers vertoonden in de loop van de dag een consistent individueel karakteristieke rooktopografie, waardoor een gepersonaliseerd rookprofiel kon worden gemodelleerd per roker. Deze rookprofielen werden vervolgens gebruikt als instellingen voor experimenten met de rookmachine om TNCO-emissies te genereren. De toepassing van humane rookprofielen leidde tot TNCO-blootstellingen die meer in het bereik van $\mathrm{HCl}$ TNCO- dan ISO-TNCO emissies lagen. Vergeleken met het ISO-protocol, dat een lager trekvolume toepast ten opzichte van rokers, kan de generatie van TNCO minstens twee keer hoger zijn wanneer humane rookprofielen worden toegepast op de rookmachine. Rokers vertoonden een hogere trekfrequentie en daarmee een hogere trekintensiteit en dus meer trekjes per sigaret dan voor zowel ISO als $\mathrm{HCl}$.

\section{Hoofdstuk 5}

Filterventilatiegaatjes hebben invloed op het nicotinegehalte in sigarettenrook. De aanwezigheid van filterventilatiegaatjes kan ertoe leiden dat rokers hun rooktopografie aanpassen aan de mate van filterventilatie, een fenomeen dat compenserend roken wordt genoemd. Er is echter ook gerapporteerd dat rokers tijdens het roken een kenmerkende rooktopografie toepassen, ongeacht de nicotine concentratie. Bovendien is de hypothese geopperd dat een zeer lage nicotineopbrengst van sigaretten met een hoge filterventilatie zelfs onder de drempel kan liggen die nodig is om nicotineverslaving in stand te houden. Daarom hebben we het effect bestudeerd van filterventilatie op de rooktopografie van rokende vrijwilligers, op het aantal sigaretten die door hen per dag worden geconsumeerd en op hun nicotinebloedspiegels. Omdat zowel compenserend roken als het kenmerkende rookprofiel de blootstelling aan rookcomponenten kan beïnvloeden, hebben we ook de blootstelling aan $\mathrm{CO}$ bestudeerd door carboxyhemoglobine $(\mathrm{COHb})$ in het bloed te meten. In een humane studie met rokende vrijwilligers (leeftijd 25-35 jaar) zijn twaalf ervaren Marlboro Red (43\% filterventilatie) rokers gedurende een week overgegaan op het roken van een laag-TNCO (en dus hoog filtergeventileerde (83\%)) sigaret, de Marlboro Prime. Ze rookten ad libitum op drie verschillende dagen onder natuurlijke omstandigheden (niet in het lab) Marlboro Red, de Marlboro Prime en de Marlboro Prime met afgeplakte filterventilatiegaatjes. De meeste rokers veranderden hun dagelijkse aantal sigaretten of karakteristieke rooktopografie niet bij het overgaan van hun normale Marlboro Red naar Marlboro Prime of de afgeplakte Marlboro Prime. We vonden vergelijkbare nicotine- en cotinine-bloedspiegels na het roken 
van Marlboro Red en de afgeplakte Marlboro Prime gedurende de dag. Er werden slechts iets lagere nicotineconcentraties gevonden bij het roken van Marlboro Prime. Na een week Marlboro Prime roken, werden lagere concentraties cotinine en significant hogere $\mathrm{COHb}$-spiegels gevonden in vergelijking met Marlboro Red. Wanneer rokers hun eigen karakteristieke rooktopografie toepassen, extraheren ze vergelijkbare hoeveelheden nicotine uit sigaretten met verschillende filterventilatie om hun nicotineverslaving in stand te houden en rookt ze een vergelijkbaar aantal sigaretten per dag. We concluderen dan ook dat compenserend roken van sigaretten met filterventilatie een twijfelachtig concept is, aangezien sigaretten met een 'lage' en 'gewone' opbrengst vergelijkbare hoeveelheden nicotine leveren aan chronische rokers met minimale veranderingen in hun rooktopografie.

\section{Discussie}

Op basis van de gegevens die in dit proefschrift worden beschreven, worden verschillende belangrijke kwesties met betrekking tot sigarettenregulering en risicobeoordeling met betrekking tot emissies van giftige stoffen behandeld. In onze onderzoeken laten de meeste rokers geen, of minimale, karakteristieke aanpassingen van de trekparameters zien bij het overstappen op een ander sigarettenmerk. De kenmerkende rooktopografie is significant verschillend tussen rokers, maar alle rokers rookten een vergelijkbaar aantal sigaretten per dag van de verschillende merken en bereikten hiermee nog steeds vergelijkbare nicotine-, COHB- en VOCbloedspiegels, onafhankelijk van het type sigaret. In studies gerapporteerd in de literatuur met zeer laag nicotine sigaretten (ZLNS) is een significant verminderde opname van nicotine waargenomen wat verklaard kan worden door het feit dat er nauwelijks nicotine aanwezig is in de tabak en dat nicotine niet geproduceerd wordt tijdens het verbrandingsproces. Het was echter onverwacht dat ZLNS-rokers bleven roken en dat er slechts kleine veranderingen in rooktopografie en sigaretten per dag werden waargenomen. Deze waarnemingen zijn niet consistent met de hypothese dat ervaren rokers van reguliere sigaretten alleen blijven roken om te voldoen aan hun nicotinebehoefte. Het is echter consistent met de hypothese dat tabaksverslaving slechts gedeeltelijk een farmacologische verslaving is en meer is dan een nicotineverslaving. Bovendien, in overeenstemming met onze gegevens van de experimenten van de vrijwilligers, meldt de literatuur ook dat met ZLNS rooktopografie niet wordt gecontroleerd voor directe blootstelling aan nicotine tijdens het roken. Hoewel elke individuele roker een kenmerkende rooktopografie heeft, is het algemene doel van roken in wezen het bereiken van een (hersen) beloning. Aangezien de opname van nicotine door de longen en het transport naar de hersenen meer dan 10 seconden duurt en de trekduur maximaal twee 
seconden is, is het onwaarschijnlijk dat dit mechanisme een cruciale rol speelt bij de rooktopografie. $\mathrm{Er}$ is een grotere kans dat nicotineopname in de mondholte wordt gecontroleerd door de reuk- en trigeminusneuronen. Hersenactiviteit reacties op blootstelling in de mondholte kunnen zeer snel zijn ( $<4$ seconden) en vereisen weinig tot geen nicotine. Bij elke trek inhaleert een roker nicotine en andere rookbestanddelen, die de snelle beloningsreactie activeren via het reuk- en trigeminus neurale systeem. Deze processen vinden plaats onafhankelijk van het type sigaret (light, regulier, filtergeventileerd, enz.) aangezien elke sigaret voldoende nicotine bevat ( $16 \mathrm{mg}$ in de tabak van één sigaret) om de gewenste hoeveelheid per trekje en per sigaret te leveren. Een roker raakt gewend aan zijn sigarettenmerk en ontwikkelt een karakteristiek rookprofiel. Het enige aspect dat het design van de sigaret moet waarborgen is dat er niet te weinig of te veel nicotine per trekje wordt afgegeven, wat leidt tot respectievelijk te weinig beloning of een overreactie van de nervus trigeminus. Vandaar dat een roker voornamelijk de nicotine-inname regelt door zijn trek-pulsritme (trekduur en trekinterval). Bovendien zal de roker, zodra de karakteristieke rooktopografie is ontwikkeld, deze topografie ook voor andere tabaksproducten gebruiken. Zelfs wanneer de nicotineconcentraties in de rook lager zijn, blijft het karakteristieke rookgedrag behouden zolang andere belonende zintuiglijke elementen van de tabaksrook door de sigaret worden afgegeven. Aangezien een hoge filterventilatie, evenals het gebruik van nicotinevrije tabak, het algehele gevoel van een trek nemen kan beïnvloeden, kunnen kleine veranderingen in de topografie worden waargenomen wanneer rokers van merk veranderen. Onze studie suggereert dat 'compensatie' niet te wijten is aan een lagere nicotine-opbrengst en ondersteunt de hypothese dat als rokers hun rooktopografie veranderen bij het gebruik van een ander merk, ze dit waarschijnlijk doen vanwege andere sensorische effecten in de mondholte.

Bij het roken van VLNC werden gewoonlijk geen verlaagde CO-niveaus gevonden bij rokers, wat suggereert dat de werkelijke blootstelling van de roker aan $\mathrm{CO}$, gegenereerd tijdens pyrolyse en verbranding, voornamelijk wordt bepaald door de rooktopografie en niet noodzakelijk gerelateerd is aan blootstelling en inname van nicotine. In plaats daarvan bepalen $\mathrm{CO}$ en andere rookbestanddelen die worden geproduceerd tijdens het verbrandingsproces, het smeulen en de trekparameters zoals de duur van de trek, het trek volume en het aantal trekjes, de blootstelling van de roker. Voor nicotine speelt ook de hoeveelheid die aanwezig is in de tabak een rol bij de blootstelling van de roker tijdens het rookproces. Blootstelling aan verbrandingsproducten in tabaksrook wordt dus niet altijd weerspiegeld door blootstelling aan nicotine. 
Voor risicobeoordeling en regelgeving moet rekening worden gehouden met de onderliggende overeenkomsten en verschillen tussen de processen die de aanwezigheid van verschillende klassen van bestanddelen in de rook bepalen. Voor chemicaliën die voornamelijk door verdamping in de rook vrijkomen, zoals nicotine, evenals bestanddelen die worden geproduceerd tijdens het verbrandingsproces, heeft de rooktopografie echter een grote invloed. Deze bevinding geeft aan dat wanneer risicobeoordeling en regulering gebaseerd zijn op gestandaardiseerde gegevens van rookmachinemetingen, het rookmachine rookprofiel dicht bij de humane rookprofielen moet liggen met betrekking tot de trekfrequentie, het trekvolume, de trekduur en het aantal trekjes. Het gebruik van de schadelijek stof tot nicotine ratio kan echter beperkingen hebben voor sigaretten met een laag of hoog nicotinegehalte. De blootstelling is een essentieel aspect van de risicobeoordeling omdat het de omvang, frequentie en duur van blootstelling aan een schadelijke stof, evenals het aantal en de kenmerken van de blootgestelde populatie bevat. In het verleden werden de TNCO-concentraties gebruikt als een overkoepelende term voor de opbrengst aan toxische stoffen in sigarettenrook. Gelukkig wordt er steeds meer onderzoek gedaan naar componenten met specifieke eigenschappen, zoals carbonylen en VOCs die deel uitmaken van de sigarettenrook. Metingen van verschillende chemicaliën met vergelijkbare fysisch-chemische kenmerken in de sigarettenrook geproduceerd met de rookmachine kunnen worden gebruikt als schatting van de blootstelling aan een chemische klasse bij risicobeoordelingen voor mensen. Ons onderzoek toont aan dat de trekinstellingen van de rookmachine en de kenmerken van het sigarettenontwerp (met name filterventilatie) belangrijke determinanten zijn voor de concentraties van schadelijke stoffen in sigarettenrook. $\mathrm{Bij}$ het bepalen van de concentratie van toxische stoffen is het belangrijk om meer dan één rookprofiel en verschillende typen sigaretten te gebruiken om een representatief bereik voor humaan roken in sigarettenrook te garanderen. Zoals gezegd zou een rookprotocol, met sigaretten in zowel (half)afgeplakte en niet-afgeplakte staat, met een iets hoger trekvolume $(60-70 \mathrm{ml} /$ trek) en een hogere trekfrequentie ( 3 trekjes per minuut in plaats van 2 trekjes per minuut) nuttig zijn.

\section{Conclusie}

De nadelige gevolgen voor de gezondheid van individuen en hun omgeving door het roken van sigaretten is onbetwist. Het roken van tabak verhoogt het gezondheidsrisico en niet roken is het enige gezonde alternatief. Sigaretten zijn echter legaal verkrijgbaar op de consumentenmarkt en internationale regeringen hebben strategieën gekozen die de schadelijkheid van tabaksgebruik verminderen. Tabaksrook bevat duizenden chemicaliën, waarvan vele beschikbaar zijn in toxische 
concentraties, en alleen nicotine en $\mathrm{CO}$ zijn daarvan tot nu toe wettelijk gereguleerd. Dit proefschrift bevat informatie om toekomstige regelgeving te ondersteunen.

I. Ervaren rokers stellen zich meer dan 100 keer per dag gedurende 1 a 2 seconden bloot aan het chemische mengsel van sigarettenrook door hun eigen karakteristieke rookprofiel toe te passen. De rooktopografie van ervaren rokers lijkt niet gereguleerd te worden door de opname van nicotine door de longen, maar door sensorische effecten in de mond- en neusholte, een kwestie die nader onderzoek behoeft. Verschillen tussen het individuele rookgedrag (aantal sigaretten per dag en rooktopografie) leiden al snel tot verschillen van twee tot drie keer hogere blootstelling aan sigarettenrook wanneer de rokers hetzelfde merk gebruiken (hoofdstuk 3). In risicobeoordelingsmodellen wordt meestal rekening gehouden met variatie in blootstelling waarbij deze variatie tussen de hoogste en de laagste blootstelling vaak kleiner is dan een factor 10. Voor ervaren rokers geldt deze aanname voor nicotine, aangezien de variatie tussen nicotineconcentraties in het bloed kort na het roken tussen gebruikers vergelijkbaar is (hoofdstuk 5), ongeacht het merk dat gerookt wordt. Dit is ook aangetoond voor CO (hoofdstuk 5) en voor andere rookcomponenten in de gasfase zoals aldehyden en VOCs (hoofdstuk 3 en 4), ondanks de verschillende rooktopografie tussen rokers en verschillen tussen merken. Dit proefschrift beschrijft onvoldoende gegevens om een volledige statistische analyse van de invloed van rooktopografie, merkvariatie en werkelijke blootstelling mogelijk te maken. Op basis van de experimenten met roken door mensen is de werkelijke blootstellingsvariatie tussen individuen echter niet veel meer dan een factor 10. Een dergelijke beperkte variatie is niet geheel onverwacht, aangezien de tabaksindustrie waarschijnlijk veel investeert in het ontwerpen en vervaardigen van sigaretten om tabaksrook te produceren binnen een nauw bereik van nicotineblootstelling.

II. Een smal bereik van emissies van gasfase componenten wordt gevonden wanneer sigarettenrook wordt geproduceerd met een gestandaardiseerde rookmachine. De tegenwoordig gebruikte rookprotocollen onderschatten de blootstelling van de mens echter aanzienlijk omdat de trekvolumes en de trekfrequentie te laag zijn. Bovendien resulteert dit ook in een te laag aantal trekjes in vergelijking met roken door mensen. Wanneer ISO 3308-gegevens worden gebruikt, kan de blootstelling van de mens gemakkelijk worden onderschat met een factor 2 tot 3 voor gewone sigaretten en zelfs meer voor sterk geventileerde sigaretten. Afplakken van ventilatiegaatjes tijdens metingen is van cruciaal belang omdat testen zonder afplakken onrealistisch lage opbrengsten genereert voor 
sigaretten met een hoge filterventilatie. Een voorgestelde wijziging is half blokkeren met het gebruik van houders die het filter gedeeltelijk afdekken bij gebruik in rookmachine-experimenten. Een andere optie is om filterventilatie tot op zekere hoogte (bijvoorbeeld een maximaal toegestaan filterpercentage) als ontwerpkenmerk uit te sluiten. Hierbij moet opgemerkt worden dat het aantal trekjes per sigaret een grote invloed heeft op de samenstelling van de sigarettenrook, vooral omdat de concentraties van rookbestanddelen in de laatste trekjes van een sigaret hoger kunnen zijn dan in de eerdere trekjes. Het zou nog beter zijn om het $\mathrm{HCl}$-protocol op een rookmachine aan te passen naar 3 in plaats van 2 trekjes per minuut.

III. Op basis van dit proefschrift stellen we dat een dergelijke gewijzigde gestandaardiseerde $\mathrm{HCl}$-test (punt II) op een rookmachine tabaksrook produceert met rookbestanddelen in concentraties $(\mu \mathrm{g} / \mathrm{mL})$ die gerelateerd kunnen worden aan rook onder omstandigheden van vergelijkbare rooktopografie (aantal trekjes, trekvolume, trekfrequentie, totaal rookvolume). Maar zelfs een gestandaardiseerd gemodificeerd $\mathrm{HCl}$-protocol zal het roken door mensen niet volledig nabootsen en één testmethode is gevoelig voor (aanpassings)designkenmerken van producten, zoals is aangetoond met ISO 3308 en filtergeventileerde producten. Daarom is altijd een tweede testmethode vereist om samen met een aangepast $\mathrm{HCl}$-protocol te worden gebruikt. Een aangepaste ISO 3308 kan een optie zijn als tweede protocol als de intensiteit van de trekjes wordt verhoogd door middel van een hoger trekvolume en een hogere trekfrequentie. 



\section{Curriculum vitae}





\section{Curriculum vitae}

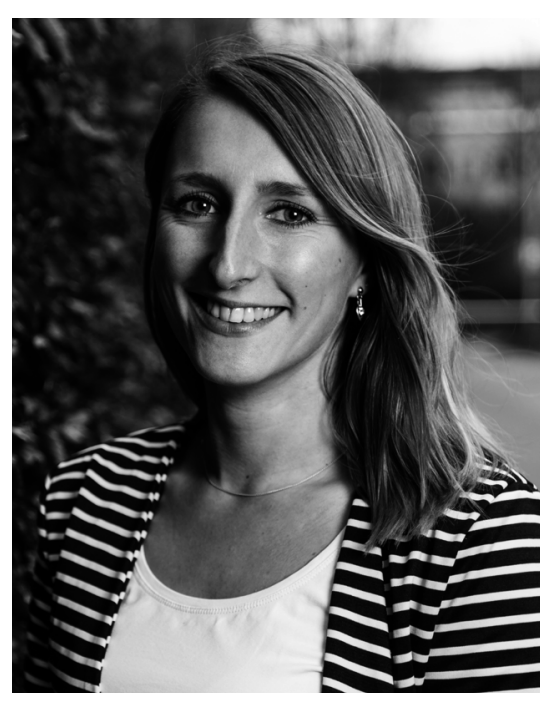

Charlotte (Gabriella Guido Margueritte) Pauwels was born in Duffel, Belgium, on April 6th 1990. In 2008, she graduated from preuniversity education at Johannes Fontanus College in Barneveld, The Netherlands. In September 2008, she enrolled in the Bachelor program Biomedical Sciences at the Radboud University in Nijmegen, The Netherlands. In 2012, she enrolled in the Master program Biomedical Sciences and graduated in 2014 with 2 majors: Toxicology and Human Pathobiology. During her studies, she was active as year representative and member of the board of the Organisation for Education and Study, and member of the Program Committee Education and Examinations Regulations, both at the Faculty of Medicine, Radboud University. In 2014, Charlotte started with her PhD project that was a collaboration of the department of Pharmacology \& Toxicology at Maastricht University, the Centre for Health Protection at the National Institute for Public Health and the Environment (RIVM) and the Office of Risk Assessment and Research of the Netherlands Food and Consumer Product Safety Authority (NVWA). During her PhD project, she attended a variety of international conferences and visited several international research institutes. Additionally, she was involved in various teaching activities including practical supervision, leading problem-based learning groups, grading reports and supervising interns. Charlotte was involved in the NUTRIM PhD Council, was a member of the Faculty PhD Committee and of the Organising Committee Netherlands Society for Toxicology (NVT) Annual Meeting. Furthermore, she completed the Postgraduate Education in Toxicology training program and will be registered as a European Recognized Toxicologist (ERT). Charlotte now continues her career as scientific researcher in tobacco-related research at the Centre of Health Protection at the RIVM. 



\section{List of publications}





\section{List of publications}

Pauwels, C.G.G.M., Boots, A.W., Visser, W.F., Pennings, J.L.A., Talhout, R., Schooten, F.J., and Opperhuizen, A. (2020) Characteristic Human Individual Puffing Profiles Can Generate More TNCO than ISO and Health Canada Regimes on Smoking Machine When the Same Brand Is Smoked. Int. J. Environ. Res. Public Health 2020, 17(9), 3225. DOI: 10.3390/ijerph17093225

Pauwels, C.G.G.M., Hintzen, K., Talhout, R., Cremers, H.W.J.M., Pennings, J.L.A., Smolinska, A., Opperhuizen, A., van Schooten, F.J., and Boots, A.W. (2020) Smoking regular and low-nicotine cigarettes results in comparable levels of volatile organic compounds in blood and exhaled breath. J Breath Res. 2020 Oct 7.

DOI: $10.1088 / 1752-7163 / a b b f 38$

Pauwels, C.G.G.M., Klerx, W.N.M., Pennings, J.L.A., Boots, A.W., van Schooten, F.J., Opperhuizen, A., and Talhout, R. (2018) Cigarette Filter Ventilation and Smoking Protocol Influence Aldehyde Smoke Yields. Chem Res Toxicol 31, 462-471. DOI: 10.1021/acs.chemrestox.7b00342.

van Osch, F.H.M., Pauwels, C.G.G.M., Jochems, S.H.J., Fayokun, R., James, N.D., Wallace, D.M.A., Cheng, K.K., Bryan, R.T., van Schooten, F.J., and Zeegers, M.P. (2019) Tar, nicotine and carbon monoxide yield of UK cigarettes and the risk of nonmuscle-invasive and muscle-invasive bladder cancer. Eur J Cancer Prev 28, 40-44. DOI: 10.1097/CEJ.0000000000000404.

Reda, A., Raaijmakers, A., Dorst, S.V., Pauwels, C.G.G.M., Allegaert, K., Elmonem, M.A., Masereeuw, R., den Heuvel, L.V., Levtchenko, E., and Arcolino, F.O. (2017) A Human Proximal Tubular Epithelial Cell Model to Explore a Knowledge Gap on Neonatal Drug Disposition. Curr Pharm Des 23, 5911-5918. DOI: 10.2174/13816 12823666171009143146.

Benevento M., Oomen C.A., Horner A.E., Amiri H., Jacobs T., Pauwels C.G.G.M., Frega, M., Kleefstra, T., Kopanitsa, M. V., Grant, S. G., Bussey, T. J., Saksida, L. M., Van der Zee, C. E., van Bokhoven, H., Glennon, J. C. and Kasri, N. N. (2017) Haploinsufficiency of EHMT1 improves pattern separation and increases hippocampal cell proliferation. Sci Rep. 2017;7:4028. DOI: 10.1038/srep40284. 



\section{Dankwoord}





\section{Dankwoord}

Ein-de-lijk, daar is hij dan, mijn langverwachte thesis. Ik ben ontzettend trots dat ik mijn $\mathrm{PhD}$ project heb kunnen afronden! Dit proefschrift zou er niet zijn geweest zonder de hulp, support en het geduld van een heleboel mensen die ik daarvoor graag wil bedanken.

Allereerst wil mijn dank en waardering uitspreken voor het promotieteam: Reinskje, Agnes, Antoon en Frederik-Jan. Bedankt voor de kans die jullie mij geboden hebben om dit promotietraject te volgen. Zonder jullie hulp was dit boekje er nooit geweest. Reinskje, we werken nog steeds samen aan tabak-gerelateerd onderzoek, en dat doe ik elke werkdag met veel plezier.

Ik wil ook graag de leden van de beoordelingscommissie Prof. dr. D. Sijm, Prof.dr. C. Van Schayck, Prof. dr. P. Borm, Prof. dr. T. Eissenberg, en Dr. A. Remels bedanken voor het beoordelen van mijn proefschrift.

Tijdens mijn promotietraject heb ik me thuis gevoeld in niet één maar twee groepen van PhD-kandidaten. Zowel mijn tijd bij het RIVM, als in Maastricht heb ik genoten van de uitjes, koffiedates en klaagmomenten. RIVM-PhDs en Phartox-PhDs bedankt! Enkele PhD-collega's reken ik nu ook tot mijn vrienden, bedankt voor jullie steun Alie, Rianne, Carmen en Misha, en ook Kim, Victoria, Gina en Astrid. We stay in touch!

Alle collega's, zowel bij Phartox als bij PRS, die het mogelijk hebben gemaakt dat ik mijn onderzoek kon uitvoeren, DANKJEWEL! In het bijzonder Walther en Hans, mijn rookmachine experimenten partners in crime, en Jeroen die altijd voor me klaar stond om weer een statistische analyse uit te voeren. Bo, bedankt dat je mijn onmisbare student-assistent tijdens de 2e humane rookstudie wilde zijn. Lisa, Maura en Falco, ik heb jullie stages met veel plezier begeleid. Jullie hebben mij goed geholpen en een mooie bijdrage geleverd aan mijn onderzoek, waarvoor dank.

Naast de mensen binnen de universiteit en het RIVM was het voor mij heel belangrijk om mijn vrienden en familie om me heen te hebben voor afleiding en ontspanning. Hiervoor wil ik graag een enorm gemeende DANKJULLIEWEL zeggen tegen mijn lieve vrienden waarmee we al jaren de hechte vriendengroep Elephas Maximus FFCOCB vormen. Bedankt voor alle avonden, dagen, weekendjes en vakanties van ontspanning die we samen hebben meegemaakt (en nog mee zullen maken). Ook 
252 |

DANKJEWEL aan de 'skifamilie', onze avonturen in de sneeuw waren en zijn altijd zeer welkom.

Lieve Marlot, dank voor je steun tijdens mijn PhD, en met alles in m'n leven. Ik hoop dat je weet hoeveel jouw vriendschap voor mij betekent.

Kim, mijn paranimf, ook wij hebben al behoorlijk wat (buitenlandse) ervaringen mogen delen. Dankjewel dat je er bent, en blijft!

Uiteraard wil ik ook mijn gezin heel erg bedanken. Mama en papa, Amélie en PieterJan, bedankt dat jullie er altijd zijn. Ik ben dankbaar dat ik bij jullie terecht kan, in goede en slechte tijden. Dat geldt ook voor Annemarie, Henny en de overige schoonfamilie, dank voor jullie steun.

Mijn allerlaatste dankbetuiging gaat uit naar Martijn. Onze 10 jaar samen bestaat uit vele avonturen die vaak parallel lopen en liepen. Mijn promotie traject is een uit de hand gelopen avontuur wat niet altijd leuk was, zeker niet toen we ook privé behoorlijk wat te verwerken kregen en we in het verre Limburg woonden. Ik ben je dankbaar voor je geduld en steun, en dat ik altijd bij je mocht ventileren. Ik ben trots dat ik het, doordat jij me die ruimte gaf, heb kunnen afmaken. Als ik terugkijk op wat wij al bereikt en gedaan hebben, voel ik alleen maar liefde, blijdschap en trots. Ik kijk uit naar nog meer avonturen, samen met ons gezin.

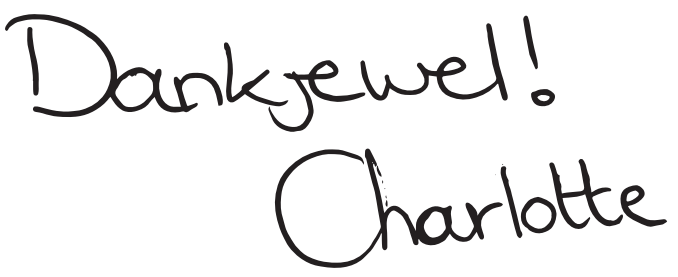





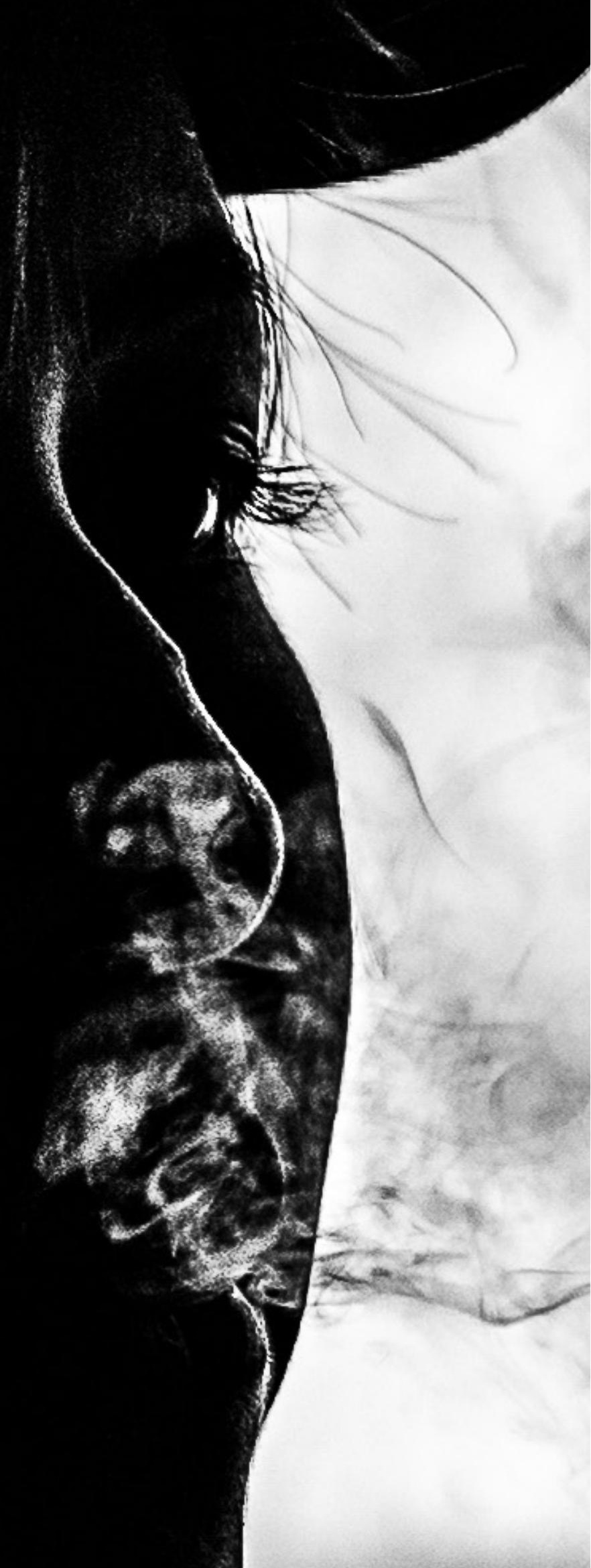

